UNIVERSIDAD NACIONAL DE LA PLATA

FACULTAD DE HUMANIDADES Y CIENCIAS DE LA EDUCACIÓN SeCRETARía de Posgrado

\title{
ENSEÑANZA DEL SABER TÁCTICO EN CATEGORÍAS FORMATIVAS DE BASQUETBOL
}

\author{
Lic. A. Gabriel Fessia
}

Tesis para optar por el grado de Magister en Deporte

Director: Prof. Doctor Pablo Juan Greco (EEFFTO- UFMG)

Co-Director: Lic. Marcelo Giles (FaHCE - UNLP)

La Plata, 17 de febrero de 2016 
"La felicidad se alcanza cuando lo que uno piensa,

lo que uno dice y lo que uno hace están en armonía"

\author{
Mahatma Gandhi
}




\section{AGRADECIMIENTOS}

A los profesores Pedro Roldán y Raúl de Philippis, modelos integrales en cuanto a la labor docente y - principalmente - a la calidad humana.

Al profesor Mario Mouche mi más profunda gratitud por la confianza y dedicación para mi formación profesional y personal a lo largo de tantos años.

Al profesor Pablo Greco por su colaboración, incentivo irrestricto, soporte profesional - humano y disponibilidad constante para elevar el trabajo al más alto nivel que se pueda alcanzar.

Al profesor Marcelo Giles por su guía en la maestría y colaboración para colocar en duda todos los supuestos, obligando a la reflexión permanente y su gestión del culto a la diferencia de criterios.

A Emiliano y Marisa - amigos y compañeros de trabajo con los que aprendo día a día - por sus conocimientos, apoyo y colaboración atenta e insustituible en interminables rondas de diálogo, disensos y consensos.

A mis eternos amigos que siempre están presentes.

A mi familia fuente constante de inspiración y amor.

A los jugadores, porque todo esfuerzo debe sustentar la idea de tener más chicos disfrutando del basquetbol a los cuales brindarles un proceso de enseñanza-aprendizaje-entrenamiento de calidad.

A los entrenadores de basquetbol por brindar y transmitir su compromiso, confianza y pasión por el deporte a los jugadores y sus familias.

A James Naismith, por su inteligencia, creatividad, pasión y compromiso para inventar este maravilloso deporte. 


\section{RESUMEN}

El objetivo general fue analizar la enseñanza y aplicación del saber táctico en categorías formativas de basquetbol. Para lo cual se realizaron dos estudios: (a) Opinión de los entrenadores de basquetbol sobre la enseñanza del saber táctico en las categorías formativas: Objetivo: reconocer la importancia dada por los entrenadores de basquetbol a la enseñanza del saber táctico en categorías U-13 y U-15. Metodología: estudio transversal descriptivo. Participaron 43 entrenadores de la ciudad de Santa Fe (Argentina) con categoría ENEBA (Escuela Nacional de Entrenadores en Basquetbol de Argentina) y experiencia de enseñanza-aprendizaje-entrenamiento en categorías $U-13$ y $U$ 15. Se categorizaron los métodos de entrenamiento en analítico, global, de confrontación, parcial, concepto recreativo del juego deportivo y situacional (Greco, 1995). Tratamiento estadístico con software SPSS versión 17.0. Resultados: experiencia de los entrenadores $\bar{X}=14,7 \pm 3,9$ años. Moda de frecuencia semanal de entrenamiento $U-13=3$ sesiones $\times 75$ minutos, $U-15=3$ sesiones $\times 90$ minutos. Importancia de la táctica $U-13$ : $\Sigma$ muy + totalmente importante $=45,0 \%, U-15=53,4 \% ; U-13: \sum$ poca + muy poca importancia $=$ $13,3 \%, U-15=3,3 \%$. Preponderancia del método situacional durante el periodo competitivo ( $\mathrm{Me}=28,6 \%, \mathrm{IC}=22,36-34,84), \Sigma$ muy + totalmente importante = $49 \%(n=21)$. (b) Aplicación del saber táctico en categorías formativas de basquetbol: Objetivo: describir la aplicación del saber táctico realizada por los jugadores de basquetbol de categoría U-13 y U-15 en situación real de competición mediante el análisis de: (i) Dinámicas de Creación de Espacios (DCE) realizadas que precedieron al término de la posesión del balón en lanzamiento, falta o pérdida de balón en situaciones contra defensa individual; (ii) determinación de la eficiencia de las DCE contra defensa individual; y (iii) utilización de las Dinámicas de Protección de Espacios (DPE) en defensa individual. Metodología: estudio analítico observacional. Se filmaron y analizaron 12 partidos de categoría U-13 y 12 de U-15 (Campeonato Interasociaciones Federación Basquetbol Provincia de Santa Fe - Argentina). Para el análisis se utilizaron las Dinámicas de Creación de Espacios (DCE) (LAMAS et al., 2011) y las Dinámicas de Protección de Espacios (DPE) (LAMAS, 2012; SANTANA et al., 2015). Tratamiento estadístico con software SPSS versión 17.0. Resultados: 
(i) Dinámicas de Creación de Espacios (DCE): U-13 ( $n=1072)$ : DCE en 1x1 (55\%, eficiencia $32 \%)$, $2 \times 2(41 \%$, eficiencia $34 \%$ ) y $3 \times 3$ (4\%, eficiencia $31 \%)$. U-15 $(n=1232)$ : DCE $1 \times 1$ (64\%, eficiencia $36 \%), 2 \times 2$ (31\%, eficiencia $30 \%$ ) y $3 \times 3(5 \%$, eficiencia $34 \%$ ). Diferencia significativa entre la utilización de las DCE agrupadas en función del número de jugadores implicados en $1 \times 1$ y $2 \times 2$. Situaciones $1 \times 1 \mathrm{U}-$ 13: DCBD (49\%), DCSD (20\%), APe (14\%), Al (17\%); U-15: DCBD (37\%), DCSD (12\%), APe (23\%), AI (28\%). Situaciones 2x2 U-13: DSB (81\%), BD (19\%); U15: DSB (36\%), BD (64\%). No existiendo diferencias significativas en el aprovechamiento de las DCE DSB (U-13 36\%, U-15 38\%) y BD (U-13 27\%, U15 26\%). (ii) Dinámicas de Protección de Espacios (DPE): U-13 n=1074; U-15 n=1232. 1x1 (U-13 55\%; U-15 62\%), 2x2 (U-13 41\%; U-15 31\%), 3×3 (U-13 4\%; U-15 5\%). 1x1: DPE neutro para DCE DCBD (U-13 59\%; U-15 46\%), DCE DBSD (U-13 92\%; U-15 80\%), DCE APe (U-13 71\%; U-15 64\%). DPE fondo para DCE DCBD (U-13 22\%; U-15 37\%), DBSD (U-13 8\%; U-15 17\%). DPE por detrás (U13 87\%; U-15 73\%) para DCE Al. 2x2: DCE DSB: DPE Próximo (U-13 75\%; U$1581 \%$ ). DCE BD (jugador con balón) U-13: DPE cambio (39\%), por delante (31\%), doblaje (25\%). U-15: variedad. 3×3: DCE BI (receptor del bloqueo) DPE Por el medio (U-13 3\%; U-15 37\%), Evitar (U-13 40\%; U-15 24\%), Cambio (U-13 47\%; U-15 15\%). BI (realizador del bloqueo) DPE abrirse (U-13 12\%; U-15 32\%), DPE alejarse (U-13 14\%; U-15 21\%). Consideraciones finales: (i) la enseñanza del saber táctico en las categorías formativas del basquetbol resulta fundamental para los entrenadores, acrecentándose su importancia conforme aumenta la edad de los jugadores; (ii) el método situacional es - en la opinión de los entrenadores - el principal en las categorías U-13 y U-15. Lo cual denota el desarrollo de modelos de enseñanza de la táctica deportiva que propician un comportamiento proactivo - empoderamiento de los jugadores como base para desarrollar la inteligencia y creatividad táctica; (iii) la aplicación del saber táctico en situaciones reales de competición en las categorías formativas de basquetbol evoluciona desde comportamientos reactivos a proactivos conforme aumenta la edad de los jugadores; y (iv) se evidencia - a través de la realización de acciones de juego de complejidad creciente - una mejor lectura de juego, una toma de decisión más diversificada y el desarrollo de una mayor capacidad de juego en la cual se expresan tanto la inteligencia como la creatividad táctica.

Palabras clave: basquetbol, saber táctico, categorías formativas. 


\section{SUMARIO}

\section{INTRODUCCIÓN}

I - PRESENTACIÓN

Fundamentación del problema. Objetivos. Estructura de trabajo.

\section{ASPECTOS TEÓRICOS}

II - JUEGOS DEPORTIVOS COLECTIVOS.

Características. Denominadores comunes. Carácter dinámico. Acciones de juego. Principios defensivos y ofensivos. Interrelación de tareas. Categorías de problemas.

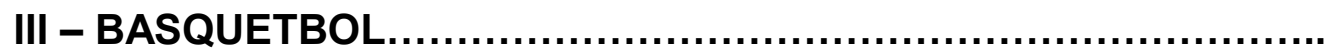

Aspectos identitarios. Punto de vista reglamentario. Perspectiva del rendimiento físico. Características psicológicas. Aspecto técnico. Ámbito táctico. Aspectos perceptivos. Dinámica de juego.

IV - CATEGORÍAS FORMATIVAS EN BASQUETBOL

Aspectos reglamentarios específicos. Fases de desarrollo del jugador de basquetbol: etapa Train to train y Develop the game. Efecto relativo de la edad.

V - ENTRENADOR.

Funciones. Intervención pedagógica. Condicionantes. Competencias. Toma de decisiones. Perfiles teóricos. Formación específica. Contexto de formación. Experiencia.

VI - TÁCTICA DEPORTIVA.

Estrategia, táctica y técnica deportiva. Conocimiento táctico. Conocimiento del juego. Capacidad, decisión y maestría táctica. Conocimiento táctico declarativo. Conocimiento táctico procedimental. Tiempo táctico. Inteligencia táctica. Inteligencia de juego. Creatividad táctica.

II - TOMA DE DECISIÓN EN EL DEPORTE.

Procesos cognitivos. Toma de decisión. Pensamiento táctico. Proceso de toma de decisiones. Modelos teóricos explicativos: ABC, SMART y SMART-ER. Acción. Decisión. Acto táctico. Acción de juego. Contexto 
situacional (persona, tarea, ambiente). Factores condicionantes de la toma de decisión en la acción táctica.

VIII - MODELOS DE ENSEÑANZA DE LA TÁCTICA DEPORTIVA......

Importancia. Diferenciación. Clasificación. Modelos tradicionales: técnico y táctico. Modelos alternativos estructurales: fenómeno estructural y praxiológico. Modelos alternativos comprensivosituacionales transversal-comprensivos: Teaching Games for Understanding, Desarrollo de los contenidos de los juegos, Educación Deportiva, Competencia en los juegos de invasión, Escuela del Balón, Iniciação Esportiva Universal. Modelos alternativos comprensivosituacionales ecológico-sistémicos.

IX - MÉTODOS DE ENSEÑANZA-APRENDIZAJE-ENTRENAMIENTO

Proceso de construcción de conocimiento significativo. Importancia. Clasificación. Características.

$X$ - ANÁLISIS DEL JUEGO

Aplicación. Particularidades. Dominios. Objetivos. Especificidad del análisis del desempeño técnico-táctico.

\section{SECCIÓN INVESTIGATIVA}

XI - INVESTIGACIÓN DE CAMPO.

XI.1.- OPINIÓN DE LOS ENTRENADORES DE BASQUETBOL SOBRE LA ENSEÑANZA DEL SABER TÁCTICO EN LAS CATEGORÍAS FORMATIVAS.

Introducción. Métodos. Resultados y discusión. Conclusiones.

XI.2.- APLICACIÓN DEL SABER TACTICO EN CATEGORÍAS FORMATIVAS DE BASQUETBOL

Introducción. Métodos. Resultados y discusión. Análisis general. Dinámicas de Creación de Espacios: situaciones $1 \times 1$, situaciones 2x2, situaciones $3 \times 3$. Dinámicas de Protección de Espacios: situaciones 1x1, situaciones $2 \times 2$, situaciones $3 \times 3$. Conclusiones.

XII - CONSIDERACIONES FINALES 
BIBLIOGRAFÍA.

ANEXOS

ANEXO 1 - OPINIÓN DE LOS ENTRENADORES DE BASQUETBOL SOBRE LA ENSEÑANZA DEL SABER TÁCTICO EN LAS CATEGORÍAS FORMATIVAS

ANEXO 2 - APLICACIÓN DEL SABER TÁCTICO EN CATEGORÍAS FORMATIVAS DE BASQUETBOL 


\section{I - PRESENTACIÓN}

\section{FUNDAMENTACIÓN DEL PROBLEMA}

El deporte es un patrimonio cultural de la humanidad de carácter plural, polisémico y polifónico (TANI et al., 2011) que exige una multiplicidad de miradas específicas para revelar su significado y demostrar su valía. Debiendo sus escuelas teóricas y sus profesores luchar ardua y constantemente - de un modo incesante y desigual - por el espacio académico para probar, afirmar y sustentar en la Universidad (e instituciones de apoyo a la investigación) la autonomía y relevancia de esta área, de su estudio, reflexión y teorización. De este modo, quien trabaja en el deporte tiene mucho que reflexionar y escribir para fundamentar y justificar un estatuto intelectual. Por ello el deporte precisa ser defendido frente a sus desvíos y sus opositores; defensa que requiere un abordaje a partir de un tratamiento científico pautado por un pensamiento crítico, riguroso, profundo y actualizado sobre sus prácticas. Recordando que el hilo conductor y pilar central del área de estudios de las ciencias del deporte es la práctica deportiva propiamente dicha, y al no abordar la misma se arriesga a renunciar a la identidad y especificidad que justifican su existencia como campo de conocimiento.

En nuestro país, a pesar de la práctica extendida del basquetbol, son pocos los estudios científicos que procuran investigar esta modalidad deportiva. Las publicaciones existentes están volcados principalmente a los aspectos físicos y técnicos, habiendo una ausencia casi completa de estudios referentes al área de la táctica deportiva para la enseñanza-aprendizaje-entrenamiento de los Juegos Deportivos Colectivos en general y del basquetbol en particular.

En concordancia, del contenido de la literatura específica a nivel internacional, se desprende que los investigadores han recurrido a diversas categorías de observación y a distintos niveles de análisis con el objeto de proceder a caracterizar la actividad desarrollada por los jugadores y los equipos durante los partidos, focalizando - inicialmente - los estudios en el ámbito de la preparación física (TAVARES; FARIA, 1996). El direccionamiento de las líneas de investigación fue ampliando su campo de análisis evolucionando hacia el denominado análisis de tiempo-movimiento, a través del cual se procura 
identificar detalladamente el número, tipo y frecuencia de las tareas motoras realizadas por los jugadores durante el desarrollo del partido. El análisis de las habilidades técnicas ha sido otro de los campos explorados en el análisis del juego. No obstante, las conclusiones obtenidas a partir de los resultados provenientes de estudios cuantitativos centrados en las acciones técnicas individuales llevaron a los especialistas a cuestionar la poca relevancia contextual de los datos y dudar de su pertinencia - utilidad. Lo cual hizo sobresalir la necesidad de considerar la dimensión técnica en relación con los condicionantes tácticos, dado que aquella no perfila per se los trazos dominantes del juego (GARGANTA, 2001).

A partir de la segunda mitad de la década de los ochenta del siglo pasado el reconocimiento de que la expresión táctica asume una importancia capital en los deportes hace que la identificación de regularidades realizadas por los jugadores y por los equipos en el cuadro de las acciones colectivas se desarrolle como una nueva tendencia de investigación (SOLÀ, 2005), así como la importancia dada a esta área del entrenamiento deportivo por parte de los entrenadores en los Juegos Deportivos Colectivos (IBÁÑEZ, 2008).

Siendo el proceso de entrenamiento deportivo caracterizado como un proceso de toma de decisiones (ABRAHAM; COLLINS; MARTINDALE, 2006) donde el entrenador es el principal gestor de las decisiones y las acciones que definirán el entrenamiento (NASH; COLLINS, 2006), con la función específica de conducir dicho proceso y haciéndolo encuadrado en un conjunto de saberes propios que sustentan la capacidad de desempeño profesional. Procurando el entrenador - dentro de la esfera de sus competencias profesionales - percibir cuales son los elementos necesarios y como estos se combinan para tratar de inducir alteraciones positivas en el comportamiento de los practicantes intentando enseñar, desarrollar y perfeccionar los contenidos de entrenamiento para que su equipo obtenga suceso. Asimismo, al ser las capacidades de los jugadores condicionadas por las imposiciones del medio, la intervención va mucho más allá del dominio de las habilidades técnicas, orientándose en función de principios de acción, reglas de gestión de juego y habilidades perceptivas y decisionales (RAAB, 2015). No obstante, en la tentativa de conducir el proceso de enseñanza-aprendizaje-entrenamiento en los Juegos Deportivos Colectivos, 
los entrenadores han enfatizado en la dimensión técnica (o reproductiva) en detrimento de la dimensión estratégico táctica (o comprensiva) (GRAÇA, 2014).

Debe señalarse que en los Juegos Deportivos Colectivos - dentro de los cuales se encuentra el basquetbol - la dimensión táctica ocupa el núcleo de la estructura de rendimiento, siendo la dimensión unificadora que da sentido y lógica a todas las otras, por lo cual la función principal de los demás factores de rendimiento es la de cooperar facilitando el acceso a los desempeños tácticos de nivel cada vez más elevado (COSTA et al., 2011). Entendiendo que la táctica consiste en determinar medios y encontrar soluciones para los problemas prácticos surgidos en las situaciones de juego (GRECO; CHAGAS, 1992; GARGANTA, 1998).

En este sentido, la formación en los juegos deportivos debería contemplar los presupuestos cognitivos indispensables para la regulación de las acciones, obteniéndose los mismos a partir de la estructuración, perfeccionamiento y estabilización de la percepción de la situación, su anticipación, la fase de toma de decisión y el aprendizaje de la ejecución motora (GRECO; CHAGAS, 1992). Es por ello que desde esta perspectiva, se trata de formar jugadores inteligentes y creativos (GRECO, 1999), con (i) capacidad de lectura e interpretación del juego y decisión; (ii) dotados de recursos y experiencias significativas; y (iii) conocimientos para solucionar las diferentes situaciones de juego con considerables niveles de autonomía y creatividad (GRECO, 2006; RAAB, 2015).

Se debe resaltar que los Juegos Deportivos Colectivos en general y el basquetbol en particular se caracterizan por una gran variabilidad de situaciones y riqueza de contenidos, exigiendo del deportista la capacidad de tratar un número grande y variado de informaciones en un corto espacio de tiempo. La pluralidad de esas exigencias y su diversificación situacional reclama de los jugadores la expresión máxima de sus capacidades.

Al mismo tiempo, cuanto más elevado sea el nivel de rendimiento en la especialidad deportiva mayor paridad existirá en los niveles de dominio técnico y físico. En consecuencia, las diferencias en el alto rendimiento serán determinadas por la calidad de la toma de decisión por parte de los jugadores (TAVARES, 2002).

Dentro de este contexto resulta pertinente realizar un análisis sobre la enseñanza del saber táctico en categorías formativas de basquetbol, las cuales 
reglamentariamente se dividen en función de la fecha y año de nacimiento de los jugadores participantes. Específicamente se abordaran las categorías U-13 (under 13) y U-15 (under 15). Siendo la categoría U-13 la primer categoría competitiva a nivel local, provincial y nacional, por lo cual es la primera en la cual se evalúa al jugador de manera directa o indirecta en función de resultados deportivos colectivos y actuaciones individuales; mientras que la categoría U-15 constituye la primera categoría competitiva a partir de la cual se organizan selecciones nacionales para participar en competencias a nivel internacional. Estando los equipos de las categorías U-13 y U-15 incluidos en la etapa "Train to train" (T2T - Entrenar para entrenar) de la fase "Develop the game" (Desarrollar el juego) del "Long-Term Athlete Development" (proceso de desarrollo del deportista a largo plazo), siendo la primer etapa en la cual se debe hacer foco en la excelencia (BALYI; 2001; BALYI; WAY; HIGGS, 2013).

\section{OBJETIVOS}

Basado en lo expuesto precedentemente, en el presente trabajo sobre la enseñanza del saber táctico en categorías formativas de basquetbol se propone como objetivo general el analizar la enseñanza y aplicación del saber táctico en categorías formativas de basquetbol. Mientras que como objetivos especificos se propone (i) reconocer la importancia dada por parte de los entrenadores a la enseñanza del saber táctico en la formación del jugador de basquetbol en categorías formativas U-13 y U-15; así como (ii) describir la aplicación del saber táctico por parte de los jugadores de basquetbol de las categorías formativas U13 y U-15 en situación real de competición.

Procurando que los datos obtenidos presenten potencial para ser aplicados en el contexto de la praxis - tanto en el entrenamiento como en el juego formal - para la mejoría de los procesos de evaluación de la performance deportiva de jugadores y equipos. Pretendiendo establecer una contribución científica para la reflexión y toma de decisión, sirviendo de referencia a los entrenadores de basquetbol para el diseño de sus planificaciones deportivas a corto, mediano y largo plazo durante el proceso de desarrollo del deportista. 
En el sentido de cumplir los objetivos propuestos la estructura del presente trabajo se desarrolla en dos etapas.

Una primera parte constituida por el análisis y descripción del marco teórico, abordando los siguientes temas: (i) los Juegos Deportivos Colectivos (JDC): caracterizándolos desde sus componentes para el rendimiento y como sistemas dinámicos que exigen a los jugadores superar la imprevisibilidad de las estructuras de juego a partir la realización de acciones que poseen una finalidad táctica; (ii) el Basquetbol: describiendo sus aspectos identitarios en relación al rendimiento físico, psicológico, técnico, táctico, perceptivo, reglamentario y de la dinámica de juego en relación con los procesos cognitivos; (iii) las Categorías formativas en el basquetbol: analizando las mismas desde los aspectos reglamentarios tanto como desde el proceso de desarrollo del deportista a largo plazo; (iv) el Entrenador: puntualizando en el rol a cumplir dentro del proceso de enseñanza-aprendizaje-entrenamiento, su intervención pedagógica, el proceso de formación, sus competencias y posibles perfiles; (v) la Táctica deportiva: definiendo y diferenciando los conceptos de estrategia, táctica, técnica deportiva, conocimiento táctico, decisión táctica, tiempo táctico, inteligencia y creatividad táctica; (vi) la Toma de decisión en el deporte: explicando el proceso de toma de decisión que precede a la ejecución en juego, su relación con el pensamiento táctico, condicionantes y modelos teóricos explicativos; (vii) los Modelos de enseñanza de la táctica deportiva: exponiendo la importancia, diferenciación, análisis y descripción de los modelos tradicionales, distinguiendo entre técnico y táctico; y de los modelos contemporáneos estructurales (fenómeno-estructural y praxiológico) y contemporáneos comprensivosituacionales (transversal-comprensivos y ecológico-sistémicos); (viii) los Métodos de abordaje de los juegos deportivos colectivos: expresando su importancia en el proceso de enseñanza-aprendizaje-entrenamiento, diferenciación y características principales de cada método; y (ix) el Análisis del juego: refiriendo su aplicación, particularidades, objetivos y dominios en la caracterización de los modelos de actividad de jugadores y equipos.

Mientras que la segunda parte o sección investigativa se compone de dos estudios en función de los aspectos precitados. El primero es un estudio transversal descriptivo que tiene como objetivo realizar un registro e 
interpretación de la opinión de los entrenadores de basquetbol sobre la importancia de la enseñanza del saber táctico de la modalidad en las categorías formativas U-13 y U-15, su carga en el periodo competitivo del ciclo anual y la importancia de los métodos de enseñanza utilizados para su desarrollo en las categorías formativas. El segundo es un estudio de corte analítico observacional que objetiva describir la aplicación del saber táctico realizada por los jugadores de basquetbol de categoría U-13 y U-15 en situación real de competición mediante el análisis de: (i) Dinámicas de Creación de Espacios (DCE) realizadas que precedieron al término de la posesión del balón en lanzamiento, falta o pérdida de balón en situaciones contra defensa individual; (ii) determinación de la eficiencia de las DCE contra defensa individual; y (iii) utilización de las Dinámicas de Protección de Espacios (DPE) en defensa individual. 


\section{II - JUEGOS DEPORTIVOS COLECTIVOS}

El deporte es un patrimonio cultural de la humanidad de carácter plural, polisémico y polifónico; el cual ha sido creado, transmitido y modificado a lo largo del tiempo (TANI et al., 2011). Los Juegos Deportivos Colectivos (JDC) constituyen una parte importante de la actividad de niños, jóvenes y adultos, por lo cual ocupan un lugar destacado en la cultura contemporánea atravesando las diversas clases sociales, los diferentes elementos de estructuración de la personalidad y de la propia condición humana.

Los JDC y sus componentes para el rendimiento han sido una temática creciente dentro del ámbito académico (GRECO, 1995; GARGANTA, 2002; SOUZA, 2002; TAVARES, 2013). A partir de los años sesenta del siglo XX se han realizado numerosos e importantes estudios sobre las estructuras de los JDC, siendo posible citar entre los autores precursores a Mahlo (1969), Bunker y Thorpe (1982), Teodorescu (1984), Bayer (1986), Greháigne y Guillon (1991), y Hernández Moreno (1994).

Si bien cada deporte es definido por sus reglas y posee una lógica interna precisa y exclusiva que va a condicionar los comportamientos de los jugadores (TAVARES, 2013), todos los JDC poseen denominadores comunes (BAYER, 1986) que permiten definir las semejanzas entre ellos y las particularidades que dan expresión a sus respectivas diferencias.

Dentro de la diversidad de clasificaciones y de indicadores utilizados para agrupar o diferenciar los JDC (TEODORESCU, 1984; THORPE; BUNKER; ALMOND, 1986; HERNÁNDEZ MORENO, 1994; WERNER; THORPE; BUNKER, 1996), existe una subcategoría designada como deportes con una meta a alcanzar, deportes de cooperación/oposición o deportes de invasión, que se caracterizan por ser deportes de participación simultánea y espacio común de actuación, donde cada equipo intenta proteger su meta e invade la del adversario para finalizar (básquet, futbol, hándbol, hockey, rugby) (HERNÁNDEZ MORENO, 1994; 2000).

La característica fundamental de los Juegos Deportivos Colectivos es la confrontación entre dos equipos y la cooperación entre los miembros de un mismo equipo, cuyo comportamiento es condicionado por el cumplimiento de un reglamento (GARGANTA, 2006). Se trata de actividades deportivas que ocurren 
en contextos aleatorios (GARGANTA, 2001) en los cuales los equipos que se enfrentan disputan objetivos comunes (un balón y una meta a atacar o defender), luchando para orientar - en provecho propio - el tiempo y el espacio (ubicándose en el terreno de juego y moviéndose de forma particular), con la finalidad de recuperar, conservar y hacer progresar el móvil de juego (balón), teniendo como objetivo crear situaciones de finalización y marcar goles o puntos para ganar (GRÉHAIGNE; GUILLON, 1992), realizando acciones reversibles de señal contrario (ataque versus defensa) sustentadas en relaciones de oposición versus cooperación (GARGANTA, 2002). Debiendo los jugadores integrarse y confrontar de manera activa y constante con todos los componentes (KONZAG, 1991; TAVARES, 1996).

La interacción, ya sea entre los miembros de un mismo equipo como con los adversarios, explica el carácter dinámico y complejo de los JDC. Durante la confrontación los jugadores y los equipos - frente a determinadas formas de oposición y basados en la cohesión colectiva - intentan articular y sintonizar acciones técnicas y tácticas con el objetivo principal de traspasar el balón por la meta del equipo adversario y evitar que alcancen la suya (TEODORESCU, 1984; BAYER, 1986; GRECO, 2003; GARGANTA, 2006).

Por consiguiente, las sucesivas configuraciones que se experimentan durante el tiempo reglamentario son el resultado de la forma como ambos equipos dirigen las relaciones de ventaja y desventaja en función de los objetivos.

Se trata de situaciones fértiles en acontecimientos que ocurren en un contexto permanentemente variable de oposición y cooperación, y cuya frecuencia, orden cronológico y complejidad no pueden - por lo tanto - ser determinados anticipadamente (GARGANTA, 2002). Por esta razón, las situaciones que surgen en el contexto de los JDC deben ser entendidas como encadenamientos de unidades de acción que poseen una naturaleza compleja, como consecuencia no sólo del número de variables en juego, sino también de la imprevisibilidad y aleatoriedad de las situaciones que se presentan a los jugadores (KONZAG, 1991; RIERA, 1995).

En función de lo expresado los JDC son representados teóricamente como sistemas dinámicos (GREHAIGNE; GODBOUT; BOUTHIER, 2001), dado que presentan todas sus características: (i) son estructurados por elementos en 
interacción; (ii) presentan posibilidad de variación a lo largo del tiempo; (iii) poseen una finalidad como medida de evaluación del resultado; (iv) necesitan de sujetos que decidan y de procesos de decisión; y (v) son secuenciales e intentan resistir las perturbaciones (GARGANTA, 2004). Siendo los factores informacional y organizacional (derivados de la relación establecida entre los participantes de la tarea y el ambiente) sus características más relevantes (NITSCH, 2009). Existiendo un "caos determinista" - dado que se juega en la frontera entre caos y orden - pues a pesar de un aparente desorden y aleatoriedad, traducidas en la variabilidad e inestabilidad de formas que pueden asumir, exhiben un orden que es el resultado de procesos sistemáticos de autoorganización (HUGHES; EVANS; WELLS, 2001). En esta situación irrumpen patrones que expresan un comportamiento caótico del sistema a pequeña escala, pero que a gran escala evidencian una cierta regularidad (TAVARES, 2013).

Además, los Juegos Deportivos Colectivos se caracterizan, entre otros factores, por la aciclicidad técnica, por solicitaciones y efectos acumulativos morfológico-funcionales y motores y por una intensa participación psíquica (TEODORESCU, 1984).

Reconociendo que las acciones de juego son la resultante de las interacciones de los jugadores, realizadas en un espacio común y en un contexto diversificado, para alcanzar un determinado objetivo. Por lo tanto, esta interacción exige un sistema de relaciones reciprocas de comunicacióncooperación que es coordinado por medio de la realización de acciones individuales, grupales y colectivas.

Expresándose la identidad y características de los mismos en la variabilidad del ataque y la defensa, el aumento de la velocidad de juego, la imprevisibilidad del contexto ambiental, así como en la riqueza y velocidad de las variaciones tácticas (TAVARES; GRECO; GARGANTA, 2006). Procurando los jugadores y los equipos resolver en situación, varias veces y simultáneamente, multiplicidad de problemas que encierran una elevada imprevisibilidad (METZLER, 1990) respecto al orden en que aparecen, su frecuencia y complejidad (GRÉHAIGNE; GODBOUT; BOUTHIER, 2001).

Requiriendo a los jugadores expresar actitudes y comportamientos que les permitan superar la imprevisibilidad de las estructuras de juego con que se 
encuentran, exigiendo rapidez en la toma de decisiones tácticas y velocidad en la realización de las acciones motoras. Debiendo realizar los jugadores acciones en las cuales utilicen de forma adecuada el espacio y el tiempo disponible.

En las modalidades deportivas de invasión la previsibilidad es menor en la medida que la profusión de relaciones entre colegas y adversarios aumenta el número de variables, las decodificaciones y consecuentemente la complejidad de las acciones (McGARRY; FRANKS, 1994).

En el mismo sentido los deportes en los cuales existe mayor presión temporal, es decir el tiempo disponible para realizar las acciones motoras condiciona la posibilidad de discriminar todos los estímulos informacionales del proceso de cooperación/oposición (KIBELE, 2006), presentan un aumento en el grado de incerteza de la evolución secuencial del propio juego (GARGANTA, 1999).

En ese contexto toda acción que un deportista realiza en las diferentes situaciones de juego con las cuales se enfrenta posee una finalidad táctica (TAVARES, 1993). La acción táctica en los JDC contempla presupuestos cognitivos indispensables para la solución de las tareas y problemas que el juego presenta (GARGANTA, 2004), demandando de los participantes el dominio de las capacidades perceptivas y cognitivas de la toma de decisión (GARGANTA, 2006; GRECO; MEMMERT; MORALES, 2010).

En todos los deportes la cualidad de conocimiento táctico de los deportistas se expresa en la capacidad para seleccionar "que hacer", "como hacer", "donde hacer" y "cuando hacer" para poder resolver el problema que el juego presenta (GARGANTA; CUNHA E SILVA, 1999; TAVARES; GRECO; GARGANTA, 2006; SOLÀ, 2010). Constituyendo el proceso de toma de decisión que precede a la ejecución en el juego una peculiaridad especifica de los deportes (BUNKER; THORPE, 1982).

Se puede reconocer en este punto la importancia de la coordinación de las acciones de los jugadores frente a situaciones de oposición de los adversarios. Donde la relación de oposición es establecida por las situaciones de ataque y defensa, pudiendo ser caracterizada por principios generales de ataque y defensa. Siendo los principios defensivos: (i) la búsqueda por la recuperación de la posesión del balón; (ii) impedir o dificultar la progresión de los jugadores y/o del balón hacia la meta; y (iii) la protección de la meta y las zonas 
propicias al lanzamiento del adversario. Mientras que en el ámbito ofensivo los principios fundamentales son: (i) la conservación de la posesión del balón; (ii) la progresión hacia la meta adversaria y la creación de una buena condición de finalización; y (iii) la consecución de una ventaja momentánea que permita marcar puntos/goles (BAYER, 1986).

En función de esto, existen cuatro tareas interrelacionadas que los jugadores de los JDC tienen que desarrollar: (i) atacar el campo adversario; (ii) defender su propio campo; (iii) ofrecer oposición a los oponentes; y (iv) cooperar con sus compañeros. En función de esa interrelación, el desafío básico de cada jugador es cooperar con sus compañeros con el objetivo de oponerse más eficazmente a sus adversarios al atacar (estando presto para defender) o al defender (estando presto para atacar) (GRÉHAIGNE; GODBOUT; BOUTHIER, 2001).

Este modo de perspectivar los JDC coloca tres grandes categorías de problemas (GREHAIGNE; GUILLON, 1991): (i) en el plano espacial y temporal: por la presión ejercida por el espacio limitado en que debe acontecer el juego y por la presión ejercida por el tiempo (que generalmente es escaso) para que los jugadores tomen decisiones de forma acertada, tanto en ataque como en defensa; (ii) en el plano informacional: problemas ligados a la producción de incerteza para los adversarios y de certeza para los compañeros; y (iii) en el plano organizacional: problemas relacionados con la integración del proyecto colectivo en la acción individual y viceversa.

De todo lo expresado anteriormente, y en función del condicionamiento a las capacidades de los jugadores generadas por las imposiciones del medio, se desprende que la intervención del jugador en los JDC es mucho más que la realización de habilidades técnicas, debiendo orientarse en función de principios de acción, reglas de gestión de juego y habilidades perceptivas y decisionales (GRÉHAIGNE; GODBOUT, 1995; GARGANTA, 2004).

Asimismo, no obstante sus características comunes, los diferentes deportes colectivos constituyen realidades diversas con su propia especificidad: poseen reglamentos únicos, balones con tamaños y características diferentes, terrenos de juego de dimensiones y restricciones de utilización de los espacios disímiles. Donde la interacción de estos elementos con los practicantes produce limitaciones en cada modalidad deportiva que condicionan su actividad, 
exigiendo comportamientos y acciones específicas en función de su propia estructura y naturaleza diferenciada (TAVARES, 2013). 


\section{III - BASQUETBOL}

El basquetbol es un juego deportivo colectivo (JDC) de tipo abierto, de situación y acíclico. Siendo clasificado dentro de los Tactical Games como juego de invasión (MITCHELL; OSLIN; GRIFFIN, 2003) e incluyéndose por sus limitaciones temporales entre los deportes dependientes del factor tiempo (timedependent) (FRANKS; McGARRY, 1996). Dado que el tiempo de juego es de cuatro períodos de 10 minutos de tiempo neto cada uno. Mientras que el equipo en ataque tiene 24 segundos para lanzar al aro, debiendo llegar a la zona de ataque en los primeros 8 segundos de posesión.

Siendo determinadas las principales características del basquetbol por la interacción ataque - defensa, en la cual se apoya la estructura funcional que destaca la relación espacio temporal, las relaciones entre compañeros, adversarios y el balón, y las reglas que limitan y condicionan esa interacción (DE ROSE JR; TRICOLI, 2005). Siendo la acción de juego resultante de las interacciones entre los jugadores (HERNANDEZ MORENO, 1994).

Se caracteriza por la gran cantidad de situaciones cambiantes, inciertas, variables y con alto nivel de complejidad (GARGANTA, 2006). Este deporte implica la movilización de un objeto (en caso de estar en posesión del mismo) o su recuperación, y una lucha por un espacio que es necesario ocupar o por evitar que sea ocupado, todo ello en colaboración u oposición con unos compañeros y rivales que continuamente modifican su situación en el campo de juego e intentan alcanzar una meta determinada (PARLEBAS, 1986; BAYER, 1986; TAVARES, 1993; HERNANDEZ MORENO, 1994; GARGANTA, 2004). Siendo el objetivo de cada equipo marcar puntos en el cesto de sus adversarios e impedir al otro equipo que tome el control del balón y marque puntos. Efectuándose las acciones con interacciones del sistema neuromuscular con la toma de decisión, interrelacionándose de forma dinámica y compleja con participación de los ámbitos físico, técnico, táctico y psicológico.

En la filosofía del basquetbol el concepto de ataque está siempre presente conduciendo al objetivo principal: la obtención de la conversión. Cuando el equipo está con posesión del balón procura atacar y convertir (si es posible) antes que el equipo adversario organice su defensa, es decir de manera eficiente y rápida. Mientras que cuando no tiene posesión del balón busca presionar al 
jugador con balón para recuperarla. Por lo cual la actitud activa que el equipo defensor posee también caracteriza una forma de ataque (LAMAS; NEGRETI; DE ROSE JR, 2005).

Desde el punto de vista reglamentario, la competición puede ser percibida como una secuencia encadenada de eventos que se desarrollan de forma alternativa dentro de una dinámica de regulación y contra-regulación en la cual el reglamento no solo define la naturaleza del juego, sino que también condiciona toda la funcionalidad de su desarrollo. Lo que se puede y lo que no se puede hacer son cuestiones que el reglamento clarifica con objetividad, estableciendo un cierto determinismo previamente aceptado por los jugadores y demás participantes en la competición (FERREIRA; IBÁÑEZ; SAMPAIO, 2009). Moviéndose los comportamientos de los jugadores entre dos polos de un sistema: (i) el vínculo, lo establecido, las reglas; y (ii) la posibilidad, la innovación, lo nuevo.

Considerándose un equipo exitoso al que posee elevada competencia para la cooperación entre sus jugadores, lo que se traduce en la calidad de su actuación colectiva. Adicionalmente, el éxito depende de la correcta adecuación entre la forma de jugar, las características del adversario que se enfrenta y la adaptación al reglamento (LAMAS; NEGRETI; DE ROSE JR, 2005).

Por lo cual, a pesar de los perfiles de un determinismo creciente de las reglas del basquetbol, uno de los mayores alicientes del juego de alto nivel es la incertidumbre de su desarrollo y - muchas veces - sus apretados resultados finales. Las reglas determinan, pero el mérito de saber jugar y de jugar bien es el factor que más influye en el desarrollo y el resultado funcional del sistema (FERREIRA; IBÁÑEZ; SAMPAIO, 2009). Se trata de una lucha incesante por el tiempo y el espacio dentro de las limitaciones impuestas por el reglamento, en el sentido que sean realizadas las tareas pretendidas, con el objetivo de convertir más puntos que el equipo adversario.

Desde la perspectiva del rendimiento físico se caracteriza como un deporte intermitente, con acciones de alta intensidad intercaladas con momentos de recuperación y pausa (APOSTOLIDIS et al., 2004). En los últimos años, y sobre todo desde la modificación del tiempo de posesión a 24 segundos, el nivel de exigencia física se ha incrementado significativamente (CORMERY; MARCIL; BOUVARD, 2008). Teniendo en cuenta que en el basquetbol cada jugador 
desarrolla alrededor de mil acciones por partido y que las mismas presentan una duración media de entre 2 y 5 segundos, parece evidente que a mayor capacidad de repetir esfuerzos cortos de alta o muy alta intensidad, mejores prestaciones tendrán el jugador y el equipo (TERRADOS; CALLEJA; SCHELLING, 2011). Siendo, de las acciones que se pueden dar en un partido de basquetbol, la más frecuente el cambio de dirección de la carrera. Se trata de acciones cuyo inicio puede deberse tanto al intento de librarse o alcanzar al contrario como al reaccionar ante una pelota en movimiento (TOUS, 2008).

El basquetbol requiere tanto la resistencia aeróbica, manifestada en la recuperación eficiente y el desempeño adecuado, como la resistencia anaeróbica (o específica) presente en la ejecución de acciones técnico-tácticas de acuerdo a la situación de competición, para mantener esfuerzos de alta intensidad el mayor tiempo posible dentro de los 40 minutos de juego (McINNES et al., 1995; CALLEJA et al., 2008a). Cubriendo los jugadores aproximadamente 5000-6000 metros con una variedad de movimientos multidireccionales con velocidades variables como la carrera y el dribbling, lo cual exige combinar actividades físicas de intensidad baja (la carrera de baja velocidad) con intensidad alta (sprints, saltos, arranques, detenciones) (CRISAFULLI et al., 2002; TERRADOS; CALLEJA; SCHELLING, 2011). Exteriorizando la fuerza explosiva en el rebote y el lanzamiento, la fuerza velocidad en los desplazamientos, la fuerza resistencia en la mantención del adecuado desempeño en la ejecución de los gestos técnicos, la flexibilidad en la capacidad de aprendizaje de movimientos y en ejecuciones eficaces y seguras. Mientras que la coordinación se exterioriza en todas las acciones (principalmente en las técnico-tácticas), mediante una mejor capacidad de aprendizaje de los gestos deportivos, una conversión y adaptación más rápidas y efectivas a las situaciones inesperadas del juego y en la habilidad de anticipar los movimientos del balón, del adversario y de los propios compañeros (DE ROSE JR.; TRICOLI, 2005; CALLEJA et al., 2008b).

Desde el punto de vista psicológico las situaciones que causan mayor estrés en los deportistas son: (i) errar en momentos decisivos; (ii) perder partidos prácticamente ganados; (iii) repetir los mismos errores; y (iv) cometer errores que causen la derrota del equipo. Pudiendo experimentar emociones precompetitivas relacionadas a las auto-expectativas positivas cuando se percibe algún tipo de 
control sobre las competiciones futuras y su nivel de preparación. Cuanto más incierto es el resultado deportivo y más importante el evento competitivo, el deportista experimenta emociones precompetitivas relacionadas con la preocupación y la ansiedad (BUCETA, 1998; MIGUEL; BRANDÃO; SOUZA, 2009; LORENZO; CALLEJA, 2010).

En el aspecto técnico se puede señalar que: (i) en los bases se destaca el aprovechamiento de los lanzamientos de tres puntos y los tiros libres; (ii) los aleros tienen mayor participación en los intentos y aciertos de lanzamientos y en la puntuación en general; y (iii) los pívots son mejores en los rebotes, en el aprovechamiento de los lanzamientos de dos puntos, en el aprovechamiento general de las situaciones y en los bloqueos. Siendo el resultado final de un partido de basquetbol determinado, entre otros factores, por la asociación entre la eficacia en los lanzamientos de dos puntos y los rebotes ofensivos (DE ROSE JR.; TAVARES; GITTI, 2004; IBAÑEZ, 2008). Las técnicas que presentan una mayor frecuencia de utilización, además del drible, son el lanzamiento de jump, la entrada en bandeja, el pase de pecho y el pase de pique (CALLEJA et al., 2008b).

Mientras que en el ámbito táctico existe una predominancia en la utilización del ataque posicionado en relación al contraataque. Se observa que más del $80 \%$ de los puntos son convertidos a partir de este tipo de ataque. Sin embargo, los equipos ganadores utilizan el contraataque con mayor suceso. Los parámetros de ataque presentan una predominancia de la iniciativa individual por medio de las penetraciones con drible, de situaciones $1 \mathrm{x} 1$ y de la asistencia del jugador que penetra con drible (DE ROSE JR.; LAMAS, 2006; IBAÑEZ, 2008; LAMAS, 2012). Existiendo un compromiso de relación entre la táctica principalmente a nivel individual - con la técnica, en virtud de existir diversas alternativas de respuesta operacionalizadas por el uso ajustado de determinada habilidad técnica para cada situación (KONZAG, 1991).

Una de las características principales de las acciones de juego en el basquetbol es su clara determinación desde el punto de vista táctico, lo cual coloca gran exigencia al sistema perceptivo-decisional dado que el desarrollo del partido varía continuamente (TAVARES, 1999). Ocupando la dimensión táctica el núcleo de la estructura de rendimiento (GARGANTA, 1994).

En cuanto a los aspectos perceptivos, el basquetbol se encuentra dentro 
de los deportes de tareas abiertas y regulación externa en los cuales la actividad está limitada por las condiciones del entorno y cuya dificultad perceptiva es alta (SINGER, 1980). Constituyéndose la rápida percepción e identificación de los patrones de posicionamiento del balón y de los demás jugadores en criterios de eficiencia (LAMAS, 2012). Poniéndose de manifiesto los procesos más complejos desde el punto de vista perceptivo, decisional y de ejecución (RUIZ; SÁNCHEZ BAÑUELOS, 1997; TAVARES, 1997; REFOYO ROMAN, 2001); con una gran exigencia en los mismos de un modo casi simultáneo, razón por la cual se encuentra entre los deportes de mayor dificultad dado su elevado componente táctico que exige una constante regulación perceptiva para actuar adecuadamente a las situaciones cambiantes (SÁNCHEZ BAÑUELOS; RUIZ, 2000).

Siendo la capacidad perceptiva determinada por: (i) las condiciones cambiantes del ambiente; (ii) el tipo de control prioritario basado en información sensorial externa; (iii) el tiempo y ritmo de ejecución que es externamente impuesto; (iv) el movimiento en que se encuentran el jugador y el balón; (v) las condiciones variables entre una respuesta y otra; y (vi) la gran cantidad de estímulos presentes y a atender, con estímulos ambiguos de poca duración y mucha velocidad (RUIZ; SÁNCHEZ BAÑUELOS, 1997; GARCÍA; RODRÍGUEZ; GARZÓN, 2011).

Con relación a la dinámica de juego, el basquetbol - como la totalidad de los JDC - presenta comportamiento similar a un sistema dinámico no lineal por su carácter aleatorio oriundo de la confrontación (SAMPAIO; MAÇAS, 2012; MIKOLAJEC; MSZCZYK; ZAJAC, 2013). La teoría de los sistemas dinámicos engloba al cambio y la auto organización como elementos básicos para el desarrollo del sistema (GREHAIGNE; GODBOUT; BOUTHIER, 2001; LAMAS, 2012). Entendiendo al desarrollo motor como la estabilización y desestabilización de atractores, definidos de acuerdo a una variable colectiva (THELEN; SMITH, 1998). El comportamiento motor se da en el tiempo en base a los componentes del sistema interactuando entre sí y también con la tarea y el ambiente (NITSCH, 2009). Es decir que cada JDC constituye un sistema complejo que interactúa con varios grados de libertad (siendo caracterizado como inestable o no estacionario), el cual sufre constantes cambios irregulares a lo largo del tiempo de juego entre sus elementos, con gran oscilación de equilibrio entre los equipos 
(con alternancia de ventaja entre ellos y momentos de equilibrio) sin un orden definido (ARAÚJO; DAVIDS; HRISTOVSKI, 2006; GUTIERREZ; RUIZ, 2013; DREZNER, 2014).

Por ello, al ser un sistema dinámico, presenta cuatro niveles de organización (GREHAIGNE; GODBOUT, 1995; GREHAIGNE; GODBOUT; BOUTHIER, 1999): (i) de organización juego, formado por el enfrentamiento entre los dos equipos. Esa relación de oposición se denomina combate de fuerzas (rapport of strengh), dado que se crea durante las secuencias de juego de los JDC una dinámica de movilización de una meta a la otra, la cual es potencialmente reversible. El macrosistema juego se divide en relaciones de oposición parciales que dan origen a tres subsistemas que interactúan entre sí; (ii) de organización equipo, estructuralmente formado por los jugadores y su distribución formal en la cancha. Funcionalmente se caracteriza por la evolución de la distribución de los jugadores en la cancha, así como por la red de comunicaciones utilizada que puede basarse en experiencias de juego actuales o pasadas; (iii) parcial forefront, incluye un número de jugadores directamente involucrados en la acción ofensiva por parte del ataque y defensiva por parte del adversario, es decir, que pueden interactuar directamente con el atacante en posesión del balón; y (iv) primario, el cual es la unidad mínima de oposición, incluyendo - por lo tanto - al atacante en posesión del balón y a su marcador directo.

Describir el básquetbol sobre esta perspectiva implica reconocer que en un partido el sistema formado manifestará comportamientos emergentes e impredecibles, los cuales consisten en un gran número de partes en interacción con la capacidad de formación espontanea de patrones (por ej.: 1x1, 2x1, etc.) y las transiciones entre ellos - que emergen, persisten, cambian y se reorganizan de acuerdo a lo que sucede durante el desarrollo del juego (LAMAS; SEABRA, 2006).

A partir de este punto de vista el juego del basquetbol puede ser abordado como un conjunto de situaciones de exploración dinámica, creando condiciones de confrontación entre dos grupos con objetivos diferentes, los cuales se consustancian en un campo de fuerzas que tienden a mantenerse en un equilibrio (un caos determinista) que nunca se disuelve completamente (GREHAIGNE; GODBOUT; ZERAI, 2011). Definiendo al jugar como un equilibrio 
precario, y en organización ofensiva principalmente, un equilibrio dinámico identitario de un proceso de culturización donde los principios de juego de un equipo actúan como un atractor extremo o como una unidad fractal del modelo de juego (FRADE, 2015).

Sintetizando, el jugador de basquetbol se encuentra obligado - por la acción de competición - a una continua anticipación de las situaciones de juego y de las consecuencias de los resultados de sus acciones (HOFFMANN, 1993; 2009). En ese sentido los procesos cognitivos solicitan una percepción y anticipación compleja y diferencial del juego, identificando y jerarquizando los estímulos propios y del entorno más significativos para llevar a cabo los comportamientos motores perseguidos (atención selectiva), una toma de decisión original (no sólo estímulo-respuesta) adecuada a la situación que debe resolver una vez analizadas las condiciones de los estímulos propios y del entorno, y una permanente solución motora que debe estar dotada de la precisión requerida en el momento oportuno (SEIRUL-LO, 1993).

Hoffmann (1993) plantea el modelo ABC (Anticipatory Behavioral Control), siendo la principal característica del control adaptable de acción voluntaria la capacidad de anticipar los acontecimientos futuros de corto y de largo plazo. Según esta teoría, las anticipaciones de las acciones están basadas en la adquisición de representaciones acerca del efecto de una acción, resultando más fuertes las representaciones si más a menudo una cierta acción conduce al efecto deseado. Las acciones voluntarias no sólo van unidas a las representaciones, sino también al contexto circunstancial en el cual una cierta acción realizada coherentemente produce el efecto deseado.

El papel de la anticipación en el control de acción voluntaria va más allá de la anticipación de los efectos de la acción. Por ejemplo, las pre señales y señales que alertan son usadas para preparar el que hacer (MEIRAN, 1996), cuando interpretar o esperar un acontecimiento (CALLEJAS; LUPIANEZ; TUDELA, 2004) y para anticipar un conflicto (CORREA; RAO; NOBRE, 2009). Existiendo al menos tres modos de anticipación flexible involucrados en el control de la conducta: (i) anticipar el estado futuro del ambiente; (ii) la anticipación ante situaciones inespecíficas (o desconocidas); y (iii) la anticipación para actuar ante situaciones específicas (o conocidas) (HOFFMANN, 2009). 
Por ello, el desarrollo de las acciones en entornos cambiantes de realización, está sujeto a un proceso de ejecución constantemente mediatizado por factores externos, razón por la cual el control de movimiento es de regulación externa. La forma en que se encuentran incardinadas las habilidades y destrezas básicas, y el orden secuencial de ejecución de los mismos puede ser absolutamente variable (tanto en ritmo como en intensidad) de una circunstancia a otra, mientras que las exigencias de este deporte al respecto de los mecanismos de percepción-decisión-ejecución son determinantes. 


\section{IV - CATEGORÍAS FORMATIVAS EN BASQUETBOL}

El basquetbol se encuadra dentro de las modalidades de especialización tardía, por lo cual debe definirse la orientación del entrenamiento de acuerdo con objetivos que se encuadran en el desarrollo del practicante a largo plazo (BALYI, 2001). Mientras que la enseñanza del basquetbol debe ser enfocada en atender el desarrollo integral del alumno, mediante una pedagogía capaz de enfrentar los aspectos biológicos, cognitivo, psicológico, filosófico y social del individuo (SANCHEZ et al., 2006).

Reglamentariamente las categorías formativas en el basquetbol se dividen en función de la fecha y año de nacimiento de los jugadores participantes. Siendo la categoría U-13 (under 13) la primer categoría competitiva a nivel local, provincial y nacional, por lo cual es la primera en la cual se evalúa al jugador de manera directa o indirecta en función de resultados deportivos colectivos y actuaciones individuales; mientras que la categoría U-15 (under 15) constituye la primera categoría competitiva a partir de la cual se organizan selecciones nacionales para participar en competencias a nivel internacional.

Las mismas se diferencian porque la categoría U-13 (under 13) comprende los jugadores que cumplen 13 años de edad entre el 1 de enero y el 31 de diciembre del año calendario en que se dispute la competencia. Mientras que la categoría U-15 (under 15) comprende los jugadores que cumplen 14 y 15 años de edad entre el 1 de enero y el 31 de diciembre del año calendario en que se dispute la competencia.

Del reglamento de la CABB (Confederación Argentina de Basquetbol) para la categoría U-13 (under 13) resultan destacables los siguientes puntos: (i) Sus protagonistas se hallan en un proceso de transición entre actividades lúdicas y experiencias competitivas con aprendizajes de nuevas normas y reglas que constituyen el marco regulador del juego; (ii) En esta Categoría los aprendizajes no solo están orientados al desarrollo de habilidades deportivas sino a la adquisición de conductas y valores destinados a la formación integral del deportista; (iii) La defensa individual es obligatoria, debiendo todos los defensores tener la responsabilidad de controlar a un atacante rival. El defensor del atacante sin balón que se ubica en el lado débil (cruzando el eje de cancha y del lado opuesto al balón) deberá tener como mínimo un pie fuera de la pintura, 
excepto que el atacante produzca cortes o esté en el límite con la pintura (zona de tiro libre), donde el movimiento defensivo será libre. El defensor del atacante sin balón que se ubica en el lado fuerte (del lado del balón) debe permanecer en una posición más próxima a su defensor que del hombre balón. Está permitida todo tipo de ayuda defensiva en acciones de penetración como así también defensa del 2 × 1 sobre el hombre con balón (artículo 2 del Reglamento de la $C A B B$ ); y (iv) La regla de los 24 segundos es modificada en relación a la Regla Oficial FIBA (International Basketball Federation), permitiendo que el equipo con control de balón tenga 24 segundos de posesión a partir de su control en campo de ataque, lo cual permite la posibilidad de mayor tiempo de posesión del balón por el equipo en ataque.

Mientras que del reglamento de la CABB (Confederación Argentina de Basquetbol) para la categoría U-15 (under 15) resultan destacables los siguientes puntos: (i) Están permitidas todo tipo de variantes defensivas; y (ii) La regla de 24 segundos se aplica de acuerdo a la Regla Oficial FIBA, permitiendo que el equipo con control de balón tenga 24 segundos de posesión a partir de su control en cualquier sector del campo de juego.

Los equipos de las categorías U-13 (under 13) y U-15 (under 15) están incluidos en la etapa "Train to train" (T2T - Entrenar para entrenar) de la fase "Develop the game" (Desarrollar el juego) del "Long-Term Athlete Development" (proceso de desarrollo del deportista a largo plazo), siendo la primer etapa en la cual se debe hacer foco en la excelencia. En la misma - durante las competiciones - los deportistas juegan para ganar y hacer lo mejor, pero el foco principal del entrenamiento y la competición debe ser la aplicación de las habilidades, estrategias y táctica aprendidas en el entrenamiento en situaciones competitivas (BALYI, 2001; BALYI; WAY; HIGGS, 2013). El entrenamiento debe tener intensidad elevada durante toda esta etapa y debe ser individualizado en los aspectos de la preparación física, psicológica, técnica y decisional (BALYI, 2003), aumentando considerablemente las horas de entrenamiento específicas para la mejora de su rendimiento (BAKER; CÔTÉ; ABERNETHY, 2003).

Situándose los jugadores de basquetbol de la categoría U-13 en la "fase de preparación multilateral orientada" (11 - 13 años), en la cual (entre otras características): (i) se encuentran muchas diferencias individuales; (ii) se dan las condiciones necesarias para comenzar a desarrollar aspectos tácticos 
específicos ; y (iii) constituye una etapa importante para continuar desarrollando experiencias motrices amplias para una formación deportiva sólida sin centrarse en la búsqueda del perfeccionamiento ni grandes rendimientos (SERRABONA, 1997). En esta categoría el entrenador debe ayudar a los jugadores a adaptarse progresivamente a un nivel de exigencia mayor, profundizando en el desarrollo de los fundamentos técnicos y las decisiones de táctica individual y grupal (las decisiones del 1x1, 2x2, 3×3, etc.) (BUCETA, 2000). Mientras que los jugadores de la categoría U-15 se sitúan en la "fase de especialización específica" (14 - 16 años), en la cual se destaca que: (i) debe existir una iniciación a la especialización; y (ii) el entrenamiento deportivo comienza a ser orientado hacia un mayor rendimiento (SERRABONA, 1997). En esta categoría el entrenador debe fomentar la iniciativa controlada, estableciendo criterios que faciliten las decisiones de los jugadores y valorando el mérito de los que intentan hacer cosas siguiendo esos criterios (BUCETA, 2000).

Dado que la construcción de un proyecto de vida deportiva está sujeto a los procesos de crecimiento, maduración y desarrollo del individuo, así como a las diversas condiciones socio-culturales que lo rodean (LORENZO; CALLEJA, 2010), las diferentes fases de desarrollo del jugador de basquetbol no constituyen compartimentos estancos, sino que son partes de un proceso continuo en el cual deben ser consideradas las diferencias individuales.

En los jugadores de basquetbol - como en todas aquellas modalidades deportivas en que la evolución se realiza en categorías que comprenden al menos dos años de edad - se observa un incremento en el abandono deportivo durante los años de transición entre una categoría y la siguiente, cuando pasan de ser un referente y competente a ocupar los últimos puestos del equipo (LORENZO; CALLEJA, 2010). Además debe tenerse en consideración que, por el hecho de tratarse de jugadores jóvenes, una diferencia de casi un año en el desarrollo tiene un gran reflejo en variables importantes para el contexto deportivo tales como la coordinación, peso, talla, fuerza, velocidad (HELSEN; WHINCKEL; WILLIAMS, 2005), percepción, reflejos, maduración psicológica y emocional, habilidades tácticas y estratégicas, así como el mayor tiempo de practica en la modalidad (JIMÉNEZ; PAIN, 2008). Todas esas diferencias en el desarrollo pueden provocar una desventaja para los jugadores nacidos al final de un mismo año y este fenómeno es conocido como efecto de la edad relativa 
(LORENZO; CALLEJA, 2010), entendido como la diferencia de edad entre individuos que han sido agrupados juntos para un propósito concreto o función (THOMPSON; BARNSLEY; STEBELSKY, 1991). Dado que en la etapa entre los 12-14 años de edad cronológica se produce la mayor variación interindividual en la maduración biológica (ASTRAND, 1996), el efecto relativo de la edad resulta más evidente en las categorías de formación de los deportes de equipo donde las diferencias intra-equipo son mucho más determinantes para el rendimiento (MANONELLES et al. 2003). Siendo este efecto indiferente e independiente de las diferentes fechas de corte y de una gran variedad de factores ambientales, socioculturales o políticos (MUSCH; HAY, 1999). 


\section{V - ENTRENADOR}

El entrenamiento deportivo es un proceso intencional, sistemático y planificado basado en los principios pedagógico - científicos de la educación y la formación deportiva, con el objeto de conducir a los deportistas a lograr los máximos rendimientos en un deporte o disciplina deportiva, actuando sobre la capacidad de rendimiento y la disposición para éste (HARRE, 1987). Donde la búsqueda de la excelencia deportiva resulta esencial para la formación de deportistas que tengan el deseo de vencer, de trascender defectos y fracasos, asumiendo los esfuerzos necesarios para la consecución de las metas propuestas.

El proceso de entrenamiento deportivo ha sido caracterizado como un proceso de toma de decisiones (ABRAHAM; COLLINS; MARTINDALE, 2006), donde el entrenador es el principal gestor de las decisiones y las acciones que definirán el entrenamiento (NASH; COLLINS, 2006), con la función específica de conducir dicho proceso y haciéndolo encuadrado en un conjunto de saberes propios que sustentan la capacidad de desempeño profesional.

Destacándose entre las diferentes funciones del entrenador (MARTENS, 2002): (i) confección del equipo; (ii) dirección del equipo; y (iii) planificación del entrenamiento en todos sus aspectos (físico, psicológico, teórico y técnico táctico). Orientando el proceso de entrenamiento en una dirección determinada (GARGANTA, 2000) con la finalidad específica de promover intencionalmente el aprendizaje con los medios adecuados a la naturaleza del mismo (MESQUITA, 2010).

El entrenador debe proporcionar experiencias de aprendizaje significativas, que conduzcan al deportista a comprender mejor el juego, aprender el juego y jugar el juego (IBÁÑEZ, 2008). Lo cual requiere una riqueza de conocimientos y dominio de la metodología de enseñanza articulado con las exigencias técnicas y tácticas del juego, así como con los conocimientos provenientes de la pedagogía deportiva.

Para que el proceso de entrenamiento sea un medio adecuado para la formación del jugador, la relación entre el deporte (como contenido) y la pedagogía implica la utilización de una serie de estrategias y de medios de entrenamiento que el entrenador debe conocer para el diseño de sus sesiones 
(CAÑADAS et al., 2011). Mientras que para que una tarea practica sea efectiva esta tendrá que, entre otros factores, estar en consonancia con el modelo de enseñanza-aprendizaje-entrenamiento en el que el entrenador se fundamenta, así como con el método que emplea para el desarrollo de los contenidos (IBAÑEZ et al., 2013).

Reconociendo que todo juego carga en su interior la invitación al ejercicio de una misión, de un plan estratégico constituido con la intención de obtener el éxito. Enseñar un juego es proveer al sujeto de la capacidad de ejecutar con éxito la misión de jugar, de ser capaz de vencer a través del ejercicio de un comportamiento eminentemente estratégico - táctico (SANTOS, 2013). La formación del jugador - de la cual es el principal responsable el entrenador deportivo - depende de factores psicológicos, cognitivo-motores y socio-afectivos (PIÑAR; CÁRDENAS, 2009; TARODO et al., 2011).

En opinión de los deportistas los entrenadores son los elementos más influyentes del universo deportivo (ERIKSSON, 2003) y la calidad de enseñanza - entrenamiento está directamente relacionada con la calidad de la información que el entrenador es capaz de transmitir (SANTOS et al., 2009). La intervención pedagógica del entrenador puede ejercer una influencia significativamente positiva en el aprendizaje de los deportistas (SANTOS et al., 2009). Teniendo como objetivos: (i) el facilitamiento de los aprendizajes; (ii) la obtención de rendimiento tanto individual, grupal como colectivo (GALLEGO; VÉLEZ; LÓPEZ, 2007; LAMAS, 2012); (iii) enseñar a los jugadores a tomar decisiones correctas en el juego; y (iv) enriquecer el conocimiento declarativo sobre el deporte y su inserción cultural, coadyuvando en la formación de la personalidad de los mismos (JONES; TURNER, 2006).

Por lo cual - independientemente del nivel competitivo en cuestión - ser entrenador siempre es una función extremamente compleja de carácter riguroso, en la medida que se asume un papel y una misión preponderante, con exigencia del ejercicio de una lista interminable de tareas, habilidades, actitudes y comportamientos (FEU, 2006; IBÁÑEZ et al., 2013). Debiendo tener la capacidad de asumir y aceptar la función de dirigir, orientar y enseñar una disciplina deportiva, lo cual implica un compromiso con tres requisitos previos: (i) tener un gran entusiasmo por la práctica deportiva en cuestión; (ii) disfrutar con la enseñanza y el permanente contacto con los jóvenes; y (iii) acreditar un mínimo 
valor formativo que le permita contribuir al desarrollo deportivo (ANTON, 2000; IBÁÑEZ et al., 2013).

En este sentido, el entrenamiento con niños y jóvenes posibilita una diversidad de situaciones, razón por la cual constituye un medio formativo por excelencia de ciudadanía y de formación deportiva (AFONSO; GRAÇA, 2013). Reconociendo que el ser entrenador es una actividad social, por lo cual requiere el desarrollo de habilidades interpersonales basadas en el proceso recíprocamente influenciado de sistemas de interacciones sociales, como por ejemplo las relaciones con los atletas, la comunidad de entrenadores y la comunidad local (CÔTÉ; GILBERT, 2009; MESQUITA et al., 2012).

Existiendo multitud de condicionantes directos $\mathrm{O}$ indirectos para el entrenador. Pudiendo ser agrupados en cinco grandes dimensiones: (i) sociodemográficas del entrenador (edad, género, etc.); (ii) el grupo de jugadores; (iii) los aspectos del contexto de entrenamiento; (iv) las características personales del entrenador; y (v) la formación del mismo (FEU, 2004).

El deporte enfrenta a los entrenadores con una gran cantidad de variables, incluidas en todas las áreas del entrenamiento y de la competición, las cuales originan una gran complejidad en sus sistemas de toma de decisión (LYLE, 2002; ABRAHAM; COLLINS; MARTINDALE, 2006). Áreas que dada su especificidad requieren de profesionales competentes capaces de dar respuesta a esos desafíos (SANTOS et al., 2010). Entendiendo la competencia como la capacidad de aplicación del conocimiento en un entorno específico (WESTERA, 2001); interpretándola como una función de los conocimientos, las habilidades, la situación, la autoconfianza y los valores (KIRSCHNER et al., 1997; STEPHENSON; WEIL, 1992). El entrenador competente posee el conocimiento y capacidad de saber cuándo, cómo, en qué contexto y el para qué utilizar sus habilidades y capacidades. Dichos conocimientos permiten que los entrenadores realicen diagnósticos y resuelvan los problemas específicos del deporte. Permitiendo la elaboración de estrategias, abordajes e intervenciones más adecuadas para diferentes jugadores, contextos y situaciones (NASCIMENTO et al. 2009; SANTOS et al., 2010).

Dentro de las competencias exigidas al entrenador se destaca el dominio de habilidades prácticas, conocimientos científicos, capacidad de reflexión y toma de decisión. Las cuales se desarrollan mediante experiencias, intereses, 
necesidades y demandas de los entrenadores en el transcurso de su trayectoria personal y profesional (CORBI; COSTA, 2003).

En los deportes de equipo, por su complejidad estructural y funcional así como por el número de deportistas que conforman un equipo, los entrenadores deben acompañarse de una serie de colaboradores especialistas en diferentes facetas del juego (ataque, defensa, física, rehabilitación, médica, psicológica, preparación de partidos, etc.), que conforman el cuerpo técnico de un equipo (ZIANE, 2004; IBAÑEZ et al., 2013). Recayendo sobre el entrenador y su cuerpo técnico la responsabilidad de la planificación, el desarrollo y control de entrenamiento (IBAÑEZ, 2008).

Constituyendo la toma de decisiones que debe llevar a cabo el entrenador una selección de estrategias educativas, realizada luego de evaluar y comparar las consecuencias de las distintas alternativas posibles y teniendo en cuenta los sujetos o destinatarios a los que se dirige, los objetivos educativos, así como las tareas correspondientes (CÔTÉ; SEDGWICK, 2003; DEMERS; WOODBURN; SAVARD, 2006; DUFFY, 2008). Siendo dos de las decisiones más importantes a tomar por el entrenador (i) la selección o diseño de las tareas que formarán parte del programa práctico del proceso de entrenamiento unido a (ii) su intervención didáctica (FEU; IBÁÑEZ; DELGADO, 2010).

Asimismo, los entrenadores deportivos presentan diversos perfiles $u$ orientaciones a la hora de desarrollar su actividad profesional, en función de las variables contextuales que rodean al entrenamiento, de las características personales del entrenador y del proceso de formación realizado. Pudiendo reconocerse seis perfiles teóricos de entrenador (IBAÑEZ, 1997), los cuales no son excluyentes entre sí ni rígidos, pudiendo modificarse en función de muchas variables y del aumento de la experiencia en la función. Los perfiles y sus características básicas son: (i) Tradicional: transmite prioritariamente modelos de reconocida eficacia. Emplea estilos de enseñanza tradicionales como el mando directo o asignación de tareas. Prefiere un clima de entrenamiento serio y tenso donde los jugadores y sus ayudantes sigan sus instrucciones. No suele modificar ni innovar, posee un alto conocimiento en táctica y técnica, y los que le rodean saben sus funciones y las exigencias del entrenador hacia ellos; (ii) Tecnológico: basa sus actuaciones en el estudio y control de los factores que influyen en su deporte (número de posesiones - conversiones, tipos de defensa 
utilizadas, metros recorridos, etc.). Necesita que sus ayudantes sean especialistas en la medición y análisis de esos factores. Los jugadores deben estar dispuestos a colaborar dado que se analiza jugador por jugador y al equipo como un todo. Tiene una planificación meticulosa y un control exhaustivo del trabajo a desarrollar posteriormente; (iii) Innovador: se caracteriza por innovar estrategias y elementos en el entrenamiento. Experimenta constantemente e introduce cambios para buscar mayor eficacia, prefiere que sus ayudantes sugieran novedades para mejorar el entrenamiento. Suele haber un buen clima debido a la variabilidad de los entrenamientos, aunque a veces los jugadores están desconcertados con tanto cambio; (iv) Colaborador: prefiere delegar funciones en sus ayudantes especialistas en distintas facetas, ya que es difícil que pueda ser un experto en todas las facetas del entrenamiento. El entrenamiento es conducido por él o por cada especialista de acuerdo al objetivo perseguido. Mantiene un clima de confianza con los jugadores y los ayudantes, que suelen ser intermediarios entre los jugadores y el entrenador; (v) Dialogador: intenta favorecer el buen clima de entrenamiento y controlar mediante el dialogo todos los elementos que lo rodean (medios de comunicación, directiva, ayudantes, jugadores, etc.) para convencerles sobre el trabajo que se está haciendo. El dialogo tiene un gran poder de convicción entre sus jugadores, mantiene con ellos charlas previas al entrenamiento. El clima es bastante bueno, delegan responsabilidades y los jugadores pueden ser reconducidos hacia los objetivos fijados; y (vi) Crítico: analiza, reflexiona y critica el proceso de entrenamiento que está desarrollando y por lo tanto es inconformista. Busca la perfección y el clima de trabajo es tenso, incluso a veces con sus ayudantes.

Por otra parte, la intervención del entrenador debe ser orientada por referenciales de calidad. Esto exige una formación específica capaz de responder a las exigencias particulares de la modalidad deportiva y, simultáneamente, lo suficientemente amplia en lo que se refiere a la exploración de las posibilidades educativas del deporte en la formación de niños y jóvenes (MESQUITA et al., 2012).

Para desarrollar sus competencias, la educación de los entrenadores debe proporcionar un plan de estudios diseñado para estimular a los futuros entrenadores para convertirse en estudiantes activos, reflexivos, solucionadores de problemas, desarrollando habilidades evaluativas y la capacidad de investigar 
sus propias prácticas. Para ello la formación didáctica de los entrenadores debe estar orientada a la intersección de tres preocupaciones: (i) conocer el juego como materia de enseñanza; (ii) percibir la potencialidad pedagógica del juego, de saber jugar con y contra el otro; y (iii) ser capaz de construir los escenarios de enseñanza y entrenamiento donde se pueda aprender a jugar bien. Estas tres preocupaciones deben ser contenidas por una identificación cognitiva y por una adhesión afectiva, es decir por una vinculación a una cultura deportiva pedagógicamente referenciada y didácticamente sustentada (GRAÇA; MESQUITA, 2009).

El contexto de formación del entrenador puede ser: (i) Formal (mediante un sistema de certificación de medio y largo plazo ofrecido por entidades gubernamentales, federaciones deportivas, entre otras); (ii) No formal (conocimiento específico organizado y transmitido por fuera de la estructura del sistema formal a través de conferencias, seminarios, workshops y clínicas); e (iii) Informal (proceso en el cual cada persona construye conocimientos, actitudes y discernimientos propios a partir de experiencias de la cotidianeidad del entrenamiento) (JIMÉNEZ; LORENZO; GÓMEZ, 2009).

La formación inicial y permanente del entrenador, tanto formal como no formal, condiciona el perfil del entrenador. Siendo la construcción de un estilo personal uno de los requisitos para alcanzar la expertise, lo cual es potenciado por la práctica reflexiva (MESQUITA, 2010).

Asimismo se debe tener en cuenta que la experiencia del entrenador tiene un papel determinante en el éxito de la preparación deportiva, ya que su responsabilidad en el diseño de objetivos, la selección de contenidos y la aplicación de las metodologías de entrenamiento es de vital importancia (LEITE; SAMPAIO, 2012).

Exigiendo la importancia del entrenamiento deportivo - para una adecuada formación de los jugadores - la selección adecuada de las condiciones de práctica. Teniendo, la estructuración y organización de las tareas de entrenamiento una importancia vital, debiendo ser el resultado de un proceso reflexivo y concienzudo (IBAÑEZ, 2008). De este modo, la identidad del entrenador es provisoria $e$ inacabada y se encuentra en constante transformación a lo largo de su vida personal y profesional. Debiendo procurar y 
reformular constantemente su conocimiento adoptando una actitud investigadora (CASARIN et al., 2011).

Mientras que - independientemente del nivel de formación del entrenador y su experiencia - el énfasis del proceso debe ser colocado en el desarrollo y la promoción del pensamiento crítico, en la capacidad de detectar y resolver problemas, en la elevación de los valores que el entrenador perfila y transmite y en el desarrollo de su capacidad de liderazgo y de comunicación, considerados ejes nucleares del desarrollo de la excelencia profesional (MESQUITA, 2010). 


\section{VI - TÁCTICA DEPORTIVA}

\section{ESTRATEGIA, TÁCTICA Y TÉCNICA DEPORTIVA}

Un partido de basquetbol no es, ni debe ser, una simple disputa espontánea e imprevisible. Por el contrario, es algo pensado, programado y racionalizado para intentar responder a cualquier iniciativa contraria. Siendo aquel equipo que mejor utiliza los factores y componentes del juego el que estará más cercano de la victoria. Dentro de los factores que influencian la actuación de un equipo se destacan la estrategia, la táctica y la técnica (SAMPEDRO, 1999).

La obtención del éxito en el transcurso de un partido se concreta a partir de las acciones tácticas que los jugadores realizan de acuerdo a la preparación del equipo en los entrenamientos, así como de la aplicación, mantenimiento y modificación del plan elaborado en el transcurso del partido (MATIAS, 2009).

Siendo estrategia, táctica y técnica conceptos frecuentemente utilizados al hablarse de los Juegos Deportivos Colectivos (JDC) (GRECO, 1995; GARGANTA, 2006). Orientando la planificación, entrenamiento y evaluación del desempeño, cuyo entendimiento influencia las concepciones de entrenadores, deportistas, dirigentes e inclusive de la prensa deportiva (LAMAS, 2012).

En este sentido, la estrategia ha sido definida a lo largo del tiempo por diferentes autores como:

Arte de adaptar las tácticas al objetivo escogido. Aplicación sobre el terreno de un plan de acción individual o colectivo con la finalidad de resolver el problema propuesto por una situación motriz determinada (PARLEBAS, 1981).

Plan táctico especial y otras medidas previas al juego que, por lo tanto, preceden a la táctica que posee un carácter aplicativo y operativo (TEODORESCU, 1984). Representa lo que está determinado previamente para permitir la organización (GREHAIGNE; GODBOUT, 1995).

Es la totalidad del plano teórico de organización del equipo. Constituye el plan previo de actuación a corto, mediano y largo plazo, formulado a partir del análisis del objetivo principal y de los aspectos intervinientes en la actuación del equipo (RIERA, 1995).

Proceso de carácter prospectivo que define los límites de la actuación táctica del 
jugador (GARGANTA, 2006).

Mientras que la táctica ha sido definida en función del paradigma en que se sustenta de la siguiente manera:

Aplicación concreta de los medios de acción (PARLEBAS, 1981).

Interrelación de los factores de juego: espacio, tiempo, compañeros, adversarios, balón, todo en cada situación particular y en dependencia directa del objetivo final del deporte y de los objetivos generales y específicos de la acción (BAYER, 1986).

Conjunto de normas y comportamientos (individuales y colectivos) con el objetivo de realizar una prestación con éxito a partir de una contribución activa y consciente durante el juego (TAVARES, 1993).

Método de acción propio del sujeto en una situación de juego a través del cual este utiliza al máximo los condicionantes, la incerteza y la imprevisibilidad del juego (GREHAIGNE; GODBOUT, 1995).

Gestión intelectual del comportamiento en las situaciones de conflicto (GARGANTA, 1997).

Capacidad de lectura de juego, que permite mayores posibilidades para resolver los problemas que se presentan en el mismo a través de la decisión más adecuada (REZER; SAAD, 2005).

Entendimiento deportivo de oposición entre sujetos (y equipos) que utilizan secuencias en ataque y en defensa encaminadas al logro de un objetivo físico final (SOLA, 2010).

Capacidad de manipular el ambiente, en medio de la dinámica ataque-defensa, y la ponderación de los límites de la propia capacidad de respuesta con el objetivo de resolver el problema táctico impuesto por el adversario, en un plano individual o colectivo (LAMAS, 2012).

En función de las definiciones anteriores se puede establecer que la táctica consiste en determinar medios y encontrar soluciones para los problemas prácticos surgidos en las situaciones de juego (GRECO; CHAGAS, 1992; GARGANTA, 2000).

Siendo la estrategia y la táctica factores determinantes en la ejecución de las diferentes tareas de competición en los JDC que se encuentran estrechamente relacionadas por medio de la acción deportiva (GARGANTA, 2002). Dado que la estrategia se relaciona a la elaboración de los diferentes 
planes de acción y la táctica a la aplicación de la estrategia en el contexto de una situación de juego o de la competición (GARGANTA, 2000). De este modo, la estrategia y la táctica son dos conceptos que pueden recibir una misma denominación, componente estratégico-táctica (GARGANTA, 1997).

La dimensión estratégico - táctica emerge como un polo de atracción, campo de configuración y territorio de sentido de las tareas de los jugadores en el transcurrir del juego. Dado que la situación determina: (i) el qué (objetivo); (ii) cuando (momento); (iii) donde (espacio); y (iv) el cómo (forma) de las tareas ejecutadas por los jugadores en el juego (GARGANTA, 1997).

Siendo el componente estratégico-táctico el principal medio de lucha contra el azar y la imprevisibilidad del juego, toda vez que la estrategia y la táctica se sirven de lo aleatorio, procurando encontrar en ello las informaciones para contrariarlo (TAVARES, 2013).

Es por esto que la dimensión estratégico-táctica es el elemento central de los JDC, asumiendo un papel determinante en el éxito deportivo, en la medida que el juego se caracteriza por una red compleja de relaciones de oposición y cooperación (TAVARES, 1993; GARGANTA, 2005; SANTOS, 2004; ZIANE, 2004; GREHAIGNE; RICHARD; GRIFFIN, 2005; GRECO, 2009).

La táctica se constituye como elemento central y coordinador de los juegos de oposición a través de un complejo mecanismo que engloba la percepción y el análisis de la situación, la decisión a tomar y la ejecución (AGUILÁ, 1991; GRECO; CHAGAS, 1992; RIERA, 1995; MOYA, 1996; COSTA et al., 2002).

De este modo, la dimensión táctica alcanza su nivel de expresión más alto y ocupa el núcleo de la estructura de rendimiento en el contexto de los JDC, condicionando de esta forma a las demás estructuras del rendimiento deportivo (RIERA, 1995; TAVARES, 1999; GARGANTA, 2006). Constituyendo la componente táctica en los JDC un requisito básico para una performance de excelencia (JANELLE; HILLMAN, 2003).

Por lo cual, el concepto clave que diferencia estructuralmente los deportes, no es la posibilidad de percibir habilidades técnicas o la posibilidad de entender aspectos teóricos y cognoscitivos previos a la competición, sino la presencia (o no) del comportamiento táctico (SOLÁ, 2010). 
En tanto que la técnica se define como la interpretación en el tiempo, espacio y situación, del medio instrumental operativo inherente a la concreción de la respuesta para la solución de tareas o problemas motores (GRECO; BENDA, 1998). Es decir, el sistema de acciones motoras racionales que, realizadas de forma eficiente, permiten elevados niveles de eficacia en la obtención de un resultado. Siendo condicionada por las restricciones que imponen los factores externos (TAVARES, 1996). El carácter informacional de la técnica es un aspecto valioso para la actuación libre y creativa de los deportistas, toda vez que los coloca como sujetos del sistema (LAMAS, 2012).

Se puede afirmar que la técnica y la táctica constituyen una unidad dialéctica (ARAUJO, 2009), condicionándose e influenciándose recíprocamente, dado que la resolución táctica está condicionada por la preparación técnica, la que a su vez ofrece los medios a utilizar (KNAPP, 1963; TEODORESCU, 1984).

El gesto deportivo determinado por la toma de decisión implica una acción táctica. Denominándose de este modo a las variadas posibilidades motoras que cada jugador dispone para resolver los problemas que se presentan en el juego (MAHLO, 1969).

\section{CONOCIMIENTO TÁCTICO}

El conocimiento es una información representada mentalmente en un formato especifico, estructurado y organizado de alguna forma (EYSENCK; KEANE, 1994). Es el proceso de percibir y pensar; un saber seguro de una coyuntura que se puede probar y corresponder con la realidad (DORSCH, 2008). Mientras que conocer es comprender, es aprender a relacionar lo nuevo con lo ya conocido (MARINA, 1993).

En los JDC el concepto de conocimiento es entendido como conocimiento técnico-táctico, esto es un conocimiento situacional específico del deporte en cuestión (THOMAS; FRENCH; HUMPHRIES, 1986; GRECO; BENDA, 1998; DA COSTA; DO NASCIMENTO, 2004). El conocimiento técnico dice respecto a la habilidad específica de la modalidad, la acción propiamente dicha, el gesto motor descontextualizado. Mientras que el conocimiento táctico es definido como el conocimiento en acción, o la capacidad del jugador de tomar decisiones tácticas de un modo intencional, dinámico y dirigido a un objetivo (GREHAIGNE; 
GODBOUT, 1995; GREHAIGNE; GODBOUT; BOUTIER, 2001; GARGANTA, 2006).

El conocimiento táctico es adquirido a través de la experiencia, sirviendo de sustento para la toma de decisión adecuada en el juego (TENEMBAUM; BARELI, 1993; GRECO; BENDA, 1998; GREHAIGNE; GODBOUT; BOUTHIER, 2001; GREHAIGNE; RICHARD; GRIFFIN, 2005). Dicho conocimiento se basa en las diferentes representaciones inherentes a la capacidad táctica, almacenadas en la memoria del deportista, constituyendo el fundamento que orienta el funcionamiento de las estructuras de recepción, elaboración de la información, así como la toma de decisión (BUSCA; RIERA, 1999; GRECO, 2006; MATIAS, 2009).

Ese conocimiento permitirá al deportista saber el que y el cómo observar, dado que de lo contrario no sabrá distinguir lo fundamental de lo accesorio y menos aún evaluarlo. Eso significa que la elección pertinente, realizada por cada jugador en lo relativo a los objetivos a alcanzar y a los efectos a producir, constituye un presupuesto fundamental para el éxito (TAVARES, 1997).

Los procesos decisionales presentan un carácter dinámico dentro de un marco socio-ambiental delimitado por el contexto situacional específico (ecológico), único y difícilmente reproducible; caracterizándose los comportamientos de los deportistas por ser eminentemente tácticos (GRECO, 2009).

El conocimiento del juego se refiere no solo a la capacidad de ejecutar habilidades motoras complejas, sino además a tomar decisiones sobre el uso de habilidades apropiadas dentro del contexto de una situación de juego (MATIAS; GRECO, 2013).

Es por ello que el conocimiento táctico aparece como aspecto fundamental dentro de este dominio cognitivo no sólo por su importancia en el rendimiento deportivo, sino también por su implicación en la selección de la mejor opción táctica posible en una situación deportiva determinada (JANELLE; HILLMAN, 2003; MORENO et al., 2006).

El desarrollo del conocimiento que el deportista tiene sobre el juego posibilita el incremento de las posibilidades de elección, lo que forma parte de la construcción de la actitud táctica del jugador. Debido a la continuidad, velocidad, amplitud, variabilidad y el número de cambios del contexto de juego, el jugador 
está obligado a decidir y elaborar respuestas - acciones tácticas - correctas, precisas y rápidas (GARGANTA, 1997; 2005). Resulta imprescindible ser más rápido y mejor al pensar, al encontrar soluciones, al percibir el error, al decodificar las señales de desarrollo. En síntesis, más rápido y mejor al percibir, al pensar y al actuar, lo que quiere decir ser más eficiente y eficaz en el plano cognitivo-motor (GARGANTA, 2002).

En este sentido, la capacidad táctica de un jugador es determinada por la interacción de las capacidades cognitivas, coordinativas, técnicas y psicológicas (MENEZES; REIS, 2010) que desencadenan la toma de decisiones, las cuales objetivan la ejecución motora direccionada a la obtención de la meta deseada (GRECO; BENDA, 1998).

\section{DECISIÓN TÁCTICA}

El basquetbol es un juego táctico por excelencia, por lo cual la performance de los equipos depende ampliamente del nivel de desarrollo de las facultades perceptivas e intelectuales de los jugadores (TAVARES, 1993).

Tomar una decisión táctica en los deportes significa que el jugador debe decidir: (i) que hacer; (ii) porque hacer; (iii) como hacer; (iv) cuando hacer; y (iv) donde hacer. Es decir, con cual acción táctica será expresada la toma de decisión necesaria para solucionar la tarea o problema que el deportista enfrenta en esa situación (DE PINHO et al., 2010). Constituyendo parámetros imprescindibles para la comprensión del juego, posibilitando al practicante comportarse de manera táctica inteligente durante un partido (SOUZA, 2002).

Por consiguiente, la maestría táctica es producto de la excelencia del pensamiento operativo del deportista, esto es, del pensamiento estrictamente ligado a la actividad específica del juego. Distinguiéndose los mejores jugadores de los otros, no solo por la velocidad sino también por la exactitud con que son tomadas las decisiones (WRZOS, 1984).

Siendo varios los autores que sostienen que la maestría deportiva es producto de dos tipos fundamentales de conocimiento: el conocimiento táctico declarativo (CTD) y el conocimiento táctico procedimental (CTP) (CHI, 1981; THOMAS; THOMAS, 1994; HOUSNER; FRENCH, 1994; GARGANTA, 2000).

EI CTD en los deportes se refiere al saber que hacer (CHI, 1981; 
ANDERSON, 1982; EYSENCK; KEANE, 1994). El CTD representa al conocimiento que el deportista tiene estructurado en la forma de representaciones mentales que le permiten establecer relaciones entre los diferentes conceptos que constituyen el conjunto de saberes sobre el reglamento, estrategias, tácticas ofensivas y defensivas, así como de las diferentes posiciones de los jugadores en la cancha, sus funciones y cómo actuar en las diferentes situaciones que pueden constituirse en problemas que debe enfrentar en la competición (GARGANTA, 2000; MORALES, 2007).

Mientras que el CTP en el deporte puede ser considerado como "sistemas de producción" (THOMAS; THOMAS, 1994) que constituyen la base para la creación de acciones, con la decisión de cuando y como hacer, seleccionando las acciones adecuadas conforme la situación - problema que debe solucionarse en una competición (GARGANTA, 2000; MORALES, 2007). Esto es, saber cómo hacer por medio del empleo de las diferentes habilidades técnicas de la modalidad en un contexto táctico. Es la capacidad del deportista de conocer cómo utilizar las acciones, es decir que el CTP constituye la realización de un comportamiento que difícilmente explicamos (COSTA et al, 2002).

Ambos conocimientos se relacionan porque el CTD es la base del CTP, dado que saber "qué hacer" determina el "cómo hacer" en el contexto de una situación - problema propia de la competición. Mientras que los niveles de CTD y CTP influencian la capacidad de toma de decisión, determinando el éxito o fracaso de la acción ejecutada, constituyéndose en factores diferenciadores de la pericia en el deporte (WILLIAMS et al., 1993; GARGANTA, 2002; MORALES, 2007). Interactuando en la búsqueda de soluciones ambientales en función de las condiciones concretas del mismo (GRECO, 2006).

En síntesis, dado que la performance en los JDC depende de realizar la elección más apropiada entre las variadas opciones que posee el deportista a su disposición y la velocidad de la toma de decisión (GREHAIGNE; GODBOUT; BOUTHIER, 2001). Mientras que la toma de decisión en los JDC depende de mecanismos cognitivos, en los cuales los procesos interactúan dinámicamente para - en función de la experiencia y la situación - seleccionar un comportamiento activo (TAVARES; GRECO; GARGANTA, 2006; RAAB, 2007; 2015). Por lo tanto, los procesos cognitivos son solicitados para contribuir en la resolución de problemas presentes en el contexto del juego, por medio de una acción táctica 
que le permita responder rápida y óptimamente (MESQUITA, 2006; MATIAS; LIMA; GRECO, 2012). Siendo la gran capacidad adaptativa - creativa que caracteriza a un deportista excelente el producto de un largo proceso de construcción cultural y de formación deportiva que implica procesos de aprendizaje de habilidades de diversa naturaleza mediado por intervenciones pedagógicas (SCAGLIA, 1999; AVILES et al., 2014).

\section{TIEMPO TÁCTICO}

Si bien las secuencias temporales en basquetbol vienen en gran medida supeditadas al reglamento, pudiendo esto provocar limitaciones en el comportamiento de cada jugador y a su vez del equipo, existe una presión de tiempo para resolver los problemas y tareas del juego. Estando todas las acciones condicionadas por el parámetro situacional, constituidos por una trilogía que comprende tiempo - espacio - situación (GRECO, 1998).

Es decir que el reglamento expresa las condiciones de ejecución temporales, las cuales no se deben confundir en ningún momento con el tiempo táctico, entendido como el momento de aplicación de la táctica, o dicho de otro modo como las secuencias de movimiento humano construidas sobre el parámetro temporal que la define (SOLÁ, 2010).

Siendo una de las principales características que distingue el desempeño del experto la capacidad de reaccionar a situaciones deportivas específicas con aparente tiempo de sobra (YARROW; BROWN; KRAKAUER, 2009). Aún más, considerando la presión de tiempo impuesta a los deportistas en situaciones de juego, la capacidad de anticipar las situaciones también permite anticipar elecciones en la toma de decisión.

De este modo, la elección del momento de la ejecución táctica resulta decisiva. El tiempo establecido como un criterio de éxito del comportamiento táctico acontece cuando se está en el lugar y el momento oportuno no por azar, sino por la fina lectura de la situación presente que exige saber responder no solo al que hacer, sino también al cuando hacerlo (SOLÁ, 2010). Por lo cual el ajuste temporal de las acciones en el tiempo, juntamente con la elección de la respuesta cognitiva más apropiada para cada situación de juego, es sinónimo de eficacia y desarrollo táctico (I BALASH, 1998). 


\section{INTELIGENCIA TÁCTICA}

La inteligencia se define como una capacidad mental que permite razonar, planear, resolver problemas, pensar de manera abstracta, comprender ideas complejas y aprender (MARINA, 1993; FLOREZ MENDOZA; NASCIMENTO, 2001; COLOM, 2006); constituyendo la adaptación propositiva que comprende una amplia cantidad de aptitudes aplicadas en un contexto especifico (STERNBERG, 2000), exigiendo la adaptación de lo que se piensa a nuevas solicitaciones que el juego presenta (GRECO, 2006).

No existe un solo tipo de inteligencia, existen una pluralidad de inteligencias que se manifiestan de modo combinado. Presentando cada jugador una combinación única de formas diferentes de inteligencia y diferentes grados de manifestación. Esta combinación de formas de inteligencia define para cada jugador un perfil con características y cualidades distintivas. Si bien la inteligencia es importante, lo es más aun la inteligencia específica, una inteligencia subyacente al juego especifico, un saber sobre un saber hacer que se concretiza en la acción (REFOYO ROMAN, 2001).

Mientras que la inteligencia ejecutiva es la capacidad de dirigir bien el comportamiento, eligiendo las metas, aprovechando la información y regulando las emociones. Es decir, aquellas destrezas que unen la idea con su realización y que sirven para elegir objetivos, elaborar proyectos y organizar la acción para realizarlos. Añadiendo la inteligencia humana al movimiento natural, el cual es un movimiento intencional determinado por metas conscientes (MARINA, 2012).

El conocimiento específico de una determinada área tiene importancia decisiva en la solución efectiva de los problemas que esa área de actividad presenta (CHI; GLASER, 1992). Por lo cual el conocimiento específico es el que da las condiciones al deportista de configurar la solución (organización) y evocar las acciones motoras para la obtención del éxito (orientación), tomando una decisión que es exteriorizada en un movimiento.

Precisando los deportistas del conocimiento táctico para proceder - a través de las capacidades de recepción de información, selección y codificación de señales (percepción, atención, entre otros) - a la elaboración de una toma de decisión (capacidad de pensamiento táctico) y una adecuada conversión de las 
hipótesis generadas para la solución del problema en una acción motora, ejecutando para ello una técnica específica (capacidades técnicas y habilidades motoras), que van a permitir que el deportista consiga sostener sus decisiones durante un juego (GRECO, 2003).

Teniendo como consecuencia la decisión tomada - a partir de las interacciones de las estructuras de conocimiento, de recepción y de elaboración - una acción inteligente o creativa (GRECO, 2006; 2009).

En los JDC es importante que el jugador evidencie inteligencia táctica, una inteligencia deportiva específica que pasa por el reconocimiento por parte del mismo de varios escenarios posibles de juego, en la búsqueda continua de interpretación del significado de las situaciones inesperadas que afrontan (GRECO, 1989). Un jugar inteligente se define en la capacidad del jugador de "leer el juego", expresada en la competencia del jugador para hacer - saber hacer, poder hacer - frente a aquello que el juego solicita. Siendo el deportista capaz de detectar en pleno partido las evoluciones nacientes en la complejidad de las relaciones de cooperación-oposición y deducir las elecciones sucesivamente más apropiadas a las situaciones que se materializan instante a instante sobre el terreno de juego (TAVARES, 1993; ARAUJO, 2003; BUSCÀ, 2005; MATIAS, 2009).

Pudiendo ser definida la inteligencia táctica como el proceso psicológico multidimensional de adaptación a las diferentes variables del juego (posicionales, situacionales, temporales, entre otras) y a la capacidad de conocimiento y control de los factores condicionantes del deporte (como la preparación física, la fundamentación técnica, los principios tácticos y las destrezas psicológicas) y de dominio de habilidades psicológicas básicas en el rendimiento deportivo (percepción, atención, toma de decisiones, pensamiento) que tiene como fin la resolución más eficaz de las situaciones que el juego plantea bajo los criterios de rapidez, exactitud y anticipación (GARCíA; RODRÍGUEZ; GARZÓN, 2011).

Siendo el juego una construcción activa en la medida que su desarrollo transcurre por la afirmación y actualización de las elecciones y decisiones de los jugadores, realizadas en un ambiente de diversas restricciones y posibilidades (GARGANTA, 2005). Exigiendo el juego el apelar a la inteligencia de juego, entendida esta como la capacidad de adaptación a un ambiente en permanente 
cambio que permite al jugador percibir las múltiples configuraciones que el juego presenta optando por la mejor solución.

Consecuentemente la capacidad para prever y leer las intenciones de los adversarios y formular una respuesta apropiada basada en aspectos estratégicos, tácticos y técnicos ha sido considerada como crucial para el rendimiento (TAVARES; GRECO; GARGANTA, 2006).

Es a través de la inteligencia de juego que el deportista es capaz de percibir la situación y decidir la mejor solución. De este modo, la capacidad de tomar decisiones adecuadas es determinada por su inteligencia táctica (COSTA et al., 2002). El jugador inteligente es aquel que revela un mejor conocimiento específico del juego, lo que le posibilita una toma de decisión eficaz y adecuada en función de las varias soluciones posibles de resolución del problema. Teniendo una ventaja frente a los demás participantes, dado que suele estar mejor situado y prevé lo que va a suceder, de manera que asume una posición favorable, decide y actúa antes que los oponentes, añadiendo al conocimiento posicional el conocimiento de la temporalización de las acciones (I BALASH, 1998; PINO MEDINA et al., 2009).

En los jóvenes y adolescentes el desarrollo de las capacidades cognitivas especificas (capacidades tácticas) ayudan a desarrollar la capacidad de juego y, por lo tanto, la inteligencia de juego (GRECO, 1995).

De este modo el comportamiento inteligente de un equipo resulta de la actividad cognitiva y motora de los jugadores. Este comportamiento asocia la resolución de los problemas colocados por la relación entre las perturbaciones relativas al funcionamiento de los diferentes subsistemas y de las elecciones efectuadas por los jugadores para compensar o acentuar los desequilibrios (GARGANTA; GREHAIGNE, 1999).

Para lo cual los jugadores deben saber seleccionar y organizar las informaciones inherentes a las situaciones de juego, que incluyen decisiones del tipo: que hacer, cuando hacer, donde hacer y cómo hacer, posibilitando la adecuación de comportamientos inteligentes (GARGANTA, 1997; 2002).

\section{CREATIVIDAD TÁCTICA}

La creatividad desempeña un papel importante en la resolución de 
problemas. Descubrir una buena y creativa solución para un problema involucra la orientación consciente de los procesos mentales, procurando nuevas visiones y posibilidades ajustadas a las capacidades del deportista y a las restricciones del contexto de juego (STERNBERG, 2005).

La creatividad es la capacidad de recombinar informaciones ya existentes para resolver problemas de nuevas maneras, pero principalmente es producto de la flexibilidad cognitiva entendida como la capacidad del individuo de adaptarse a los cambios del ambiente y modificar sus respuestas en función de los acontecimientos (HERCULANO-HOUZEL, 2005). El concepto de creatividad establece una fuerte relación con el acto creativo en el deporte. La confluencia de diferentes restricciones, tales como proficiente capacidad cognitiva, conocimiento de las reglas y principios de juego, recursos técnicos eficaces y calidad de las condiciones proporcionadas por el entrenamiento, permiten al jugador desarrollar su potencial creativo y alcanzar la excelencia en el juego. Los mismos, actuando sinérgicamente, son necesarios para promover el desempeño creativo.

La creatividad en el deporte puede ser definida como una habilidad del deportista para producir acciones deportivas que son originales e innovadoras y que aspiran a la obtención del éxito en beneficio de la persona (deporte individual) o en beneficio social (deportes colectivos) (SAMULSKI et al., 2008). El concepto de creatividad está asociado al conocimiento e inteligencia que el atleta evidencia en el juego, concretizándose esta en tomas de decisión ajustadas a las circunstancias de juego (MATIAS, 2009).

El deportista creativo incorpora lo nuevo y lo inesperado, superando los parámetros normales de resolución de problemas en el juego y cumpliendo los principios de juego adoptados en relación al modelo de juego creado, seleccionado o escogido. La novedad y la utilidad son aspectos que se relacionan con la producción creativa en el juego. Demostrando el jugador una flexibilidad y una capacidad de adaptación a cualquier adversidad, estando preparado para incorporar en cualquier circunstancia una situación diferente en el juego, mejor que aquella que demostraría si todo estuviese programado (SAMULSKI; NOCE; DA COSTA, 2006).

En función de lo expuesto, el jugador creativo es aquel que posee variados recursos técnicos y eficiente capacidad para resolver los problemas del juego de 
un modo ajustado e imprevisible para los adversarios. Produciendo acciones con el objetivo de transformar momentánea o definitivamente la relación de oposición de forma ventajosa (TAVARES, 1997).

Resultando fundamental el asumir comportamientos creativos, inesperados, que a través de la sorpresa provoquen rupturas en la organización previa del adversario (GARGANTA, 1997). En esta operación acontece la diferenciación entre aquellos jugadores que poseen de forma satisfactoriamente desarrollada la capacidad de actuar tácticamente, de aquellos otros que solamente responden tácticamente a las solicitaciones de la competición.

En este sentido, toda acción táctica puede ser considerada creativa en la medida que contenga tres parámetros: (i) originalidad (decisión poco común); (ii) flexibilidad (cantidad, variedad y variabilidad de las respuestas); y (iii) adecuación/fluidez (cantidad de respuestas adecuadas de forma continua) (GRECO; ROTH; SCHÖRER, 2004). Por lo cual toda acción creativa es inteligente, pero no toda acción inteligente es creativa (GRECO, 2006). 


\section{VII - TOMA DE DECISIÓN EN EL DEPORTE}

\section{PROCESOS COGNITIVOS}

Los Juegos Deportivos Colectivos (JDC) implican una solicitación importante de las capacidades cognitivas (GRECO; SISTO, 1995; GRÉHAIGNE; GODBOUT, 1995; SOLÁ, 1998), en tanto subestructuras de la táctica (KONZAG, 1991; GARGANTA, 2002), en la medida en que la competencia de los jugadores se refleja en su habilidad de percibir las alteraciones de la situación de juego y de adaptarse rápidamente (KNAPP, 1963; TAVARES, 1993).

Por ello en los JDC, a partir de los problemas situacionales y de las exigencias organizacionales de las tareas a ser realizadas, se presenta una alta exigencia cognitiva en los comportamientos de los deportistas (GARGANTA, 2002). Mientras que la comprensión del juego pasa por la captación de los elementos que lo configuran en su complejidad.

La pericia deportiva se estructura principalmente en dos componentes del rendimiento: una cognitiva y otra motora (ALLARD; BURNETT, 1985; McPHERSON, 1994; GONZALEZ et al., 2007; MATIAS, 2009), es decir, el "qué hacer" y el "cómo hacer" respectivamente, en la medida que la capacidad para ejecutar una técnica influencia la tendencia para elegir una opción táctica en la situación de juego (GARGANTA, 2005). En virtud de esto se puede establecer que el comportamiento de los jugadores durante un partido se sitúa en una tensión permanente entre cognición y acción (GARGANTA, 2002), dado que el conocimiento táctico es fundamental para el conocimiento en la acción. Para un jugador el saber táctico y la performance se encuentran fuertemente ligados. Esto significa que la capacidad para jugar implica un desarrollo de saberes (GREHAIGNE; GODBOUT, 1995).

La cognición es considerada como la interpretación y ordenamiento de las informaciones en la consciencia (DORSCH, 2008). En los JDC tiene como base las estructuras de conocimiento técnico-táctico de la modalidad deportiva para que las acciones sean ejecutadas en el juego.

Los procesos cognitivos son la resultante de un sistema de múltiples referencias, una acción en el deporte, un proceso intencional, dinámico, direccionado a una meta y regulado psíquicamente dentro de un contexto 
específico (SAMULSKI, 2002; SAMULSKI et al., 2008); que ofrecen al jugador el reconocimiento y la orientación de la acción en las diferentes situaciones de competición (MATIAS, 2009). Los procesos cognitivos son fundamentales en la performance en los JDC debido a la alta imprevisibilidad, aleatoriedad y variabilidad que componen el contexto ambiental en esas modalidades (ALLARD; BURNETT, 1985; THOMAS; THOMAS, 1994; GRECO, 2006). Siendo requisitos esenciales para la excelencia del desempeño deportivo las capacidades tácticas y los procesos cognitivos subyacentes para la toma de decisión (McPHERSON, 1994; COSTA et al., 2011).

Mientras que la calidad de la toma de decisiones en una situación de juego es tan importante como la ejecución de las destrezas motoras, siendo ambas determinantes para el rendimiento deportivo (THOMAS, 1994; BLOMQVIST; LUHTANEN; LAAKSO, 2001).

Es por ello que las capacidades cognitivas se sitúan dentro de las más importantes capacidades a ser desarrolladas para obtener una calidad diferenciada en la prestación deportiva (SAMULSKI, 2009; NITSCH, 2009). Ya que condicionan la adquisición y el desarrollo del conocimiento técnico-táctico, tanto declarativo como procedimental (MORALES; GRECO, 2007).

La cognición en los deportes comprende las estructuras internas de recepción de la información (percepción, atención y anticipación), del procesamiento de la información (pensamiento, memoria e inteligencia) y de la decisión táctica (toma de decisión) (WILLIAMS et al., 1993; McPHERSON, 1994; GRECO; SISTO, 1995; BORTOLI; BORTOLI; MARQUEZ, 2002; BANKS; MILLWARD, 2007; MORALES; GRECO, 2007; MATIAS; GRECO, 2010) que permiten adquirir el conocimiento (declarativo o procedimental) necesario para la ejecución de tareas o para la solución de problemas. Siendo la cognición una condición sine qua non de la eficacia de la acción motora en los JDC (GRECO, 2004).

Mientras que la acción en los deportes es definida como el acto de interactuar con el ambiente en tareas específicas (NITSCH, 2009). Siendo concretizadas por los movimientos y comportamientos técnico-tácticos conscientes e intencionales que ocurren en un determinado contexto social (SAMULSKI, 2009).

La acción táctica que el deportista realiza se constituye de este modo en 
un acto orientado en la búsqueda de un objetivo específico que le posibilita aprovechar - de la manera más apropiada - todos los medios y comportamientos permitidos en las reglas específicas de los deportes para volver posibles sus acciones motoras y limitar las del adversario (GRECO, 2001). Por ello la acción táctica debe ser entendida como la dimensión unificadora que da sentido y lógica a todas las otras dimensiones tradicionales del juego (COSTA et al., 2009).

De forma tal que cognición y acción resultan conceptos inseparables, representados desde el "qué hacer", para la toma de decisión, la elección mental entre diferentes opciones y alternativas que pueden presentarse en una situación hasta el momento de la realización por vía de la ejecución del movimiento (GRECO, 1999).

\section{TOMA DE DECISIÓN}

Varios autores realzan el significado y la importancia de la toma de decisión en el deporte, considerándola como una de las más importantes capacidades del deportista, determinando muchas veces el éxito de las acciones técnicas y tácticas, siendo frecuentemente responsable por las diferencias individuales en el rendimiento y condicionando de este modo los resultados grupales y colectivos.

En los JDC el jugador es confrontado constantemente con la variabilidad de las situaciones de juego, siendo importante la rapidez con la que se deben tomar decisiones tácticas adecuadas y la velocidad de realización de las acciones motoras. En este sentido, las acciones tácticas escogidas por los jugadores deben estar de acuerdo con la anticipación de las acciones que el adversario tiene intención de realizar (TAVARES, 2002; 2013).

Es por ello que los deportistas deben percibir y usar las informaciones relevantes del ambiente para guiar sus acciones, adaptando sus movimientos a las situaciones de juego (HOFFMANN, 1993; 2009; RANGANATHAN; CARLTON, 2007). Siendo importante que los jugadores desarrollen una perfeccionada capacidad de alternancia de la percepción, en función de la velocidad del juego y de la constante variabilidad en las situaciones. La actividad de decisión en el deporte refleja la gestión inmediata de la actividad motora en función de los objetivos de la acción, en presencia de incertidumbre, bajo presión 
temporal y con exigencias de precisión (TAVARES, 1993).

En las actividades deportivas donde la incertidumbre es parte constituyente del medio, el éxito depende de la capacidad de escoger o crear una respuesta apropiada en función de la lectura de una situación en constante cambio. Efectuándose las decisiones en una dinámica relacional colectiva, debiendo ser coordinadas en el seno de unidades amplias que las convierten en sistemas de decisión. De este modo la decisión no es solo funcional porque participa en la resolución de la tarea, sino que es también significante al influir en las decisiones de adversarios y colegas (TEMPRADO, 1989).

Entendiendo que jugar bien consiste en elegir la opción de juego más adecuada en cada momento y ser capaz de llevarla a cabo de forma eficiente y consistente a lo largo de un encuentro (GRÉHAIGNE; GOODBOUT; BOUTHIER, 1999; 2001). Esta capacidad táctica para elegir la acción pertinente en cada situación requiere un análisis previo del entorno de juego por parte del jugador. La adquisición independiente de tal conocimiento requiere una acumulación de experiencias de comportamiento que conducen a reconocer los efectos que se dan bajo determinadas circunstancias (HOFFMANN et al., 2007; RAAB, 2015).

Como consecuencia de ello, enseñar a los jugadores a tomar decisiones correctas en el juego resulta una tarea de gran complejidad, dada la gran variedad de situaciones y opciones que presenta el mismo.

En este sentido, la toma de decisión se relaciona con el pensamiento táctico, el cual puede ser definido como un pensamiento operativo que permite a los deportistas manejar mayores cantidades de información y actuar más acertadamente, discriminando de forma más certera la información relevante y anticipando los escenarios posibles de actuación; y - fundamentalmente - tener un comportamiento eficaz que permita resolver el problema al que se enfrentan (LOPEZ ROS, 2011). Siendo los elementos constitutivos de dicho pensamiento: (i) el tratamiento de grandes unidades de acción organizadas en conjuntos estructurados; (ii) la capacidad para reconocer la situación-problema relacionada con el objetivo a conseguir; y (iii) la formación de soluciones aplicables a una determinada clase de situaciones (RUIZ PÉREZ; ARRUZA, 2005).

Asimismo, la toma de decisiones en el deporte supone el proceso de seleccionar una respuesta en un ambiente de múltiples respuestas posibles (SANFEY, 2007), es decir que consiste en determinar las posibilidades de éxito 
al analizarse ciertos resultados entre diferentes posibilidades (GRECO, 2009).

Cuando se decide percibir una señal a través de los procesos cognitivos ya se realiza una toma de decisión. El proceso de toma de decisión es complejo, dado que el mismo debe atender no solo a los problemas concretos en que se coloca al jugador, como también a las cuestiones y objetivos contrarios que mueven al adversario (PRUDENTE, 2006).

Los procesos de toma de decisión tratan del uso de la información para determinar cuál es la respuesta necesaria y si esa respuesta es adecuada para la situación y momento dado del partido; es decir que son la selección del modo correcto de actuar de acuerdo con las circunstancias, con el contexto y con las experiencias pasadas. La toma de decisión se realiza en interacción con diferentes procesos cognitivos, que comprenden los mecanismos de percepción, atención, anticipación, memoria, pensamiento y la propia toma de decisión (GRECO, 1995; 2006). Consolidándose en el deportista por la realización de una habilidad motora y está relacionada al contexto de la situación (GRECO, 2001; RAAB, 2003; RAAB; MASTERS; MAXWELL, 2005; NITSCH, 2009; RAAB, 2015). Abarcando el qué, cuándo y cómo ejecutar la respuesta seleccionada (PAULA, 2000; MATIAS, 2009).

Es decir que envuelve la percepción, el análisis de la situación, la decisión a tomar y la ejecución; resultando la acción en una aplicación creadora del saber, de las diferentes capacidades y de un saber hacer. Para lo cual el deportista detecta y reconoce en la situación las informaciones que revelan posibilidades de acción direccionadas para la consecución del objetivo (ARAUJO; VOLOSSOVITCH, 2005), seleccionando la más favorable en función del contexto y de sus capacidades.

Por consecuencia lo que parece ser decisivo para el éxito de las acciones en el juego es la adecuación a las circunstancias del momento, es decir, la cualidad táctica del jugador y del equipo (TAVARES, 2013).

De este modo el proceso de toma de decisiones resulta determinante en el rendimiento deportivo, pues es a través de esta capacidad cognitiva que el deportista elije la mejor acción a ejecutar en el juego; para tal efecto se deben tener en cuenta las variables situacionales y de objetivo, las alternativas de respuesta y las reglas o criterios de decisión del contexto deportivo (IGLESIAS et al., 2002). 
Igualmente, en el juego el deportista se enfrenta con problemas en los cuales existen presiones y solicitaciones fisiológicas y funcionales, siendo requeridas las funciones psicológicas en conjunto, entre ellas los procesos cognitivos (GRECO, 2004). El componente cognitivo, que se centra en los procesos de selección de la respuesta, resulta relevante en los deportes de alta componente táctica - como el basquetbol - debido a la alta incertidumbre con la que actúan los deportistas en un entorno de juego real (THOMAS, 1994; MORENO et al., 2006).

Los aspectos cognitivos están íntimamente ligados a la capacidad táctica y a la acción en los deportes. En las modalidades deportivas colectivas el deportista debe, además de percibir, anticipar los movimientos de los compañeros, de los oponentes y del balón, y por lo tanto sus acciones deberán ser anticipativas, proactivas y no meramente reactivas (SILVA, 2007).

La capacidad para "leer" y prever las intenciones de los adversarios y formular una respuesta apropiada basada en aspectos estratégicos, tácticos y técnicos es considerada como crucial para el rendimiento en los JDC (TAVARES, 1993; 2002; CASANOVA, 2012).

La calidad de la toma de decisión (en términos de velocidad y precisión) será influenciada por la calidad de información sensorial recibida, pero también por el conocimiento del individuo acerca del contexto y de las expectativas de sus experiencias anteriores (NOCE et al., 2012).

Pudiendo definirse la toma de decisión como el proceso de elección de una o más alternativas de acción que antecede a la ejecución (ABURACHID; GRECO, 2010) con la intención de resolver la situación problema en la cual el jugador se encuentra (ARAUJO; VOLOSSOVITCH, 2005).

Destacando que la toma de decisión siempre surge por la necesidad del jugador (o del equipo) de resolver los problemas del juego creados por el adversario o por el factor espacio temporal en el caso específico del basquetbol. Ocurriendo el proceso en un contexto de gran variabilidad de situaciones, las que pueden tener diferentes grados de complejidad, dinamismo e incerteza (PÉREZ; GABILONDO, 2005) y en las que tanto la toma de decisión como la ejecución motora deben ocurrir muy rápidamente (TAVARES, 1993).

La performance de un deportista en una situación de juego es consecuencia del nivel de desarrollo de las diferentes capacidades inherentes al 
rendimiento deportivo, siendo importante observar que esa performance depende en gran parte de su potencial para interrelacionar los diferentes parámetros que la componen (GRECO, 2006). Destacándose que el vector predominante de las tareas motoras en los JDC se refiere a los aspectos informacionales, perceptivos y de toma de decisión (MORALES, 2007).

A partir de esto la formación del jugador en los JDC debe contemplar los presupuestos cognitivos indispensables para la regulación de las acciones, lo cual se obtiene estructurando, perfeccionando y estabilizando la percepción de la situación, su anticipación, la fase de toma de decisión y el aprendizaje de la ejecución motora (GRECO, 1989; KONZAG, 1990; GARGANTA, 2004). Con el objetivo de formar jugadores inteligentes, con la capacidad de decisión, dotados de recursos, experiencias y conocimientos para solucionar diferentes situaciones de juego (GRECO, 1988).

\section{PROCESO DE TOMA DE DECISIONES}

La toma de decisión por parte de los jugadores en los deportes de equipo depende de al menos tres factores: (i) las propias capacidades del deportista; (ii) la tarea que se debe resolver; y (iii) las características del entorno de actuación (NITSCH, 2009). Dentro de las primeras el entendimiento que se posee del juego, la capacidad de lectura de juego y la de ejecución de las habilidades técnicas resultan determinantes (ARAUJO; VOLOSSOVITCH, 2005; LÓPEZ ROS et al., 2010).

El jugador competente desarrolla una serie de mecanismos cognitivos y emocionales antes y durante el proceso de toma de decisiones, los cuales determinarán su actuación. En este contexto la decisión no está separada de la acción motora, dado que también se da durante la misma. La racionalidad de la situación no puede ser disociada de las conductas motoras, cuyas características energéticas, afectivas y relacionales condicionan la realización efectiva del proyecto motor (GARGANTA; OLIVEIRA, 1996). Por lo tanto, la toma de decisiones es una actividad que se influenciada por aspectos racionales y también por factores emocionales (IGLESIAS et al., 2003). Obligando los avances neurocientíficos a replantear la necesidad de concederle una mayor importancia al desarrollo de las habilidades psicológicas que permiten el control 
emocional, debido a las evidencias empíricas que demuestran la influencia de las emociones en la toma de decisiones del ser humano (DAMASIO, 1996; 2011).

Para integrar las relaciones entre las acciones voluntarias, sus efectos y el contexto situacional Hoffmann (1993; 2009) propone el modelo teórico de aprendizaje para la construcción de estructuras anticipativas del control voluntario del comportamiento - ABC (Anticipatory Behavioral Control) (Figura 1).

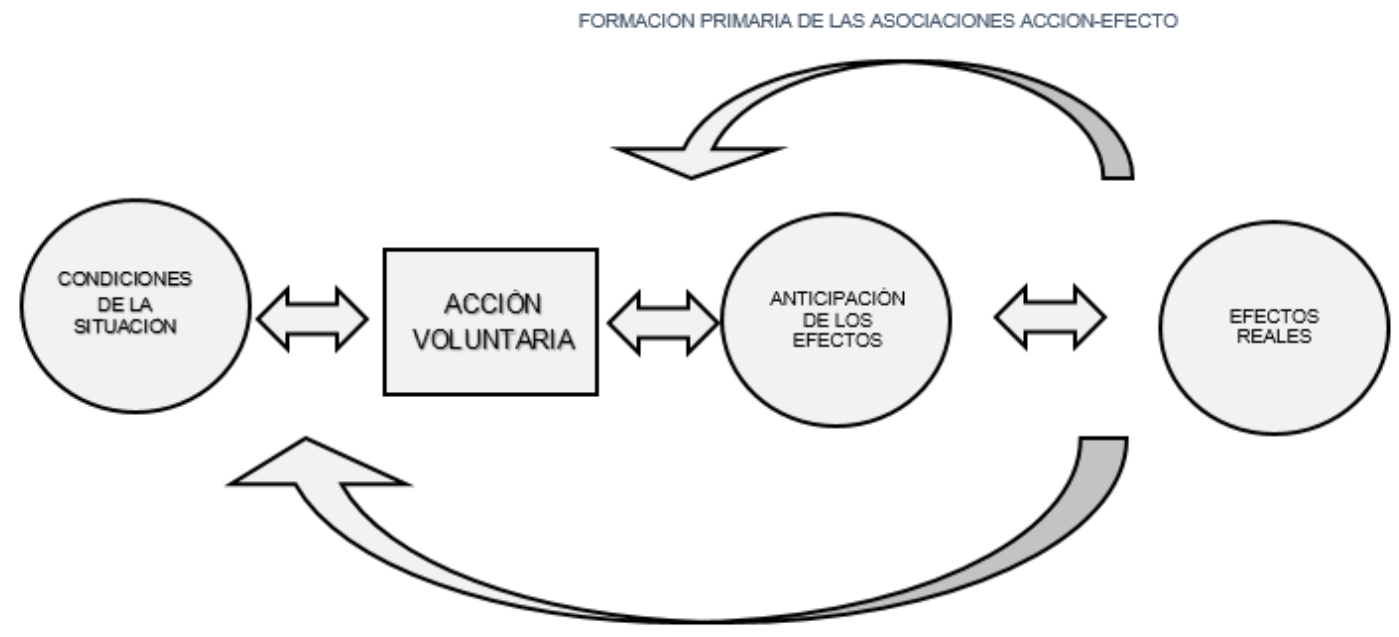

CONTEXTUALIZACION SECUNDARIA DE LAS ASOCIACIONES ACCION-EFECTO

Figura 1: ABC (Anticipatory Behavioral Control). Modelo teórico de aprendizaje para la construcción de estructuras anticipativas del control voluntario del comportamiento (Hoffmann, 1993; 2009).

El modelo $A B C$ se basa en los siguientes postulados: (i) el comportamiento es casi siempre orientado hacia el objetivo en vez de ser conducido por el estímulo, por lo cual todo acto voluntario es precedido por las correspondientes anticipaciones de su efecto; (ii) el aprendizaje no es solo conducido por la satisfacción de necesidades sino también por anticipaciones flexibles, las que pueden referirse a cualquier objetivo, donde: (a) la formación de representaciones integradas del efecto de la acción es considerada como el proceso de aprendizaje primario en la adquisición de la competencia conductual. Cualquier efecto que encuentra un resultado esperado actuará como un reforzador, mientras que cualquier efecto con resultado inesperado actuara como diferenciador; y (b) una necesidad o un deseo concreto activan representaciones de acción-efecto. Así, las anticipaciones dirigen las acciones 
que son representadas como apropiadas. En general, la acción será realizada en el contexto situacional más probable para producir el efecto deseado o necesitado; (iii) el comportamiento voluntario es determinado principalmente por los efectos de la acción en vez de por asociaciones del tipo estímulo-respuesta; y (iv) el efecto de la acción está condicionado por el contexto situacional. Si el contexto de la acción es invariante y el efecto de una acción es experimentado repetidamente se integra a las representaciones del efecto de la acción, pero si el contexto se modifica sistemáticamente las contingencias entre las acciones y sus efectos también se modifican. Esto puede ser considerado como un proceso de aprendizaje secundario, por lo que cierto resultado repetido por un determinado tipo de acción en un contexto situacional dado puede provocar la preparación para producir ese mismo resultado por esa acción.

Estando la habilidad en los deportes de equipo determinada por la técnica y la toma de decisiones. Es por ello que el proceso de toma de decisiones de un jugador y el cómo actúa durante su participación en el entrenamiento o la competición se debe, entre otros factores, al conocimiento previo que posee y a su capacidad para analizar nueva información. En un deporte en el que las situaciones de juego cambian constantemente se sugiere que el jugador utiliza su conocimiento base para relacionar y aplicar nuevos conceptos. Es decir, para decidir qué, cómo, cuándo y por qué desarrollar un comportamiento técnicotáctico $u$ otro en función del contexto concreto de juego en el que se encuentra (GRÉHAIGNE; WALLIAN; GODBOUT, 2005).

El conocimiento táctico diferenciado sobre la posibilidad de éxito y la frecuencia de la aplicación de soluciones en la competición que presentan los deportistas expertos les permite anticipar las consecuencias de sus decisiones (Hoffmann, 1993; 2010). Basándose la competencia en el conocimiento sobre cómo comportarse satisfactoriamente en diferentes situaciones. Requiriendo la adquisición independiente de tal conocimiento una acumulación de experiencias de comportamiento que conducen a reconocer que efectos se dan bajo determinadas circunstancias (HOFFMANN et al., 2007).

El conocimiento táctico proveniente de la experiencia sustenta la elaboración de una toma de decisión a partir de la búsqueda de señales relevantes que lleven a la realización posterior de una técnica específica en la situación de juego con que se enfrentan (VESTBERG et al. ,2012). Señales que 
los especialistas definen como importantes para elaborar con mayor velocidad y calidad las informaciones y, de esta forma, tener más "tiempo" para realizar la acción (GRECO, 2003).

Siendo indispensable tener en cuenta que el proceso por el cual el sujeto es capaz de tomar decisiones en el deporte depende en gran medida del tiempo disponible para procesar la información. Existiendo situaciones en las que el jugador, pese a que el tiempo disponible es escaso, cuenta con el suficiente para percibir y decidir de forma consciente, por lo que el proceso podemos entenderlo como reflexivo. A partir de los cuales se puede relacionar la calidad de la capacidad de decisión con los modelos cognitivistas y constructivistas de explicación del conocimiento procedimental que el sujeto tiene del dominio en cuestión, con el objetivo de comprender la relación de los procesos cognitivos con la capacidad para tomar decisiones tácticas (TENEMBAUM; BAR-ELI, 1993).

Los modelos que consideran la representación interna en la decisión y ejecución de un movimiento habilidoso establecen que el proceso de toma de decisiones por parte de un sujeto está mediatizado por las estructuras de conocimiento almacenadas en la memoria. De tal forma que los deportistas, a partir de su formación y acumulación de experiencia a través de la práctica deliberada, van mejorando su conocimiento tanto conceptual como procedimental sobre el juego, es decir su capacidad para optar por la acción de juego más propicia en cada situación. Desarrollando su pericia por medio de la práctica, elaborando procedimientos de selección cada vez más acertados y de forma más rápida (THOMAS; GALLAGHER; THOMAS, 2001).

Proponiéndose la siguiente solución para ese problema: (i) si la orden tiene que ser creada entre las posibilidades disponibles, ella tiene que seguir una secuencia; (ii) si tienen que ser ordenadas, entonces son necesarios criterios de valores o preferencias; y (iii) los criterios son producidos por la experiencia, que se basan tanto en los circuitos neuronales como en la herencia biológica, apoyándose en aquellos establecidos por la repetición de acciones exitosas (DAMASIO, 1996).

En otros casos el tiempo es tan reducido que el deportista se ve obligado a decidir la respuesta utilizando mecanismos cognitivos reactivos, tomando decisiones intuitivas (ARAUJO; DAVIDS; HRISTOVSKIC, 2006; DAVIDS et al., 
2007), en los que no es posible analizar la situación y las consecuencias de las posibles respuestas de forma consciente. Surgiendo los abordajes de las teorías dinámicas de toma de decisión, que entienden que el comportamiento decisional emerge sin la necesidad de recurrir a representaciones internas y por lo tanto sin la necesidad de almacenamiento (LOPES et al. 2008; ARAUJO, 2009). En esa propuesta las acciones son condicionadas pero no determinadas por los procesos cognitivos.

El concepto de teoría dinámica reúne las teorías ecológicas de la percepción directa, las teorías de los sistemas dinámicos, las teorías de la autoorganización y las teorías sinérgicas; sosteniendo que la toma de decisión emerge del ambiente (LAMAS et al., 2014). En esas teorías se considera que el tiempo para procesar una información y compararla con conceptos y representaciones mentales almacenadas en la memoria no es suficiente para permitir una respuesta.

Actualmente, las divergencias en la investigación en deportes entre las posturas cognitivistas y las ecológicas tienden a ser mediadas por el tiempo disponible para tomar decisiones, siendo la postura interaccionista una alternativa viable de llegar a un consenso entre ambas posibilidades (RAAB 2002; 2007).

Pudiendo presentarse el pensamiento en el proceso de toma de decisión bajo dos formas: el pensamiento convergente y el divergente. El pensamiento convergente responde a los procesos que conducen a la definición jerárquica de alternativas, estando directamente relacionado a la inteligencia de juego y la producción de una respuesta adecuada (GRECO, 2004). Mientras que el pensamiento divergente se relaciona con la creatividad para resolver situaciones en las que varias alternativas son válidas; caracterizándose cuando es creativa, por la originalidad, flexibilidad y el carácter adecuado de las acciones. Resulta relevante comprender que esos procesos no son excluyentes, interactúan entre sí y se auxilian de un modo recíproco (MEMMERT; ROTH, 2007).

Dentro de las posturas interaccionistas el Modelo de Situación de consecuencias de Respuesta Anticipada en decisiones Tácticas (SMART) (RAAB, 2007) describe los efectos del aprendizaje implícito y explícito sobre las consecuencias de las respuesta esperadas de las acciones. En el mismo las decisiones (por ejemplo: bajo presión de tiempo en el basquetbol, la opción 
táctica de lanzar al aro o pasar el balón) son explicadas como una función de la interacción de los procesos bottom-up (o procesamiento inducido por el estímulo que se refiere a los procesos de aprendizaje de modo implícito o no incidental) y los procesos top-down (o procesamiento inducido por el análisis que se refiere a los procesos de aprendizaje de modo explícito o intencional).

El modelo SMART-ER (RAAB, 2015) (Figura 2) amplía y revisa el SMART (RAAB, 2007), planteando que los procesos top-down y bottom-up interactúan dinámicamente, pero además se produce la selección de un formato de representación de las consecuencias de respuesta anticipada de las interacciones sensitivo motoras. En dicho formato se predicen los futuros cambios del entorno como una consecuencia de la acción. Haciendo foco, más allá de la persona, sobre las situaciones en las cuales ocurren las interacciones sensitivo motoras dinámicas específicas. Pudiendo presentar opciones únicas o variables en función de la complejidad de la situación, la cual puede manifestarse en el número de opciones de elección, la información visual disponible y la velocidad en que la decisión debe ser tomada (RAAB, 2003). Para finalmente, en función de la experiencia y la situación, seleccionar un comportamiento activo.

SELECTIVA

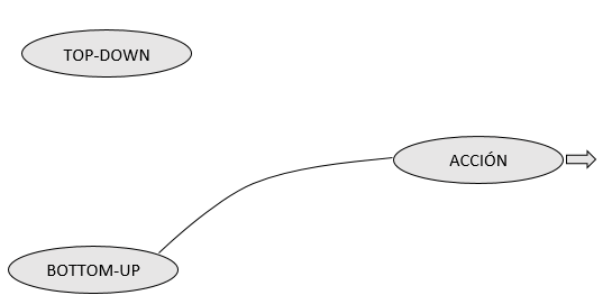

CONSOLIDADA

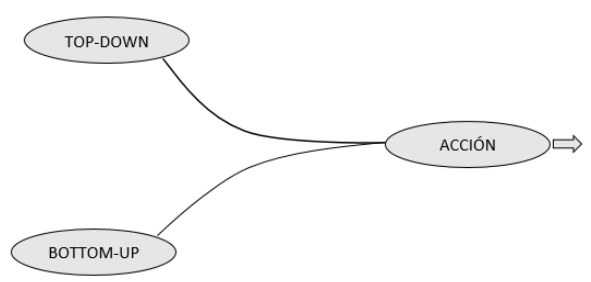

COMPETITIVA

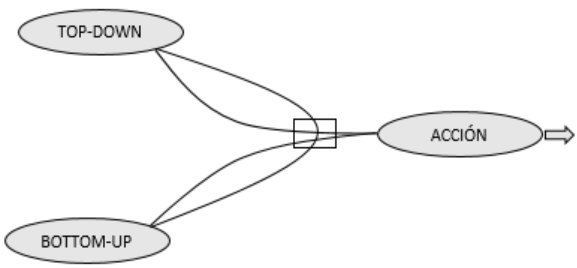

CORRECTIVA

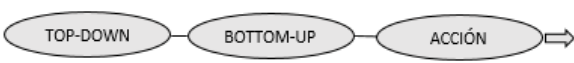

Figura 2: Modelo SMART-ER. Vías de interacción dinámica entre los procesos top-down y bottom-up (RAAB, 2015). 
Existiendo al menos cuatro vías diferentes de interacción dinámica - las cuales pueden depender tanto de la experiencia anterior como del éxito experimentado - entre los procesos top-down y bottom-up (RAAB, 2015): (i) Selectiva, en la cual se elige una acción en función sólo de los conocimientos previos; (ii) Competitiva, donde ambos procesos contribuyen pero uno de los dos domina; (iii) Consolidada, en la cual ambos procesos están implicados en la opción. Si hay conflicto en la selección se produce un "congelamiento" en la actividad o un retardo en la misma, mientras que si ambos objetivos del proceso concurren en la misma dirección ocurren respuestas más rápidas; y (iv) Correctiva, que describe los efectos secuenciales de los procesos. Pudiendo tomar una decisión en base a su conocimiento previo y luego decidir en base al estímulo situacional.

En este sentido, una acción es entendida como una interacción funcional entre un individuo y su entorno con un determinado propósito (ARAÚJO; DAVIDS; HRISTOVSKI, 2006) y una decisión como un proceso emergente, una estrategia activa de búsqueda de soluciones caracterizada por secuencias espacio-temporales en una relación entre sujeto y entorno (RIERA, 1989; 1995; ARAÚJO et al., 2003; MOUCHET, 2005).

Las situaciones y las acciones emergentes dependen de las situaciones y acciones precedentes, basadas en: (i) su influencia directa; y (ii) su influencia indirecta mediada por interpretaciones subjetivas del pasado. La organización de las acciones en el presente implica adicionalmente anticipar futuros cambios situacionales y demandas estructurales - funcionales de la acción subsiguiente (PRINZ, 1990).

Mientras que el acto táctico se desarrolla y realiza a través de un complejo mecanismo que engloba la percepción, el análisis de la situación de juego, la decisión a tomar y la ejecución; resultando este en una aplicación creadora del saber, de las diferentes capacidades y de un saber hacer (GARGANTA, 2002) frente a las restricciones reglamentarias, de tiempo, de la pericia de los practicantes, de su estado emocional y de su fatiga (ARAUJO; VOLOSSOVITCH, 2005), pero también por la capacidad mental de anticipación del comportamiento de los adversarios y de la acción que los compañeros prevén realizar en un determinado contexto de juego (GARGANTA, 2004).

Es por ello que la resolución de los problemas motrices en juego define la 
acción de juego, entendida como la combinación significativa, más o menos complicada de los diversos procesos motores y psíquicos, indispensables a la solución de un problema nacido de la situación de juego; y no la más pequeña operación de la actividad, que podría ser un movimiento aislado, es decir un proceso puramente motor (MAHLO, 1969; REFOYO ROMAN, 2001).

La acción de juego se enmarca en un contexto situacional que es constituido por la interrelación funcional de tres componentes: persona, entorno y tarea. Esta perspectiva implica estructuras dinámicas funcionales que se acentúan. Así, las explicaciones científicas no se refieren a relaciones solamente causales entre variables aisladas, sino a interdependencias funcionales dentro de y entre los sistemas complejos. Donde la optimización de esa interrelación es el objetivo general de la acción y la intención general de las intervenciones prácticas. Para lo cual resulta necesario diferenciar la configuración de las propiedades de los componentes de la situación: las que determinan la urgencia de la adaptación son llamadas relación de valencia, mientras que las que determinan la dificultad de adaptación son denominadas relación de competencia (NITSCH, 2009). De este modo, la situación real determina lo que debería (o no) y puede (o no) ser hecho, como, cuando y donde (GARGANTA, 1997).

Cada uno de los componentes de la situación (persona, tarea, ambiente) es valorado subjetivamente por el deportista (o el entrenador) en lo que concierne a las dos dimensiones de situación mencionadas anteriormente: (i) valencia, relacionado con el atractivo (o rechazo) subjetivo de la situación; y (ii) competencia, relacionada con el control subjetivo de la situación. Dependiendo la decisión de actuar (o no) de la interpretación del grado de valencia y de competencia percibido, y de la relación de valencia-competencia (NITSCH, 2009).

Asimismo las características de la persona, la tarea y el ambiente son consideradas como condicionantes poderosos en el marco teórico de eslabones dinámicos bidireccionales entre la toma de decisión, la percepción y la acción (DE OLIVEIRA et al., 2009). Dicha propuesta plantea la existencia de cuatro características principales: (i) Bidireccional: la toma de decisiones, la percepción y la acción presentan interacciones específicas; (ii) No consecutiva: el proceso no ocurre en una manera ordenada consecutiva. Una toma de decisión puede 
conducir (y a menudo lo hace) a una acción, sin embargo el eslabón entre la decisión y la acción también puede ser interrumpido por nuevas percepciones o por condicionantes inesperados; (iii) Naturaleza dinámica: la interacción entre la toma de decisiones, la percepción, y la acción ocurre en diferentes momentos de la continuidad temporal. Por la vía a corto plazo, el marco es dinámico porque la percepción no se termina cuando se toma la decisión o una acción es realizada; estos procesos son continuos e influyen el uno en el otro. Por la vía a largo plazo, los eslabones entre la toma de decisión, la percepción, y la acción son reforzados con el tiempo por la repetición y el entrenamiento, permitiendo al jugador aprender; y (iv) Influencia de los condicionantes: los comportamientos son fuertemente afectadas por las características de la tarea, el ambiente y la persona.

Destacándose que los factores condicionantes de la toma de decisión en la acción táctica son: (i) el objetivo de la tarea específica; (ii) el número de decisiones posibles; (iii) el tiempo disponible para la decisión; (iv) el tiempo disponible para la acción; (v) el nivel de incertidumbre de la decisión; (vi) el orden secuencial de las acciones; y (vii) el número de elementos necesarios para la decisión. Como se presenta, son siete parámetros/variables que interfieren en la toma de decisión en los JDC. Inclusive, la complejidad del proceso decisorio no pasa solamente por los condicionantes citados, sino también por el aspecto cultural, ambiental y las condiciones subjetivas de análisis de la situación de juego (GRECO, 2003).

Por lo tanto, las tomas de decisión en el deporte no son asépticas en cuanto a intencionalidad y objetivo, ya que están generadas precisamente a instancias o requerimiento de la propia situación de juego (SOLÁ, 2010). Por lo cual si en un momento determinado de un partido una toma de decisión es válida, esa misma respuesta con otro condicionante estratégico puede no serlo (SAMPEDRO, 1999). 


\section{VIII - MODELOS DE ENSEÑANZA DE LA TÁCTICA DEPORTIVA}

Entre los aspectos con influencia determinante para el éxito del proceso de enseñanza del deporte se encuentran el modelo de enseñanza de la táctica adoptado y los métodos utilizados para desarrollarla. Debiendo reconocerse que la táctica deportiva no ha sido presentada a los practicantes a lo largo de la historia del deporte siempre de la misma forma, ni de manera homogénea, por parte de los entrenadores.

Todo modelo de enseñanza debe fundamentarse en una teoría, constituyendo una herramienta que el entrenador - profesor puede seleccionar y utilizar en el momento apropiado con un determinado contenido, con el fin de ayudar a los alumnos en el proceso de enseñanza-aprendizaje-entrenamiento de un modo más eficaz. Basándose en la perspectiva de la enseñanza, la cual incluye consideraciones simultaneas de la teoría de aprendizaje, de los objetivos a largo plazo, del contexto, del contenido, de la gestión del aula, de las estrategias relacionadas a la enseñanza, de la verificación del proceso y de la evaluación del aprendizaje del alumno. Razón por la cual el modelo de enseñanza debe incluir la planificación, diseño, implementación y evaluación funcional (METZLER, 2005), siguiendo una evolución continua de la forma de enseñar el deporte a los alumnos de todas las edades.

Dado que el conocimiento teórico permite entender el alcance de los respectivos modelos así como su verdadera funcionalidad en el campo práctico, las propuestas de modelos de enseñanza de los deportes en general y de la enseñanza de la táctica deportiva en particular deben estar asociadas a métodos de enseñanza que sean funcionales a los mismos. Debiendo existir una fuerte ligación entre contenidos, nivel de enseñanza, objetivos de aprendizaje establecidos y el modelo de enseñanza a ser utilizado por el profesor en una unidad de enseñanza-aprendizaje-entrenamiento.

Los modelos aparecen de este modo como un avance en coherencia e intencionalidad en comparación con las ideas más fragmentarias de estrategias, procedimientos y habilidades de enseñanza; como una profundización y una flexibilización relativamente a la idea más casuística o más estereotipada de método; y, finalmente, como un cambio de escala en lo relativo a la idea más circunscripta y parcelada de estilo de enseñanza (METZLER, 2005). Siendo la 
ventaja principal de recurrir al concepto de modelo, la posibilidad de conferir coherencia a la actividad de enseñar por la combinación entre las partes en torno a una idea global (GRAÇA, 2014).

Las corrientes de enseñanza se basan predominantemente en los paradigmas conductual y cognitivo de la psicología del aprendizaje, los cuales en lugar de actuar complementariamente se han comportado a lo largo de la historia del deporte de forma antagónica disputándose el protagonismo de intereses y metodologías (BELTRÁN et al., 1992).

En el campo práctico la enseñanza del deporte ha estado tradicionalmente asociada a una orientación mecanicista basada en el aprendizaje de la técnica. Esta concepción es una lógica consecuencia del proceso de racionalización que, desde su aparición, ha experimentado el deporte moderno en la búsqueda de conocimientos y métodos que mejoren el rendimiento de los deportistas (GARCÍA FERRANDO, 1990).

En este sentido, la concepción tradicional se muestra muy limitada para resolver muchos de los problemas propios del proceso de enseñanza y aprendizaje. Lo cual originó que en la década de los años '60 del siglo pasado se iniciara un cambio de concepción educativo que progresivamente ha ido dando mucha más importancia al proceso, donde se consideran factores claves el pensamiento y la participación del alumnado en su proceso de aprendizaje.

Dada la variedad de modelos de enseñanza de la táctica deportiva y las diversas clasificaciones de los mismos se adopta a los fines explicativos la siguiente clasificación como guía organizativa para su análisis:

1.- Modelos tradicionales, la cual comprende los modelos técnico y táctico.

2.- Modelos alternativos (o contemporáneos), la cual comprende los modelos estructurales (fenómeno-estructural y praxiológico) y los modelos comprensivosituacionales (transversal-comprensivos y ecológico-sistémicos). 


\section{1.- MODELOS TRADICIONALES}

Una de las características más importantes de estos modelos ha sido la obsesión por los aspectos de la enseñanza y el aprendizaje relacionados sobre todo con el desarrollo - perfeccionamiento de la técnica individual, dejando prácticamente de lado su aplicación en el juego. Se fundamentan en una propuesta analítica, mecanicista y directiva (CONTRERAS; DE LA TORRE; VELAZQUEZ, 2001).

Los postulados generales en los que se basan estos modelos son: la preocupación por la eficacia con el objeto de conseguir un buen resultado final, realización de las actividades según estereotipos, medición del progreso en función del grado de dominio de la técnica específica y encasillamiento de las situaciones en esquemas preestablecidos. Donde el volumen de trabajo y el número de repeticiones son claves para lograr la eficacia (ROMERO, 2001).

Pudiendo subdividirse al mismo en dos vertientes:

\section{1.- TÉCNICO}

Este modelo se basa en la pedagogía analítica, proponiendo una metodología específica de intervención educativa en base al control ambiental y la compartimentalización de la realidad a aprender en diferentes partes y secuencias (SOLÁ, 2010). También puede denominarse como ambientalista (LASIERRA; LAVEGA, 1993) o modelo vertical de la enseñanza del juego (SÁNCHEZ BAÑUELOS, 1986; DEVIS; SÁNCHEZ, 1996) ya que la especificidad de la técnica los hace aplicables a cada modalidad deportiva.

Parte de la concepción del ser humano como una biomáquina. Descomponiendo la totalidad de las prácticas deportivas en técnicas básicas estereotipadas consideradas imprescindibles hasta desarrollar técnicas más complejas y alcanzar la ejecución total de la práctica deportiva (GIMENEZ, 2005). Orientándose la enseñanza del deporte hacia la coordinación de una serie de habilidades motrices específicas indispensables para la práctica de un deporte, pretendiendo que el sujeto aprenda de lo particular y preciso (la técnica) a lo general y complejo (situación real de juego) por acumulación (BLÁZQUEZ, 1995). 
Desde este enfoque de la enseñanza del deporte el aprendizaje de los componentes técnicos debe preceder a la introducción de los contenidos tácticos. El modelo sostiene que el comportamiento táctico es una manifestación superior del deportista que tan solo es accesible posteriormente a un cierto dominio de las habilidades perceptivo-motrices especificas del deporte de referencia (RUIZ, 1996; JIMENEZ, 2002; ALARCON et al., 2009; SOLÁ, 2010).

Esta orientación técnica de la enseñanza deportiva apenas permitiría abordar la comprensión táctica de los contenidos deportivos, dado el carácter previo y de prerrequisito que tiene el aprendizaje de la técnica en este modelo.

\section{2.- TÁCTICO}

A partir de los años '60 del siglo pasado aparecen sectores de la educación física que se interesan por cómo mejorar las deficiencias que existían en el aspecto táctico de los deportes de equipo. Proponiéndose para ello el modelo de enseñanza táctico, el cual refleja la metodología de entrenamiento de los deportes individuales, donde se intenta transferir un modelo de enseñanza perceptivo y técnico a los deportes tácticos colectivos.

Si bien la teoría psicológica cognitiva - contrariamente al ambientalismo reflexológico - a través del modelo cognitivo cibernético aportó múltiples modelos del funcionamiento mental en la realización del comportamiento táctico. La aplicación práctica para la enseñanza- aprendizaje-entrenamiento de los deportes de equipo en este modelo sigue un guion similar al de la metodología analítica (SOLA, 2005; 2010): partiendo de las habilidades técnicas llegar al juego interactivo social que caracteriza la táctica en el deporte (MAHLO, 1969; SÁNCHEZ BAÑUELOS, 1986; MONDONI, 2002).

Pudiéndose establecer que la diferencia entre ambos modelos es que la perspectiva ambientalista se limitó tradicionalmente a la presentación de habilidades motrices aisladas, vinculadas estrechamente a la eficiencia técnica y descontextualizada del juego, mientras que el cognitivismo evolucionó pedagógicamente hacia los modelos comprensivos. 


\section{2.- MODELOS ALTERNATIVOS (o contemporáneos)}

Frente al primer posicionamiento teórico surgen propuestas que intentan dar solución a los problemas de los modelos tradicionales de diversas formas. Pudiendo agruparse éstos bajo la denominación de modelos alternativos (TEODORESCU, 1984; THORPE; BUNKER; ALMOND, 1986; HERNANDEZ MORENO, 1994; 2000; 2005; GRAÇA; OLIVEIRA, 1995; WERNER; RIERA, 1995; DEVÍS; PEIRÓ, 1995; THORPE; BUNKER, 1996; ALLISON; THORPE, 1997; CONTRERAS; DE LA TORRE; VELAZQUEZ, 2001; GARGANTA, 2002).

Planteando la enseñanza del deporte a partir de situaciones más globales y reales basadas en la táctica (CONTRERAS, 1998) existen dos criterios básicos que identifican estos modelos de enseñanza de la táctica deportiva: (i) la orientación deportiva dirigida a uno o varios deportes; y (ii) la relevancia de los principios tácticos normalmente centrados en el juego.

Dentro de los modelos alternativos podemos realizar a su vez la diferenciación entre modelos alternativos estructurales y modelos alternativos comprensivos. Ambos coinciden en el planteo de que, dado que los deportes se pueden agrupar en categorías con unos fundamentos técnicos o tácticos similares, la enseñanza de cada categoría de deportes se puede emprender de manera conjunta. De esta manera deportes con características similares pueden ser abordados mediante una primera fase de aprendizaje común.

Diferenciándose en que los modelos estructurales sostienen que previamente a los aprendizajes tácticos debe existir un aprendizaje básico de las herramientas a utilizar en los diferentes deportes, aunque este aprendizaje nunca pierda de vista la función de dicha técnica (GARCIA LOPEZ, 2001). Mientras que en la totalidad de los abordajes clasificados dentro de los modelos comprensivos el proceso es pautado por el enfrentamiento progresivo del problema de juego, iniciando por estructuras de menor complejidad en las cuales el desafío propuesto resulta accesible a la capacidad de los jugadores. Complejizándose a medida que aumenta la capacidad de juego de los deportistas (MESQUITA, 2013).

\section{1.- ESTRUCTURALES}


En su variante estructural las propuestas que se han desarrollado han estado referidas a los juegos deportivos de cooperación/oposición de espacio común y participación simultánea. Pudiendo denominarse también como modelo horizontal estructural (SÁNCHEZ BAÑUELOS, 1986; DEVIS; SÁNCHEZ, 1996) ya que parten de la idea de buscar en primer lugar una iniciación común en la enseñanza de la táctica para las diferentes modalidades deportivas que compartan una misma naturaleza estructural y funcional, es decir que participen de una misma lógica interna.

Este posicionamiento defiende la necesidad de que, previo al aprendizaje perceptivo de habilidades gestuales, resulta necesario enseñar a los participantes la situacionalidad grupal, el posicionamiento interactivo y la contextualización de los movimientos tácticos del juego en los cuales la técnica se desarrollará y tendrá un sentido realmente significativo de la propuesta para diferentes modalidades deportivas con interacciones tácticas similares (SOLÁ, 2005).

Se vincula a la pedagogía global (LASIERRA; LAVEGA, 1993). La cual, en contraposición a la pedagogía analítica, presenta un marco de aprendizaje que entiende a la realidad como un todo. A partir del cual el conocimiento de los principios generales de un deporte facilita el aprendizaje de otros deportes de equipo con características similares (BAYER, 1986). Presentando a la táctica como portal de entrada al posterior desarrollo técnico.

Asimismo dentro de los modelos alternativos de enseñanza de la táctica deportiva en su variante estructural pueden reconocerse dos subcategorías de análisis: (i) fenómeno estructural y (ii) praxiológico.

\subsection{1.- FENÓMENO ESTRUCTURAL}

A partir de la teoría globalista se postula una propuesta estática, en la cual la táctica se aprende exclusivamente en el marco de una organización colectiva de equipo y donde lo realmente relevante es la disposición de los jugadores como sistema de juego. Estableciendo principios, fases, factores y formas del ataque y la defensa (TEODORESCU, 1977).

Dicha propuesta evoluciona hacia el modelo fenómeno estructural (BAYER, 1986). El cual se basa en el planteamiento de un análisis funcional para 
justificar los principios comunes de juego. Estableciendo una perspectiva dialéctica entre el ataque y la defensa e identificando unos principios generales del juego para el ataque y la defensa, sin relacionarlos con los roles ni con los elementos estructurales.

Este planteamiento metodológico se basa en la consideración de las características evolutivas de los jugadores para adecuar la enseñanza a los mismos, así como en la priorización del desarrollo de los aspectos perceptivos de la conducta y de la reflexión táctica. Ofreciendo una perspectiva de enseñanza basada en la noción de transferencia de elementos comunes a los deportes de invasión (CONTRERAS; DE LA TORRE; VELAZQUEZ, 2001). De manera que se propicie el aprendizaje de los principios tácticos ofensivos y defensivos, tanto como el de las habilidades específicas implícitas en la aplicación de tales principios.

Este modelo para la enseñanza de la táctica deportiva se basa en una pedagogía global - sintética, desarrollada a partir de la propuesta de situaciones pedagógicas que demanden del jugador toma de decisiones e iniciativa para la solución de las mismas (ALARCÓN LOPEZ et al., 2009).

\subsection{2- PRAXIOLÓGICO}

Por otro lado, el modelo praxiológico (PARLEBAS, 1986; 2001) se construye a partir de una teoría de corte estructuralista que reconoce una ciencia de la acción motriz. Estableciendo que los deportes poseen estructuras específicas propias definidas por siete universales ludomotores (red de comunicación motriz, red de interacción de marca, sistema de puntuación, sistema de roles, sistema de subroles, código gestémico y código praxémico), los cuales son invariantes capaces de explicar la estructura subyacente de los juegos para desvelar su lógica interna.

Desde el estructuralismo praxiológico las propuestas se establecen, primero en función de la complejidad estructural de los deportes progresando de psicomotrices a sociomotrices, de cooperación y oposición; y en segundo lugar atendiendo a la dinámica de los parámetros que componen la estructura, lo que significa atender los objetivos prioritarios de cada modalidad deportiva (HERNÁNDEZ MORENO, 1994; 2000). 


\section{2- COMPRENSIVO-SITUACIONALES}

\subsection{1- TRANSVERSAL COMPRENSIVOS}

Desde fines del siglo pasado el debate situado en torno de la enseñanza de los deportes condujo al desarrollo de propuestas de enseñanza de la táctica deportiva que realzan el papel del alumno en el proceso de aprendizaje. Proponiendo el desarrollo de la capacidad crítica del deportista para resolver los problemas que el juego le presenta.

Destacándose como el más difundido - en el marco de los modelos alternativos y basado en el cognitivismo - el modelo comprensivo denominado Teaching Games for Understanding (TGfU) o enseñanza del juego por la comprensión (BUNKER; THORPE, 1982). En el mismo se fundamenta la explicación del comportamiento táctico en las conductas de toma de decisión, influido por los esquemas cibernéticos (MAHLO, 1969) y de esquema motor (SCHMIDT, 1975; SHEA; WULF, 2005). Sin embargo, se apoyan también en los planteamientos constructivistas (VYGOTSKY, 1979; AUSUBEL, 1982) sobre el papel del alumno en el proceso de aprendizaje, colocándolo en una posición de constructor activo de sus propios aprendizajes y valorizando los distintos procesos cognitivos (ROVEGNO; NEVETT; BABIARZ, 2001; TEOLDO et al., 2010).

Surgiendo a partir del TGfU diversas interpretaciones del mismo. Tales como el Game Sense (BROOKER et al., 2000), Tactical Approach (MORTÁGUA; PEÑAS, 2007; MITCHELL; OSLIN; GRIFFIN, 2013), Play Practice Approach (LAUNDER, 2001), Tactical Decision Making Approach (GRÉHAIGNE; WALLIAN; GODBOUT, 2005), Game Concept Approach (McNEILL et al., 2004), entre otros.

En este tipo de modelos se busca en primer lugar una iniciación común a varios juegos deportivos. Pudiendo en un momento posterior del proceso de enseñanza - aprendizaje pasar a una transferencia vertical de juegos modificados y formas jugadas hasta llegar a la estructura del deporte formal, o se puede continuar con una transferencia horizontal para llegar a la práctica de diferentes juegos deportivos. 
Los modelos comprensivos de enseñanza de los deportes intentan desarrollar en el aprendiz la apreciación del juego, el conocimiento táctico, la toma de decisión y la ejecución técnica integrada en el juego deportivo. Con el objetivo de que el deportista desarrolle una idea cierta acerca del qué, el para qué, el porqué y el cuándo de su conducta, lo que le va a permitir dar sentido, significado y funcionalidad al cómo de sus acciones (BUNKER; THORPE, 1982; TAVARES, 1993; GARGANTA; CUNHA e SILVA, 1999; GARGANTA, 2004; SOLÁ, 2005; 2010; TAVARES; GRECO; GARGANTA, 2006; GRECO; MEMMERT; MORALES, 2010).

Es por ello que, si bien los modelos comprensivos comparten elementos educativos con el planteamiento fenómeno estructural en la búsqueda de los principios comunes de los deportes semejantes estructuralmente. Además pretenden una doble integración de elementos simultáneos: las actuaciones individuales en las actuaciones de colaboración y - al mismo tiempo - las habilidades técnicas con las resoluciones tácticas (SOLÁ, 2010).

Caracterizándose principalmente por evolucionar desde la táctica hacia la técnica, utilizando como medio para ello juegos modificados que tienen numerosas similitudes con el deporte para el que se plantean, buscando la comprensión de los principios tácticos particulares, estimulando la comprensión y el descubrimiento de la lógica subyacente en los juegos deportivos (THORPE; BUNKER, 1989; CONTRERAS, 1998; GRIFFIN; PATTON, 2005).

Dejando de ver el juego como un momento de aplicación de técnicas para pasar a verlo como un espacio de resolución de problemas (VALENZUELA, 2005). Buscando de este modo integrar la técnica, la táctica y el rendimiento. Sosteniendo que sólo de esta manera se garantiza que la técnica responderá a las necesidades del juego y estará estrechamente contextualizada en la realidad del deporte (KIRK; McPHAIL, 2002).

Por consiguiente, el foco didáctico incidirá sucesiva y cíclicamente sobre: (i) la apreciación de los aspectos constituyentes del juego; (ii) la toma de consciencia de los principios tácticos del juego; (iii) la toma de decisión del que hacer y cómo hacer en las diferentes situaciones del juego; (iv) la ejercitación de las habilidades necesarias para mejorar la performance en el juego; y $(v)$ sobre la integración de los aspectos técnicos y tácticos necesarios para la mejora del rendimiento en el juego (GRAÇA; MESQUITA, 2007). 
Pudiendo resumirse que los enfoques alternativos - representados principalmente por los denominados juegos deportivos para la comprensión - son caracterizados por la conciencia táctica y la toma de decisiones dentro de la estructura de un juego deportivo determinado, por el uso de juegos modificados y por la enseñanza de habilidades cuando son apropiadas, siempre adaptadas a los niveles de desarrollo individual y grupal (ALLISON; THORPE, 1997).

Asimismo surgieron - de un modo muy próximo conceptualmente al TGfU - otras propuestas, como lo es el modelo de Desarrollo de los contenidos de los juegos, basado en el modelo de enseñanza direct instruction (RINK; FRENCH; WERNER, 1991; RINK; FRENCH; TJEERDSMA, 1996). El cual se caracteriza por una secuencia estructurada de tareas de aprendizaje; la optimización de las oportunidades de respuestas / posibilidad de éxito de los alumnos en las tareas y la supervisión activa de los aprendizajes sustentada en la producción frecuente y oportuna del feedback pedagógico. La secuencia de las tareas de aprendizaje es perspectivada de modo tal que proporcione oportunidades para: (i) la progresión, porque la posibilidad de producir diferentes soluciones para un mismo escenario situacional exige que la misma incluya la articulación vertical resultante de niveles de práctica más complejos (donde las tareas seleccionadas integran formas de juego y tareas que progresivamente aumentan la complejidad), así como la articulación transversal (tareas con niveles de dificultad semejantes con diferentes alternativas posibles de respuesta para un mismo nivel de complejidad). De la conjunción de ambas articulaciones la progresión adquiere un carácter dinámico (semejante al efecto en hélice), reivindicado por la complejidad táctica propia de los JDC. Pudiendo ser todas las tareas propuestas moldeadas a través de la introducción de variantes que las modifiquen sin que la desvirtúen. Esa plasticidad resulta esencial, pues es el factor que permite la ajustabilidad de la tarea a las restricciones (condicionantes) relacionadas con el practicante y/o el medio ambiente; (ii) el refinamiento (o perfeccionamiento de determinados componentes críticos perceptivos, decisionales y/o motores); y (iii) la aplicación de las habilidades, la cual se referencia en la realización de tareas de competición y autoevaluación criteriosamente seleccionadas, permitiendo la contextualización de los contenidos de aprendizaje a los escenarios de juego que les confieren significado y auxilian al practicante en la regulación de su propio aprendizaje. Dado que las 
habilidades del juego son de naturaleza abierta - dictadas por las circunstancias y por la oportunidad - ellas no son vistas aisladamente sino en referencia a su aplicación en el juego.

Por otra parte y orientado específicamente al ámbito escolar aparece el modelo de Educación Deportiva (ED) (SIEDENTOP, 1994). El mismo posee muchos puntos de contacto con la corriente de enseñanza comprensiva del deporte. Establece como propósito fundamental la formación de un ciudadano deportivamente culto, es decir deportivamente competente, deportivamente instruido y entusiasta de la práctica deportiva. Se caracteriza por reflejar los rasgos culturales de la práctica deportiva extraescolar y el empleo de una metodología que otorga progresivamente al alumnado una mayor responsabilidad para aprender conforme la unidad didáctica o temporada educativa avanza. En el plano de la enseñanza de la táctica los juegos deportivos se practican de forma reducida y con algunas modificaciones. Integrando seis características del deporte institucionalizado: la época deportiva, la filiación, la competición formal, el registro estadístico, la festividad y los eventos culminantes.

También el modelo de Competencia en los juegos de invasión (MUSCH et al., 2002; MUSCH et al., 2006) procura abrazar las ideas del modelo de educación deportiva en lo que respecta a los aspectos de organización de la experiencia deportiva de los alumnos, favoreciendo la creación de un contexto deportivo autentico. El proceso de instrucción se orienta por los siguientes criterios pedagógicos y didácticos: (i) proporcionar más oportunidades a todos los participantes; (ii) mantener un equilibrio dinámico entre persona, tarea y su compromiso; y (iii) desafiar a todos los participantes a tener éxito. Mientras que el desarrollo de la competencia como jugador se asienta en la articulación de tres tipos de tareas de aprendizaje: (i) formas básicas de juego, las cuales proporcionan el contexto para determinar las necesidades de aprendizaje, consolidar y aplicar los aprendizajes. Son situaciones de inicio menos complejas que el juego formal pero más complejas que las habilidades que lo componen; (ii) las formas parciales de juego, situaciones de complejidad intermedia que permiten que los alumnos se concentren en los problemas y exigencias de la ejecución de una de las partes de la forma básica de juego; y (iii) las tareas basadas en el juego, situaciones de menor complejidad que tienen el propósito 
de desarrollar los medios necesarios para dar respuesta a las soluciones de los problemas del juego enfatizando los mecanismos de ejecución en un contexto muy simplificado. La utilización del juego como punto de partida y sucesivamente retomado sirve para delimitar el espacio de los problemas, contextualizar los objetivos de aprendizaje, condicionar los esfuerzos de exploración y la búsqueda de soluciones para los problemas colocados por el ataque y por la defensa e integrar la acción individual en el desarrollo de la dinámica de cooperación oposición. Es por ello que la determinación en concreto de las actividades de aprendizaje se apoya en la evaluación del nivel de desarrollo de los alumnos, así como en su nivel de comprensión y de interpretación del juego. En este modelo el desarrollo de competencias en funciones de apoyo y coordinación busca mejorar en los alumnos las capacidades de organizar su práctica de una forma responsable y autónoma, acrecentando las competencias de auto-regulación de su aprendizaje.

Considerando otros desarrollos más distantes, pero aun así centrados en la idea de juego y de aprendizaje situado en contextos de practica auténtica, aparecen la propuesta Escuela del Balón (ROTH; KRÖGER; MEMMERT, 2002; KRÖGER; ROTH, 2005; MEMMERT; ROTH, 2007) y su variante Iniciação Esportiva Universal (GRECO; BENDA, 1998, 2006). Ambas enfatizan en las formas de aprendizaje incidental, pero sustentadas en la intencionalidad del proceso de enseñanza-aprendizaje-entrenamiento planificado y sistemático. Sugiriendo que ciertas formas de información explícita ofrecida antes de la práctica de la tarea puede no ser tan útil para aprender, contrario a lo que sería descubrir la solución al problema solo mediante la realización práctica, independientemente del tipo de tarea que se esté aprendiendo (BOYD; WINSTEIN, 2006). Planteando que las formas de aprendizaje incidental en situaciones de toma de decisiones complejas permiten mejorar la eficacia de las acciones y los trastornos del doble proceso de toma de decisión y control motor. Pudiendo ser la toma de decisiones intuitiva tan exitosa como la estrategia más elaborada (RAAB, 2003; CÔTÉ; BAKER; ABERNETHY, 2007; RAAB; JOHNSON, 2008; PERALES et al., 2011). Dichas propuestas privilegian el desarrollo de la inteligencia, la creatividad y las capacidades de pensamiento convergente - divergente en la toma de decisión táctica a través de un abordaje 
no específico para desenvolver las competencias básicas en los dominios tácticos, coordinativos y técnicos (GRAÇA; MESQUITA, 2007).

La propuesta Escuela del Balón (KRÖGER; ROTH, 2002) evidencia la importancia del desarrollo de proceso de enseñanza - aprendizaje incidental apoyado en el concepto de aprendizaje implícito jugando (MSIL). Se sustenta en tres pilares que objetivan el desarrollo de: (i) las capacidades tácticas; (ii) las capacidades coordinativas; y (iii) las habilidades técnicas. Realizando luego un aprendizaje incidental general para todos los deportes, para en una tercer etapa o fase llevar a cabo un aprendizaje implícito direccionado a deportes que posean características similares $y$, por último, una etapa de aprendizaje explicito direccionado a una sola modalidad deportiva (GRECO, 2013).

Mientras que el modelo Iniciação Esportiva Universal y su evolución Iniciação Esportiva Universal: incidental-intencional (o jugar para aprender y aprender jugando), se basan en las formas de aprendizaje incidental - implícita, recurriendo al juego y privilegiando contenidos que posibiliten el desarrollo de la personalidad por medio de formas de aprendizaje incidental (GRECO; BENDA, 1998; 2006).

Proponiendo en una primera etapa la idea de aprender jugando propiciando la adquisición de experiencias de juego con énfasis en los procesos incidentales de aprendizaje, utilizando los juegos populares, ofreciendo de modo paralelo actividades direccionadas por una instrucción activa del profesor al entrenamiento de la coordinación y a las familias de habilidades deportivas. Posteriormente, cuando el aprendiz manifiesta un objetivo direccionado, el énfasis del proceso de enseñanza - aprendizaje se equilibra y la distribución temporal en la forma de enseñanza - aprendizaje se integra a la concepción jugar para aprender (proceso formal - intencional). (GRECO; SILVA; SANTOS, 2009).

En cuanto a la dimensión procedimental, se caracteriza por el equilibrio entre el desarrollo de los procesos de aprendizaje táctico y de aprendizaje motor, los cuales son relacionados entre sí por la proposición de Juegos para el desarrollo de la Inteligencia y Creatividad Táctica (JICT) (GRECO, 2013). Los cuales se caracterizan como juegos con situación de oposición y cooperación, con o sin invasión del campo del equipo adversario, pero que no presentan relación directa con una modalidad deportiva específica. Debiendo el entrenador 
colocar en este tipo de juegos reglas que posibiliten la mayor variedad de situaciones tácticas, dando opciones que permitan aumentar y alternar la atención (GRECO; SILVA; SANTOS, 2009).

Proponiendo para el desarrollo especifico de la acción táctica el Modelo pendular (GRECO; 2006), el cual plantea complementar el entrenamiento de las estructuras funcionales direccionadas mediante el empleo de estructuras funcionales generales (jugar para aprender) que permitan la adaptación a la situación de juego a través de la solicitación del pensamiento convergente y divergente. Destacando la importancia en el proceso enseñanza-aprendizajeentrenamiento de los procesos cognitivos subyacentes a la acción de forma situacional, es decir en interacción con el juego (GRECO, 2007).

En este modelo de enseñanza de la táctica deportiva pueden encontrarse algunos rasgos característicos de los métodos ecológico-sistémicos, por lo cual puede ser situado en un punto intermedio de la clasificación de modelos de enseñanza de la táctica deportiva analizados.

\subsection{2- ECOLÓGICO-SISTÉMICOS}

Las teorías ecológico-sistémicas (BERTALANFFY, 1976; BRONFRENBRENNER, 1979; GIBSON, 1979) consideran que existe una relación dinámica entre el ser humano en desarrollo y sus constantes interacciones con el ambiente. El enfoque ecológico explica el aprendizaje como un proceso de descubrimiento y optimización del acoplamiento informaciónmovimiento lo que conlleva a una estabilización de las leyes naturales de control (BARDY, 2011). Mientras que la teoría de los sistemas dinámicos considera al aprendiz como un sistema neurobiológico complejo, el cual se compone de grados de libertad o subsistemas que son independientes pero que a su vez interactúan entre ellos (DAVIDS; BUTTON; BENNET, 2008). De este modo, el deportista ya no es analizado solamente como un complejo perceptivo-cognitivomotor, sino como una persona que mediante su accionar modifica o construye el mundo - su deporte - para solventar las contingencias y problemas que en éste se presentan (PENELAUD, 2010).

Estas posturas teóricas engloban desde las facultades cognitivas más elementales como la percepción visual a las más abstractas como el 
pensamiento o la reflexión e incluyen a la emoción. Abordando lo que es el conocer, el entender y la experiencia como una actividad formativa que descubre significados a través de la acción. En éste enfoque se entrelazan conjuntamente cinco nociones fundamentales que le aportan identidad y lo constituyen: autonomía, sentido (sense-making), emergencia, corporización o encarnación (embodiment) y experiencia (DI PAOLO; ROHDE; DE JAEGHER, 2010).

En estos modelos el proceso de enseñanza - aprendizaje privilegia la resolución de problemas semejantes al juego (estructurales y funcionales), la tipología de los juegos, la exploración de la interferencia contextual y las situaciones-problema (GARGANTA, 1998; GRAÇA; MESQUITA, 2009; MENEZES, 2012). Centrándose en los juegos condicionados, los cuales se caracterizan por la posibilidad de separar el juego en unidades funcionales que pueden ser reconstruidas a lo largo del proceso de enseñanza-aprendizajeentrenamiento (GARGANTA, 1998; GARGANTA; GREHAIGNE, 1999).

Constituyendo el juego un nicho ecológico que posee propiedades específicas, las cuales solamente emergen en el contexto del mismo y que surgen del conflicto de los objetivos inherentes a su lógica. Siendo habitado por antagonismos mediados por el orden, desorden, organización e interacción (REVERDITO; SCAGLIA; MONTAGNER, 2013). Utilizan una pedagogía no lineal (DAVIDS; BUTTON; BENNETT, 2008; CHOW et al., 2010), entendida como la consideración de los constreñimientos dentro del proceso de aprendizaje para favorecer el desarrollo de la competencia de los individuos, siendo la modificación de las variables lo que estimulará la capacidad adaptativa del deportista hacia una nueva dinámica de movimiento. En esta perspectiva el profesor debe crear condiciones favorables y facilitadoras para el logro de aprendizajes significativos mediante la manipulación de los condicionantes (AVILES et al., 2014).

Planteando que el deportista necesita desarrollar su capacidad para detectar los constreñimientos específicos que afectan al objetivo, pudiendo estos corresponder al jugador, al entorno o a las exigencias específicas de la tarea (NEWELL, 1986; WARREN, 2006). Emergiendo las soluciones por la exploración del entorno y la detección de affordances (posibilidades para la acción), considerando además las capacidades de las que disponen los individuos (ARAUJO; DAVIDS, 2009; FAJEN; RILEY; TURVEY, 2009). 
Los modelos de enseñanza de la táctica deportiva basados en esta teoría coinciden en establecer al menos tres momentos (ARAUJO et al., 2011): (i) Exploración de las posibilidades de acción, especialmente relacionadas con el sistema medio-individuo. En este estadio se requiere la convergencia entre la intención del practicante y el objetivo de la tarea; (ii) Descubrimiento $y$ estabilización de las soluciones a través de la detección de la información que permitirá la consecución del objetivo. Por lo tanto se necesitará educar la atención o el ajuste con dicha información; y (iii) Aprovechamiento de las posibilidades en las que diferentes sistemas de acción, en momentos distintos, podrán acoplarse con la misma información relevante.

Estos momentos se reiteran de modo cíclico una vez alcanzado el objetivo básico de enseñanza, mediante un proceso de reformulación y aumento de la complejidad de la situación de juego, siendo desarrollados tantas veces como el proceso de enseñanza-aprendizaje lo requiera. Retomando el aprendizaje y mejora de habilidades tácticas y técnicas para que posteriormente puedan ser aplicadas en situación real de juego.

Reconociendo que durante la adquisición de cualquier habilidad el aprendiz posee intenciones, pero sin embargo la ejecución de sus movimientos no será óptima en los primeros momentos. Logrando mediante la praxis, un mejor acoplamiento entre su intencionalidad y la acción motriz. Reflejando su máxima expresión en la maestría del deportista experto, dado que con la práctica la conexión entre intención y acto se intensifica hasta que al final la sensación de diferencia entre ambos desaparece casi por completo (VARELA; ROSCH; THOMPSON, 2005).

Dentro de este marco teórico aparecen como referencia el modelo pendular (GRECO, 2006; 2007), y posteriormente el modelo didáctico funcional (SOLÁ, 2010). El cual se sustenta en siete posibilidades de intervención pedagógica (técnica individual, técnica en colaboración, técnica individual con oposición, técnica en colaboración con oposición, táctica individual, táctica en colaboración y juego real), las cuales pueden ser desarrolladas y combinadas en cualquier orden y momento del proceso de enseñanza-aprendizajeentrenamiento en función de las necesidades reales de los jugadores y del equipo, y de acuerdo a las carencias de aprendizaje realmente detectadas. 


\section{IX - MÉTODOS DE ENSEÑANZA-APRENDIZAJE-ENTRENAMIENTO}

La evolución experimentada por las diferentes modalidades deportivas con referencia a los procesos de enseñanza, entrenamiento y competición ha demostrado que los distintos factores de rendimiento generan un impacto variable en función de la especificidad de cada una de ellas. Lo cual exige que, en el complejo proceso de formación de los jugadores, se aplique una metodología - acorde al modelo de enseñanza de la táctica adoptado - que permita el desarrollo normal y armónico de las capacidades inherentes al rendimiento deportivo. Para lo cual en el proceso de enseñanza-aprendizajeentrenamiento de los Juegos Deportivos Colectivos (JDC) se debe favorecer el adecuado desarrollo de las capacidades tácticas, de las capacidades coordinativas y de las habilidades técnicas. Permitiendo al jugador integrar a través de la acción deportiva su conocimiento, sus capacidades físicas y sus emociones (MORALES; GRECO, 2007). En este sentido se debe promover la asociación entre la lógica didáctica y la lógica interna del juego.

Por lo tanto resulta necesario que el proceso de enseñanza-aprendizajeentrenamiento de las modalidades deportivas colectivas sea implementado a partir de planificaciones y programaciones influenciados por la lógica del juego (TAVARES, 2013). En concordancia, la enseñanza del basquetbol - enfocada en atender el desarrollo integral del alumno - necesita de una pedagogía capaz de integrar los aspectos biológicos, cognitivo, psicológico, filosófico y social del individuo (SANCHEZ et al., 2006).

En el proceso de formación de la capacidad táctica el deportista deberá aprender y dominar los elementos técnicos propios del deporte, la solución motriz (el cómo), seleccionar la respuesta apropiada al contexto o crearla (el qué, el por qué), reconociendo el momento exacto para expresarla (el cuándo) (SOLÀ, 2010; GARCÍA et al., 2011).

Para ello el deportista debe aprender a desarrollar ideas múltiples y variadas como forma de solución a los problemas que el juego le presenta (GRECO, 1988), con el objetivo de saber "leer el juego" de su equipo en función - relación del juego del rival (ZARAGOZA, 1995). Dado que el pensamiento en el deporte es siempre un pensamiento táctico, el cual se caracteriza por la capacidad del deportista de relacionar en una situación de competición las 
alternativas y planes de acción propios y del adversario con el objetivo de actuar de forma adecuada para lograr el éxito (GRECO, 1995). Se debe considerar la complejidad como integrante del método de enseñanza de los JDC, teniendo como principio el desarrollo del pensamiento crítico del jugador en función de la situación problema con la cual se encuentra (MENEZES, 2012).

En este sentido el aprendizaje táctico en los JDC debe referirse a un proceso de construcción de conocimiento significativo que permita a los jugadores avanzar hacia: (i) una representación genérica de los problemas del juego; (ii) disponer y utilizar diferentes sistemas de producción para resolverlo (del tipo convergente o divergente); y (iii) atender a las características profundas del problema. Siendo dirigido a la comprensión e integración de los principios de juego y de los principios de actuación en una situación específica con el objeto que el deportista alcance: (i) mayor nivel conceptual e interrelación de los conceptos; (ii) mayor capacidad de análisis de las condiciones concretas y de las acciones posibles - deseables; (iii) mayor flexibilidad en la toma de decisiones; y (iv) una toma de decisiones más rápida. Pudiendo extrapolarlos a las diversas situaciones con que va a encontrarse el jugador en el transcurso de un partido, generando una respuesta inteligente y/o creativa (IGLESIAS et al., 2003; LOPEZ ROS, 2011).

En función de ello la planificación, conducción y regulación del proceso de enseñanza-aprendizaje-entrenamiento debe (además de considerar el tipo de deporte y sus características) determinar las líneas de fuerza que permiten moldear el entrenamiento de acuerdo con la competición, dado que desde allí derivan diferentes situaciones pedagógicas, las cuales precisan ser abordadas en el programa de formación del deportista propiciando el desarrollo de la capacidad de juego (GRECO, 2013). Capacidad que se caracteriza por la interacción del desarrollo de las capacidades biotipológicas, socio ambientales, psicológicas, físicas, motoras, técnicas y tácticas (GRECO; BENDA, 1998).

En concordancia con esto, el desarrollo del pensamiento táctico y de la toma de decisiones no puede considerarse al margen de las posibilidades personales de ejecución de las habilidades motrices pertinentes, de ahí que su aprendizaje deba desarrollarse de forma coherente con las demandas deportivas y con las exigencias de los comportamientos tácticos. Resulta fundamental en 
los deportes con componentes tácticos la disponibilidad variable de los recursos motrices, así como la flexibilidad en su control y regulación (LOPEZ ROS, 2011).

Por lo expuesto precedentemente, en el proceso de enseñanzaaprendizaje-entrenamiento la metodología utilizada - con el objetivo de promover la formación de jugadores inteligentes con alto nivel de creatividad en relación a las acciones tácticas individuales, de grupo y colectivas - se torna extremamente importante para la correcta orientación del desarrollo de la capacidad de decisión táctica de los jugadores en los JDC (GRECO, 1988; SILVA; GRECO, 2009).

Los denominados métodos tradicionales presentan una forma de enseñanza-aprendizaje-entrenamiento donde primeramente se descomponen los elementos a enseñar, con una centralidad en el dominio de los gestos técnicos y sus variaciones - los cuales constituyen la mayor preocupación en los escalones de formación del jugador - dejando de lado el valor de la participación activa del alumno en cuanto sujeto de la práctica (GARGANTA, 1997). Estos métodos están guiados por la visión del alto rendimiento deportivo, apoyados en un proceso de entrenamiento similar al de los adultos en el desarrollo de las capacidades físicas, técnicas y tácticas (GRECO, 1997).

La metodología tradicional (o mecanicista) concede especial importancia a la fase de ejecución, en la cual el éxito en un deporte se determina por el dominio de las diferentes técnicas o gestos que conforman el mismo (GARGANTA, 1997). Estos métodos plantean que el participante adquiera una serie de técnicas básicas o habilidades para la práctica del deporte retardando el abordaje del juego hasta que las habilidades alcanzan el nivel de rendimiento deseado (GARGANTA, 2002). Dado el conocimiento anticipado que posee el deportista del movimiento a ser realizado los procesos de toma de decisión se encuentran limitados. Lo cual promueve un juego poco evolucionado en el que los jugadores presentan déficits de conocimientos específicos y consecuentemente - de comprensión del juego (GAMA FILHO, 2001).

Por otra parte, los métodos mixtos utilizan el juego formal como aspecto central del proceso de enseñanza. En ellos la táctica surge como respuesta a los problemas que el juego presenta y la técnica surge como concretización de esas respuestas. Esta metodología de enseñanza, a pesar de promover el desarrollo de las capacidades y conocimiento específicos de los jugadores, no consigue 
proporcionar una densidad de comportamientos deseados, tanto técnicos como tácticos, que posibiliten maximizar el desarrollo de las capacidades y de los conocimientos específicos (GRECO, 1998).

Mientras que - en contrapartida con los métodos tradicionales - los métodos activos (o situacionales) son aquellos que se apoyan en la enseñanza a través de situaciones que priorizan la adaptación del saber (teórico y práctico) al juego. Se focaliza la atención en el proceso que sigue el participante durante su aprendizaje y reclama la implicación de éste en el proceso (GIMENEZ, 2005). Diferentes autores manifiestan la adopción de esta perspectiva para la enseñanza de los deportes colectivos y en concreto para el caso del basquetbol (BARRETO, 2001; VELEZ; LÓPEZ, 2000; GRAÇA; PINTO, 2004; IBÁÑEZ, 2008) proporcionando los métodos y medios de enseñanza-aprendizajeentrenamiento bajo este planteamiento.

El método situacional (GRECO, 1998; KRÖGER; ROTH, 2002) se caracteriza por la descomposición del juego en unidades funcionales - las cuales propician el aprendizaje y la vivencia de las mismas interacciones presentes en los juegos oficiales entre la dimensión táctica, técnica, psicológica y fisiológica pero en escalas de menor complejidad - que pueden ser reconstruidas a lo largo del proceso de enseñanza-aprendizaje-entrenamiento (GARGANTA, 1998; GARGANTA; GREHAIGNE, 1999). Se sustenta en la idea de que a jugar se aprende jugando, con el objetivo de permitir al jugador aprender rápida y correctamente los contenidos tácticos de los JDC, aprendiendo las reglas tácticas básicas de forma incidental. Sustentado en que el aprendizaje de las mismas de modo incidental resulta más estable que de modo intencional (REBER, 1989). Dirigiendo la enseñanza a un objetivo, de forma precisa y controlada para que el jugador pueda actuar de forma variable y adecuada ante cada situación de juego. Este método contempla en la práctica una dinámica relacional que se desarrolla a partir de la interacción intima entre la lógica interna del juego y la lógica del propio sujeto implicado en la acción (GRECO, 1998).

El aprendizaje implícito proporcionado por esta metodología permite que los jugadores puedan construir su propio conocimiento sobre el juego y generen varias alternativas tácticas para resolver el problema (GRECO, 1998; CÁRDENAS; LÓPEZ, 2000; IBÁÑEZ, 2000; GRAÇA; MITCHELL et al., 2003; PINTO, 2004; TALLIR et al., 2007; MEMMERT, 2015). 
Creando en el terreno de juego, a través de ejercicios complejos ordenados en estructuras funcionales, los presupuestos fundamentales para el surgimiento de un clima propicio para la manifestación de comportamientos autónomos inteligentes y creativos (GRECO; BENDA, 2005; MORALES et al., 2009). Tomando como referencia el modelo de enseñanza táctica se propone comenzar por situaciones de juego real simplificadas, focalizando la atención en la exploración por parte de los aprendices de las posibilidades de resolución en ataque y en defensa como elemento indispensable para la ordenación de contenidos y tareas (GRÉHAIGNE; WALLIAN; GODBOUT, 2005).

La atención en el método situacional se centra en la toma de decisiones, en la resolución de problemas y en el conocimiento del juego. De esta forma se plantea la enseñanza de los JDC de forma tal que el jugador adquiera la capacidad de responder a las situaciones que se suceden durante el juego, determinando la eficacia de su acción por la adaptación de su comportamiento a las sucesivas modificaciones que tienen lugar en el entorno (GARGANTA, 2002).

Además, las situaciones reducidas de juego reúnen características esenciales de la unidad del juego (como la cooperación, la oposición y la finalización) que permiten que sean utilizadas en situaciones de enseñanza y entrenamiento para inducir la ejecución de acciones que pueden ocurrir con mayor probabilidad durante un partido formal (MESQUITA, 2006; ALONSO; IBAÑEZ, 2010). Para que ese objetivo sea alcanzado esas situaciones necesitan permitir la elección de diferentes soluciones posibles y satisfacer los siguientes criterios: (i) el objetivo del juego debe siempre estar presente; (ii) todos los elementos estructurales del juego deben ser conservados; (iii) las acciones de ataque y defensa siempre existen; (iv) una transición natural del ataque a la defensa y viceversa debe ser posible; y ( $v$ ) las tareas de los jugadores no deben ser totalmente determinadas (MUSCH; MERTENS, 1991).

Sintéticamente, en el caso de los JDC, los métodos de enseñanza pueden clasificarse en: (i) Método analítico: se desarrolla a partir de la fragmentación de los diversos factores de enseñanza para ser ejercitados por separado y, posteriormente, ser integrados a la situación de juego; (ii) Método global: la enseñanza se desarrolla a partir de una "serie de juegos" accesibles a las fases etarias y a las capacidades técnicas de los alumnos en el cual se busca contemplar "la idea central del juego" o sus estructuras básicas; (iii) Método de 
confrontación: se caracteriza por la idea de que la principal forma de aprender el juego es jugar el juego del adulto, con sus reglas y formas; (iv) Método parcial: el entendimiento del juego pasa por algunos aspectos que deben ser desarrollados separadamente debido a su complejidad. El proceso de enseñanza es concebido como la repetición de series de ejercicios dirigidos al dominio de las técnicas, consideradas como elementos básicos para la práctica del juego o para obtener el éxito en la acción; (v) Método "concepto recreativo del juego deportivo": busca a través de vivencias motoras conocer las relaciones sociales, los objetivos y las formas de alcanzar ese objetivo para, posteriormente, incorporar los patrones externos y las reglas oficiales; y (vi) Método situacional: pregona la enseñanza a través de situaciones de juego con número reducido de practicantes $(1 \times 0,1 \times 1,2 \times 1$, etc.), en las cuales se insertan gradualmente los elementos deportivos (técnicos, tácticos, psicológico y físico) y de situaciones típicas del deporte propiciando el aprendizaje y la vivencia del mismo (GRECO, 1998).

Además de la elección de uno u otro método (o de la combinación de varios de estos) se debe tener en cuenta que la toma de decisión comprende el qué, cuándo y cómo ejecutar la respuesta seleccionada o creada (SOLÀ, 2010). Resulta necesario que el deportista se encuentre presto para modificar las potenciales decisiones, tal como se necesita en un medio ambiente dinámico. Con la práctica y la experiencia competitiva esos mecanismos operan como una unidad, el proceso se va tornando más eficiente, con menor esfuerzo y modificado de modo automático o intencional de acuerdo a la situación (PAULA, 2000). Razón por la cual el proceso de enseñanza-aprendizaje-entrenamiento deportivo debe tener en cuenta el nivel de complejidad de la toma de decisión (RAAB, 2003). 


\section{X - ANÁLISIS DEL JUEGO}

En el ámbito de los Juegos Deportivos Colectivos (JDC) el indagar y explicitar la especificidad de cada deporte constituye un destacado objetivo de investigación. Dado que el rendimiento en los deportes de equipo es una realidad compleja con múltiples limitaciones en su estudio debido, principalmente, a la incertidumbre de las secuencias de juego (MARTIN ACERO; LAGO, 2005). Las condiciones inestables y aleatorias en que ocurren los JDC, aun cuando atribuyen originalidad e interés a las situaciones, tornan más delicada la tarea del observador y del investigador (MENAUT, 1983).

Una de las herramientas para la investigación es el análisis del juego (AJ), definido como el estudio del juego a partir de la observación de la actividad de los jugadores y de los equipos intervinientes en los más diferentes planos de análisis (técnico, físico y estratégico-táctico) (GARGANTA, 2007).

Los resultados obtenidos del análisis del juego constituyen un argumento de importancia para la futura tarea del entrenador, dado que las competiciones son la fuente privilegiada de información útil para el entrenamiento. La observación del juego permite obtener datos interpretables para la construcción de una nueva forma de ver el juego, complementando la subjetividad propia de la observación del entrenador (GARGANTA, 2001).

En este sentido, el análisis del juego resulta imprescindible para la caracterización de las exigencias específicas que definen la dinámica del juego a la que se enfrentan los deportistas y los equipos en el transcurso de la competición, llevando al perfeccionamiento de los programas de preparación y consecuentemente - a la mejoría de su desempeño en una competición o incluso en una época deportiva (TAVARES, 1993; GARGANTA, 2002; GREHAIGNE; GODBOUT; BOUTHIER, 2001; HUGHES; EVANS; WELLS, 2001; GLAZIER, 2010).

De este modo el análisis sistemático de la información acerca del juego permite configurar modelos de la actividad de los jugadores y de los equipos que posibilitan no solo construir métodos de entrenamiento más eficaces y estrategias de trabajo más convenientes en lo que respecta al principio de especificidad, sino también reconocer indicios de la tendencia evolutiva del juego (GARGANTA, 2007). 
Para lo cual debe considerarse que la acción es - por esencia - acción en contexto, por lo que se torna difícil decir si es éste el que modela la acción o es aquella la que lo influencia.

En este sentido, para percibir los comportamientos de juego hay que contextualizarlos, lo que en el caso de los JDC - dada la naturaleza abierta de las tareas consustanciada en las múltiples opciones colocadas al jugador significa analizar la performance a través de la observación en la competición. De forma tal que se garantice el circulo de validez ecológica reivindicado por los aprendizajes auténticos y contextualizados (GRAÇA; MESQUITA, 2007).

Sin embargo, no es posible suponer que a medida que aumenta la complejidad del campo de investigación, recurriendo a diversas variables y ópticas de examen, haya un método que por sí mismo satisfaga todas las exigencias de observación, análisis e interpretación de los hechos empíricos.

Por ello el análisis del juego puede ser perspectivado en, al menos, cinco dominios: (i) análisis de los resultados: compara ganadores y perdedores, se estudia la evolución de los resultados a lo largo del partido; (ii) análisis de las prestaciones: estudio de los factores relacionados con el rendimiento (capacidades motoras, técnicas y cualidades psicológicas); (iii) análisis de las cargas: estudio de la repercusión de las cargas en el organismo; (iv) análisis de las condiciones de competición: estudio de los aspectos materiales, de infraestructura, del reglamento y del comportamiento del público; y (v) análisis de los comportamientos: estudio de la estrategia y las acciones técnico - tácticas utilizadas (OLIVEIRA, 1993).

Mientras que, siempre a nivel de la investigación, se pueden reconocer los siguientes objetivos del análisis del juego en los JDC: (i) descubrir indicadores y definir criterios para la planificación del entrenamiento, proveer feedback, adquisición de datos que permitan la construcción de modelos de juego y de preparación que explican las relaciones entre las variables del juego y el éxito deportivo (FRANKS; GOODMAN, 1986); (ii) descubrir la naturaleza interna del juego, evaluación de los jugadores y de los equipos (DUFOUR; 1989); (iii) explicar la relaciones entre las variables del juego y el éxito deportivo (SAMPAIO; JANEIRA, 2003); (iv) identificación de los factores individuales y colectivos del rendimiento (GROSGEORGE; DUPUIS; VÉREZ, 1991); (v) descubrir la estructura de las regularidades del juego para mejorar la organización de la 
preparación técnico-táctica (LAMES; HANSEN, 2001); (vi) interpretar la organización de los equipos y de las acciones que contribuyen para la calidad del juego (GRÉGHAIGNE, 1992); (vii) configurar modelos de juego a partir del análisis de amplias bases de datos (GARGANTA, 1997); y (viii) planificar y organizar el entrenamiento, volviendo más específicos sus contenidos (GARGANTA, 2000).

El análisis del juego debe permitir describir la performance realizada en contexto de juego, codificando acciones individuales, grupales o colectivas, de modo de sintetizar información relevante para transformar positivamente el proceso de enseñanza-aprendizaje-entrenamiento (GARGANTA, 2007).

La cantidad de información generada en un partido tiene un volumen muy superior a la capacidad de asimilación de cualquier observador. Por eso se debe, en primer lugar, determinar el tipo de información que se desea obtener delimitando con claridad el momento del cual se pretende obtener información y también el contenido de la información que se desea extraer (LAMAS et al., 2014).

La detección de las acciones más representativas o críticas persigue como objetivo reconocer los factores que inducen perturbaciones 0 desequilibrios en el balance ataque/defensa. Buscando detectar e interpretar la permanencia de trazos comportamentales en la variabilidad de las acciones, teniendo en cuenta tanto las regularidades como las variaciones (LAPORTA et al., 2015). Para ello se sugiere que el número mínimo de partidos a observar para considerar como representativa una muestra es de seis partidos, aunque este número es dependiente de la variabilidad típica del desarrollo de los partidos (HUGHES; EVANS; WELLS, 2001).

De las diferentes vertientes de análisis del juego, el estudio de las estructuras técnico - tácticas es la que mejor encuadra en el contexto del entrenamiento y la competición en las primeras etapas de preparación deportiva dado que es en torno a estos dos factores que deberá incidir primordialmente el proceso de entrenamiento (RIERA, 1995; ARAUJO, 2009). Dado que el análisis de los comportamientos centrado en el estudio de los aspectos técnico - tácticos puede contribuir para la definición de criterios objetivos en la planificación de entrenamiento, identificar factores individuales, grupales y colectivos de 
rendimiento y encontrar la estructura de las regularidades del juego, con el objetivo de mejorar la organización de la preparación.

Entendiendo al desempeño técnico-táctico como el conjunto de factores referentes a la toma de decisión, ejecución de componentes motores y movimientos con o sin balón, adaptables a situaciones de juego que permitan la resolución de tareas, las cuales permiten jerarquizar características que discriminan atletas de distinto nivel de rendimiento (HOPPER, 2007).

En este sentido los estudios que se encuadran en el ámbito del análisis táctico en los JDC incluyen dificultades especiales derivadas del número de elementos a observar, de la gran variabilidad de comportamientos y acciones que ocurren en los partidos y de los múltiples criterios existentes para definirlos e identificarlos (MATIAS; GRECO, 2013).

Por lo tanto - aun cuando la visión del entrenador y sus colaboradores resulta fundamental e insustituible - la utilización de recursos auxiliares de evaluación se constituye en un soporte cada vez más importante para el análisis del juego. Siendo uno de los desafíos principales para el investigador en la aplicación de tecnologías en el contexto deportivo la obtención de secuencias de video apropiadas que permitan identificar y categorizar - de forma robusta individuos y comportamientos a lo largo del tiempo, en un ambiente inestable y que contiene múltiples interacciones (BARTLETT et al., 2012).

En los JDC - representados teóricamente como sistemas dinámicos (GREHAIGNE; GODBOUT; BOUTHIER, 2001) - el marco de juego es organizado y conocido pero su contenido es siempre imprevisible y aleatorio (GARGANTA, 2000), existiendo un "caos determinista" (HUGHES; EVANS; WELLS, 2001). En esta situación irrumpen patrones que expresan un comportamiento caótico del sistema a pequeña escala, pero que a gran escala evidencian una cierta regularidad (TAVARES, 2013).

Teniendo en consideración la naturaleza probabilística de los eventos en los sistemas dinámicos y la historicidad conferida por las transformaciones sufridas, el análisis del juego debe buscar describir los diferentes patrones de organización subyacentes a la complejidad interactiva de los sistemas durante un partido (o en diferentes partidos), presentando las tendencias y efectividad de los equipos en sus diferentes organizaciones (LAMAS; SEABRA, 2006). 
Siendo el convertir puntos el objetivo principal del basquetbol, uno de los aspectos que merece especial atención por parte de los investigadores es el proceso que conduce a lograrlo, esto es, las secuencias ofensivas concretadas con éxito. De este modo resulta necesario analizar las secuencias tanto individuales como de asociación colectiva.

Dado que, si no hubiera algo que ligase el juego a un territorio de posibles previsibles en el cual pontifican los denominados modelos, la preparación de los jugadores y de los equipos dejaría de tener sentido. Esto quiere decir que, no obstante el peso del factor aleatorio, las acciones de juego son categorizables, esto es, reconvertibles en categorías o tipos de ocurrencias que constituyen unidades de acción. Así los denominados modelos de juego, entendidos como conjunto de ideas y principios sobre el modo de jugar de los equipos, funcionan como referencias importantes en la construcción del proceso de entrenamiento de la táctica (GARGANTA, 2004).

Por tal motivo existe una preocupación creciente en considerar la variabilidad e inestabilidad característica del juego, considerando de forma más sistemática la influencia de las variables situacionales en la performance deportiva (MARCELINO; SAMPAIO; MESQUITA, 2011).

En el sistema juego se busca información para poder discriminar la mayor eficiencia por parte del ataque o la defensa. En el subsistema equipo, cuando el ataque vence la oposición ocurre la creación de espacios seguida de la ocupación de este por un jugador con balón para producir un lanzamiento. Cuando la defensa lleva la ventaja, la finalización no ocurre, pues la organización del equipo defensor es superior a la del ataque y permite la recuperación de la posesión del balón (LAMAS; SEABRA, 2006).

En la actualidad nos encontramos frente a un juego de anticipación donde todos atacan, unos con posesión de balón y otros sin balón pero con el objetivo de recuperar el mismo. En este sentido, los equipos apuestan a defensas activas y agresivas, caracterizadas por la utilización de una gran variedad de acciones, ejecutadas en profundidad y a un ritmo elevado. En consecuencia, los equipos pueden variar sus patrones de juego de acuerdo con las características de la oposición ofrecida por el adversario.

Analizar la efectividad de las metodologías y el desempeño de los jugadores en relación a las acciones técnico-tácticas comprende una importante 
iniciativa investigativa que podrá proporcionar subsidios teóricos y metodológicos a los entrenadores y jugadores en relación a los requisitos que componen el rendimiento deportivo (SAAD; NASCIMENTO, 2013).

En este sentido - para el caso específico del basquetbol - las Dinámicas de Creación de Espacios (DCE) (LAMAS et al., 2011; LAMAS, 2012) así como sus correspondientes Dinámicas de Protección de Espacios (DPE) (LAMAS, 2012; SANTANA et al., 2015) constituyen un aporte significativo para realizar el análisis del juego propiamente dicho. 


\section{XI - INVESTIGACIÓN DE CAMPO}

En los capítulos anteriores se evidenció la importancia de la táctica deportiva y la toma de decisión en el deporte, así como el rol que cumplen los entrenadores, los modelos de abordaje de la táctica deportiva, los métodos utilizados para desarrollarla y el análisis del juego. Todos estos aspectos presentan influencia determinante para el desarrollo a largo plazo del nivel de rendimiento del deportista. En la presente sección se presentan dos trabajos en función de los aspectos precitados. El primero es un estudio transversal descriptivo que tiene como objetivo realizar un registro e interpretación de la opinión de los entrenadores de basquetbol sobre la importancia de la enseñanza del saber táctico de la modalidad en las categorías formativas $\mathrm{U}-13$ y U-15, su carga en el periodo competitivo del ciclo anual y la importancia de los métodos de enseñanza utilizados para su desarrollo en las categorías formativas.

El segundo es un estudio de corte analítico observacional que objetiva describir la aplicación del saber táctico realizada por los jugadores de basquetbol de categoría U-13 y U-15 en situación real de competición mediante el análisis de: (i) Dinámicas de Creación de Espacios (DCE) realizadas que precedieron al término de la posesión del balón en lanzamiento, falta o pérdida de balón en situaciones contra defensa individual; (ii) determinación de la eficiencia de las DCE contra defensa individual; y (iii) utilización de las Dinámicas de Protección de Espacios (DPE) en defensa individual.

Ambos trabajos se centraron en las categorías U-13 y U-15 de basquetbol incluidas en la etapa "Train to train" (T2T - Entrenar para entrenar) de la fase "Develop the game" (Desarrollar el juego) del "Long-Term Athlete Development" (proceso de desarrollo del deportista a largo plazo) (BALYI; 2001; BALYI; WAY; HIGGS, 2013). 


\section{XI.1.- OPINIÓN DE LOS ENTRENADORES DE BASQUETBOL SOBRE LA ENSEÑANZA DEL SABER TÁCTICO EN LAS CATEGORÍAS FORMATIVAS}

\section{1.- INTRODUCCIÓN}

El basquetbol es un deporte abierto, de situación, acíclico que se caracteriza por el gran número de cambios de su dinámica de juego, variables inciertas y una estructura de rendimiento diversificada y alto nivel de complejidad. Dentro de los Tactical Games es clasificado como un juego de invasión (MITCHELL; OSLIN; GRIFFIN, 2003) en el cual se produce una participación simultanea de los jugadores en el espacio y en el tiempo con el objetivo de vencer, alternándose en situaciones de ataque y de defensa fuertemente condicionadas desde el punto de vista táctico (GARGANTA, 1998).

Entendiendo que la táctica consiste en determinar medios y encontrar soluciones para los problemas prácticos surgidos en las situaciones de juego (GRECO; CHAGAS, 1992; GARGANTA, 1998). En los juegos deportivos colectivos (JDC), la dimensión táctica ocupa el núcleo de la estructura de rendimiento, es la dimensión unificadora que da sentido y lógica a todas las otras, por lo cual la función principal de los demás factores de rendimiento es la de cooperar facilitando el acceso a los desempeños tácticos de nivel cada vez más elevado (GARGANTA, 1998; COSTA et al., 2011). La capacidad táctica está presente y se presenta también como una de las principales características para la formación y calidad de un atleta completo (SERRABONA, 1997).

El proceso de formación del jugador tiene que ser conducido adecuadamente, dado que la calidad del trabajo hecho en él es determinante para la consecución de los objetivos deportivos hasta el alto rendimiento. Los entrenadores son los responsables de seleccionar los contenidos de enseñanza a desarrollar durante el proceso de entrenamiento, organizándolos de la forma más adecuada con el objetivo de lograr un aprendizaje progresivo y significativo por parte de los jugadores. Al asumir la responsabilidad de la formación del jugador y la definición e implementación de una concepción de juego, es de fundamental importancia conocer sus métodos de entrenamiento. En virtud de eso la enseñanza del basquetbol solicita una continua investigación para el desarrollo del nivel de rendimiento de mejores jugadores que puedan resolver 
los problemas que presenta el juego (GALLEGO et al., 2007; IBAÑEZ, 2008).

Las exigencias que el deporte de formación orientado al alto nivel establece, en la constante tendencia al rendimiento de los jugadores y de los equipos en la competición, exige al entrenador un conocimiento profundo acerca de los procesos de intervención específicos. Mientras que los métodos de enseñanza - independientemente de sus orientaciones conceptuales - buscan presentar principios y orientaciones metodológicas sustentadas en un modelo de enseñanza con el objetivo de mejorar la formación deportiva y la eficacia pedagógica de los entrenadores (NASCIMENTO, 2008).

En esta perspectiva, el objetivo de este estudio fue realizar un registro $\mathrm{e}$ interpretación de la opinión de los entrenadores de basquetbol sobre la importancia de la enseñanza del saber táctico en las categorías formativas del basquetbol, su carga en el periodo competitivo del ciclo anual y la importancia de los métodos de enseñanza utilizados para su desarrollo en las categorías formativas. Comprendiendo la categoría U-13 en la cual los atletas están en la fase de "preparación multilateral orientada" (11-13 años) y la categoría U-15 donde están en la fase de "iniciación específica" (14-16 años) en la cual comienza el perfeccionamiento y especialización en la modalidad deportiva (SERRABONA, 1997).

\section{2- MÉTODOS}

Estudio transversal descriptivo. Participaron 43 entrenadores de Basquetbol de la ciudad de Santa Fe (Argentina) con categoría ENEBA (Escuela Nacional de Entrenadores en Basquetbol de Argentina) y experiencia de enseñanza-aprendizaje-entrenamiento en las categorías U-13 y U-15.

El instrumento para la recolección de datos fue un cuestionario sobre la enseñanza del saber táctico en las categorías formativas de basquetbol construido ad-hoc. El mismo consiste en una lista de características de los contenidos tácticos y de los métodos de enseñanza-aprendizaje-entrenamiento. La clasificación de los métodos de entrenamiento utilizada fue el modelo de categorización (analítico, global, de confrontación, parcial, concepto recreativo del juego deportivo, situacional) propuesto por Greco (1995). Siendo solicitada a los entrenadores su opinión a través de una escala tipo Likert de 5 puntos $(1=$ 
muy poco importante, 2 = poco importante, $3=$ importancia media, $4=$ muy importante, 5 = totalmente importante). Los participantes del estudio fueron informados al respecto de los objetivos de la investigación y estuvieron de acuerdo con los mismos, autorizando la divulgación de los resultados. Para el tratamiento estadístico de los mismos fueron realizadas medidas de tendencia central (media aritmética y mediana) y medidas de dispersión (desvío standard, amplitud total). El tratamiento estadístico fue realizado con el software SPSS versión 17.0.

\section{3- RESULTADOS Y DISCUSIÓN}

Los entrenadores de Basquetbol $(n=43)$ tienen una experiencia $\bar{X}=14,7$ $\pm 3,9$ años. La moda de la frecuencia semanal de entrenamiento fue de 3 sesiones de 75 minutos de duración en la categoría $U-13$ y de 3 sesiones de 90 minutos de duración en la categoría U-15.

En segundo lugar se verifica que los entrenadores encuestados, en lo que refiere a la importancia dada al desarrollo de la táctica en las sesiones de entrenamiento durante el periodo competitivo, conforme aumenta la categoría de los jugadores expresan darle mayor importancia (Tabla 1). Es de subrayar que la categoría "poca" o "muy poca importancia" dada a la táctica en la categoría U13 sólo es de 13,3\%, mientras que en la categoría U-15 ese porcentaje es aún menor $(3,3 \%)$.

\begin{tabular}{|l|c|c|}
\hline \multirow{2}{*}{ Importancia de la Táctica } & \multicolumn{2}{|c|}{ Categoría deportiva } \\
\cline { 2 - 3 } & $\mathrm{U}-13$ & $\mathrm{U}-15$ \\
\hline Muy poca & $5,0 \%$ & $0,0 \%$ \\
\cline { 2 - 3 } $\begin{array}{l}\text { Poco importante } \\
\text { Importancia media }\end{array}$ & $8,3 \%$ & $3,3 \%$ \\
\cline { 2 - 3 } $\begin{array}{l}\text { Muy importante } \\
\text { Totalmente importante }\end{array}$ & $41,7 \%$ & $43,3 \%$ \\
\cline { 2 - 3 } & $31,7 \%$ & $31,7 \%$ \\
\hline
\end{tabular}

TABLA 1: Importancia expresada por los entrenadores para la táctica en las categorías U-13 e U-15 
En lo que refiere a los métodos de enseñanza-aprendizaje-entrenamiento durante el periodo competitivo, se observa una preponderancia del método situacional $(\mathrm{Me}=28,6 \%, \mathrm{IC}=22,36-34,84)$ en la importancia expresada por los entrenadores para las categorías U-13 y U-15 (Gráfico 1). Se destaca que el valor del cuartil 1 correspondiente al método situacional se encuentra por encima del cuartil 3 (75\% de los datos) de los métodos analítico, global, parcial y recreativo; y por sobre el valor de la mediana del método de confrontación. La poca importancia expresada por los entrenadores de los métodos analítico (Me $=15 \%$ ) y parcial $(\mathrm{Me}=15 \%)$, así como la importancia dada al método situacional resulta concordante con lo que afirman Greco, Memmert y Morales (2010), de que el proceso de enseñanza-aprendizaje-entrenamiento con base en el aprendizaje incidental o practica deliberada permiten una adecuada adquisición de comportamientos tácticos creativos en el basquetbol.

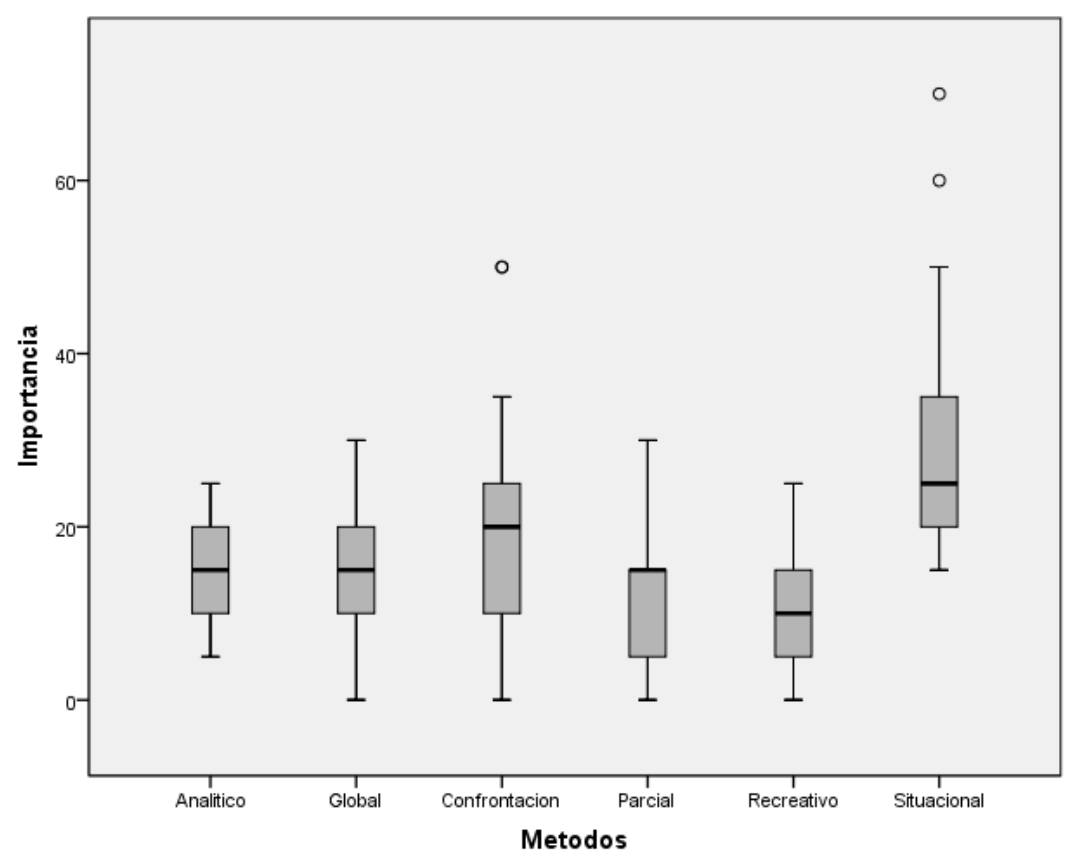

Gráfico 1: Importancia de los métodos de enseñanza-aprendizaje-entrenamiento de la táctica.

Se observa en el Gráfico 2 que el 49\% (21) de los entrenadores de las categorías U-13 y U-15 dan al método situacional una importancia de 3 o 4 en la escala de Likert durante el periodo competitivo, lo que puede indicar que este método basado en situaciones propias del juego con número reducido de practicantes $(1 \times 0,1 \times 1,2 \times 1$, etc. $)$ - y que a veces no abarcan la idea total del juego, no obstante presentar el elemento central del mismo - es preponderante 
por sobre los otros métodos de enseñanza-aprendizaje-entrenamiento, lo que está de acuerdo con lo expresado en el Gráfico 1.

Acordando con los resultados de Leite et al. (2011) en lo que respecta a la importancia dada por los entrenadores a las situaciones reducidas de juego en la etapa de "Train to train" del proceso de desarrollo del deportista a largo plazo (BALYI; WAY; HIGGS 2013); y con lo expresado por Alonso e Ibáñez (2010), así como por López Ros (2011) sobre la necesidad de basar el proceso enseñanza-aprendizaje-entrenamiento en el diseño y aplicación de tareas abiertas (procedimientos heurísticos) que obliguen a los deportistas a tomar decisiones, para contribuir a la formación adecuada de jugadores y el desarrollo de los procesos cognitivos inherentes a la acción táctica.

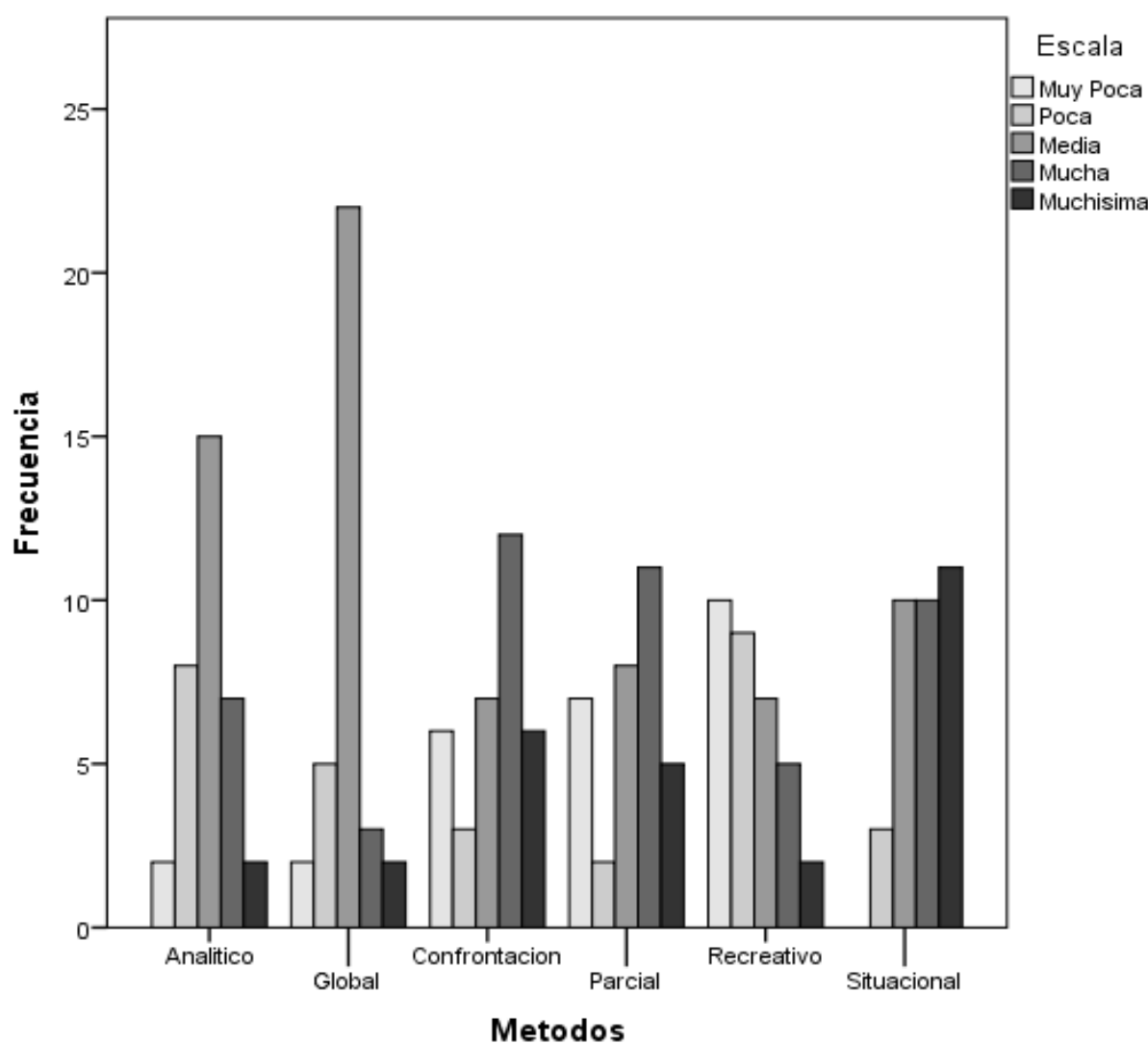

Gráfico 2: Frecuencia de utilización de los métodos de enseñanza-aprendizaje-entrenamiento de la táctica

\section{4- CONCLUSIONES}

Frente a las evidencias encontradas en esta investigación y las limitaciones metodológicas inherentes a su realización, los resultados del presente estudio sugieren que la enseñanza del saber táctico en las categorías 
formativas del basquetbol resulta fundamental para los entrenadores de basquetbol en las categorías U-13 y U-15, acrecentándose su importancia conforme aumenta la edad de los jugadores. Junto a ello se puede afirmar que el método situacional es, en la opinión de los entrenadores de basquetbol, el principal método utilizado en las categorías U-13 y U-15.

Dado que la metodología de enseñanza-aprendizaje-entrenamiento a ser utilizada se revela como extremamente importante para la correcta orientación del desarrollo de la capacidad de decisión táctica de los jugadores de los JDC. La preponderancia del método situacional en la importancia expresada por los entrenadores para las categorías U-13 y U-15 denota una transición entre el paradigma de los modelos de enseñanza sustentados en las estrategias instruccionales centradas en el entrenador hacia modelos de enseñanza de la táctica deportiva que propician un comportamiento proactivo y un empoderamiento de los jugadores como base para el desarrollo de la inteligencia y creatividad táctica.

De ello se desprende que la estructuración de las actividades y la presentación de los contenidos de entrenamiento con base en los modelos centrados en la táctica pueden propiciar adecuados procesos de desarrollo y posibilitar una comprensión del juego como medio para su formación y éxito en la carrera deportiva a largo plazo (PEREIRA et al., 2010). Esto resulta esencial para actualizar programas de entrenamiento, crear nuevas formas de organización del trabajo y realizar una integración de los elementos constitutivos del entrenamiento para mejorar la calidad del mismo. De este modo la investigación procura establecer una contribución científica para la reflexión y toma de decisión en el proceso formativo a largo plazo en el dominio de los juegos deportivos colectivos en general y del basquetbol en particular.

Asimismo, se debe tener en cuenta que la experiencia del entrenador tiene un papel determinante en el éxito de la preparación deportiva, ya que su responsabilidad en el diseño de objetivos, la selección de contenidos y la aplicación de las metodologías de entrenamiento es de vital importancia (LEITE; SAMPAIO, 2012). Por lo cual se considera relevante el desarrollo de investigaciones futuras que aborden: (i) la planificación y la aplicación de los métodos de enseñanza-aprendizaje-entrenamiento en la enseñanza del saber táctico en otras categorías de la formación deportiva; (ii) la identificación de las 
características diferenciadores de la planificación de los entrenadores en las categorías formativas del basquetbol, y (iii) la relación entre lo que se puede observar en el juego formal y lo que los entrenadores expresan de modo declarativo. De modo tal que permita profundizar el nivel de conocimiento y las concepciones sobre las metodologías empleadas en el proceso de enseñanzaaprendizaje-entrenamiento como contribución en la formación permanente de los entrenadores. 


\section{XI.2.- APLICACIÓN DEL SABER TÁCTICO EN CATEGORÍAS FORMATIVAS DE BASQUETBOL}

\section{1- INTRODUCCIÓN}

El basquetbol es un deporte abierto, de situación, acíclico que se caracteriza por el gran número de cambios en su dinámica de juego, con variables inciertas y una estructura de rendimiento diversificada y alto nivel de complejidad. Los equipos presentan un comportamiento táctico basado en acciones individuales, grupales y colectivas con la intención de retomar la posesión del balón en la condición de defensa y finalizar efectivamente (convertir puntos) en la condición de ataque (LAMAS et al., 2011a). La dinámica de juego presenta comportamiento similar a un sistema dinámico no lineal por su carácter aleatorio oriundo de la confrontación (SAMPAIO; MAÇAS, 2012; MIKOLAJEC; MSZCZYK; ZAJAC, 2013).

Reglamentariamente las categorías formativas en el basquetbol se dividen en función de la fecha y año de nacimiento de los jugadores participantes. Siendo la categoría U-13 (under 13) la primer categoría competitiva a nivel local, provincial y nacional, por lo cual es la primera en la cual se evalúa al jugador de manera directa o indirecta en función de resultados deportivos colectivos y actuaciones individuales; mientras que la categoría U-15 (under 15) constituye la primera categoría competitiva a partir de la cual se organizan selecciones nacionales para participar en competencias a nivel internacional.

Los equipos de las categorías U-13 y U-15 están incluidos en la etapa "Train to train" (T2T - Entrenar para entrenar) de la fase "Develop the game" (Desarrollar el juego) del "Long-Term Athlete Development" (proceso de desarrollo del deportista a largo plazo), siendo la primer etapa en la cual se debe hacer foco en la excelencia. En la misma - durante las competiciones - los deportistas juegan para ganar y hacer lo mejor, pero el foco principal del entrenamiento y la competición debe ser la aplicación de las habilidades, estrategias y táctica aprendidas en el entrenamiento en situaciones competitivas (BALYI; 2001; BALYI; WAY; HIGGS, 2013).

En los juegos deportivos colectivos (JDC) la dimensión táctica ocupa el núcleo de la estructura de rendimiento, es la dimensión unificadora que da 
sentido y lógica a todas las otras, por lo cual la función principal de los demás factores de rendimiento es la de cooperar facilitando el acceso a los desempeños tácticos de nivel cada vez más elevado (COSTA et al., 2011). Entendiendo que la táctica consiste en determinar medios y encontrar soluciones para los problemas prácticos surgidos en las situaciones de juego (GRECO; CHAGAS, 1992; GARGANTA, 1998).

Mientras que jugar bien consiste en elegir la opción de juego más adecuada en cada momento y ser capaz de llevarla a cabo de forma eficiente y consistente a lo largo de un encuentro (GRÉHAIGNE; GOODBOUT; BOUTHIER, 1999; 2001). La toma de decisión se realiza en interacción con diferentes procesos cognitivos que comprenden los mecanismos de percepción, atención, anticipación, memoria, pensamiento y la propia toma de decisión (GRECO, 1995; 2006). Dependiendo la toma de decisión por parte de los jugadores en los deportes de equipo de al menos tres factores: las propias capacidades del deportista, la tarea que se debe resolver y las características del entorno de actuación; consolidándose por la realización de una habilidad motora (RAAB, 2003; 2015; NITSCH, 2009). Abarcando el qué, cuándo y cómo ejecutar la respuesta seleccionada (PAULA, 2000; MATIAS, 2009). Entendiendo al desempeño técnico-táctico como el conjunto de factores referentes a la toma de decisión, ejecución de componentes motores y movimientos con o sin balón, adaptables a situaciones de juego que permitan la resolución de tareas, las cuales permiten jerarquizar características que discriminan atletas de distinto nivel de rendimiento (HOPPER, 2007).

En este sentido, la presente investigación objetiva describir la aplicación del saber táctico (conocimiento declarativo / verbalizable) realizada por los jugadores de basquetbol de categoría U-13 y U-15 en situación real de competición mediante: (i) análisis de Dinámicas de Creación de Espacios (DCE) realizadas que precedieron al término de la posesión del balón en lanzamiento, falta o pérdida de balón en situaciones contra defensa individual; (ii) determinación de la eficiencia de las DCE contra defensa individual; y (iii) utilización de las Dinámicas de Protección de Espacios (DPE) en defensa individual.

\section{2- MÉTODOS}


Estudio analítico observacional. Se filmaron y analizaron a posteriori 12 partidos de la categoría U-13 (under 13) y 12 partidos de la categoría U-15 (under 15) correspondientes al Campeonato Interasociaciones de selecciones de la Federación de Basquetbol de la Provincia de Santa Fe (FBPSF) - Argentina, desarrollados en el año 2014. Para la filmación se utilizó una cámara digital (Samsung HMX-F80BN). La misma se posiciono en la tribuna a dos metros como mínimo de altura y en la prolongación de la línea central de la cancha, con distanciamiento suficiente para optimizar el encuadramiento de los jugadores y del balón, considerando las líneas laterales y finales del campo. Las acciones fueron editadas y posteriormente analizadas anotando los datos en formularios específicos elaborados ad-hoc. La utilización del medio audiovisual se realizó para permitir la visualización repetida y detallada del comportamiento táctico cuantas veces sea necesario, minimizando los errores de la observación.

Para el análisis, una posesión del balón fue definida como el periodo del juego que se inicia cuando un equipo adquiere control del balón y finaliza en el momento en el cual el otro equipo recupera el control del mismo.

El tipo de ataque fue dividido en: (i) posicionado (la situación de oposición involucra a todos los atacantes y defensores en la media cancha ofensiva); (ii) contraataque (existe superioridad numérica ofensiva en la media cancha de ataque frente a la defensa); y (iii) perdida del balón (situación de perdida de la posesión del balón antes de producirse la acción de creación de espacio para la finalización).

Los tipos de organización defensiva fueron divididos en: (i) individual (cada defensor es responsable de uno de los atacantes) y (ii) zonal (cada defensor es responsable por un espacio del sector defensivo).

Para realizar el análisis de la aplicación del saber táctico se utilizaron las DCE (Dinámicas de Creación de Espacios) (LAMAS et al., 2011b) y las DPE (Dinámicas de Protección de Espacios) (LAMAS, 2012; SANTANA et al., 2015). Las DCE (Dinámicas de Creación de Espacios) son definidas como comportamientos ofensivos que tienen como objetivo crear espacio en el sector defensivo proporcionando las condiciones para que ocurra una finalización. Definiendo siete clases de DCE: a) DCBD (Desmarque con balón con drible); b) DCSD (desmarque con balón sin drible); c) APe (Aclarado en el perímetro); d) Al 
(Aclarado interior); e) DSB (Desmarque sin balón); f) BD (Bloqueo directo); g) BI (Bloqueo indirecto). Mientras que las DPE (Dinámicas de Protección de Espacios) son definidas como comportamientos defensivos que tienen como objetivo una ocupación del espacio de manera de impedir que ocurra una finalización y producir una recuperación del balón. Existiendo una relación de una DCE para diversas posibilidades de las respectivas DPE (Tabla 1).

\begin{tabular}{|l|l|l|}
\hline N.J. & $\begin{array}{l}\text { Dinámicas de Creación de } \\
\text { Espacios }\end{array}$ & $\begin{array}{l}\text { Dinámicas de Protección de } \\
\text { Espacios }\end{array}$ \\
\hline $1 \times 1$ & $\begin{array}{l}\text { DCBD (desmarque con balón } \\
\text { con drible); DCSD (desmarque } \\
\text { con balón sin drible); APe } \\
\text { (aclarado en el perímetro) }\end{array}$ & $\begin{array}{l}\text { Neutro; Orientado para el fondo; } \\
\text { Orientado para el medio. }\end{array}$ \\
\hline $1 \times 1$ & Al (aclarado interior) & $\begin{array}{l}\text { Por delante; Por detrás; } \\
\text { Orientado 3/4 por detrás; } \\
\text { Orientado 3/4 por delante. }\end{array}$ \\
\hline $2 \times 2$ & DSB (desmarque sin balón) & $\begin{array}{l}\text { Alejado (de la línea de pase); } \\
\text { Próximo (a la línea de pase). }\end{array}$ \\
\hline $2 \times 2$ & $\begin{array}{l}\text { BD (bloqueo directo) - jugador } \\
\text { con balón }\end{array}$ & $\begin{array}{l}\text { Por delante; Por el medio; Por } \\
\text { detrás; Evitar el bloqueo; Cambio } \\
\text { defensivo; Doblaje defensivo. }\end{array}$ \\
\hline $2 \times 2$ & $\begin{array}{l}\text { BD (bloqueo directo) - jugador } \\
\text { que realiza el bloqueo }\end{array}$ & $\begin{array}{l}\text { Contener; Mostrarse; Alejarse; } \\
\text { Abrirse; Cambio defensivo; } \\
\text { Doblaje defensivo. }\end{array}$ \\
\hline $3 \times 3$ & $\begin{array}{l}\text { BI (bloqueo indirecto) - receptor } \\
\text { del bloqueo }\end{array}$ & $\begin{array}{l}\text { Por delante; Por el medio; Por } \\
\text { detrás; Evitar el bloqueo; Cambio } \\
\text { defensivo; Doblaje defensivo. }\end{array}$ \\
\hline $3 \times 3$ & $\begin{array}{l}\text { BI (bloqueo indirecto) - jugador } \\
\text { que realiza el bloqueo }\end{array}$ & $\begin{array}{l}\text { Contener; Mostrarse; Alejarse; } \\
\text { Abrirse; Retrasar; Cambio } \\
\text { defensivo; Doblaje defensivo. }\end{array}$ \\
\hline
\end{tabular}

Tabla 1: Dinámicas de Creación de Espacios (DCE) (LAMAS et al., 2011b) y sus correspondientes Dinámicas de Protección de Espacio (DPE) (LAMAS, 2012; SANTANA et al., 2015), donde N.J. es el número de jugadores participantes.

Para realizar el análisis, tanto para las DCE como para las DPE, se utilizaron los siguientes criterios de inclusión: (i) la existencia de posesión de balón; (ii) una diferencia de puntaje menor o igual a 10 puntos; y (iii) la utilización de defensa individual $(\mathrm{H}-\mathrm{H})$ por parte del equipo sin posesión del balón.

El procedimiento estadístico utilizado fue de estadística descriptiva, se describieron todas las variables calculando frecuencia relativa y eficiencia, se realizó análisis de diferencias de proporciones y test de contingencia para 
relacionar variables. El tratamiento estadístico fue realizado con el software SPSS versión 17.0.

\section{3- RESULTADOS Y DISCUSIÓN}

\section{1- ANÁLISIS GENERAL}

En total se observaron 4322 posesiones de balón, de las cuales 2265 correspondieron a la categoría U-13, mientras que 2057 correspondieron a la categoría U-15. Cumpliendo con el criterio de inclusión se analizaron 3308 posesiones de balón, de las cuales 1557 correspondieron a la categoría U-13, mientras que 1751 correspondieron a la categoría U-15 (Tabla 1).

\begin{tabular}{|c|c|c|c|c|c|}
\hline \multirow{3}{*}{ Ataque } & \multicolumn{4}{|c|}{ Categoría deportiva } & \multirow{3}{*}{ Total } \\
\hline & \multicolumn{2}{|c|}{$U-13$} & \multicolumn{2}{|c|}{ U-15 } & \\
\hline & $\mathrm{n}$ & $\%$ & $\mathrm{n}$ & $\%$ & \\
\hline Contraataque & 220 & 14 & 181 & 10 & 401 \\
\hline $\begin{array}{l}\text { Perdida del } \\
\text { balón }\end{array}$ & 263 & 17 & 262 & 16 & 525 \\
\hline $\begin{array}{c}\text { Ataque } \\
\text { posicionado }\end{array}$ & 1074 & 69 & $\begin{array}{c}1308 \\
(1232 \mathrm{c} / \mathrm{H}- \\
\mathrm{H}, 76 \\
\text { c/zona) }\end{array}$ & 74 & 2382 \\
\hline Total & 1557 & & 1751 & & 3308 \\
\hline
\end{tabular}

Tabla 1: Ocurrencia de situaciones en las categorías U-13 y U-15

Para ambas categorías se verifica significante prevalencia del ataque posicionado en relación al contraataque y las pérdidas del balón $\left(p=2,5 \times 10^{-4}\right)$. La disminución porcentual de las situaciones de contrataque en la categoría U-15 en comparación con la categoría U-13 puede deberse a una mejor organización y ocupación de los espacios por parte del equipo que defiende durante la transición ataque - defensa. Mientras que no se observan diferencias significativas en las pérdidas de balón entre ambas categorías (Test diferencia de proporciones $p=0,12$ ).

Los tipos de defensa utilizados contra ataque posicionado en cada categoría son expresados en la Tabla 2, observándose que en la categoría U-15 un $6 \%$ de las situaciones corresponden a la defensa zonal. Existiendo diferencia 
significativa en la categoría U-15 entre la utilización de defensa individual y zonal $(p<0.0001)$. Defensa zonal que por reglamento de la Confederación Argentina de Basquetbol se encuentra prohibida en la categoría U-13.

\begin{tabular}{|c|c|c|c|}
\hline \multirow{2}{*}{ Defensa } & \multicolumn{2}{|c|}{ Categoría deportiva } & \multirow{2}{*}{ Total } \\
\cline { 2 - 3 } & $\mathrm{U}-13$ & $\mathrm{U}-15$ & \\
\hline Individual $(\mathrm{H}-\mathrm{H})$ & 1074 & 1232 & 2306 \\
\hline Zonal & 0 & 76 & 76 \\
\hline Total & 1074 & 1308 & 2382 \\
\hline
\end{tabular}

Tabla 2: Tipo de defensa utilizado contra ataque posicionado en las categorías U-13 y U-15

\section{2- DINÁMICAS DE CREACIÓN DE ESPACIOS (DCE)}

Para el análisis de las DCE se consideraron sólo las utilizadas en posesión del balón contra defensa individual. En lo que refiere al total de situaciones contra defensa individual, para la categoría U-13 las DCE en situación $1 \times 1$ se utilizaron 592 veces ( $55 \%$ del total), en situación $2 \times 2437$ veces ( $41 \%$ del total) y en situación $3 \times 345$ veces ( $4 \%$ del total). Mientras que para la categoría U-15 las DCE en situación 1x1se utilizaron 795 veces (64\% del total), en situación 2x2 372 veces ( $31 \%$ del total) y en situación $3 \times 365$ veces $(5 \%$ del total). Expresándose su utilización en la Tabla 3 y en el Gráfico 1.

\begin{tabular}{|c|c|c|c|c|c|}
\hline \multirow{3}{*}{ SITUACIÓN } & \multirow{2}{*}{ DCE } & \multicolumn{4}{|c|}{ Categoría deportiva } \\
\cline { 3 - 6 } & & \multicolumn{2}{|c|}{ U-13 } & \multicolumn{2}{c|}{ U-15 } \\
\cline { 3 - 6 } & & $\mathrm{n}$ & $\%$ & $\mathrm{n}$ & $\%$ \\
\hline \multirow{3}{*}{$1 \times 1$} & $\mathrm{DBCD}$ & 289 & 27 & 294 & 24 \\
\cline { 2 - 6 } & $\mathrm{DCSD}$ & 117 & 11 & 94 & 7 \\
\cline { 2 - 6 } & $\mathrm{APe}$ & 80 & 7 & 183 & 15 \\
\cline { 2 - 6 } & $\mathrm{Al}$ & 106 & 10 & 224 & 18 \\
\hline \multirow{2}{*}{$2 \times 2$} & $\mathrm{DSB}$ & 354 & 33 & 135 & 11 \\
\cline { 2 - 6 } & $\mathrm{BD}$ & 83 & 8 & 237 & 20 \\
\hline $3 \times 3$ & $\mathrm{BI}$ & 45 & 4 & 65 & 5 \\
\hline
\end{tabular}

Tabla 3: Dinámicas de Creación de Espacios (DCE) utilizadas contra defensa individual en las categorías U-13 y U-15 


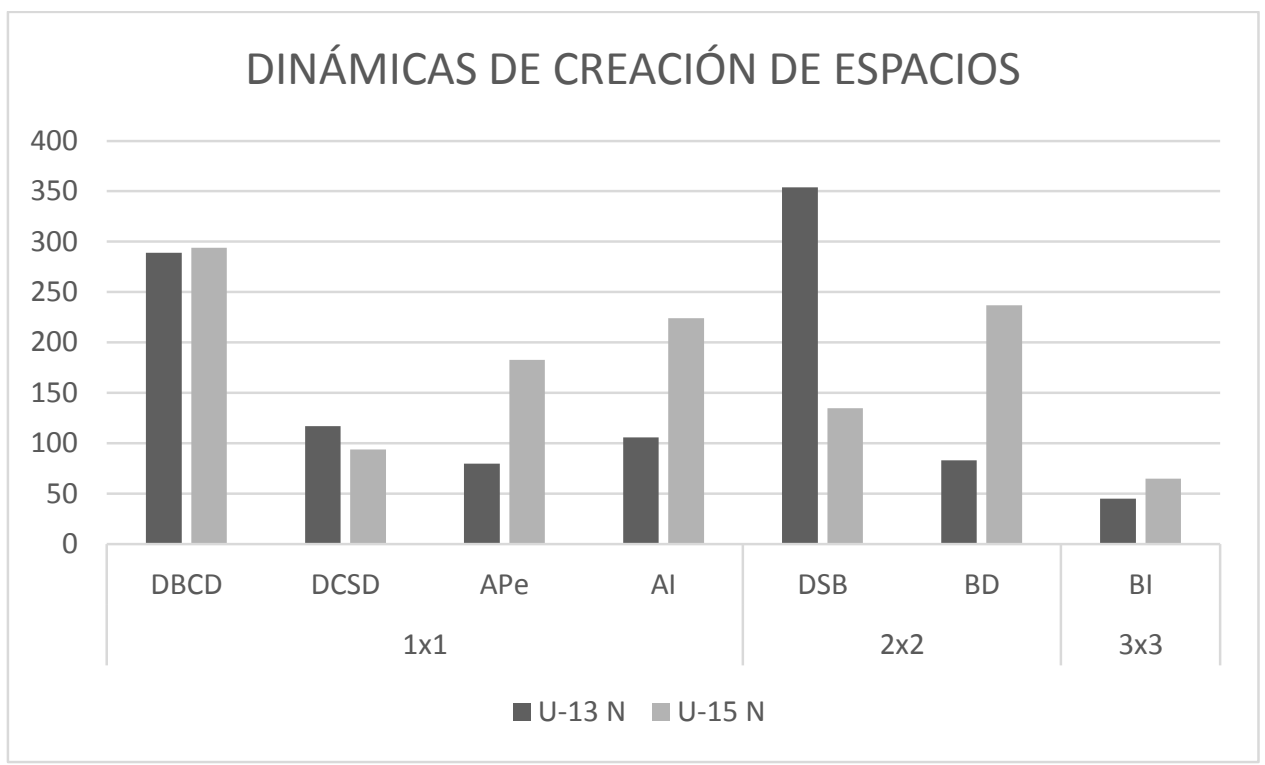

Gráfico1: Utilización de las Dinámicas de Creación de Espacio (DCE) contra defensa individual en las categorías U-13 y U-15

Diferenciándose en la Tabla 4 la ocurrencia de situaciones y su eficiencia - determinada a partir de la proporción entre la frecuencia de éxito en la finalización como consecuencia de la realización de la DCE y la frecuencia total de ocurrencia de la DCE en cuestión - en categoría U-13 y U-15. No encontrándose diferencia significativa entre la utilización de las DCE agrupadas en función del número de jugadores implicados, ni diferencia significativa de eficiencia entre las categorías U-13 y U-15.

\begin{tabular}{|c|c|c|c|c|c|}
\hline \multirow{2}{*}{\multicolumn{2}{|c|}{ SITUACIÓN }} & \multicolumn{4}{|c|}{ Categoría deportiva } \\
\hline & & \multicolumn{2}{|r|}{$\mathrm{U}-13$} & \multicolumn{2}{|c|}{ U-15 } \\
\hline & & $\mathrm{n}$ & Eficiencia (\%) & $\mathrm{n}$ & Eficiencia (\%) \\
\hline \multirow[t]{2}{*}{$1 \times 1$} & $\mathrm{~s} / \mathrm{c}$ & 400 & \multirow[t]{2}{*}{$32 \%$} & 507 & \multirow[t]{2}{*}{$36 \%$} \\
\hline & CC & 192 & & 281 & \\
\hline \multirow[t]{2}{*}{$2 \times 2$} & $\mathrm{~s} / \mathrm{c}$ & 289 & \multirow[t]{2}{*}{$34 \%$} & 259 & \multirow[t]{2}{*}{$30 \%$} \\
\hline & $\mathrm{CC}$ & 148 & & 113 & \\
\hline \multirow[t]{2}{*}{$3 \times 3$} & s/c & 31 & \multirow[t]{2}{*}{$31 \%$} & 43 & \multirow[t]{2}{*}{$34 \%$} \\
\hline & $\mathrm{CC}$ & 14 & & 22 & \\
\hline
\end{tabular}

Tabla 4: Ocurrencia y eficiencia de las Dinámicas de Creación de Espacios (DCE) utilizadas en situaciones de 1x1, 2x2 y $3 \times 3$ en las categorías U-13 y U-15. Donde s/c: sucedió sin convertir y cc: sucedió con conversión 
En las situaciones de $1 \times 1$ para la categoría $\mathrm{U}-13$ se observó que la $\mathrm{DCBD}$ se utilizó 289 veces (49\% del total de las situaciones 1x1), la DCSD 117 veces ( $20 \%$ del total), el APe 80 veces ( $14 \%$ del total) y el Al 106 veces ( $17 \%$ del total). Mientras que para la categoría U-15 en situación $1 \times 1$ se observó que la DCBD se utilizó 294 veces ( $37 \%$ del total), la DCSD 94 veces ( $12 \%$ del total), el APe 183 veces ( $23 \%$ del total) y el Al 224 veces ( $28 \%$ del total). De lo cual se desprende que el DBCD y el DCSD se utilizan en una proporción mayor en la categoría U-13 con respecto a la categoría U-15, mientras que para el caso de las DCE APe y Al se invierte la relación. Dichas variaciones entre categorías se puede deber a la necesidad de mayor variedad de opciones por parte del atacante en la categoría U-15 para contrarrestar la mejora de la aptitud defensiva y a la mejor coordinación con el resto de los jugadores del equipo que implica la utilización del $\mathrm{APe}$ y el $\mathrm{Al}$ en cuanto a la lectura de juego por parte de todos los jugadores integrantes del equipo en situación de ataque.

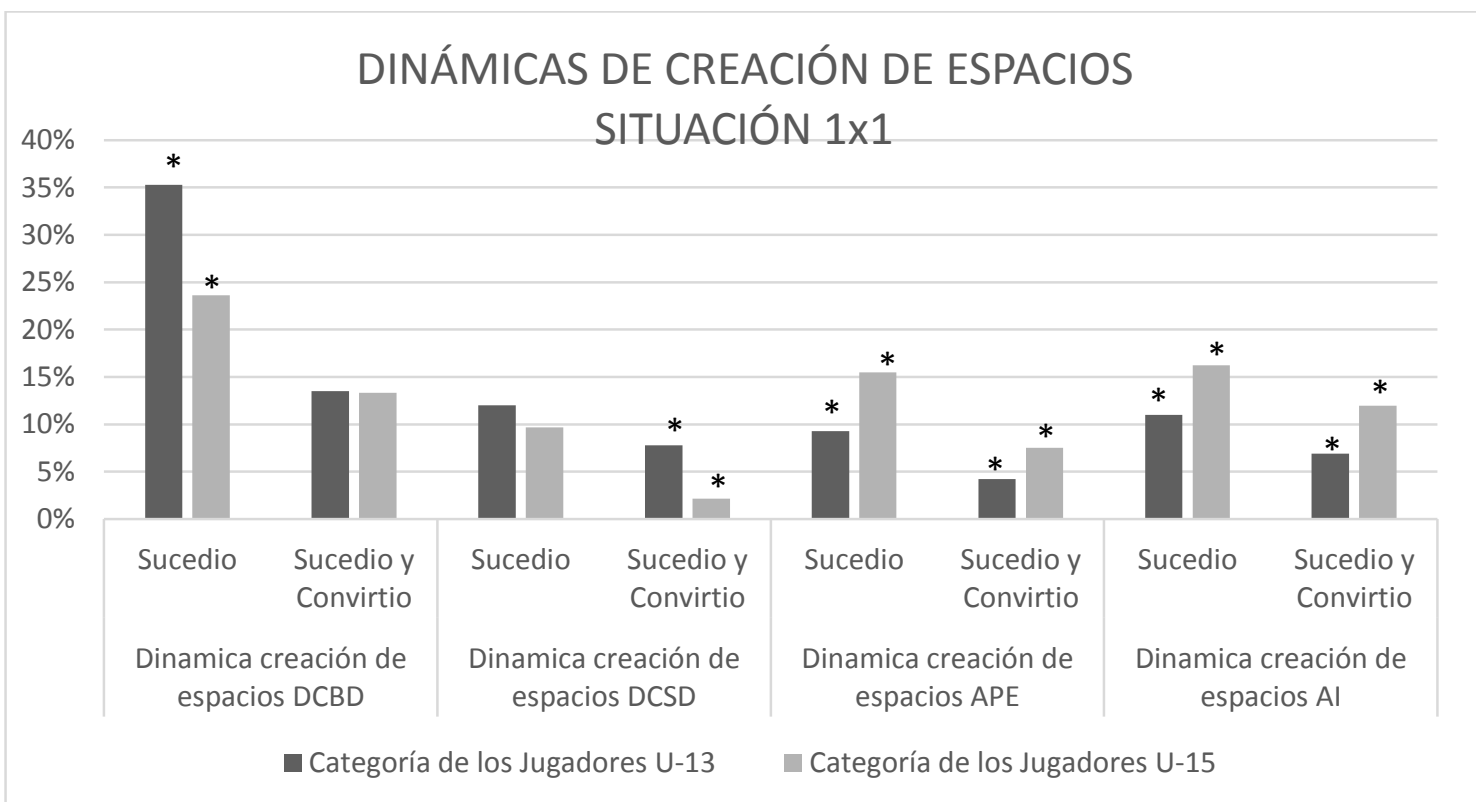

Gráfico 2: Ocurrencia y eficiencia de las Dinámicas de Creación de Espacio (DCE) en situaciones de 1x1 en las categorías U-13 y U-15. Donde los asteriscos indican que existe diferencia significativa entre las proporciones comparadas.

En lo concerniente al aprovechamiento de las situaciones para obtener puntos (Gráfico 2) se puede destacar que la notoria disminución de la eficiencia en la categoría U-15 del DCSD puede deberse a la mejora en la atención por parte de los defensores y a una mayor lectura anticipatoria del juego por parte de los mismos. Para la misma categoría, en el caso del DCBD el aumento del 
aprovechamiento de la situación puede derivarse de la mejora en la lectura de la situación de juego por parte del atacante y al aumento en paralelo de la capacidad de ejecución técnica. Mientras que para las situaciones de APe y de Al existen diferencias significativas en el aprovechamiento entre las categorías, presentando valores mayores de eficiencia en estas situaciones con respecto al DCBD y al DCSD por un posible bajo desarrollo de la fundamentación defensiva para hacer frente a estas DCE.

\section{DINÁMICAS DE CREACIÓN DE ESPACIOS (DCE) - SITUACIONES 2×2}

Las DCE en situación $2 \times 2$ contra defensa individual fueron utilizadas para la categoría U-13 y U-15, de la siguiente manera: el DSB se utilizó 354 veces ( $81 \%$ del total de las situaciones $2 \times 2$ ) en categoría $U-13$ y 135 veces (36\% del total) en categoría U-15, mientras que el BD se utilizó 83 veces (19\% del total) en la categoría U-13 y 237 veces (64\%del total) en la categoría U-15 (Gráfico 3).

\section{DINÁMICAS DE CREACIÓN DE ESPACIO \\ SITUACIÓN 2X2}

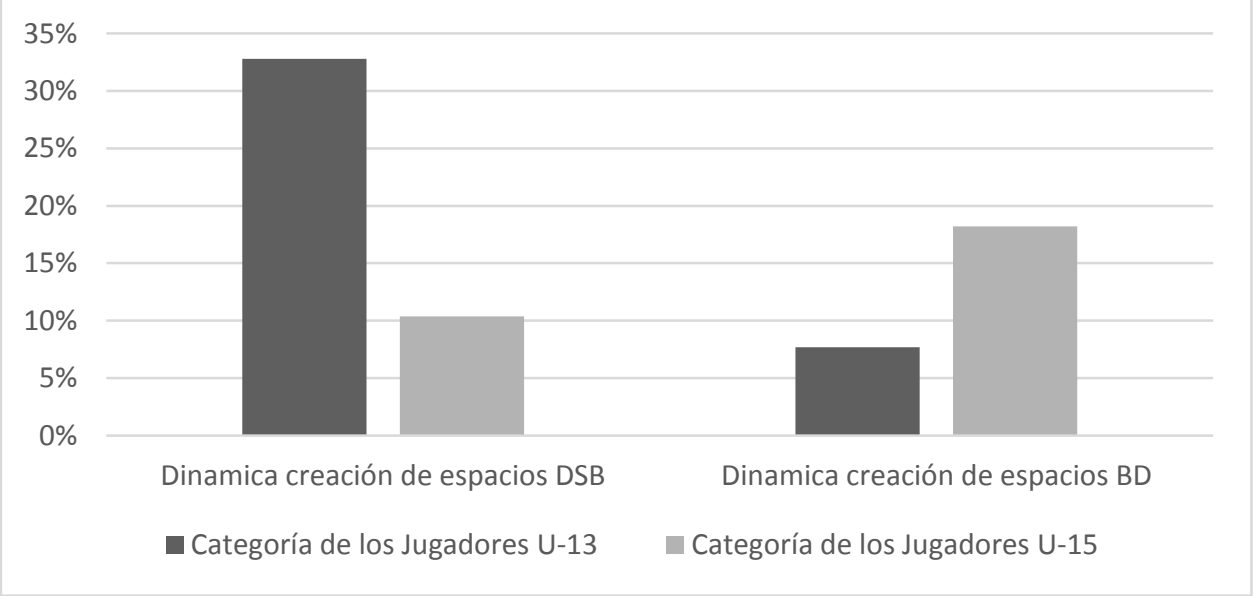

Gráfico 3: Utilización de las Dinámicas de Creación de Espacio (DCE) Desmarque sin balón (DSB) y Bloqueo directo (BD) en las categorías U-13 y U-15.

La preponderante utilización del DSB en categoría U-13 puede deberse a que ésta se constituye en una de las primeras acciones de juego de coordinación grupal que desarrollan los jugadores como producto de la utilización del método situacional por parte de los entrenadores. 
El aumento en la utilización del BD en la categoría U-15 puede sustentarse en la mejora de la variedad de opciones presentadas a los jugadores por parte de los entrenadores para actuar frente a la imprevisibilidad y aleatoriedad de las situaciones de juego, así como el empoderamiento de los jugadores con dichas opciones. En el mismo sentido, el BD implica un mayor nivel de coordinación espacio temporal entre los jugadores partícipes en la situación de ataque.

No existiendo diferencias significativas (nivel de confianza del 95\%) en el aprovechamiento de las DCE DSB y BD en las categorías U-13 y U-15 (Tabla 5).

\begin{tabular}{|c|c|c|c|c|c|}
\hline \multirow{3}{*}{\multicolumn{2}{|c|}{ DCE }} & \multicolumn{4}{|c|}{ Categoría deportiva } \\
\hline & & \multicolumn{2}{|r|}{$U-13$} & \multicolumn{2}{|c|}{ U-15 } \\
\hline & & $\mathrm{n}$ & Eficiencia (\%) & $\mathrm{n}$ & Eficiencia (\%) \\
\hline \multirow[t]{2}{*}{ DSB } & $\mathrm{s} / \mathrm{c}$ & 228 & \multirow[t]{2}{*}{$36 \%$} & 84 & \multirow[t]{2}{*}{$38 \%$} \\
\hline & $\mathrm{cc}$ & 126 & & 51 & \\
\hline \multirow[t]{2}{*}{ BD } & $\mathrm{s} / \mathrm{c}$ & 61 & \multirow[t]{2}{*}{$27 \%$} & 175 & \multirow[t]{2}{*}{$26 \%$} \\
\hline & cC & 22 & & 62 & \\
\hline
\end{tabular}

Tabla 5: Ocurrencia y eficiencia de las Dinámicas de Creación de Espacio (DCE) en situaciones de 2x2 en las en las categorías U-13 y U-15. Donde s/c: sucedió sin convertir y cc: sucedió con conversión

\section{DINÁMICAS DE CREACIÓN DE ESPACIOS (DCE) - SITUACIONES 3×3}

En lo concerniente a las DCE en situación $3 \times 3$ contra defensa individual, para la categoría U-13 se observó que el BI se utilizó 45 veces, convirtiendo puntos en 14 ocasiones (31\% de eficiencia); mientras que en la categoría U-15 se utilizó 65 veces, convirtiendo puntos en 22 ocasiones (34\% de eficiencia).

La poca utilización del $\mathrm{BI}$ en ambas categorías puede deberse a la elección por parte de los entrenadores de un proceso de desarrollo del jugador en el cual las DCE son abordadas en forma progresiva en función del aumento de su complejidad en cuanto a las variables tiempo, espacio y número de jugadores involucrados para su realización. Así como a la problemática que presenta para la elección por parte de los jugadores por implicar un elevado grado de cooperación y coordinación en la ejecución.

\section{3- DINÁMICAS DE PROTECCIÓN DE ESPACIOS (DPE)}


Las DPE utilizadas en defensa individual contra las DCE aplicadas por el equipo atacante en los partidos observados $y$ analizados de las categorías $\mathrm{U}-13$ y U-15 en situaciones $1 \times 1,2 \times 2$ y $3 \times 3$ se expresan cuantitativamente en la Tabla 6.

\begin{tabular}{|c|c|c|c|c|}
\hline \multirow{2}{*}{ SITUACIÓN } & \multicolumn{4}{|c|}{ Categoría deportiva } \\
\cline { 2 - 5 } & \multicolumn{2}{|c|}{$\mathrm{U}-13$} & \multicolumn{2}{c|}{$\mathrm{U}-15$} \\
\cline { 2 - 5 } & $\mathrm{n}$ & $\%$ & $\mathrm{n}$ & $\%$ \\
\hline $1 \times 1$ & 592 & 55 & 795 & 64 \\
\hline $2 \times 2$ & 437 & 41 & 372 & 31 \\
\hline $3 \times 3$ & 45 & 4 & 65 & 5 \\
\hline
\end{tabular}

Tabla 6: Ocurrencia de situaciones en las categorías U-13 y U-15

\section{DINÁMICAS DE PROTECCIÓN DE ESPACIOS (DPE) - SITUACIONES 1x1}

En las situaciones de 1x1 para la categoría U-13 (Gráfico 4) se observó que para contrarrestar la DCE DCBD los jugadores recurrieron en el $19 \%$ de las situaciones a la defensa orientada hacia el medio $(n=56)$, el $22 \%(n=64)$ a la defensa orientada hacia el fondo y el $59 \%(n=109)$ a mantener una posición neutra con respecto al ataque; mientras que para la misma DCE en la categoría $\mathrm{U}-15$ el $16 \%$ de las situaciones la defensa orienta hacia el medio $(n=48)$, el $37 \%$ de las veces $(n=110)$ la defensa orienta hacia el fondo y en el $46 \%$ restante $(n=136)$ mantiene una posición neutra con respecto al ataque.

Para la DCE DCSD se destaca la utilización de la DPE neutro tanto en categoría U-13 (92\%, n=108) como en categoría U-15 (80\%, n=75); mientras que la DPE orientar hacia el fondo se utiliza en un $8 \%(n=9)$ de las situaciones en $U$ 13 y un $17 \%$ ( $n=16)$ en U-15; y la DPE orientar hacia el medio no es utilizada en U-13 y representa el 3\% de las opciones defensivas en U-15.

El notorio incremento en la utilización de la DPE fondo en la categoría U15 en relación a la categoría U-13 para las DCE DCBD y DCSD se apoya tanto en el énfasis de la enseñanza por parte de los entrenadores de esta opción defensiva en la categoría U-15 como a la decisión por parte del jugador defensor de orientar el juego de ataque en una dirección determinada para condicionar el mismo reduciéndole las posibles opciones de acción al atacante.

Para la defensa de la DCE Ape, la elección de DPE por parte del defensor no presenta variaciones importantes entre su aplicación en la categoría U-13 y 
la categoría U-15 para ninguna de las opciones defensivas. La orientación para el medio en U-13 se utilizó el 8\% ( $n=6)$ de las veces y en U-15 se empleó el 10\% $(n=19)$, la orientación para el fondo un $21 \%(n=17)$ en $U-13$ y un $26 \%(n=47)$ en U-15, y finalmente a la opción neutro se recurrió en el $71 \% \quad(n=57)$ de las situaciones de APe en U-13 y en el 64\% ( $n=117)$ en la categoría U-15.

La preponderancia de la elección de la DPE neutro para defender el APe y el DSBD puede deberse en U-13 a la necesidad de contener el ataque en primera instancia de un modo individual para, a partir de la categoría U-15, donde aumenta levemente la orientación hacia un sector específico de la cancha, contener en función de posibles ayudas, rotaciones o doblajes defensivos (las cuales no son analizadas en el presente trabajo).

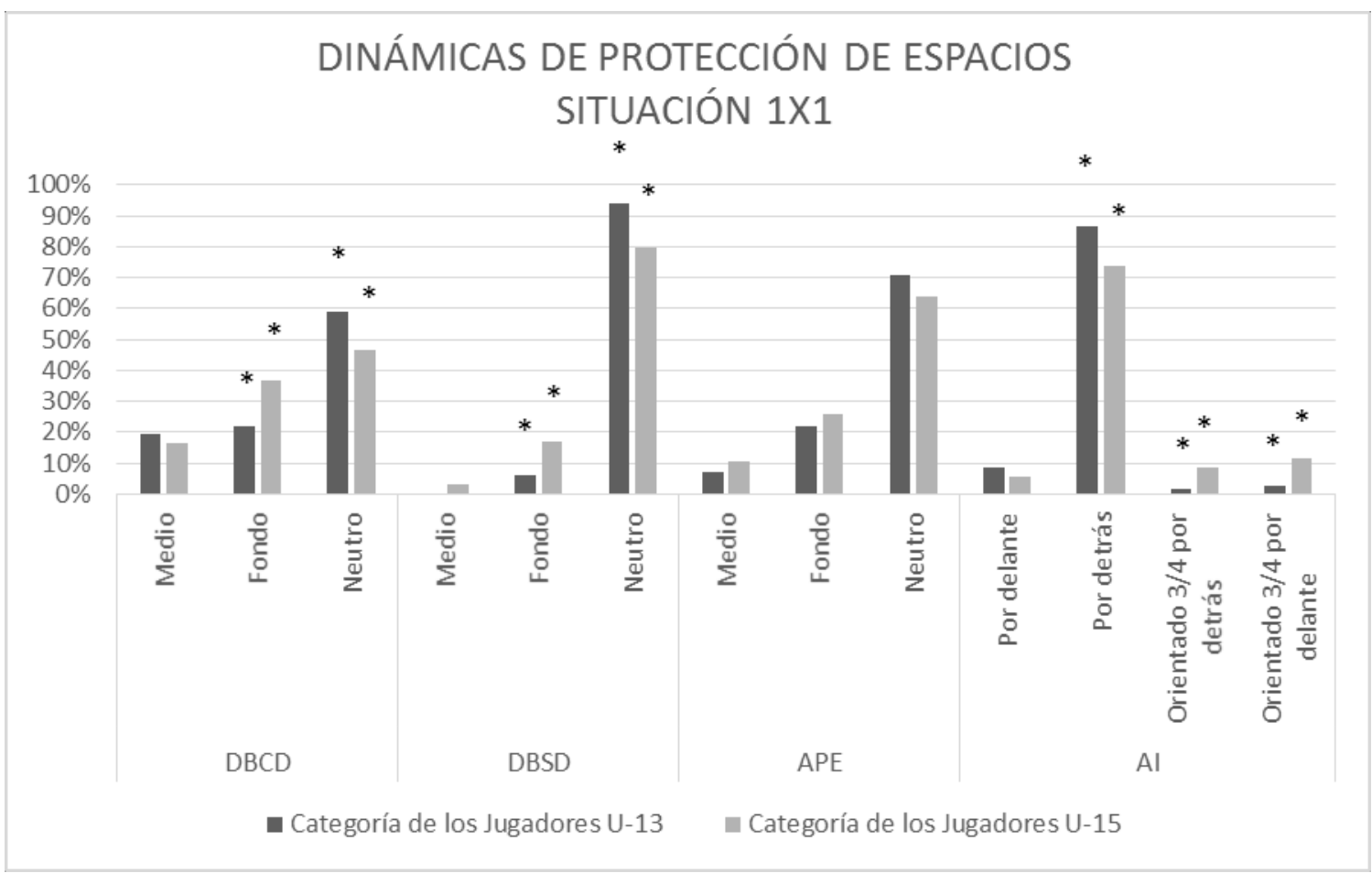

Gráfico 4: Frecuencia de utilización de las Dinámicas de Protección de Espacio (DPE) en situaciones de 1x1 en las categorías U-13 y U-15. Donde los asteriscos indican que existe diferencia significativa entre las proporciones comparadas.

Ante la DCE Al los defensores de las categorías $U-13$ y U-15 emplearon las DPE de acuerdo a lo expresado en la Tabla 7. De la misma se puede destacar que en la categoría U-13 la DPE por detrás es la más utilizada por los defensores, mientras que en $U-15$ disminuye su ocurrencia, pudiendo deberse esta situación al énfasis por parte de los entrenadores en la enseñanza del resto de las DPE 
para defender la situación de Al, así como la mejor lectura del juego por parte de los defensores, lo cual conlleva una elección en función de las características del atacante y de las posibilidades de la defensa.

\begin{tabular}{|c|c|c|c|c|}
\hline \multirow{2}{*}{ DPE para AI } & \multicolumn{4}{|c|}{ Categoría deportiva } \\
\cline { 2 - 5 } & \multicolumn{2}{|c|}{ U-13 } & \multicolumn{2}{c|}{ U-15 } \\
\cline { 2 - 5 } & $\mathrm{n}$ & $\%$ & $\mathrm{n}$ & $\%$ \\
\hline Por delante & 9 & 8 & 10 & 6 \\
\hline Por detrás & 92 & 87 & 127 & 73 \\
\hline Orientado $3 / 4$ por detrás & 2 & 2 & 15 & 9 \\
\hline Orientado $3 / 4$ por delante & 3 & 3 & 20 & 12 \\
\hline
\end{tabular}

Tabla 7: Ocurrencia de las Dinámicas de Protección de Espacio (DPE) utilizadas para defender la Dinámica de Creación de Espacio (DCE) Aclarado interior (Al) en las categorías U-13 y U-15.

DINÁMICAS DE PROTECCIÓN DE ESPACIOS (DPE) - SITUACIONES 2x2

En el análisis de las DPE utilizadas en las situaciones de 2x2 para la categoría U-13 se observó que para contrarrestar la DCE DSB los equipos recurrieron en el $25 \%$ de las situaciones $(n=86)$ a la defensa al receptor del balón (jugador que corta) Alejado de la línea de pase y en el $75 \%(n=268)$ a ubicarse Próximo a la línea de pase; mientras que para la misma DCE en la categoría U15 el $19 \%$ de las situaciones el defensor se sitúa alejado de la línea de pase $(n=25)$ y en el $81 \%$ restante $(n=110)$ se dispone próximo a la línea de pase.

Para la defensa de la DCE BD, en lo concerniente a la defensa del jugador con balón (Gráfico 5) se puede señalar que en la categoría U-13 existe preponderancia de la utilización de la DPE cambio defensivo (39\%), por delante (31\%) y doblaje defensivo (25\%); constituyendo entre las tres categorías de análisis el 95\% de las decisiones defensivas. Diferenciándose la categoría U-15 por una mayor variedad de opciones defensivas utilizadas por los defensores, entre los que se destaca la disminución de la utilización de la DPE cambio defensivo y por delante, así como el incremento del empleo de la DPE por el medio, por detrás y evitar el bloqueo. Situaciones que ponen de manifiesto, entre otros factores, el mayor desarrollo de la capacidad de análisis por parte del defensor de las características del jugador atacante así como una mejora de sus recursos para responder a la variabilidad del juego. Existiendo diferencias 
significativas en lo concerniente a la utilización de las diferentes DPE entre las categorías U-13 y U-15.

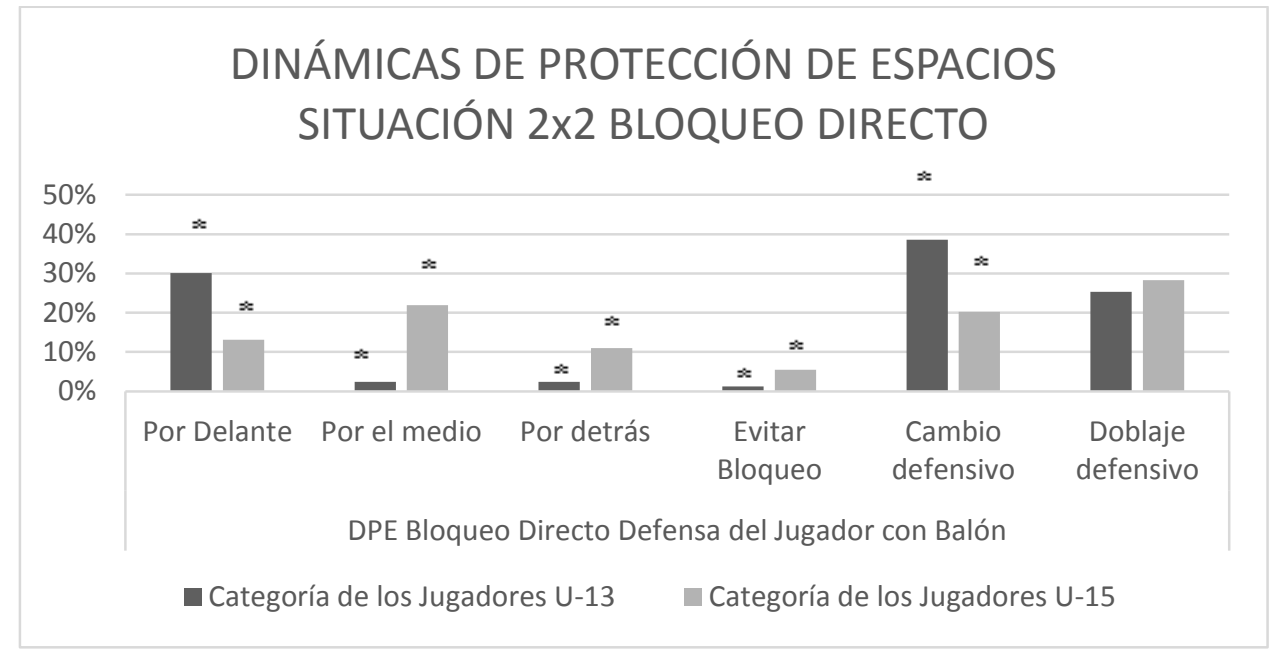

Gráfico 5: Frecuencia de utilización de las Dinámicas de Protección de Espacio (DPE) en situaciones de 2x2 para defensa del Bloqueo directo - Jugador con balón - en las categorías U-13 y U-15. Donde los asteriscos indican que existe diferencia significativa entre las proporciones comparadas.

En la misma situación de defensa de la DCE BD, pero en lo concerniente a las DPE empleadas para la defensa del jugador que realiza el bloqueo (Gráfico 6) en U-13 se observa una primacía del cambio defensivo (39\%) y del doblaje defensivo (25\%), lo cual es concordante con lo que ocurre con la defensa del jugador con balón dada la interdependencia de la acción defensiva en estas DPE. En la misma categoría de juego, la DPE abrirse constituye el $26 \%$ de las acciones defensivas en esta categoría. Mientras que en la categoría U-15 la elección de DPE por parte del jugador defensor presenta una mayor variedad, manteniéndose casi igual la situación doblaje defensivo (28\%), disminuyendo la utilización del cambio defensivo (20\%) y el abrirse (11\%). Al mismo tiempo las DPE contener, mostrarse y alejarse incrementan su utilización con respecto a la categoría U-13, colocando en evidencia, tanto la acción reactiva ante el reconocimiento de las características de la decisión táctica del atacante, así como el aprovechamiento de la variedad de posibilidades de elección de DPE de modo proactivo con el objetivo de generar incertidumbre al ataque en su objetivo de conseguir puntos. Existiendo diferencias significativas en lo concerniente a la utilización de las diferentes DPE entre las categorías U-13 y U-15, excepto en el caso del doblaje defensivo. 


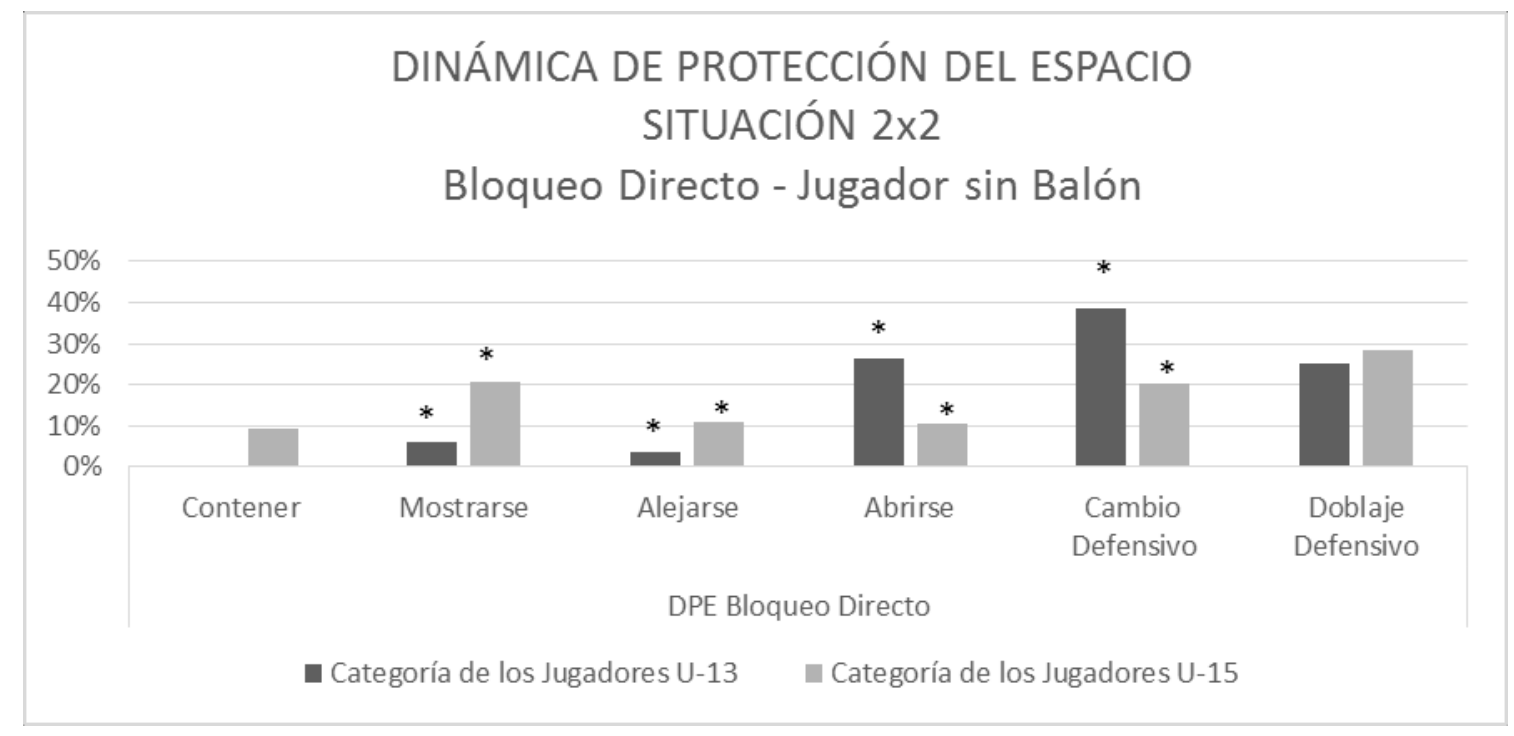

Gráfico 6: Frecuencia de utilización de las Dinámicas de Protección de Espacio (DPE) en situaciones de 2x2 para defensa del Bloqueo directo - Jugador sin balón - en las categorías U-13 y U-15. Donde los asteriscos indican que existe diferencia significativa entre las proporciones comparadas.

DINÁMICAS DE PROTECCIÓN DE ESPACIOS (DPE) - SITUACIONES 3×3

En las situaciones de $3 \times 3$ analizadas en lo que respecta a la defensa del receptor del bloqueo en la DCE BI para la categoría U-13 $(n=45)$ se destaca (Gráfico 7) la preponderancia del empleo de la DPE cambio defensivo (47\%), lo cual evidencia una lectura limitada del juego por parte del defensor y un accionar eminentemente reactivo ante la propuesta ofensiva del equipo contrario. Asimismo se puede subrayar la utilización de la DPE evitar el bloqueo (40\%), lo cual constituye una acción que no precisa una lectura de la totalidad de la acción ofensiva.

Por otro lado, para la categoría U-15 $(n=65)$ resalta la utilización de la DPE por el medio (37\%) y el incremento en la DPE por detrás (18\%). En esta categoría se evidencia la utilización de un mayor número de variantes defensivas, la existencia de una mayor capacidad reactiva y la existencia de una mejor capacidad proactiva por parte de los jugadores defensores, lo cual implica una mayor coordinación grupal para establecer interrelaciones con el resto de los defensores implicados en la acción de juego en pos del objetivo de evitar la acción de ruptura. Existiendo diferencias significativas en lo concerniente a la 
utilización de las DPE Por el medio, Evitar el bloqueo y Cambio defensivo entre las categorías U-13 y U-15.

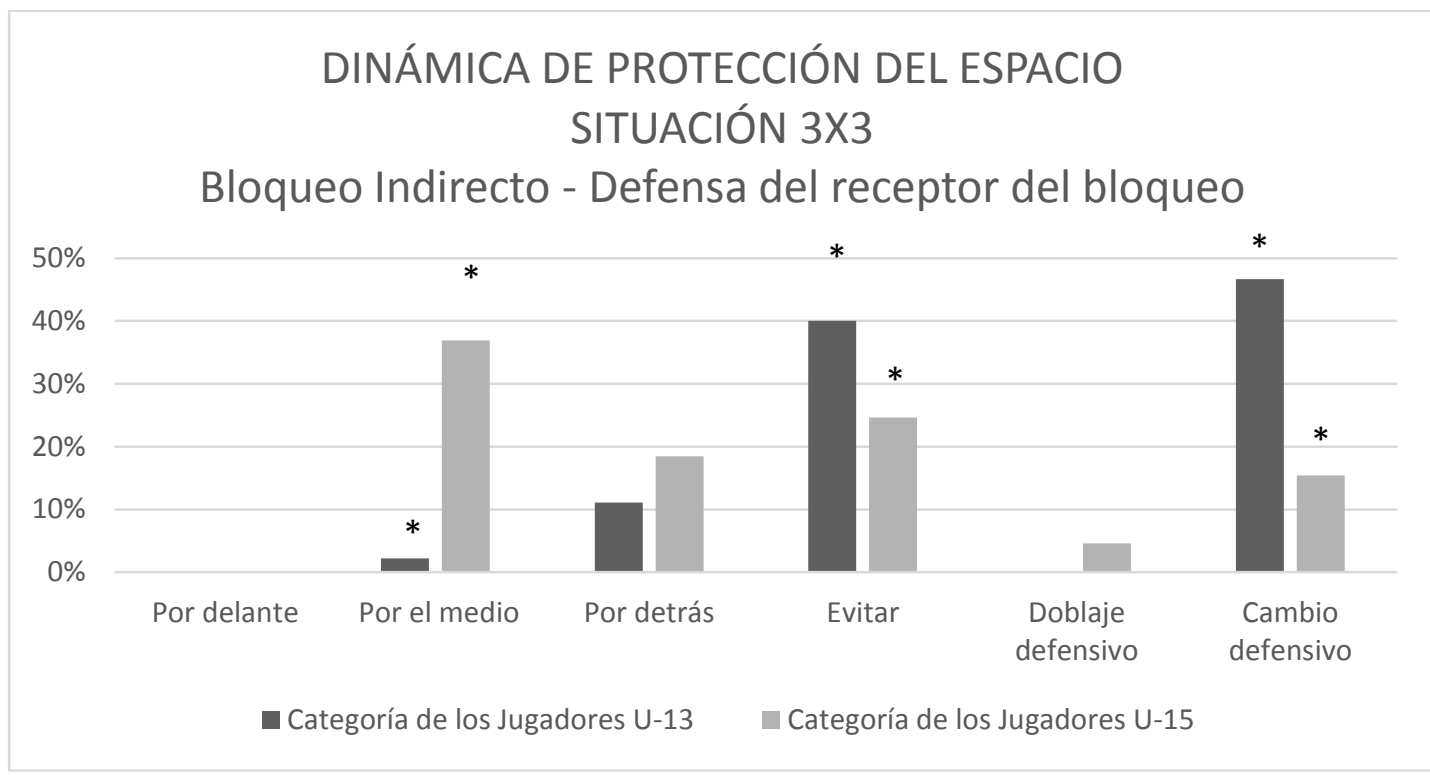

Gráfico 7: Frecuencia de utilización de las Dinámicas de Protección de Espacio (DPE) en situaciones de 3×3 para defensa del Bloqueo indirecto - Jugador receptor del bloqueo - en las categorías U-13 y U-15. Donde los asteriscos indican que existe diferencia significativa entre las proporciones comparadas.

Para el caso de la defensa del jugador que realiza el bloqueo en el Bloqueo Indirecto (Gráfico 8) se observa que la DPE más utilizada en la categoría U-13 es el cambio defensivo (47\%), mientras que el resto de las DPE son utilizadas por el jugador defensor sin preponderancia de ninguna de ellas (sin emplear la DPE retrasar y la DPE doblaje defensivo). Esta utilización equilibrada de las DPE contener, mostrarse, alejarse y abrirse puede indicar una mejor lectura - por parte de defensor - de la acción ofensiva del jugador que va a establecer el bloqueo con respecto a la lectura del juego por parte del defensor del jugador que recibe el bloqueo, lo cual puede producirse por la disposición de mayor tiempo por parte del defensor del bloqueador para poder reconocer la situación, seleccionar la DPE en función de la misma y actuar de un modo proactivo en función de provocar el aumento de la incertidumbre en el jugador atacante con el objetivo de demorar su accionar y/o provocar su equivocación.

Del análisis de la DCE BI, en el caso de la defensa del jugador que realiza el bloqueo para la categoría U-15 se observa que la situación preponderante es la DPE abrirse (32\%), seguida de la DPE alejarse (21\%). La elección y utilización 
de estas DPE por el defensor del bloqueador puede deberse a la lectura de la situación de juego en la cual el jugador que realiza el bloqueo no se constituye en el principal posible receptor del balón, razón por la cual su defensor genera espacio para dar lugar al pasaje del defensor del receptor del bloqueo. Demostrando la existencia de una mejor interrelación de los defensores para actuar de un modo coordinado con el objetivo de evitar el desequilibrio por parte del equipo atacante. Existiendo diferencias significativas en lo concerniente a la utilización de las DPE Abrirse y Cambio defensivo entre las categorías U-13 y U15.

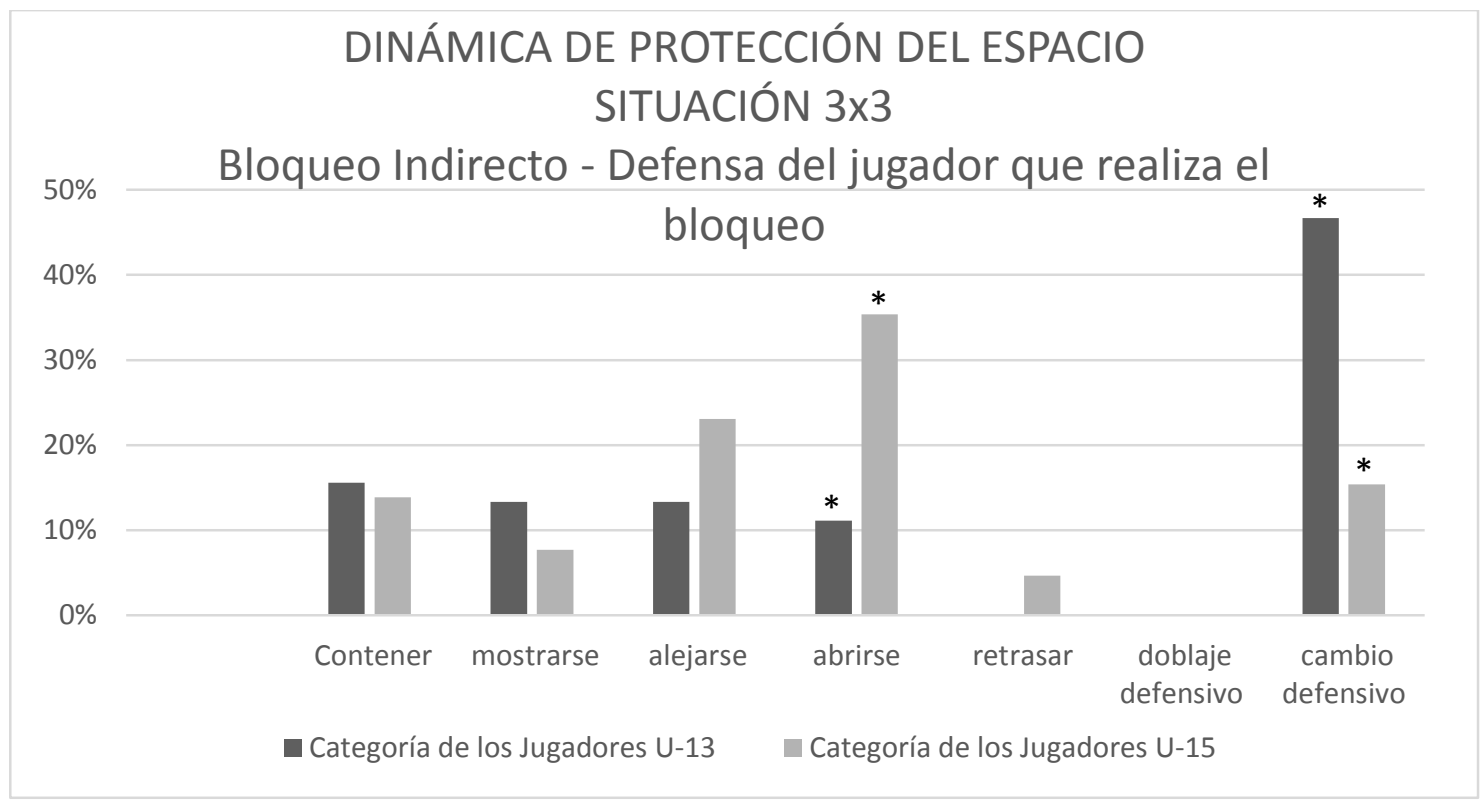

Gráfico 8: Frecuencia de utilización de las Dinámicas de Protección de Espacio (DPE) en situaciones de 3×3 para defensa del Bloqueo indirecto - Jugador que realiza el bloqueo - en las categorías U-13 y U-15. Donde los asteriscos indican que existe diferencia significativa entre las proporciones comparadas.

\section{4- CONCLUSIONES}

Los resultados del análisis de la utilización de las Dinámicas de Creación de Espacios (DCE) y las Dinámicas de Protección de Espacios (DPE) en las categorías $U-13$ y U-15 de basquetbol en el contexto de situaciones reales de competición permiten destacar que la aplicación del saber táctico en las categorías formativas de basquetbol evoluciona desde comportamientos reactivos a proactivos conforme aumenta la edad de los jugadores. Evidenciándose - a través de la realización de acciones de juego de complejidad creciente - una mejor lectura de juego, una toma de decisión más diversificada y 
el desarrollo de una mayor capacidad de juego en la cual se expresan tanto la inteligencia como la creatividad táctica. Resaltando que la ocupación espacial y la sincronización temporal son factores clave en la eficacia de utilización de las DCE y DPE en función de los objetivos de la acción, en presencia de incertidumbre y bajo presión temporal.

Para lo cual el jugador de basquetbol se encuentra obligado por la acción de competición a una continua percepción y anticipación compleja - diferencial del juego que le permitan actuar de modo proactivo; lo cual se sitúa en el núcleo de la toma de decisión en el contexto deportivo. Es por ello que el reconocimiento y la definición del contenido, las exigencias y las características específicas de la competición, así como el análisis del comportamiento táctico de los jugadores y equipos permiten el control del desarrollo del proceso de entrenamiento. De este modo, la identificación de la utilización de las DCE y DPE, así como la determinación de la eficiencia de las DCE colabora en la orientación de la planificación del proceso de desarrollo de la capacidad de juego perfilando la especificidad de la disciplina deportiva y orientando el ajuste de los procesos de entrenamiento con el objetivo de potenciar el desarrollo del comportamiento táctico de los jugadores en la dirección pretendida.

Asimismo, los datos obtenidos presentan potencial para ser aplicados en el contexto de la praxis - tanto en el entrenamiento como en el juego formal para la mejoría de los procesos de evaluación de la performance deportiva de jugadores y equipos. En el mismo sentido, la presente investigación procura establecer una contribución científica para la reflexión y toma de decisión, sirviendo de referencia a los entrenadores de basquetbol para el diseño de sus planificaciones deportivas a corto, mediano y largo plazo durante el proceso de desarrollo del deportista. Así como la necesidad de considerar en futuras investigaciones los efectos de la utilización de la metodología situacional de enseñanza-aprendizaje-entrenamiento por parte de los entrenadores de basquetbol y su relación con el desarrollo de la expertise de los jugadores en el juego formal. 


\section{XII - CONSIDERACIONES FINALES}

En función de los resultados de los estudios realizados se pueden establecer las siguientes consideraciones: (i) la enseñanza del saber táctico en las categorías formativas del basquetbol resulta fundamental para los entrenadores, acrecentándose su importancia conforme aumenta la edad de los jugadores; (ii) el método situacional es - en la opinión de los entrenadores - el principal método utilizado en las categorías U-13 y U-15; (iii) la aplicación del saber táctico en el contexto de situaciones reales de competición en las categorías formativas de basquetbol evoluciona desde comportamientos reactivos a proactivos conforme aumenta la edad de los jugadores; y (iv) se evidencia - a través de la realización de acciones de juego de complejidad creciente - una mejor lectura de juego, una toma de decisión más diversificada y el desarrollo de una mayor capacidad de juego en la cual se expresan tanto la inteligencia como la creatividad táctica.

Los aportes que se pueden extraer a partir de las consideraciones precedentemente expuestas son: (i) la preponderancia del método situacional para la enseñanza-aprendizaje-entrenamiento expresada por los entrenadores para las categorías U-13 y U-15 denota una transición entre el paradigma de los modelos de enseñanza sustentados en las estrategias instruccionales centradas en el entrenador hacia modelos de enseñanza de la táctica deportiva que propician un comportamiento proactivo y un empoderamiento de los jugadores como base para el desarrollo de la inteligencia y creatividad táctica; (ii) la estructuración de las actividades y la presentación de los contenidos de entrenamiento con base en los modelos centrados en la táctica pueden propiciar adecuados procesos de desarrollo y posibilitar una comprensión del juego como medio para su formación y éxito en la carrera deportiva a largo plazo; y (iii) la identificación de la utilización de las DCE y DPE, así como la determinación de la eficiencia de las DCE colabora en la orientación de la planificación del proceso de desarrollo de la capacidad de juego perfilando la especificidad de la disciplina deportiva y orientando el ajuste de los procesos de entrenamiento con el objetivo de potenciar el desarrollo del comportamiento táctico de los jugadores.

De este modo los datos obtenidos presentan potencial para ser aplicados en el contexto de la praxis - tanto en el entrenamiento como en el juego formal - 
para la mejoría de los procesos de evaluación de la performance deportiva de jugadores y equipos. En el mismo sentido, la presente investigación establece una contribución científica al análisis de la enseñanza del saber táctico, proporcionando información relevante para la reflexión y toma de decisiones en el proceso de enseñanza-aprendizaje-entrenamiento en el dominio de los juegos deportivos colectivos en general y del basquetbol en particular sirviendo de referencia a los entrenadores de formación para el diseño de sus planificaciones deportivas a corto, mediano y largo plazo durante el proceso de desarrollo del deportista.

De acuerdo con lo expresado anteriormente se sugiere el desarrollo de futuras investigaciones que aborden (entre otras posibilidades): (i) la planificación y la aplicación de los métodos de enseñanza-aprendizajeentrenamiento en la enseñanza del saber táctico en otras categorías de la formación deportiva; (ii) la identificación de las características diferenciadores de la planificación de los entrenadores en las categorías formativas del basquetbol; (iii) la relación entre la información resultante de la observación del juego formal, del proceso de enseñanza-aprendizaje-entrenamiento y lo que los entrenadores expresan de modo declarativo sobre el mismo; (iv) la influencia del sistema de competición y su organización pedagógica - didáctica en relación a los objetivos que se pretenden alcanzar en cada una de las etapas constituyentes del desarrollo del deportista a largo; y (v) analizar los efectos de la utilización de diferentes metodologías de enseñanza-aprendizaje-entrenamiento y su relación con el desarrollo de la expertise de los jugadores en el juego formal. 


\section{XIII - REFLEXIÓN}

Si bien el éxito deportivo es un concepto relativo cuya valoración depende de contextos concretos, fines, aspiraciones y expectativas personales - sociales diferentes en cada caso. El compromiso central de los entrenadores debe ser el favorecer la construcción de aprendizajes significativos basados en la calidad de la enseñanza-aprendizaje-entrenamiento de los jugadores durante el proceso de desarrollo del deportista a largo plazo, respetando el normal crecimiento, desarrollo y maduración biológica así como su estilo propio.

Lo cual debe evidenciarse (entre otros factores) - a través de la realización por parte de los jugadores de acciones de juego de complejidad creciente - en una mejor lectura de juego, una toma de decisión más diversificada y el desarrollo de una mayor capacidad de juego en la cual se expresan tanto la inteligencia como la creatividad táctica.

Entendiendo al deporte como el legado de una sociedad y una cultura específicas, el cual debe ser considerado como una construcción social e histórica - y por ende - política y cultural resulta necesario formular un programa de desarrollo del deportista a largo plazo basado en la construcción de un paradigma propio. Para lo cual es preciso, por no decir imprescindible, crear y sostener espacios de participación donde todos los actores involucrados interactúen con capacidad de opción y decisión, donde puedan reflexionar, proponer, proyectar, desarrollar y evaluar respecto de una acción que debe ser generada por la propia comunidad deportiva para sí misma y para su entorno.

En este sentido es seguro que el precedente análisis puede estar lejos de expresar la totalidad del proceso de enseñanza-aprendizaje-entrenamiento con contundencia, también es posible que no sea el camino adecuado. Pero difícilmente alguien pueda afirmar que es posible potenciar el desarrollo del basquetbol argentino sin un análisis situacional que permita reconocer el estado actual para que - entre todos - podamos dejar de lado los tiempos del crecimiento y desarrollo orientado en función de esfuerzos sectoriales o individuales y comencemos el proceso de maduración hacia la construcción diaria e incesante de acciones que nos conduzcan a la concreción de proyectos institucionales dialógicos - sustentables - de formación deportiva a largo plazo basados en un paradigma propio de la República Argentina. 


\section{BIBLIOGRAFÍA}




\section{I -INTRODUCCIÓN}

Abraham, A.; Collins, D.; Martindale, R. (2006). The coaching schematic: Validation through expert coach consensus. Journal of sports sciences, 24 (06), 549564.

Balyi, I. (2001). Sport system building and long-term athlete development in British Columbia. Coaches Report, 8 (1), 22-28.

Balyi, I.; Way, R.; Higgs, C. (2013). Long-term athlete development. Human Kinetics.

Costa, I.T.; Greco, P.J.; Garganta, J.; Costa, V.T.; Mesquita, I. (2011). Ensino-aprendizagem e treinamento dos comportamentos tático-técnicos no futebol. Revista Mackenzie de Educação Física e Esporte, 9 (2), 41-61.

Garganta, J. (1998). O ensino dos jogos desportivos coletivos: perspectivas e tendências. Movimento. Porto Alegre. 4 (8), 19-26.

Garganta, J. (2001). A análise da performance nos jogos desportivos. Revisão acerca da análise do jogo. Revista Portuguesa de Ciências do Desporto, 1 (1), 57 64.

Graça, A. (2014). Sobre as questões do quê ensinar e aprender em educação física. Professor de Educação Física: Fundar e dignificar a profissão. Porto: Editora FADEUP. 93-117.

Greco, P.J. (2006). Conhecimento técnico-tático: o modelo pendular do comportamento e da ação tática nos esportes coletivos. Revista Brasileira de Psicologia do Esporte e do Exercício, 107-129.

Greco, P.J.; Chagas, M.H. (1992). Considerações teóricas da tática nos jogos esportivos coletivos. Revista paulista de educação física, 6 (2), 47-58.

Ibáñez, S.J. (2008). La planificación y el control del entrenamiento técnico-táctico en baloncesto. In: Terrados, N.; Calleja, J. (Coord.). Fisiología, entrenamiento y medicina del Baloncesto. Barcelona: Paidotribo, 299-314.

Nash, C.; Collins, D. (2006). Tacit knowledge in expert coaching: science or art? Quest, 58 (4), 465-477.

Raab, M. (2015). SMART-ER: a Situation Model of Anticipated Response consequences in Tactical decisions in skill acquisition-Extended and Revised. Frontiers in psychology, 5, 1533.

Sola, J. (2005). Tècnica, Tàctica $i$ Estratègia. Un enfocament funcional. Tesis Doctoral. Departament de Psicologia Bàsica, Evolutiva i de l'Educació, Universitat Autònoma de Barcelona.

Tani, G.; Bruzi, A. T.; Bastos, F. H.; Chiviacowsky, S. (2011). O estudo da demonstração em aprendizagem motora: estado da arte, desafios e perspectivas.

Revista Brasileira de Cineantropometria \& Desempenho Humano, 13 (5), 392-403.

Tavares, F (2002): Análise da estrutura e dinâmica do jogo nos jogos desportivos. In: Barbanti, V; Amadio, C; Bento, J; Marques, A. (Eds.). Esporte e atividade física. Interação entre rendimento e saúde. Editora Manole. São Paulo. 129-144.

Tavares, F.; Faria, R. (1996). A capacidade de jogo como pré-requisito do rendimento para o jogo. In: Oliveira, J.; Tavares, F. (eds.). Estratégia e tática nos Jogos Desportivos Coletivos. FCDEF. Porto. 1996. 3950.

\section{II - JUEGOS DEPORTIVOS COLECTIVOS}

Bayer, C. (1986). La Enseñanza de los juegos deportivos colectivos. Hispano europea.

Bunker, D.; Thorpe, R. (1983). A model for the teaching of games in secondary schools. Bulletin of physical education, 19 (1), 5-8.

Garganta, J. (2001). Tactical modelling in Soccer: a critical view. In: Hughes, M.; Tavares, F. (eds.). Proceedings of IV World Congress of Notational Analysis of Sport. FCDEF-UP, 33-40.

Garganta, J. (2002). O treino da táctica e da técnica nos jogos desportivos à luz do compromisso cogniçãoacção. In: Barbanti, V.; Amadio, A.; Bento, J; Marques, A. (eds.). Esporte e atividade física: interação entre rendimento e qualidade de vida. São Paulo: Manole, 281-306.

Garganta, J. (2004). A formação estratégico-tática nos jogos desportivos de oposição e cooperação. In: Gaya, A.; Marques, A.; Tani, G. (eds.) Desporto para crianças e jovens. Razões e finalidades. Porto Alegre: Editora UFRGS, 217-233.

Garganta, J. (2006). (Re) Fundar os conceitos de estratégia e táctica nos jogos desportivos coletivos, para promover uma eficácia superior. Revista Brasileira Educação Física e Esporte, 20 (5), 201-203.

Garganta, J.; Cunha e Silva, P. (1999). O jogo de futebol: entre o caos e a regra. Horizonte Revista de Educação Física e Desporto, 16 (91), 5-8.

Greco, P.J. (1995). O ensino do comportamento tático nos Jogos Esportivos coletivos: Aplicação no Handebol. (Tese de Doutorado - Departamento de Psicologia Educacional - Faculdade de Educação). Campinas (SP) Universidade Estadual de Campinas. Greco, P. J. (2003). Processos cognitivos: Dependência e interação nos jogos esportivos 
coletivos. In: Lemos; K.L.M.; Silami Garcia, E. (org.). Temas atuais VIII em educação física e esportes. Belo Horizonte: Escola de Educação Física da UFMG, 7384.

Greco, P.; Memmert, D.; Morales, J.C. (2010). The effect of deliberate play on tactical performance in basketball. Perceptual and motor skills, 110 (3), 849856.

Gréhaigne, J. F.; Godbout, P. (1995). Tactical knowledge in team sports from a constructivist and cognitivist perspective. Quest, 47 (4), 490-505.

Gréhaigne, J. F.; Guillon, R. (1991). Du bon usage des règles d'action. Echanges et controverses, 4, 43-46.

Gréhaigne, J.; Guillon, R. (1992). L'utilisation des Jeux d'opposition à 1'école. Revue de l'Education Physique, 32 (2), 51-67.

Gréhaigne, J. F.; Godbout, P.; Bouthier, D. (2001). The teaching and learning of decision making in team sports. Quest, 53 (1), 59-76.

Hernández Moreno, J. (1994). Fundamentos del deporte: Análisis de la estructura del juego deportivo. Barcelona: Ed. INDE.

Hernández Moreno, J. (2000). La iniciacion a los deportes desde su estructura y su dinámica. Barcelona: Ed. INDE.

Hughes, M.; Evans, S.; Wells, J. (2001). Establishing normative profiles in performance analysis. International Journal of Performance Analysis in Sport, 1 (1), 1-26.

Kibele, A. (2006). Non-consciously controlled decision making for fast motor reactions in sports-A priming approach for motor responses to non-consciously perceived movement features. Psychology of Sport and Exercise, 7 (6), 591-610.

Konzag, I. (1991). A formação técnico-táctica nos jogos desportivos coletivos. Treino desportivo, 19, 27-37.

Mahlo, F. (1969). L'acte tactique en jeu. Paris: Vigot Freres.

McGarry, T.; Franks, I. M. (1994). A stochastic approach to predicting competition squash match-play. Journal of Sports Sciences, 12 (6), 573-584.

Metzler, M. W. (1990). Teaching in competitive games-not just playin'around. Journal of Physical Education, Recreation \& Dance, 61 (8), 57-61.

Nitsch, J. R. (2009). Ecological approaches to sport activity: A commentary from an action-theoretical point of view. International Journal of Sport Psychology, 40 (1), 152-176.

Riera, J. R. (1995). Estrategia, táctica y técnica deportivas. Apunts: educación física y deportes, (39), 45-56.
Solà, J. (2010). Inteligencia táctica deportiva: entenderla y entrenarla. Barcelona: INDE.

Souza, P. (2002). Validação de teste para avaliar a capacidade de tomada de decisão e o conhecimento declarativo em situações de ataque no Futsal. Dissertação de Mestrado. Escola de Educação Física, Fisioterapia e Terapia Educacional, Universidade Federal de Minas Gerais. Belo Horizonte.

Tani, G.; Bruzi, A. T.; Bastos, F. H.; Chiviacowsky, S. (2011). O estudo da demonstração em aprendizagem motora: estado da arte, desafios e perspectivas. Revista Brasileira de Cineantropometria \& Desempenho Humano, 13 (5), 392-403.

Tavares, F. (1993). A capacidade de decisão táctica no jogador de basquetebol. Estudo dos processos perceptivo-cognitivos em atletas seniores e cadetes. Tese de Doutorado. Universidade do Porto. Porto.

Tavares, F. (1996). Bases teóricas do componente táctico nos jogos desportivos coletivos. In: Oliveira, J.; Tavares, F. (eds.) Estratégia e táctica nos jogos desportivos coletivos. Porto, Centro de Estudos dos Jogos Desportivos.

Tavares, F. (2013). Jogos Desportivos coletivos: contributos para a sua análise e funcionamento. In: Ramos, V.; Saad, M. A.; Milistetd, M. (orgs.). Jogos desportivos coletivos: investigação e prática pedagógica. Coleção temas em movimento 3. Florianópolis: UDESC. 17-51.

Tavares, F.; Greco, P.; Garganta, J. (2006). Perceber, conhecer, decidir e agir nos jogos desportivos coletivos. In: Tani, G.; Bento, J.; Petersen, R. (eds.). Pedagogia do desporto, Rio de Janeiro: Guanabara Koogan. 284298.

Teodorescu, L. (1984). Problemas de teoria e metodologia nos jogos desportivos. Lisboa: Livros Horizonte.

Thorpe, R.; Bunker, D.; Almond, L. (1986). Rethinking games teaching. Loughborough: University.

Werner, P.; Thorpe, R.; Bunker, D. (1996). Teaching games for understanding: Evolution of a model. Journal of Physical Education, Recreation \& Dance, 67 (1), 2833.

\section{III - BASQUETBOL}

Apostolidis, N.; Nassis, G. P.; Bolatoglou, T.; Geladas, N. D. (2003). Physiological and technical characteristics of elite young basketball players. Journal of Sports Medicine and Physical Fitness, 44 (2), 157-163. 
Araujo, D.; Davids, K.; Hristovski, R. (2006). The ecological dynamics of decision making in sport. Psychology of Sport and Exercise, 7 (6), 653-676.

Bayer, C. (1986). La Enseñanza de los juegos deportivos colectivos. Hispano europea.

Buceta, J.M. (1998) Psicología del entrenamiento deportivo. Madrid: Dykinson.

Calleja, J.; Del Campo, J.; Lorenzo, A.; Terrados, N. (2008a). Valoración de la capacidad aeróbica en baloncesto. In: Terrados, N.; Calleja, J. (coord.). Fisiología, entrenamiento y medicina del baloncesto. Barcelona: Paidotribo, 65-75.

Calleja, J.; Lekue, J.; Leibar, X.; Terrados, N. (2008b). In: Terrados, N.; Calleja, J (coord.), Fisiología, entrenamiento y medicina del Baloncesto. Barcelona: Paidotribo, 7-21.

Callejas, A.; Lupiánez, J.; Tudela, P. (2004). The three attentional networks: On their independence and interactions. Brain and cognition, 54 (3), 225-227.

Cormery, B.; Marcil, M.; Bouvard, M. (2008). Rule change incidence on physiological characteristics of elite basketball players: a 10-year-period investigation. British journal of sports medicine, 42 (1), 25-30.

Correa, Á.; Rao, A.; Nobre, A. C. (2009). Anticipating conflict facilitates controlled stimulus-response selection. Journal of cognitive neuroscience, 21 (8), 1461-1472.

Crisafulli, A.; Melis, F.; Tocco, F.; Laconi, P. (2002). External mechanical work versus oxidative energy consumption ratio during a basketball field test. Journal of sports medicine and physical fitness, 42 (4), 409-417.

De Rose Jr., D.; Lamas, L. (2006). Análise de jogo no basquetebol: perfil ofensivo da Seleção Brasileira Masculina. Revista Brasileira de Educação Física e Esporte, 20 (3), 165-173.

De Rose Junior, D.; Tricoli, V. (2005). Basquetebol: conceitos e abordagens gerias. In: De Rose Junior, D.; Tricoli, V. (orgs.). Basquetebol: uma visão integrada entre ciência e prática. Barueri: Manole, 1-14.

De Rose Jr., D.; Tavares, A.; Gitti, V. (2004). Perfil técnico de jogadores brasileiros de basquetebol: relação entre os indicadores de jogo e posições específicas. Revista Brasileira De Educação Física E Esporte, 18 (4), 377-384.

Drezner, R. (2014). Análise do jogo de futebol por sistemas dinâmicos categóricos. Dissertação de Mestrado, Escola de Educação Física e Esporte, Universidade de São Paulo, São Paulo.

Ferreira, A. P.; Ibáñez, S. J.; Sampaio, J. E. (2009). Las reglas y la casualidad en Baloncesto: una aproximación histórica. Retos: nuevas tendencias en educación física, deporte y recreación, (15), 9-13.

Frade, V. (2015) In: Borges, P. H. Periodização tática: fundamentos e perspectivas. Entrevista com Dr. Vitor Manuel da Costa Frade. Conexões: Revista da Faculdade de Educação Física da UNICAMP, 13 (1), 180-204.

Franks, I.; Mc Garry, T. (1996). The science of match analysis. In: Reilly, T. Science and soccer. London: Routledge, 363-375.

García, S.; Rodríguez, A.; Garzón, A. (2011). Conceptualización de inteligencia táctica en fútbol: Consideraciones para el desarrollo de un instrumento de evaluación en campo desde las funciones ejecutivas. Cuadernos de psicología del deporte, 11 (1), 69-78.

Garganta, J. (1997). Modelação táctica do jogo de Futebol: estudo da organização ofensiva em equipas de alto rendimento. Tese de doutoramento - FCDEF, Universidade do Porto, Porto.

Garganta, J. (2004). A formação estratégico-tática nos jogos desportivos de oposição e cooperação. In: Gaya, A.; Marques, A.; Tani, G. (eds.) Desporto para crianças e jovens. Razões e finalidades. Porto Alegre: Editora UFRGS, 217-233.

Garganta, J. (2006). (Re) Fundar os conceitos de estratégia e táctica nos jogos desportivos coletivos, para promover uma eficácia superior. Revista Brasileira Educação Física e Esporte, 20 (5), 201-203.

Ibáñez, S. J.; Sampaio, J.; Feu, S.; Lorenzo, A., Gómez, M. A.; Ortega, E. (2008). Basketball game-related statistics that discriminate between teams' season-long success. European Journal of Sport Science, 8 (6), 369372.

Gréhaigne, J. F.; Godbout, P. (1995). Tactical knowledge in team sports from a constructivist and cognitivist perspective. Quest, 47 (4), 490-505.

Grehaigne, J.; Godbout, P.; Bouthier, D. (1999). The foundations of tactics and strategy in team sports. Journal of teaching in physical education, 18, 159-174. Grehaigne, J.; Godbout, P.; Bouthier, D. (2001). The teaching and learning of decision making in team sports. Quest, 53 (1), 59-76.

Gréhaigne, J. F.; Zerai, Z.; Godbout, P. (2011). How the "rapport de forces" evolves in a soccer match: the dynamics of collective decisions in a complex system. Revista de Psicología del Deporte, 20 (2), 747-765.

Gutiérrez, O.; Ruiz, J.L. (2013). Game Performance Versus Competitive Performance in the World Championship of Handball 2011. Journal of human kinetics, 36 (1), 137-147. 
Hoffmann, J. (1993). Vorhersage und Erkenntnis: Die Funktion von Antizipationen in der menschlichen Verhaltenssteuerung und Wahrnehmung [Prediction and Realisation: The function of anticipations in human behavioural control and perception]. Göttingen: Hogrefe.

Hoffmann, J. (2009). ABC: A psychological theory of anticipatory behavioral control. In: Pezzulo, G.; Butz, M. V.; Sigaud, O.; Baldassarre G. (eds.). Anticipatory Behavior in Adaptive Learning Systems. From Psychological Theories to Artificial Cognitive Systems. Heidelberg: Springer, 10-30.

Konzag, I. (1991). A formação técnico-táctica nos jogos desportivos coletivos. Treino desportivo, 19, 27-37.

Lamas, L. (2012). Modelagem estratégico-tática em esportes coletivos de invasão: aplicação ao basquetebol. Tese (Doutorado) - Escola de Educação Física e Esporte, Universidade de São Paulo, São Paulo.

Lamas, L.; Seabra, F. (2006). Estratégia, tática e técnica nas modalidades esportivas coletivas: conceitos e aplicações. In: De Rose Jr., D. Modalidades esportivas coletivas. Rio de Janeiro: Guanabara Koogan, 40-59.

Lamas, L.; Negreti, L.; De Rose Jr., D. (2005). A análise tática ofensiva no basquetebol. In: De Rose Jr., D.; Tricoli, V. (eds.) Basquetebol: uma visão integrada entre ciência e prática. Barueri: Manole, cap. 8.

Lorenzo, A., Calleja, J. (2010). Factores condicionantes del desarrollo deportivo. Bilbao: Diputación Foral de Vizcaya.

McInnes, S. E.; Carlson, J. S.; Jones, C. J.; McKenna, M. J. (1995). The physiological load imposed on basketball players during competition. Journal of sports sciences, 13 (5), 387-397.

Meiran, N. (1996). Reconfiguration of processing mode prior to task performance. Journal of Experimental Psychology: Learning, Memory, and Cognition, 22 (6), 1423-1442.

Miguel, M.; Brandão, M.; Souza, V. (2009). Jogadores de basquetebol de alto rendimento e a vivência de emoções pré-competitivas. Motriz: revista de educação física (Impresso), 15 (4), 749-758.

Mikołajec, K.; Maszczyk, A.; Zając, T. (2013). Game Indicators Determining Sports Performance in the NBA. Journal of human kinetics, 37 (1), 145-151.

Mitchell, S.; Oslin, J.; Griffin, L. (2003). Sports foundation for elementary physical education. A tactical games approach. Champaing, IL. Human Kinetics.
Hernández Moreno, J. (1994). Fundamentos del deporte: Análisis de la estructura del juego deportivo. Barcelona: Ed. INDE.

Nitsch, J. R. (2009). Ecological approaches to sport activity: A commentary from an action-theoretical point of view. International Journal of Sport Psychology, 40 (1), 152-176.

Parlebás, P. (1986). Activités physiques et éducation motrices. Paris: Revue Éducation Physique et Sport.

Refoyo Román, I. (2001). La decisión táctica de juego y su relación con la respuesta biológica de los jugadores: una aplicación al baloncesto como deporte de equipo. Tesis de Doctorado. Universidad Complutense de Madrid, Servicio de Publicaciones.

Ruiz, L., Sánchez Bañuelos, F. (1997). Rendimiento deportivo. Claves para la optimización de los aprendizajes. Madrid. Gymnos.

Sampaio, J.; Maçãs, V. (2012). Measuring tactical behaviour in Football. International Journal of Sports Medicine, 33 (5), 395-401.

Sánchez Bañuelos, F.; Ruiz, L.M. (2000). Optimización del aprendizaje de la técnica. Máster de Alto Rendimiento Deportivo. Madrid. C.O.E. - U.A.M.

Seirul-lo, F. (1993). Preparación física aplicada a los deportes de equipo. Colección Cadernos TécnicoPedagóxicos do INEF de Galicia - a Coruña: Centro Galego de Documentación e Edicións Deportivas.

Singer, R. (1980). Motor learning and human performance. Nueva York. McMillan.

Tavares, F. (1993). A capacidade de decisão táctica no jogador de basquetebol. Estudo dos processos perceptivo-cognitivos em atletas seniores e cadetes. Tese de Doutorado. Universidade do Porto. Porto.

Tavares, F. (1997). El proceso de la información en los juegos deportivos. In: Graça, A.; Oliveira, J. La enseñanza de los juegos deportivos. Barcelona. Paidotribo. 35-48.

Tavares, F. (1999). A investigação da componente tática nos jogos desportivos: conceitos e ilustrações. In: Tavares, F. (ed.). Estudo dos jogos desportivos: concepções, metodologias e Instrumentos. Porto: Multitema, 7-13.

Terrados, N.; Calleja-González, J.; Schelling, X. (2011). Bases fisiológicas comunes para deportes de equipo. Revista Andaluza de Medicina del Deporte, 4 (2), 8488.

Thelen E.; Smith, L. B. (1998). Dynamic systems theories. In: Lerner, R.M. Handbook of Child Psychology: Vol. 1. Theoretical Models of Human Development. New York: Wiley, 563-635. 
Tous, J. (2008). Entrenamiento de la fuerza en baloncesto. In: Terrados, N.; Calleja, J. (coord.). Fisiología, entrenamiento y medicina del Baloncesto. Barcelona: Paidotribo, 163-174.

\section{IV - CATEGORIAS FORMATIVAS EN BASQUETBOL}

Astrand, P.O. (1996). Influencias de la edad biológica y de la selección. In: Shephard, R.J.; Astrand, P.O. (eds.) La resistencia en el deporte. Barcelona: Paidotribo, 305-317.

Baker, J.; Cote, J.; Abernethy, B. (2003). Sport-specific practice and the development of expert decisionmaking in team ball sports. Journal of applied sport psychology, 15 (1), 12-25.

Balyi, I. (2001). Sport system building and long-term athlete development in British Columbia. Coaches Report, 8 (1), 22-28.

Balyi, I. (2003). O desenvolvimento do praticante a longo prazo-sistema e soluções. Treino Desportivo, Lisboa, (23), 22-27.

Balyi, I.; Way, R.; Higgs, C. (2013). Long-term athlete development. Human Kinetics.

Buceta, J.M. (2000). El papel del baloncesto en el desarrollo y la formación de los jóvenes. In: Buceta, J. M.; Mondoni, M.; Avakumovíc, A.; Killik, L. Baloncesto para jugadores jóvenes. Guia para entrenadores.

FIBA, 1-35.

Helsen, W.W.F.; Whinckel, J.V.; Williams, A.M. (2005). The relative age effect in youth soccer across Europe. Journal of Sports Sciences, 23 (6): 629-636.

Jiménez, I. P.; Pain, M. T. (2008). Relative age effect in Spanish association football: Its extent and implications for wasted potential. Journal of sports sciences, 26 (10), 995-1003.

Lorenzo, A., Calleja, J. (2010). Factores condicionantes del desarrollo deportivo. Bilbao: Diputación Foral de Vizcaya.

Manonelles, P., Álvarez, J., Coloma, M., Sain de Aja, C., Corona, P. y Giménez, L. (2003) Edad cronológica como factor de elección de jugadores de las selecciones españolas de baloncesto de formación. Archivos de Medicina del Deporte. Vol. XX, (96), 321328.

Musch, J.; Hay, R. (1999). The Relative Age Effect in Soccer: Cross-cultural evidence for a systematic discrimination against children born late in the competition year. Sociology of Sport Journal, 16, 54-64. Sánchez, M. S.; Buñuel, P.; Ibáñez, S. J.; Robles, Á. S.; Fuentes-Guerra, F. J. (2006). El desarrollo de la pericia en baloncesto: claves para la formación del jugador de alto rendimiento. Apunts: Educación física y deportes, (83), 52-60.

Serrabona, M. (1997). Generalizaciones sobre un proyecto de vida deportiva en el jugador de baloncesto. Revista Clinic, (37), 12-16.

Thompson, A.; Barnsley, R.; Stebelsky, G. (1991). "Born to play ball" The relative age effect and Major League Baseball. Sociology of Sport Journal, 8, 146151.

\section{V - ENTRENADOR}

Abraham, A.; Collins, D.; Martindale, R. (2006). The coaching schematic: Validation through expert coach consensus. Journal of sports sciences,24 (06), 549564.

Afonso, C.; Graça, A. (2013). O conhecimento do treinador a respeito das metodologias de ensino e do treino do voleibol na formação. In: Ramos, V.; Saad, M. A.; Milistetd, M. (orgs.). Jogos desportivos coletivos: investigação e prática pedagógica. Coleção temas em movimento 3. Florianópolis: UDESC. 271-293.

Antón, J. L. (2000). Balonmano, perfeccionamiento e investigación. Barcelona: Inde.

Cañadas, M. C.; Ibáñez, S. J.; Feu, S.; García, J.; Parejo, I. (2011). Análisis de los medios de entrenamiento de un equipo de Minibásket y la influencia de un programa formativo para el entrenador: un estudio de caso. Agora para la Educación Física y el Deporte, 13 (3), 363-382.

Corbi, R. G.; Costa, J. L. C. (2003). El desarrollo de la competencia experta: implicaciones para la enseñanza. Editorial Club Universitario.

Casarin, R. V.; Reverdito, R. S.; de Lima Greboggy; D., Afonso, C. A.; Scaglia, A. J. (2011). Modelo de jogo e processo de ensino no futebol: princípios globais e específicos. Movimento (ESEF/UFRGS), 17 (3), 133152.

Cote, J.; Sedgwick, W. A. (2003). Effective behaviors of expert rowing coaches: A qualitative investigation of Canadian athletes and coaches. International Sports Journal, 7 (1), 62-77.

Côté, J.; Gilbert, W. (2009). An integrative definition of coaching effectiveness and expertise. International Journal of Sports Science and Coaching, 4 (3), 307323.

Demers, G., Woodburn, A. Savard, C. (2006). The development of an undergraduate competency-based coach education program. Sport Psychologist, 20 (2), 
162-173.

Duffy, P. (2008). Implementation of the Bologna process and model curriculum development in coaching. Higher Education in Sport in Europe. From labour market demand to training supply, 80-108.

Ericsson, K. A. (2003). Development of elite performance and deliberate practice. Expert performance in sports: Advances in research on sport expertise, 49-83.

Feu, S. (2004). Estudio de los modelos y variables que afectan al entrenador español de balonmano. Tesis doctoral. Universidad de Extremadura.

Feu, S. (2006). El perfil de los entrenadores de balonmano. La formación como factor de cambio. Cáceres: Ilustre Colegio Oficial de Licenciados en Educación Física y en Ciencias de la Actividad Física y del Deporte de Extremadura.

Feu, S.; Ibáñez, S.; Delgado, M. (2010). Influencia de la formación formal y no formal en las orientaciones que adoptan los entrenadores deportivos. Revista de Educación, (353), 615-640.

Garganta, J. (2000). O treino da táctica e da estratégia nos jogos desportivos. Horizontes e órbitas no treino dos jogos desportivos. Porto: CEJD, 51-61.

Gallego, D. I.; Vélez, D. C.; López, F. A. (2007). La comunicación durante la intervención didáctica del entrenador: consideraciones para el desarrollo del conocimiento táctico y la mejora en la toma de decisiones en baloncesto. Cultura, ciencia y deporte: revista de ciencias de la actividad física y del deporte de la Universidad Católica de San Antonio, (7), 43-50.

Graça, A.; Mesquita, I. (2009). Modelos instrucionais no Ensino do Desporto. Pedagogia do Desporto, 39-68.

Harre, D. (1987). Teoría del entrenamiento deportivo. Buenos Aires: Stadium.

Ibáñez, S.J. (1997). Análisis del proceso de formación del entrenador español de baloncesto. Tesis doctoral. Universidad de Granada.

Ibáñez, S.J. (2008). La planificación y el control del entrenamiento técnico-táctico en baloncesto. In: Terrados, N.; Calleja, J. (Coord.). Fisiología, entrenamiento y medicina del Baloncesto. Barcelona: Paidotribo, 299-314.

Ibáñez, S; Feu, S.; Antúnez, A.; Cañadas, M. (2013). Avances y desafíos en la formación de los entrenadores de deportes colectivos. In: do Nascimento, J. V.; Tavares, F. (orgs.) Jogos desportivos: formação e investigação. Coleção temas em movimento 4. Florianópolis: UDESC. 319-343.
Jiménez, S.; Lorenzo, A.; Gómez, M. Á. (2009). Medios de formación de los entrenadores expertos en baloncesto. Cultura, Ciencia y Deporte, 119-125.

Jones, R. L.; Turner, P. (2006). Teaching coaches to coach holistically: can Problem-Based Learning (PBL) help? Physical Education and Sport Pedagogy, 11 (2), 181-202.

Lamas, L. (2012). Modelagem estratégico-tática em esportes coletivos de invasão: aplicação ao basquetebol. Tese (Doutorado) - Escola de Educação Física e Esporte, Universidade de São Paulo, São Paulo.

Leite, N.; Sampaio, J. (2012). Long-term athletic development across different age groups and gender from Portuguese basketball players. International Journal of Sports Science and Coaching, 7 (2), 285300.

Lyle, J. (2002). Sports coaching concepts: A framework for coaches' behaviour. New York: Psychology Press.

Martens, R. (2002). El entrenador de éxito. Barcelona: Paidotribo.

Mesquita, I. R. (2010). Contributo para uma mudança de paradigma na formação de treinadores: razões, finalidades e contextos. In: Centro de Investigação, Formação, Inovação e Intervenção em Desporto (Eds.). Desporto e Educação Física em Português. Porto: Faculdade de Desporto da Universidade do Porto, 8499.

Mesquita, I.; Borges, M.; Rosado, A.; Batista, P.M. (2012). Self-efficacy, perceived training needs and coaching competences: The case of Portuguese handball. European Journal of Sport Science, 12 (2): 168-178.

Nascimento, J. V.; Ramos, V.; Marcon, D.; Saad, M. A.; Collet, C. (2009). Formação acadêmica e intervenção pedagógica nos esportes. Motriz rev. educ. fís. (Impr.), 15 (2), 358-366.

Nash, C.; Collins, D. (2006). Tacit knowledge in expert coaching: science or art? Quest, 58 (4), 465-477.

Piñar, M. I.; Cárdenas, D. (2009). Necesidades formativas para la competición en la iniciación al baloncesto. In: Ortega, G; Jiménez, A.C. (eds.), Táctica y técnica en la iniciación al baloncesto. Sevilla: Wanceulen.

Santos, S.; Mesquita, I.; Pereira, F. Moreno, M.P. (2010). La intervención pedagógica de entrenadores de voleibol de jóvenes. Motricidad. European Journal of Human Movement, 23, 59-77.

Santos, S., Mesquita, I., Graça, A., Rosado, A. (2010). Coaches' perceptions of competence and acknowledgement of training needs related to 
professional competences. Journal of sports science \& medicine, 9 (1), 62-70.

Stephenson, J.; Weil, S. (1992). Quality in Learning: a capability approach in higher education. London: Kogan Page.

Tarodo, J. S.; Belmonte, M.; Toro, E.; Ruano, M. (2011). Opinión de los entrenadores sobre distribución de contenidos técnico-tácticos y pedagógicos en distintas categorías de baloncesto de formación. Cuadernos de psicología del deporte, 11 (2), 51-62.

Westera, W. (2001). Competences in education: a confusion of tongues. Journal of Curriculum studies, 33 (1), 75-88.

Ziane R. (2004). Contribution à la formation des entraîneurs sportifs: caractérisation et représentation des actions de jeu: l'exemple du basket-ball. Thése de Doctorat. École normale supérieure de Cachan.

\section{VI - TÁCTICA DEPORTIVA}

Aguilà, G. L. (1991). Aproximación a una propuesta de aprendizaje de los elementos tácticos individuales en los deportes de equipo. Apunts: Educación física y deportes, (24), 59-68.

Anderson, J. R. (1982). Acquisition of cognitive skill. Psychological review, 89 (4), 369-406.

Araújo, D. (2003). A auto-organização da acção táctica: Comentário a Costa, Garganta, Fonseca e Botelho (2002). Revista Portuguesa de Ciências do Desporto, 3 (3), 87-93.

Araújo, D. (2009). O desenvolvimento da competência táctica no desporto: o papel dos constrangimentos no comportamento decisional. Motriz rev. educ. fís. (Impr.), 15 (3), 537-540.

Avilés, C.; Ruiz-Pérez, L.; Navia, J.; Rioja, N.; Sanz, D. (2014). La pericia perceptivo-motriz y cognición en el deporte: del enfoque ecológico y dinámico a la enacción. Anales De Psicología, 30 (2), 725-737.

Bayer, C. (1986). La Enseñanza de los juegos deportivos colectivos. Hispano europea.

Buscà, B. (2005). Aproximació al constructe d'intel ligència esportiva. Aloma. Revista de Psicologia, Ciències de l'Educació i de l'Esport. 15, 38-46.

Buscà, B.; Riera, J.R. (1999) Orientación deportiva sobre actividades tácticas. Revista de Psicología del Deporte, 8 (2), 271-276.

Chi, M. (1981). Knowledge development and memory performance. In: Fiedman, M.; O'Connor, J. (eds.). Intelligence and Learning. New York: Plenum Press, $221-229$.
Chi, M.; Glaser, R. (1992). A capacidade para a resolução de problemas. In: Sternberg $\mathrm{R}$ (ed.). As capacidades intelectuais humanas: uma abordagem em processamento de informações. Porto Alegre: Ed. Artes médicas, 249-275.

Colom, R. (2006). O -que é inteligência? In: FlorezMendoza, C.; Colom, R. (eds.). Introdução à psicologia das diferenças individuais. Porto Alegre: Artmed, 59-71. Costa, J.C.; Garganta, J.; Fonseca, A.; Botelho, M. (2002). Inteligência e conhecimento específico em jovens futebolistas de diferentes níveis competitivos. Revista Portuguesa de Ciências do Desporto, 2 (4), 7 20.

da Costa, L. C. A.; do Nascimento, J. V. (2004). O ensino da técnica e da tática: novas abordagens metodológicas. Revista da Educação Física/UEM, 15 (2), 49-56.

de Pinho, S. T.; Alves, D. M.; Greco, P. J., Schild, J. F. G. (2010). Método situacional e sua influência no conhecimento tático processual de escolares. Motriz, Rio Claro, 16 (3), 580-590.

Dorsch, F. (2008). Diccionario de Psicología. Barcelona: Editorial Herder.

Eysenck, M. W.; Keane, M. T. (1994). Psicologia cognitiva: um manual introdutório. Porto Alegre: Artes Médicas.

Florez-Mendoza, C.E.; Nascimento, E.D. (2001). Inteligência: o construto melhor investigado em psicologia. Boletim de psicologia, 51 (114), 37-64.

García, S.; Rodríguez, A.; Garzón, A. (2011). Conceptualización de inteligencia táctica en fútbol: Consideraciones para el desarrollo de un instrumento de evaluación en campo desde las funciones ejecutivas. Cuadernos de psicología del deporte, 11 (1), 69-78.

Garganta, J. (1997). Modelação táctica do jogo de Futebol: estudo da organização ofensiva em equipas de alto rendimento. Tese de doutoramento - FCDEF, Universidade do Porto, Porto.

Garganta, J. (2000). O treino da táctica e da estratégia nos jogos desportivos. Horizontes e órbitas no treino dos jogos desportivos. Porto: CEJD, 51-61.

Garganta, J. (2002). O treino da táctica e da técnica nos jogos desportivos à luz do compromisso cogniçãoacção. In: Barbanti, V.; Amadio, A.; Bento, J; Marques, A. (eds.). Esporte e atividade física: interação entre rendimento e qualidade de vida. São Paulo: Manole, 281-306.

Garganta, J. (2005). Dos constrangimentos da acção à liberdade de (inter) acção, para um Futebol com pés... 
e cabeça. In: Araújo, D. (ed.) O contexto da decisão. A acção táctica no desporto, 179-190.

Garganta, J. (2006). (Re) Fundar os conceitos de estratégia e táctica nos jogos desportivos coletivos, para promover uma eficácia superior. Revista Brasileira Educação Física e Esporte, 20 (5), 201-203.

Garganta, J.; Gréhaigne, J.F. (1999). Abordagem sistémica do jogo de Futebol: moda ou necessidade? Movimento (ESEF/UFRGS), 5 (10), 40-50.

Greco, P. J. (1989). Consideraciones psicopedagógicas del entrenamiento táctico. Stadium, 136: 14-19.

Greco, P.J. (1995). O ensino do comportamento tático nos Jogos Esportivos coletivos: Aplicação no Handebol. (Tese de Doutorado - Departamento de Psicologia Educacional - Faculdade de Educação). Campinas (SP) Universidade Estadual de Campinas.

Greco, P.J. (1998). Iniciação esportiva universal: metodologia da iniciação esportiva na escola e no clube. Belo Horizonte: UFMG, 2, 305.

Greco, P.J. (2003). Processos cognitivos: Dependência e interação nos jogos esportivos coletivos. In: Lemos; K.L.M.; Silami Garcia, E. (org.). Temas atuais VIII em educação física e esportes. Belo Horizonte: Escola de Educação Física da UFMG, 73-84.

Greco, P.J. (2006). Conhecimento técnico-tático: o modelo pendular do comportamento e da ação tática nos esportes coletivos. Revista Brasileira de Psicologia do Esporte e do Exercício, 107-129.

Greco, P.J. (2009). Percepção. In: Samulski, D. (ed.) Psicologia do Esporte: conceitos e novas perspectivas.

2 ed. Barueri. Editora Manole, 57-84.

Greco, P.J.; Benda, R.N. (1998). Iniciação esportiva universal: da aprendizagem motora ao treinamento técnico. Belo Horizonte: UFMG, 1, 230.

Greco, P.J.; Chagas, M.H. (1992). Considerações teóricas da tática nos jogos esportivos coletivos. Revista paulista de educação física, 6 (2), 47-58.

Greco, P.J.; Roth, K.; Schörer, J. (2004). Ensinoaprendizagem-treinamento da criatividade tática nos jogos esportivos coletivos. In: Garcia, E. S.; Lemos, K. L. (ed.). Temas atuais IX: Educação Física e esportes. Belo Horizonte: Saúde, 52-63.

Gréhaigne, J.F.; Godbout, P. (1995). Tactical knowledge in team sports from a constructivist and cognitivist perspective. Quest, 47 (4), 490-505.

Gréhaigne, J.F.; Godbout, P.; Bouthier, D. (2001). The teaching and learning of decision making in team sports. Quest, 53 (1), 59-76.
Grehaigne, J.; Richard, J.; Griffin, L. (2005). Teaching and learning team sports and games. Psychology Press.

Herculano-Houzel, S. (2005). O cérebro em transformação. Rio de Janeiro: Editora Objetiva.

Housner, L. D.; French, K. E. (1994). Future directions for research on expertise in learning, performance, and instruction in sport and physical activity. Quest, 46 (2), 241-246.

i Balash, J. R. (1998). El ajuste temporal: criterio de ejecución distintivo de la inteligencia deportiva. Apunts: Educación física y deportes, (53), 10-17.

Janelle, C.; Hillman, C. (2003). Expert performance in sport: current perspectives and critical issues. In: Starks, J.; Ericsson, K. (eds.). Expert Performance in sport: Advances in research on sport expertise. Human Kinetics: 19-47.

Knapp, B. H. (1963). Skill in sport: the attainment of proficiency. London: Routledge and Kegan Paul.

Lamas, L. (2012). Modelagem estratégico-tática em esportes coletivos de invasão: aplicação ao basquetebol. Tese (Doutorado) - Escola de Educação Física e Esporte, Universidade de São Paulo, São Paulo.

Mahlo, F. (1969). L'acte tactique en jeu. Paris: Vigot Freres.

Marina, J.A. (1993). Teoría de la inteligencia creadora, Barcelona: Anagrama.

Marina, J.A. (2012). Inteligencia Ejecutiva. Barcelona: Editorial Planeta.

Matias, C. J. (2009). O conhecimento tático declarativo e a distribuição de jogo do levantador de voleibol: da formação ao alto nível. Dissertação (Mestrado em Ciências do Esportes) - EEFFTO, UFMG, Belo Horizonte.

Matias, C.J.; Greco, P.J. (2013). O conhecimento tático declarativo dos levantadores campeões de voleibol. Motriz rev. educ. fís. (Impr.), 19 (1), 184-194.

Matias, C.J.; Lima, C.O.; Greco, P.J (2012). O conhecimento tático produto de métodos de ensino combinados e aplicados em sequências inversas no voleibol. Revista Brasileira de Educação Física e Esporte, São Paulo, 26 (1), 129-147.

Menezes, R.P.; Reis, H.B. (2010). Análise do jogo de handebol como ferramenta para sua compreensão técnico-tática. Motriz rev. educ. fís. (Impr.), 16 (2), 458467.

Mesquita, I. (2006). Ensinar bem para aprender melhor o jogo de voleibol. In: Tani, G.; Bento, J.O.; Petersen, R.D. (eds.). Pedagogia do desporto. Rio de Janeiro: Guanabara Koogan, 327-344. 
Morales, J.C.P. (2007). Processo de ensinoaprendizagem-treinamento no basquetebol: influência no conhecimento tático processual. Dissertação de Mestrado, EEFFTO, UFMG, Belo Horizonte.

Moreno, A., Moreno, M. P., García, L., Iglesias, D.; Del Villar, F. (2006). Relación entre conocimiento procedimental, experiencia y rendimiento. Un estudio en voleibol. Motricidad. European Journal of Human Movement, 17, 15-24.

Moya, F.E. (1996). El concepto de táctica individual en los deportes colectivos. Apunts: Educació Física $i$ Esportes, 51, 16-22.

Parlebás, P. (1981): Contribución al léxico en las ciencias de la acción motriz. INSEP. París.

Pino Medina, J.M.; Gómez Milán, E.; Moreno Ríos, S.; Gálvez García, G.; Mula Pérez, F.J. (2009). Inteligencias múltiples y deporte. Apunts. Educación física y deportes, (95), 5-13.

Raab, M. (2007). Think SMART, not hard-a review of teaching decision making in sport from an ecological rationality perspective. Physical Education and Sport Pedagogy, 12 (1), 1-22.

Raab, M. (2015). SMART-ER: a Situation Model of Anticipated Response consequences in Tactical decisions in skill acquisition-Extended and Revised. Frontiers in psychology, 5, 1533.

Refoyo Román, I. (2001). La decisión táctica de juego y su relación con la respuesta biológica de los jugadores: una aplicación al baloncesto como deporte de equipo. Tesis de Doctorado. Universidad Complutense de Madrid, Servicio de Publicaciones.

Rezer, R.; Saad, M. A. (2005). Futebol e futsal: possibilidades e limitações da prática pedagógica em escolinhas. Argos, Editora Universitária.

Riera, J. R. (1995). Estrategia, táctica y técnica deportivas. Apunts: educación física y deportes, (39), 45-56.

Sampedro, J. (1999). Fundamentos de la táctica deportiva: análisis de la estrategia de los deportes. Madrid, Editorial Gymnos.

Samulski, D. M.; Noce, F., da Costa, V. T. (2006). A

Criatividade no Voleibol Brasileiro de Alto Rendimento: uma análise dos conceitos e diferenças existentes entre géneros. Revista Brasileira de Psicologia do Esporte e Exercício, 0, 83-106.

Samulski, D.M.; Albuquerque, M.R.; Costa, V.T.; Noce, F. (2008). Avaliaçao do perfil motivacional dos atletas de alto rendimiento: Do Taekwondo brasileiro. Revista iberoamericana de psicología del ejercicio y el deporte, 3 (1), 75-94.
Santos, L.R. (2004). Tendências evolutivas do jogo de Andebol: Estudo centrado na análise da perfomance táctica de equipas finalistas em campeonatos do mundo e jogos olímpicos. Tese Doutorado - Faculdade de Ciências do Desporto e Educação Física, Universidade do Porto, Porto.

Scaglia, A.J. (1999). O futebol que se aprende e se ensina. 1999. Dissertação (Mestrado) - UNICAMP, Campinas.

Solà, J. (2010). Inteligencia táctica deportiva: entenderla y entrenarla. Barcelona: INDE.

Souza, P. (2002). Validação de teste para avaliar a capacidade de tomada de decisão e o conhecimento declarativo em situações de ataque no Futsal. Dissertação de Mestrado. Escola de Educação Física, Fisioterapia e Terapia Educacional, Universidade Federal de Minas Gerais. Belo Horizonte.

Sternberg, R. (2000). Psicología cognitiva. Porto Alegre: Artmed.

Sternberg, R. (2005). Inteligência de sucesso: Como a inteligência de sucesso e a criativa são determinantes para uma vida de sucesso. Lisboa: Esquilo edições e multimídia, Ltda.

Tavares, F. (1993). A capacidade de decisão táctica no jogador de basquetebol. Estudo dos processos perceptivo-cognitivos em atletas seniores e cadetes. Tese de Doutorado. Universidade do Porto. Porto.

Tavares, F. (1997). El proceso de la información en los juegos deportivos. In: Graça, A.; Oliveira, J. La enseñanza de los juegos deportivos. Barcelona. Paidotribo. 35-48.

Tavares, F. (1999). A investigação da componente tática nos jogos desportivos: conceitos e ilustrações. In: Tavares, F. (ed.). Estudo dos jogos desportivos: concepções, metodologias e Instrumentos. Porto: Multitema, 7-13.

Tavares, F. (2013). Jogos Desportivos coletivos: contributos para a sua análise e funcionamento. In: Ramos, V.; Saad, M. A.; Milistetd, M. (orgs.). Jogos desportivos coletivos: investigação e prática pedagógica. Coleção temas em movimento 3. Florianópolis: UDESC. 17-51.

Tavares, F.; Greco, P.; Garganta, J. (2006). Perceber, conhecer, decidir e agir nos jogos desportivos coletivos. In: Tani, G.; Bento, J.; Petersen, R. (eds.). Pedagogia do desporto, Rio de Janeiro: Guanabara Koogan. 284298.

Tenenbaum, G.; Bar-Eli, M. (1993). Decision making in sport: A cognitive perspective. Handbook of research on sport psychology. New York: Macmillan, 171-192. 
Teodorescu, L. (1984). Problemas de teoria e metodologia nos jogos desportivos. Lisboa: Livros Horizonte.

Thomas, K.; Thomas, J. (1994). Developing Expertise in Sport: The relation of Knowledge and Performance. Journal of Sport Psychology, 25: 295-312.

Thomas, J.; French, K.; Humphries, C. (1986). Knowledge development and sport skill performance: Directions for motor behavior research. Journal of sport Psychology, 8 (4), 259-272.

Williams, A.M.; Davids, K.; Burwitz, L.; Williams, J.G. (1993). Cognitive knowledge and soccer performance. Perceptual and Motor Skills, 76 (2), 579-593.

Wrzos, J. (1984). Football. La tactique de l'attaque. Brakel: Ed. Broodcoorens.

Yarrow, K.; Brown, P.; Krakauer, J. W. (2009). Inside the brain of an elite athlete: the neural processes that support high achievement in sports. Nature Reviews Neuroscience, 10 (8), 585-596.

Ziane R. (2004). Contribution à la formation des entraîneurs sportifs: caractérisation et représentation des actions de jeu: l'exemple du basket-ball. Thése de Doctorat. École normale supérieure de Cachan.

\section{VII - TOMA DE DECISIÓN EN EL DEPORTE}

Aburachid, L. M., Greco, P. J. (2010) Processos de validação de um teste de conhecimento tático declarativo no tênis. Revista da Educação Física/UEM, 21 (4), 603-610.

Allard, F.; Burnett, N. (1985). Skill in sport. Canadian Journal of Psychology, 39 (2), 294-312.

Araújo, D. (2009). O desenvolvimento da competência táctica no desporto: o papel dos constrangimentos no comportamento decisional. Motriz rev. educ. fís. (Impr.), 15 (3), 537-540.

Araújo, D.; Volossovitch, A. (2005). Fundamentos para o treino da tomada de decisão: uma aplicação ao andebol. In: Araújo, D. (ed.). O contexto da decisão, a acção táctica no desporto, Lisboa: Visão e Contextos. 75-98.

Araújo, D.; Davids, K.; Hristovski, R. (2006). The ecological dynamics of decision making in sport. Psychology of Sport and Exercise, 7 (6), 653-676.

Araújo, D.; Davids, K.; Rocha, L.; Serpa, S.; Fernandes, O. (2003). Decision making in sport as phase transitions. International Journal of Computer Science in Sport, 2 (2), 87-88.

Banks, A. P.; Millward, L. J. (2007). Differentiating Knowledge in Teams: the effect of shared declarative and procedural knowledge on team performance. Group Dynamics: Theory, Research, and Practice, 11 (2), 95-106.

Blomqvist, M.; Luhtanen, P.; Laakso, L. (2001). Comparison of two types of instruction in badminton. European Journal of Physical Education, 6 (2), 139-155. Bortoli, R.; Bortoli, A.L.; Marquez, S. (2002) Estudio de las capacidades cognoscitivas en el Fútbol-Sala. Revista de Psicologia del Deporte, 11 (1), 53-67.

Casanova, F. (2012). Perceptual - Cognitive Behavior in Soccer players: Response to Prolonged Intermitente Exercise. Tese de Doutoramento. Faculdade de Desporto, Universidade do Porto.

da Costa, I.T.; Garganta, J.; Greco, P.J.; Mesquita, I. (2009). Princípios Táticos do Jogo de Futebol: conceitos e aplicação. Motriz rev. educ. fís.(Impr.), 15 (3), 657-668.

da Costa, I.T.; Garganta, J.; Greco, P.J.; Mesquita, I.; Muller, E. (2011). Relação entre a dimensão do campo de jogo e os comportamentos táticos do jogador de futebol. Rev. bras. Educ. Fís. Esporte, 25 (1), 79-96.

Damásio, A. (1996). O erro de Descartes: Emoção. Razão e o Cérebro Humano. São Paulo: Companhia das Letras.

Damasio, A. (2011) E o cérebro criou o Homem. São Paulo: Companhia das Letras.

Davids, K.; Araújo, D.; Button, C.; Renshaw, I. (2007). Degenerate Brains, Indeterminate Behavior, and Representative Tasks. Implications for Experimental Design in Sport Psychology Research. In: Tenenbaum, G.; Eklund, R.C. (eds.). Handbook of sport psychology. New York: Wiley. 224-244.

de Oliveira, R. F.; Damisch, L.; Hossner, E. J.; Oudejans, R. R.; Raab, M.; Volz, K. G.; Williams, A. M. (2009). The bidirectional links between decision making, perception, and action. Progress in brain research, 174, 85-93.

Dorsch, F. (2008). Diccionario de Psicología. Barcelona: Editorial Herder.

Garganta, J. (1997). Modelação táctica do jogo de Futebol: estudo da organização ofensiva em equipas de alto rendimento. Tese de doutoramento - FCDEF, Universidade do Porto, Porto.

Garganta, J. (2002). O treino da táctica e da técnica nos jogos desportivos à luz do compromisso cogniçãoacção. In: Barbanti, V.; Amadio, A.; Bento, J; Marques, A. (eds.). Esporte e atividade física: interação entre rendimento e qualidade de vida. São Paulo: Manole, 281-306.

Garganta, J. (2004). A formação estratégico-tática nos jogos desportivos de oposição e cooperação. In: Gaya, 
A.; Marques, A.; Tani, G. (eds.) Desporto para crianças e jovens. Razões e finalidades. Porto Alegre: Editora UFRGS, 217-233.

Garganta, J. (2005). Dos constrangimentos da acção à liberdade de (inter) acção, para um Futebol com pés... e cabeça. In: Araújo, D. (ed.) O contexto da decisão. A acção táctica no desporto, 179-190.

Garganta, J.; Oliveira, J. (1996). Estratégia e Táctica nos jogos Colectivos Desportivos. In: Oliveira, J.; Tavares, F. (Eds.). Estratégia e Táctica nos jogos Colectivos Desportivos. Porto: CEJD, FCDEF-UP.

González, L.G.; Gallego, D.I.; Arroyo, M.P.M.; Domínguez, A.M.; Álvarez, F.D.V. (2007). Estrategias cognitivas desarrolladas durante el juego por tenistas de diferente nivel de pericia. Apunts: Educación física y deportes, (89), 40-47.

Greco, P.J. (1988). Handball: La formación de jugadores inteligentes. Stadium, 128, 22-30.

Greco, P.J. (1989). Consideraciones psicopedagógicas del entrenamiento táctico. Stadium, 136, 14-19.

Greco, P.J. (1995). O ensino do comportamento tático nos Jogos Esportivos coletivos: Aplicação no Handebol. (Tese de Doutorado - Departamento de Psicologia Educacional - Faculdade de Educação). Campinas (SP) Universidade Estadual de Campinas.

Greco, P.J. (1999). Cognição e Ação. In: Samulski, M. D. Novos conceitos em treinamento esportivo. Brasília: Publicações Indesp. Série Ciências do Esporte, 119154.

Greco, P.J. (2001). Métodos de ensino-aprendizagem nos jogos esportivos coletivos. In: Garcia, E. S; Lemos,

K. L. M. Temas Atuais VI em educação física e esportes. Belo Horizonte: Health, 48-72.

Greco, P.J. (2003). Processos cognitivos: Dependência e interação nos jogos esportivos coletivos. In: Lemos; K.L.M.; Silami Garcia, E. (org.). Temas atuais VIII em educação física e esportes. Belo Horizonte: Escola de Educação Física da UFMG, 73-84.

Greco, P.J. (2004). Cogni (a) cão: conhecimento, processos cognitivos e modelos de ensinoaprendizagem-treinamento para o desenvolvimento da criatividade (tática). Revista Portuguesa de Ciências do Desporto, 4 (2), 56-59.

Greco, P.J. (2006). Conhecimento técnico-tático: o modelo pendular do comportamento e da ação tática nos esportes coletivos. Revista Brasileira de Psicologia do Esporte e do Exercício, 107-129.

Greco, P.J. (2009). Perceção. In: Samulski, D. (ed.) Psicologia do Esporte: conceitos e novas perspectivas. 2 ed. Barueri. Editora Manole, 57-84.
Greco, P.J.; Sisto, F.F. (1995) Comportamento táctico nos jogos esportivos colectivos. Rev. Paulista de Educação Física, 9 (1), 63-68.

Gréhaigne, J. F.; Godbout, P. (1995). Tactical knowledge in team sports from a constructivist and cognitivist perspective. Quest, 47 (4), 490-505.

Grehaigne, J.; Godbout, P.; Bouthier, D. (1999). The foundations of tactics and strategy in team sports. Journal of teaching in physical education, 18, 159-174. Grehaigne, J.; Godbout, P.; Bouthier, D. (2001). The teaching and learning of decision making in team sports. Quest, 53 (1), 59-76.

Gréhaigne, J. F., Wallian, N.; Godbout, P. (2005). Tactical-decision learning model and students' practices. Physical Education and Sport Pedagogy, 10 (3), 213-224.

Hoffmann, J. (1993). Vorhersage und Erkenntnis: Die Funktion von Antizipationen in der menschlichen Verhaltenssteuerung und Wahrnehmung [Prediction and Realisation: The function of anticipations in human behavioural control and perception]. Göttingen: Hogrefe.

Hoffmann, J. (2009). ABC: A psychological theory of anticipatory behavioral control. In: Pezzulo, G.; Butz, M. V.; Sigaud, O.; Baldassarre G. (eds.). Anticipatory Behavior in Adaptive Learning Systems. From Psychological Theories to Artificial Cognitive Systems. Heidelberg: Springer, 10-30.

Hoffmann, J. (2010) Speculations on the origin of STM. Psychologica Bélgica, 50 (3-4), 175-191.

Hoffmann, J.; Berner, M.; Butz, M. V.; Herbort, O.; Kiesel, A.; Kunde, W.; Lenhard, A. (2007). Explorations of anticipatory behavioral control $(A B C)$ : A report from the cognitive psychology unit of the University of Würzburg. Cognitive Processing, 8 (2), 133-142.

Iglesias, D.; Ramos, L. A.; Fuentes, J. P.; Sanz, D.; del Villar, F. (2003). El conocimiento y la toma de decisiones en los deportes de equipo: una revisión desde la perspectiva cognitiva. Revista de Entrenamiento Deportivo, 17 (2), 5-11.

Iglesias, D.; Moreno, M. P.; Ramos, L. A.; Fuentes, J. P.; Julián, J. A.; del Villar, F. (2002). Un modelo para el análisis de los procesos cognitivos implicados en la toma de decisiones en deportes colectivos. Revista de Entrenamiento Deportivo, 16 (2), 9-14.

Knapp, B. H. (1963). Skill in sport: the attainment of proficiency. London: Routledge and Kegan Paul.

Konzag, I. (1990). Attivita cognitiva e formazione del giocatores. Rivista Cultura di Sportiva, 20, 14-20.

Lamas, L.; Barrera, J.; Otranto, G.; Ugrinowitsch, C. (2014). Invasion team sports: strategy and match 
modeling. International Journal of Performance Analysis in Sport, 14 (1), 307-329.

Lopes, J. E.; Araújo, D.; Peres, R.; Davids, K.; Barreiros, J. (2008). The dynamics of decision making in penalty kick situations in association football. The Open Sports Sciences Journal, 1 (1), 24-30.

López Ros, V. (2011). Operaciones cognitivas en la iniciación deportiva. El pensamiento táctico. Revista Movimiento Humano, (1), 59-74.

López Ros, V.; Sargatal, J.; Jiménez Sánchez, A. C.; Mouchet, A.; Castejón Oliva, F. J.; Terrisse, A.; Lago Peñas, C. (2010). La Táctica deportiva y la toma de decisiones. Universitat de Girona.

Mahlo, F. (1969). L'acte tactique en jeu. Paris: Vigot Freres.

Matias, C. J. (2009). O conhecimento tático declarativo e a distribuição de jogo do levantador de voleibol: da formação ao alto nível. Dissertação (Mestrado em Ciências do Esportes) - EEFFTO, UFMG, Belo Horizonte.

Matias, C.J.; Greco, P.J. (2013). O conhecimento tático declarativo dos levantadores campeões de voleibol. Motriz rev. educ. fís. (Impr.), 19 (1), 184-194.

McPherson, S.L. (1994). The development of sport expertise: Mapping the tactical domain. Quest, 46 (2), 223-240.

Memmert, D.; Roth, K. (2007). The effects of nonspecific and specific concepts on tactical creativity in team ball sports. Journal of Sports Sciences, 25 (12), 1423-1432.

Morales, J.C.P. (2007). Processo de ensinoaprendizagem-treinamento no basquetebol: influência no conhecimento tático processual. Dissertação de Mestrado, EEFFTO, UFMG, Belo Horizonte.

Morales, J.C.P.; Greco, P.J. (2007). A influência de diferentes metodologias de ensino-aprendizagemtreinamento no basquetebol sobre o nível de conhecimento tático processual. Revista Brasileira de Educação Física e Esporte, 21 (4), 291-299.

Moreno, A., Moreno, M.P., García, L., Iglesias, D.; Del Villar, F. (2006). Relación entre conocimiento procedimental, experiencia y rendimiento. Un estudio en voleibol. Motricidad. European Journal of Human Movement, 17, 15-24.

Mouchet, A. (2005). Subjectivity in the articulation between strategy and tactics in team sports: an example in rugby. Italian Journal of Sport Sciences, 12 (1), 24-33.

Nitsch, J.R. (2009). Ecological approaches to sport activity: A commentary from an action-theoretical point of view. International Journal of Sport Psychology, 40 (1), 152-176.

Noce, F.; Simin, M.; Penna, E.; Ferreira, R.; Costa, V. (2012) Análise do conhecimento tático em atletas de handebol. Revista Mineira de Educação Física, Viçosa, Edição Especial, 1, 2089-2099.

Paula, A. (2000). Processo de validação de teste para avaliar a capacidade de decisão tática e o conhecimento declarativo no voleibol: situações de ataque de rede. Dissertação de Mestrado. EEFFTOUFMG. Belo Horizonte.

Pérez, L.M.R.; Gabilondo, J.A. (2005). El proceso de toma de decisiones en el deporte: clave de la eficiencia y el rendimiento óptimo. Barcelona: Paidós.

Prinz, W. (1990). A common coding approach to percepction and action. In: Neumann, O.; Prinz, W. (eds.), Relationships between percepction and action: Current approaches Berlin: Springer. 167-201.

Prudente, J.F.P.N. (2006). Análise da performance táctico-técnica no handebol de alto nível. Estudo das ações ofensivas com recurso à análise sequencial. Tese de doutoramento. Funchal, Portugal: Universidade da Madeira.

Raab, M. (2002). T-ECHO: Model of decision making to explain behaviour in experiments and simulations under time pressure. Psychology of sport and exercise, 3 (2), 151-171.

Raab, M. (2003). Decision making in sports: Influence of complexity on implicit and explicit learning. International Journal of Sport and Exercise Psychology, 1 (4), 406-433.

Raab, M. (2007). Think SMART, not hard-a review of teaching decision making in sport from an ecological rationality perspective. Physical Education and Sport Pedagogy, 12 (1), 1-22.

Raab, M. (2015). SMART-ER: a Situation Model of Anticipated Response consequences in Tactical decisions in skill acquisition-Extended and Revised. Frontiers in psychology, 5, 1533.

Raab, M., Masters, R. S., \& Maxwell, J. P. (2005). Improving the 'how'and 'what'decisions of elite table tennis players. Human movement science, 24 (3), 326344.

Ranganathan, R.; Carlton, L. G. (2007). Perceptionaction coupling and anticipatory performance in baseball batting. Journal of Motor Behavior, 39 (5), 369380 .

Refoyo Román, I. (2001). La decisión táctica de juego y su relación con la respuesta biológica de los jugadores: una aplicación al baloncesto como deporte de equipo. 
Tesis de Doctorado. Universidad Complutense de Madrid, Servicio de Publicaciones.

Riera, J. (1989). Fundamentos del aprendizaje de la técnica y la táctica deportivas. Barcelona: INDE.

Riera, J. (1995). Análisis de la táctica deportiva. Apunts. Educación Física y Deportiva, 40, 47-60.

Ruiz Pérez, L. M.; Arruza, J. (2005). El proceso de toma de decisiones en el deporte. Barcelona: Paidós.

Sampedro, J. (1999). Fundamentos de la táctica deportiva: análisis de la estrategia de los deportes. Madrid, Editorial Gymnos.

Samulski, D. (2002). Psicologia do esporte: um manual para a educação física, fisioterapia e psicologia. Psicologia do esporte: um manual para a educação física, fisioterapia e psicologia. São Paulo: Manole, 13351.

Samulski, D. (2009) Psicologia do Esporte: Conceitos e Novas perspectivas. Barueri: Manole.

Samulski, D.M.; Albuquerque, M.R.; Costa, V.T.; Noce,

F. (2008). Avaliaçao do perfil motivacional dos atletas de alto rendimiento: Do Taekwondo brasileiro. Revista iberoamericana de psicología del ejercicio y el deporte, 3 (1), 75-94.

Sanfey, A. G. (2007). Decision neuroscience new directions in studies of judgment and decision making. Current Directions in Psychological Science, 16 (3), 151-155.

Silva, M. V. (2007). Processo de ensino-aprendizagemtreinamento no futsal: influência no conhecimento tático processual. Dissertação de Mestrado, EEFFTO, UFMG.

Solà, J.S. (1998). Formación cognoscitiva y rendimiento táctico. Apunts: Educación física y deportes, (53), 33-41.

Solà, J. (2010). Inteligencia táctica deportiva: entenderla y entrenarla. Barcelona: INDE.

Tavares, F. (1993). A capacidade de decisão táctica no jogador de basquetebol. Estudo dos processos perceptivo-cognitivos em atletas seniores e cadetes. Tese de Doutorado. Universidade do Porto. Porto.

Tavares, F (2002): Análise da estrutura e dinâmica do jogo nos jogos desportivos. In: Barbanti, V; Amadio, C; Bento, J; Marques, A.(Eds.). Esporte e atividade física. Interação entre rendimento e saúde Editora Manole. São Paulo. 129-144.

Tavares, F. (2013). Jogos Desportivos coletivos: contributos para a sua análise e funcionamento. In: Ramos, V.; Saad, M. A.; Milistetd, M. (orgs.). Jogos desportivos coletivos: investigação e prática pedagógica. Coleção temas em movimento 3. Florianópolis: UDESC. 17-51.
Temprado, J.J. (1989). Prise de décision en sport: Modalités d'études et données actuelles. STAPS. Sciences et techniques des activités physiques et sportives, (19), 53-67.

Tenenbaum, G.; Bar-Eli, M. (1993). Decision making in sport: A cognitive perspective. Handbook of research on sport psychology. New York: Macmillan, 171-192.

Thomas, K. T. (1994). The development of sport expertise: From Leeds to MVP legend. Quest, 46 (2), 199-210.

Thomas, K.; Thomas, J. (1994). Developing Expertise in Sport: The relation of Knowledge and Performance. Journal of Sport Psychology, 25: 295-312.

Thomas, K.T., Gallagher, J.D.; Thomas, J.R. (2001). Motor development and skill acquisition during childhood and adolescence. In: Singer, R. N.; Hausenblas, H.A.; Janelle, C.M. (Eds.). Handbook of Sport Psychology (Second Edition). John Wiley \& Sons, INC.

Vestberg, T.; Gustafson, R.; Maurex, L.; Ingvar, M.; Petrovic, P. (2012). Executive functions predict the success of top-soccer players. PloS one, 7 (4), e34731. Williams, A.M.; Davids, K.; Burwitz, L.; Williams, J.G. (1993). Cognitive knowledge and soccer performance. Perceptual and Motor Skills, 76 (2), 579-593.

\section{VIII - MODELOS DE ENSEÑANZA DE LA TÁCTICA DEPORTIVA}

Alarcón, F.; Cárdenas, D.; Miranda, M.T.; Ureña, N. (2009). Los modelos de enseñanza utilizados en los deportes colectivos. Investigación educativa, 13 (3), 101-128.

Allison, S.; Thorpe, R. (1997). A comparison of the effectiveness of two approaches to teaching games within physical education. A skills approach versus a games for understanding approach. British Journal of Physical Education, 28 (3), 9-13.

Araújo, D.; Davids, K. (2009). Ecological approaches to cognition and action in sport and exercise: Ask not only what you do, but where you do it. International Journal of Sport Psychology, 40 (1), 5-37.

Araújo, D.; Travassos, B.; Torrents, C.; Vives, M. (2011). La toma de decisiones en el deporte escolar. Un ejemplo aplicado al fútbol. Innovació en Educació Física; 3 (2):1-7.

Ausubel, D. (1982) Psicología evolutiva. Un punto de vista cognoscitivo. México: Trillas.

Avilés, C.; Ruiz-Pérez, L.; Navia, J.; Rioja, N.; Sanz, D. (2014). La pericia perceptivo-motriz y cognición en el 
deporte: del enfoque ecológico y dinámico a la enacción. Anales De Psicología, 30 (2), 725-737.

Bardy, B. G. (2011). Learning new skills in multimodal enactive environments. In: BIO Web of Conferences, 1 , 00008.

Bayer, C. (1986). La Enseñanza de los juegos deportivos colectivos. Hispano europea.

Beltrán, J.; García-Alcaniz, E., Moraleda, M.; Calleja, G.; Santiuste, V. (1992). Psicología de la educación. Salamanca: Eudema.

Bertalanffy, L.V. (1976). Teoría general de los sistemas. Fondo de Cultura Económica de España.

Blázquez, D. (1995). Métodos de enseñanza de la práctica deportiva. La iniciación deportiva y el deporte escolar, 251-286.

Boyd, L. A.; Winstein, C. J. (2006). Explicit information interferes with implicit motor learning of both continuous and discrete movement tasks after stroke. Journal of Neurologic Physical Therapy, 30 (2), 46-57.

Bronfenbrenner, U. (1979). Contexts of child rearing: Problems and prospects. American Psychologist, 34 (10), 844-850.

Brooker, R.; Kirk, D.; Braiuka, S.; Bransgrove, A. (2000). Implementing a game sense approach to teaching junior high school basketball in a naturalistic setting. European Physical Education Review, 6 (1), 726.

Bunker, D; Thorpe, R. (1982) A model for the teaching of games in secondary schools. Bulletin of Physical Education, 18 (1), 40-44.

Chow, J. Y.; Davids, K.; Hristovski, R.; Araújo, D.; Passos, P. (2011). Nonlinear pedagogy: Learning design for self-organizing neurobiological systems. New Ideas in Psychology, 29 (2), 189-200.

Contreras, O. (1998). Didáctica de la Educación Física. Un enfoque constructivista. Barcelona: INDE.

Contreras, O.; de la Torre, E.; Velázquez, R. (2001). Iniciación deportiva. Madrid: Síntesis.

Côté, J.; Baker, J.; Abernethy, B. (2007). Practice and play in the development of sport expertise. Handbook of sport psychology, 3, 184-202.

da Costa, I.T.; Greco, P.J.; Mesquita, I.; Garganta, J. (2010). O teaching games for understanding (Tgfu) como modelo de ensino dos jogos desportivos coletivos. Revista Palestra, 10, 69-77.

Davids, K., Button, C. y Bennett, S. (2008). Dynamics of skill acquisition: A constraints-led approach. Champaign, IL: Human Kinetics.

Devís, J.; Peiró, C. (1995). Enseñanza de los deportes de equipo: la comprensión en la iniciación de los juegos deportivos. La iniciación deportiva y el deporte escolar, 333-350.

Devís, J.; Sánchez, R. (1996). La enseñanza alternativa de los juegos deportivos: antecedentes, modelos actuales de iniciación y reflexiones finales. Aprendizaje deportivo, 159-181.

di Paolo, E.A.; Rohde, M.; de Jaegher, H. (2010). Horizons for the enactive mind: Values, social interaction, and play. Enaction: Towards a new paradigm for cognitive science, 33-87.

Fajen, B.R.; Riley, M.A.; Turvey, M.T. (2009). Information, affordances, and the control of action in sport. International Journal of Sport Psychology, 40 (1), 79-107.

García Ferrando, M. (1990). Aspectos sociales del deporte. Una reflexión sociológica. Madrid: Alianza Editorial.

García López, L.M. (2001). Hacia una clasificación actualizada y unificada de los modelos alternativos de enseñanza en la iniciación deportiva. Docencia e Investigación: revista de la Escuela Universitaria de Magisterio de Toledo, 26 (11), 31-42.

Garganta, J. (1998). O ensino dos jogos desportivos coletivos: perspectivas e tendências. Movimento. Porto Alegre. 4 (8), 19-26.

Garganta, J. (2002). O treino da táctica e da técnica nos jogos desportivos à luz do compromisso cogniçãoacção. In: Barbanti, V.; Amadio, A.; Bento, J; Marques, A. (eds.). Esporte e atividade física: interação entre rendimento e qualidade de vida. São Paulo: Manole, 281-306.

Garganta, J. (2004). A formação estratégico-tática nos jogos desportivos de oposição e cooperação. In: Gaya, A.; Marques, A.; Tani, G. (eds.) Desporto para crianças e jovens. Razões e finalidades. Porto Alegre: Editora UFRGS, 217-233.

Garganta, J.; Gréhaigne, J.F. (1999). Abordagem sistémica do jogo de Futebol: moda ou necessidade? Movimento (ESEF/UFRGS), 5 (10), 40-50.

Gibson, J. J. (1978). The ecological approach to the visual perception of pictures. Psychology Press.

Giménez, A.M. (2005). Técnicas de enseñanza en la iniciación al baloncesto. Barcelona: INDE.

Graça, A. (2014). Sobre as questões do quê ensinar e aprender em educação física. Professor de Educação Física: Fundar e dignificar a profissão. Porto: Editora FADEUP. 93-117.

Graça A, Oliveira J (eds.) (1995). O ensino dos jogos desportivos. Centro de Estudos dos Jogos Desportivos, Faculdade de Ciências do Desporto e de Educação Física da Universidade do Porto, Porto. 
Graça, A.; Mesquita, I. (2007). A investigação sobre os modelos de ensino dos jogos desportivos. Revista Portuguesa de Ciências do Desporto, 7 (3), 401-421. Graça, A.; Mesquita, I. (2009). Modelos instrucionais no Ensino do Desporto. Pedagogia do Desporto, 39-68. Greco, P.J. (2006). Conhecimento técnico-tático: o modelo pendular do comportamento e da ação tática nos esportes coletivos. Revista Brasileira de Psicologia do Esporte e do Exercício, 107-129.

Greco, P.J. (2007). Tomada de decisão nos jogos esportivos coletivos: o conhecimento tático-técnico como eixo de um modelo pendular. Revista Portuguesa de Ciências do Desporto, 7 (Supl 1), 16.

Greco, P.J. (2013). Capacidade de jogo e aprendizagem tática nos modelos de ensinoaprendizagem incidental. In: do Nascimento, J. V.; Tavares, F. (orgs.) Jogos desportivos: formação e investigação. Coleção temas em movimento 4. Florianópolis: UDESC. 485-512.

Greco, P.J.; Benda, R.N. (1998). Iniciação esportiva universal: da aprendizagem motora ao treinamento técnico. Belo Horizonte: UFMG, 1, 230.

Greco, P.J.; Benda, R.N. (2006). Iniciação aos esportes coletivos: uma escola da bola para crianças e adolescentes. Modalidades esportivas coletivas. Rio de Janeiro: Guanabara Koogan, 180-193.

Greco, P.J.; Memmert, D.; Morales, J.C. (2010). The effect of deliberate play on tactical performance in basketball. Perceptual and motor skills, 110 (3), 849856.

Greco, P.J.; Silva, S.A.; Santos, R.L. (2009). Organização e desenvolvimento do esporte no Programa Segundo Tempo. Fundamentos Pedagógicos do Programa Segundo Tempo. Da reflexão a prática. Maringá: EdUEM. 163-206.

Gréhaigne, J. F., Wallian, N. y Godbout, P. (2005). Tactical-decision learning model and students' practices. Physical Education and Sport Pedagogy, 10 (3), 213-224.

Griffin, L.L.; Patton, K. (2005). Two decades of Teaching Games for Understanding: looking at the past, present, and future. Teaching Games for Understanding: Theory, research, and practice, 1-17.

Hernández Moreno, J. (1994). Fundamentos del deporte: Análisis de la estructura del juego deportivo. Barcelona: INDE.

Hernández Moreno, J. (2000). La iniciacion a los deportes desde su estructura y su dinámica. Barcelona: INDE.

Hernández Moreno, J. (2005). Analisis de las estructuras del juego deportivo. Barcelona: INDE.
Jiménez, F. (2002). Estudio praxiológico de las estructuras de las situaciones de enseñanza en los deportes de cooperación/oposición de espacio común y participación simultánea: balonmano y fútbol sala. Tesis doctoral. Las Palmas de Gran Canaria: ULPGC. Kirk, D.; MacPhail, A. (2002). Teaching games for understanding and situated learning: Rethinking the Bunker-Thorpe model. Journal of Teaching in Physical Education, 21 (2), 177-192.

Kröger, C.; Roth, K. (2002). Escola da Bola: um ABC para iniciantes nos jogos esportivos. São Paulo: Phorte. Kröger, C, Roth, K (2005). Escola da bola. São Paulo: Phorte.

Lasierra, G.; Lavega, P. (1993): 1015 juegos y formas jugadas de iniciación a los deportes de equipo. Barcelona: Paidotribo.

Launder, A. G. (2001). Play practice: The games approach to teaching and coaching sports. Human Kinetics.

Mahlo, F. (1969). L'acte tactique en jeu. Paris: Vigot Freres.

McNeill, M.C.; Fry, J.M.; Wright, S.C.; Tan, W.K.C.; Tan, K.S.S.; Schempp, P. G. (2004). 'In the local context': Singaporean challenges to teaching games on practicum. Sport, Education and Society, 9 (1), 3-32.

Memmert, D.; Roth, K. (2007). The effects of nonspecific and specific concepts on tactical creativity in team ball sports. Journal of Sports Sciences, 25 (12), 1423-1432.

Menezes, R. P. (2012). Contribuições da concepção dos fenômenos complexos para o ensino dos esportes coletivos. Motriz rev. educ. fís. (Impr.), 18 (1), 34-41.

Mesquita, I. (2013). Perspectiva construtivista da aprendizagem no ensino do jogo. In: do Nascimento, J. V.; Tavares, F. (orgs.) Jogos desportivos: formação e investigação. Coleção temas em movimento 4. Florianópolis: UDESC. 103-131.

Metzler, M. W. (2005). Implications of models-based instruction for research on teaching: $A$ focus on teaching games for understanding. Teaching Games for Understanding: theory, research, and practice. Human Kinetics, Champaign, IL, 183-197.

Mitchell, S.A.; Oslin, J.L.; Griffin, L.L. (2013). Teaching sport concepts and skills: A tactical games approach for ages 7 to 18. Human Kinetics.

Mondoni, M. (2002). Las tres" C" en el Minibasket (I). Clinic: Revista técnica de baloncesto, 15 (59), 4-9.

Mortágua, L.; Peñas, C.L. (2007). A avaliação do rendimento individual em desportos de invasão na educação física. A participação dos alunos do ensino básico numa perspectiva de coavaliação. In: $1^{\circ}$ 
Congresso Internacional de Jogos Desportivos. Porto: FADEUP.

Musch, E.; Mertens, B.; Timmers, E.; Mertens, T.; Graça, A.; Taborsky, F.; Remy, C.; de Clercq, D.; Multael, M.; Vonderlynck, V. (2002). An innovative didactical invasion games model to teach basketball and handball, presented on cd. In: 7th Annual Congress of the European College of Sport Science.

Musch, E.; Graça, A.; Pinto, D.; Mertens, B., Multael, M.; Timmers, E.; Meertens, T.; Taborsky, F.; Remy, C.; Vonderlynck, V.; de Clercq, D. (2006). Modelo de competência nos jogos de invasão: Uma ferramenta didáctica para o ensino do basquetebol. Estudos CEJD, 6, 7-28.

Newell, K. M. (1986). Constraints on the development of coordination. Motor development in children: Aspects of coordination and control, 34, 341-360.

Parlebás, P. (1986). Activités physiques et éducation motrices. Paris: Revue Éducation Physique et Sport.

Parlebas, P. (2001). Léxico de praxiología motriz. España, Paidotribo.

Perales, J.C.; Cárdenas, D.; Courel, J.; Piñar, M. I.; Sánchez, G. (2011). El efecto diferencial de la instrucción incidental e intencional en el aprendizaje de las condiciones para la decisión de tiro en baloncesto. Revista de psicología del deporte, 20 (2), 729-745.

Penelaud, O. (2010). Le paradigme de I"énaction aujourd"hui: Apports et limites d"une théorie cognitive " révolutionnaire ». Revue Transdisciplinaire de Plasticité Humaine, 18, 1-38.

Raab, M. (2003). Decision making in sports: Influence of complexity on implicit and explicit learning. International Journal of Sport and Exercise Psychology, 1 (4), 406-433.

Raab, M.; Johnson, J. (2008). Implicit learning as a means to intuitive decision making in sports. Intuition in judgment and decision making, 119-133.

Reverdito, R.; Scaglia, A.; Montagner, P. (2013). Pedagogia do esporte: aspectos conceituais da competição e estudos aplicados. São Paulo: Phorte.

Riera, J. (1995). Análisis de la táctica deportiva. Apunts. Educación Física y Deportiva, 40, 47-60.

Rink, J., French, K. Werner, P. (1991). Tactical awareness as the focus for ninth grade badminton. In: Higher Education World Congress. Congreso Mundial de Atlanta. International Association for Physical Education (AIESEP). Georgia.

Rink, J. E.; French, K.E.; Tjeerdsma, B.L. (1996). Foundations for the learning and instruction of sport and games. Journal of teaching in Physical Education, 15, 399-417.
Romero, S. (2001). Formación deportiva: nuevos retos en educación. Universidad de Sevilla.

Roth, K.; Kroger, C.; Memmert, D. (2002). Ballschule Rueckschlagspiele. Schorndorf; Germany: Hofmann.

Rovegno, I.; Nevett, M.; Babiarz, M. (2001). Learning and teaching invasion-game tactics in 4th grade: Introduction and theoretical perspective. Journal of Teaching in Physical Education, 20 (4), 341-351.

Ruiz, L.M. (1996). Iniciación en los deportes o el desarrollo de la competencia deportiva en el medio escolar: ideas para una reflexión. A. Díaz Suárez (Comp.) El deporte en Educación Primaria, 143-152.

Sánchez Bañuelos, F. (1986) Bases para una didáctica de la Educación Física y el Deporte. Madrid: Gymnos.

Schmidt, R. A. (1975). A schema theory of discrete motor skill learning.Psychological review, 82 (4), 225260.

Shea, C.H.; Wulf, G. (2005). Schema Theory: a critical appraisal and reevaluation. Journal of motor Behavior, 37 (2), 85-102.

Siedentop, D. (1994). Sport Education: Quality P.E. through positive sport experiences. Champaign, IL: Human Kinetics.

Sola, J. (2005). Tècnica, Tàctica $i$ Estratègia. Un enfocament funcional. Tesis Doctoral. Departament de Psicologia Bàsica, Evolutiva i de l'Educació, Universitat Autònoma de Barcelona.

Solà, J. (2010). Inteligencia táctica deportiva: entenderla y entrenarla. Barcelona: INDE.

Tavares, F. (1993). A capacidade de decisão táctica no jogador de basquetebol. Estudo dos processos perceptivo-cognitivos em atletas seniores e cadetes. Tese de Doutorado. Universidade do Porto. Porto.

Tavares, F.; Greco, P.; Garganta, J. (2006). Perceber, conhecer, decidir e agir nos jogos desportivos coletivos. In: Tani, G.; Bento, J.; Petersen, R. (eds.). Pedagogia do desporto, Rio de Janeiro: Guanabara Koogan. 284298.

Teodorescu, L. (1984). Problemas de teoria e metodologia nos jogos desportivos. Lisboa: Livros Horizonte.

Teodorescu, L. (1977). Theorie et methodologie des jeux sportifs. Paris: Français Reunits.

Thorpe, R.; Bunker, D. (1996). A changing focus in games teaching. In: Almond, L. (ed.). The place of physical education in schools. London: Kogan/Page, 42-71.

Thorpe, R.; Bunker, D.; Almond, L. (1986). Rethinking games teaching. Loughborough: University. 
Valenzuela, A. V. (2005). Análisis de los cambios producidos en la metodología de la iniciación deportiva. Apunts: Educación física y deportes, (79), 59-67.

Varela, F.; Rosch, E.; Thompson, E. (2005). De cuerpo presente: Las ciencias cognitivas y la experiencia humana ( $3^{\mathrm{a}}$ reimp.). Barcelona: Gedisa.

Vygotsky, L.S. (1979). El desarrollo de los procesos psicológicos superiores. Barcelona: Crítica.

Warren, W. (2006). The dynamics of perception and action. Psychological Review, 113 (2), 358-389.

Werner, P.; Thorpe, R.; Bunker, D. (1996). Teaching Games for Understanding: evolution a Model. Joperd, 67 (1), 28-33.

\section{IX - MÉTODOS DE ABORDAJE DE LOS JUEGOS DEPORTIVOS COLECTIVOS}

Alonso, M.C.; Ibáñez, S. (2010). La planificación de los contenidos de entrenamiento de baloncesto en equipos de iniciación [Planning the contents of training in early age basketball teams]. E-balonmano.com: Revista de Ciencias del Deporte, 6 (1), 49-65.

Barreto. H. (2001). Ensino do Basquetebol no ambiente do jogo. In Janeira, A.; Graça, A.; Pinto, D.; Brandao, E. Tendências actuais da investiçao em basquetebol. Porto: Universidade do Porto, 195-202.

Gama Filho, J. G. (2001). Metodologia do Treinamento técnico tático no futebol. Temas atuais VI em Educação Física e esportes. Belo Horizonte: Health, 86-106.

García, S.; Rodríguez, A.; Garzón, A. (2011). Conceptualización de inteligencia táctica en fútbol: Consideraciones para el desarrollo de un instrumento de evaluación en campo desde las funciones ejecutivas. Cuadernos de psicología del deporte, 11 (1), 69-78.

Garganta, J. (1997). Modelação táctica do jogo de Futebol: estudo da organização ofensiva em equipas de alto rendimento. Tese de doutoramento - FCDEF, Universidade do Porto, Porto.

Garganta, J. (1998). O ensino dos jogos desportivos colectivos. Perspectivas e tendências. Movimento (ESEF/UFRGS), 4 (8), 19-27.

Garganta, J. (2002). O treino da táctica e da técnica nos jogos desportivos à luz do compromisso cogniçãoacção. In: Barbanti, V.; Amadio, A.; Bento, J; Marques, A. (eds.). Esporte e atividade física: interação entre rendimento e qualidade de vida. São Paulo: Manole, 281-306.
Garganta, J.; Gréhaigne, J. (1999). Abordagem sistêmica do jogo de futebol: moda ou necessidade? Movimento (ESEF/UFRGS), 5 (10), 40-50.

Giménez, A. M. (2005). Técnicas de enseñanza en la iniciación al baloncesto. Zaragoza: Inde.

Graça, A.; Pinto, D. (2004). Por un jogo melhor jogado. Gostar de basquetebol. Ensinar a jogar e aprender jogando, 195-212.

Greco, P.J. (1988). Handball: La formación de jugadores inteligentes. Stadium, 22 (128), 22-30.

Greco, P.J. (1995). O ensino do comportamento tático nos Jogos Esportivos coletivos: Aplicação no Handebol. (Tese de Doutorado - Departamento de Psicologia Educacional - Faculdade de Educação). Campinas (SP) Universidade Estadual de Campinas. Greco, P.J. (1997). Sistematização do processo de ensino-aprendizagem-treinamento tático nos jogos esportivos coletivos. Temas Atuais em Educação Física e Esportes II. Belo Horizonte: Cultura, 43-57.

Greco, P.J. (1998). Iniciação esportiva universal: metodologia da iniciação esportiva na escola e no clube. Belo Horizonte: UFMG, 2, 305.

Greco, P.J. (2013). Capacidade de jogo e aprendizagem tática nos modelos de ensinoaprendizagem incidental. In: do Nascimento, J. V.; Tavares, F. (orgs.) Jogos desportivos: formação $e$ investigação. Coleção temas em movimento 4. Florianópolis: UDESC. 485-512.

Greco, P.J.; Benda, R.N. (1998). Iniciação esportiva universal: da aprendizagem motora ao treinamento técnico. Belo Horizonte: UFMG, 1, 230.

Greco, P.J.; Benda, R. (2005) Iniciação esportiva universal e escola da bola: uma integração das duas propostas. In: Garcia, E.; Lemos, K. (orgs.). Temas atuais $X$ em educação física e esportes. Belo Horizonte: Health, 33-62.

Gréhaigne, J.F., Wallian, N.; Godbout, P. (2005). Tactical-decision learning model and students' practices. Physical Education and Sport Pedagogy, 10 (3), 213-224.

Ibáñez, S.J. (2000). La enseñanza del baloncesto dentro del contexto educativo. Habilidad motriz: Revista de ciencias de la actividad física y del deporte, (15), 1221.

Ibáñez, S.J. (2008). La planificación y el control del entrenamiento técnico-táctico en baloncesto. In: Terrados, N.; Calleja, J. (coord.). Fisiología, entrenamiento y medicina del baloncesto. Barcelona: Paidotribo, 299-313.

Iglesias, D.; Ramos, L.A.; Fuentes, J.P.; Sanz, D.; del Villar, F. (2003). El conocimiento y la toma de 
decisiones en los deportes de equipo: una revisión desde la perspectiva cognitiva. Revista de Entrenamiento Deportivo, 17 (2), 5-11.

Kröger, C.; Roth, K. (2002). Escola da Bola: um ABC para iniciantes nos jogos esportivos. São Paulo: Phorte. López Ros, V. (2011). Operaciones cognitivas en la iniciación deportiva. El pensamiento táctico. Revista Movimiento Humano, (1), 59-74.

Memmert, D. (2015). Teaching Tactical Creativity in Sport: Research and Practice. Routledge.

Menezes, R. P. (2012). Contribuições da concepção dos fenômenos complexos para o ensino dos esportes coletivos. Motriz rev. educ. fís. (Impr.), 18 (1), 34-41.

Mesquita, I. (2006). Ensinar bem para aprender melhor o jogo de voleibol. In: Tani, G.; Bento, J.O.; Petersen, R.D. (eds.). Pedagogia do desporto. Rio de Janeiro: Guanabara Koogan, 327-344.

Mitchell, S. A.; Oslin, J. L.; Griffin, L. L. (2003). Sport foundations for elementary physical education: $A$ tactical games approach. Champaign, IL: Human Kinetics.

Morales, J.C.P.; Greco, P.J. (2007). A influência de diferentes metodologias de ensino-aprendizagemtreinamento no basquetebol sobre o nível de conhecimento tático processual. Revista Brasileira de Educação Física e Esporte, 21 (4), 291-299.

Morales, J.C.P.; Silva, E.G.; da Silva Matias, C.J.A.; Reis, R.A.; Greco, P.J. (2009). Processo de ensinoaprendizagem-treinamento no mini-basquetebol. Fitness \& Performance Journal, 8 (5), 349-359.

Musch, E.; Mertens, B. (1991). L'enseignement des sports collectifs: Une conception elaborée a l'isep de l'université de gand. Revue de l'Education Physique, 31 (1), 7-20.

Paula, A. (2000). Processo de validação de teste para avaliar a capacidade de decisão tática e o conhecimento declarativo no voleibol: situações de ataque de rede. (Mestrado em Educação Física: Treinamento Esportivo)-Escola de Educação Física, Fisioterapia e Terapia Ocupacional da Universidade Federal de Minas Gerais, Belo Horizonte.

Reber, A.S. (1989). Implicit learning and tacit knowledge. Journal of experimental psychology: General, 118 (3), 219-235.

Sánchez, M.S.; Fuentes-Guerra, F.J.G.; Buñuel, P.S.L.; Ibáñez, S.J.; Robles, Á.S. (2006). El desarrollo de la pericia en baloncesto: claves para la formación del jugador de alto rendimiento. Apunts: Educación física y deportes, (83), 52-60.

Silva, M.V.; Greco, P.J. (2009). A influência dos métodos de ensino-aprendizagem-treinamento no desenvolvimento da inteligência e criatividade tática em atletas de futsal. Revista Brasileira de Educação Física e Esporte, São Paulo, 23 (3), 297-307.

Solà, J. (2010). Inteligencia táctica deportiva: entenderla y entrenarla. Barcelona: INDE.

Tallir, I.B.; Lenoir, M.; Valcke, M.; Musch, E. (2007). Do alternative instructional approaches result in different game performance learning outcomes? Authentic assessment in varying game conditions. International journal of sport psychology, 38 (3), 263-282.

Tavares, F. (2013). Jogos Desportivos coletivos: contributos para a sua análise e funcionamento. In: Ramos, V.; Saad, M. A.; Milistetd, M. (orgs.). Jogos desportivos coletivos: investigação e prática pedagógica. Coleção temas em movimento 3. Florianópolis: UDESC. 17-51.

Velez, D.; López, M. (2000). El aprendizaje de los deportes colectivos a través de los juegos con normas. Habilidad motriz. Revista de Ciencias de la Actividad Física y del Deporte, 15, 22-29.

Zaragoza, J (1995). Oponerse para progresar. Clinic: Revista técnica de baloncesto, (29) 12-14.

\section{X - ANÁLISIS DEL JUEGO}

Araújo, D. (2009). O desenvolvimento da competência táctica no desporto: o papel dos constrangimentos no comportamento decisional. Motriz rev. educ. fís. (Impr.), 15 (3), 537-540.

Bartlett, R.; Button, C.; Robins, M.; Dutt-Mazumder, A.; Kennedy, G. (2012). Analysing team coordination patterns from player movement trajectories in soccer: methodological considerations. International Journal of Performance Analysis in Sport, 12 (2), 398-424.

Dufour, W. (1989). Les techniques d'observation du comportement moteur. Revue Education Physique et Sport, 217, 68-73.

Franks, I.M.; Goodman, D. (1986). A systematic approach to analysing sports performance. Journal of Sports Sciences, 4 (1), 49-59.

Garganta, J. (1997). Modelação táctica do jogo de Futebol: estudo da organização ofensiva em equipas de alto rendimento. Tese de doutoramento - FCDEF, Universidade do Porto, Porto.

Garganta, J. (2000). O treino da táctica e da estratégia nos jogos desportivos. Horizontes e órbitas no treino dos jogos desportivos. Porto: CEJD, 51-61.

Garganta, J. (2001). A análise da performance nos jogos desportivos. Revisão acerca da análise do jogo. 
Revista Portuguesa de Ciências do Desporto, 1 (1), 5764.

Garganta, J. (2002). O treino da táctica e da técnica nos jogos desportivos à luz do compromisso cogniçãoacção. In: Barbanti, V.; Amadio, A.; Bento, J; Marques, A. (eds.). Esporte e atividade física: interação entre rendimento e qualidade de vida. São Paulo: Manole, 281-306.

Garganta, J. (2004). A formação estratégico-tática nos jogos desportivos de oposição e cooperação. In: Gaya,

A.; Marques, A.; Tani, G. (eds.) Desporto para crianças e jovens. Razões e finalidades. Porto Alegre: Editora UFRGS, 217-233.

Garganta, J. (2007). Modelação táctica em jogos desportivos: a desejável cumplicidade entre pesquisa, treino e competição. Revista Portuguesa de Ciências do Desporto, 7 (supl 1), 9-17.

Glazier, P.S. (2010). Game, set and match? Substantive issues and future directions in performance analysis. Sports Medicine, 40 (8), 625-634.

Graça, A.; Mesquita, I. (2007). A investigação sobre os modelos de ensino dos jogos desportivos. Revista Portuguesa de Ciências do Desporto, 7 (3), 401-421.

Grehaigne, J.F. (1992). L'organisation du jeu en football. Actio.

Gréhaigne, J.F.; Godbout, P.; Bouthier, D. (2001). The teaching and learning of decision making in team sports. Quest, 53 (1), 59-76.

Grosgeorge, B.; Dupuis, P.; Vérez, B. (1991). Acquisition et analyse de déplacements en sports collectifs. Science et Motricité, 13, 27-38.

Hopper, T. (2007). Teaching tennis with assessment 'for'and 'as' learning: A TGfU net/wall example. Physical and Health Education Journal, 73 (3), 22-28.

Hughes, M.; Evans, S.; Wells, J. (2001). Establishing normative profiles in performance analysis. International Journal of Performance Analysis in Sport, 1 (1), 1-26.

Lamas, L. (2012). Modelagem estratégico-tática em esportes coletivos de invasão: aplicação ao basquetebol. Tese (Doutorado) - Escola de Educação Física e Esporte, Universidade de São Paulo, São Paulo.

Lamas, L.; Seabra, F. (2006). Estratégia, tática e técnica nas modalidades esportivas coletivas: conceitos e aplicações. In: De Rose Jr., D. Modalidades esportivas coletivas. Rio de Janeiro: Guanabara Koogan, 40-59.

Lamas, L.; Barrera, J.; Otranto, G.; Ugrinowitsch, C. (2014). Invasion team sports: strategy and match modeling. International Journal of Performance Analysis in Sport, 14 (1), 307-329.

Lamas, L.; de Rose Jr., D.; Santana, F.; Rostaiser, E.; Negretti, L.; Ugrinowitsch, C. (2011). Space creation dynamics in basketball offence: validation and evaluation of elite teams International Journal of Performance Analysis in Sports, 11, 71-84.

Lames, M.; Hansen, G. (2001). Designing observational systems to support top-level teams in game sports. International journal of performance analysis in sport, 1 (1), 83-90.

Laporta, L.; Nikolaidis, P.; Thomas, L.; Afonso, J. (2015). The Importance of Loosely Systematized Game Phases in Sports: The Case of Attack Coverage Systems in High-Level Women's Volleyball. Montenegrin Journal of Sports Science and Medicine, 4 (1), $19-24$.

Marcelino, R.; Sampaio, J.; Mesquita, I. (2011). Investigação centrada na análise do jogo: da modelação estática à modelação dinâmica. [Research on the game analysis: from static to dynamic modeling]. Revista Portuguesa De Ciências Do Desporto, 11 (1), 481-499.

Martín-Acero, R. y Lago, C. (2005). Deportes de equipo. Comprender la complejidad para elevar el rendimiento. Barcelona: INDE.

Matias, C.J.; Greco, P.J. (2013). O conhecimento tático declarativo dos levantadores campeões de voleibol. Motriz rev. educ. fís. (Impr.), 19 (1), 184-194.

Menaut, A. (1983). Jeux sportiffs collectifs: niveux de jeu et modéle opératorie. Motricité Humaine, 2, 15-21.

Oliveira, J. (1993). A análise do jogo em basquetebol. In: Bento,J.; Marques, A. (Eds.). A ciência do desporto, a cultura e o Homem, 297-306.

Riera, J. R. (1995). Estrategia, táctica y técnica deportivas. Apunts: educación física y deportes, (39), 45-56.

Saad, M.A.; Nascimento, J.V. do. (2013). Jogos Desportivos coletivos: contributos para a sua análise e funcionamento. In: Ramos, V.; Saad, M. A.; Milistetd, M. (orgs.). Jogos desportivos coletivos: investigação $e$ prática pedagógica. Coleção temas em movimento 3. Florianópolis: UDESC. 151-169.

Sampaio, J.; Janeira, M. (2003). Statistical analyses of basketball team performance: understanding teams' wins and losses according to a different index of ball possessions. International Journal of Performance Analysis in Sport, 3 (1), 40-49.

Santana, F. L., Rostaiser, E.; Sherzer, E.; Ugrinowitsch, C.; Barrera, J.; Lamas, L. (2015). Space protection dynamics in basketball: Validation and application to the 
evaluation of offense-defense patterns. Motriz: Revista de Educação Física, 21 (1), 34-44.

Tavares, F. (1993). A capacidade de decisão táctica no jogador de basquetebol. Estudo dos processos perceptivo-cognitivos em atletas seniores e cadetes. Tese de Doutorado. Universidade do Porto. Porto.

Tavares, F. (2013). Jogos Desportivos coletivos: contributos para a sua análise e funcionamento. In: Ramos, V.; Saad, M. A.; Milistetd, M. (orgs.). Jogos desportivos coletivos: investigação e prática pedagógica. Coleção temas em movimento 3. Florianópolis: UDESC. 17-51.

\section{XI - INVESTIGACIÓN DE CAMPO}

Alonso, M.C.; Ibáñez, S. (2010). La planificación de los contenidos de entrenamiento de baloncesto en equipos de iniciación [Planning the contents of training in early age basketball teams]. E-balonmano.com: Revista de Ciencias del Deporte, 6 (1), 49-65.

Balyi, I. (2001). Sport system building and long-term athlete development in British Columbia. Coaches Report, 8 (1), 22-28.

Balyi, I.; Way, R.; Higgs, C. (2013). Long-term athlete development. Human Kinetics.

Costa, I.T.; Greco, P.J.; Garganta, J.; Costa, V.T.; Mesquita, I. (2011). Ensino-aprendizagem e treinamento dos comportamentos tático-técnicos no futebol. Revista Mackenzie de Educação Física e Esporte,9 (2), 41-61.

Costa, I.T.; Greco, P.J.; Garganta, J.; Costa, V.T.; Mesquita, I. (2011). Ensino-aprendizagem e treinamento dos comportamentos tático-técnicos no futebol. Revista Mackenzie de Educação Física e Esporte, 9 (2), 41-61.

Gallego, D.I.; Vélez, D.C.; López, F.A. (2007). La comunicación durante la intervención didáctica del entrenador: consideraciones para el desarrollo del conocimiento táctico y la mejora en la toma de decisiones en baloncesto. Cultura, ciencia y deporte: revista de ciencias de la actividad física y del deporte de la Universidad Católica de San Antonio, (7), 43-50.

Garganta, J. (1998). O ensino dos jogos desportivos coletivos: perspectivas e tendências. Movimento. Porto Alegre. 4 (8), 19-26.

Greco, P.J. (1995). O ensino do comportamento tático nos Jogos Esportivos coletivos: Aplicação no Handebol. (Tese de Doutorado - Departamento de Psicologia Educacional - Faculdade de Educação). Campinas (SP) Universidade Estadual de Campinas.
Greco, P.J. (2006). Conhecimento técnico-tático: o modelo pendular do comportamento e da ação tática nos esportes coletivos. Revista Brasileira de Psicologia do Esporte e do Exercício, 107-129.

Greco, P.J.; Chagas, M.H. (1992). Considerações teóricas da tática nos jogos esportivos coletivos. Revista paulista de educação física, 6 (2), 47-58.

Greco, P.J.; Memmert, D.; Morales, J.C. (2010). The effect of deliberate play on tactical performance in basketball. Perceptual and motor skills, 110 (3), 849856.

Grehaigne, J.; Godbout, P.; Bouthier, D. (1999). The foundations of tactics and strategy in team sports. Journal of teaching in physical education, 18, 159-174.

Grehaigne, J.; Godbout, P.; Bouthier, D. (2001). The teaching and learning of decision making in team sports. Quest, 53 (1), 59-76.

Hopper, T. (2007). Teaching tennis with assessment 'for'and 'as' learning: A TGfU net/wall example. Physical and Health Education Journal, 73 (3), 22-28.

Ibáñez, S.J. (2008). La planificación y el control del entrenamiento técnico-táctico en baloncesto. In: Terrados, N.; Calleja, J. (coord.). Fisiología, entrenamiento y medicina del Baloncesto. Barcelona: Paidotribo, 299-314.

Lamas, L. (2012). Modelagem estratégico-tática em esportes coletivos de invasão: aplicação ao basquetebol. Tese (Doutorado) - Escola de Educação Física e Esporte, Universidade de São Paulo, São Paulo.

Lamas, L.; Rostaiser, E.; Santana, F.; Tricoli, V.; Ugrinowitsch, C. (2011a). Diversidade e eficiência das dinâmicas de criação de espaço e grau de cooperação entre as equipes de basquetebol paulistas: efeito da faixa etária.Rev. bras. Educ. Fís. Esporte, 25 (4), 693705 .

Lamas, L.; de Rose Jr., D.; Santana, F.; Rostaiser, E.; Negretti, L.; Ugrinowitsch, C. (2011b). Space creation dynamics in basketball offence: validation and evaluation of elite teams International Journal of Performance Analysis in Sports, 11, 71-84.

Leite, N.; Sampaio, J. (2012). Long-term athletic development across different age groups and gender from Portuguese basketball players. International Journal of Sports Science and Coaching, 7 (2), 285300.

Leite, N.; Lorenzo, A.; Sampaio, J.; Gómez, M. (2011). Los contenidos de entrenamiento en baloncesto en función de las etapas de preparación deportiva a largo plazo. Revista de psicología del deporte, 20, 287-303. 
López Ros, V. (2011). Operaciones cognitivas en la iniciación deportiva. El pensamiento táctico. Revista Movimiento Humano, (1), 59-74.

Matias, C. J. (2009). O conhecimento tático declarativo e a distribuição de jogo do levantador de voleibol: da formação ao alto nível. Dissertação (Mestrado em Ciências do Esportes) - EEFFTO, UFMG, Belo Horizonte.

Mikołajec, K.; Maszczyk, A.; Zając, T. (2013). Game Indicators Determining Sports Performance in the NBA. Journal of human kinetics, 37 (1), 145-151.

Mitchell, S.; Oslin, J.; Griffin, L. (2003). Sports foundation for elementary physical education. A tactical games approach. Champaing, IL. Human Kinetics.

Nascimento, J.V. (2008). Metodologias no processo de ensino-aprendizagem-treinamento de modalidades esportivas colectivas. In: Tavares, F.; Graça, A.; Garganta, J.; Mesquita, I. (eds.). Olhares e contextos da performance nos jogos desportivos. Porto: FADEUP; 141- 148.

Nitsch, J. R. (2009). Ecological approaches to sport activity: A commentary from an action-theoretical point of view. International Journal of Sport Psychology, 40 (1), 152-176.

Paula, A. (2000). Processo de validação de teste para avaliar a capacidade de decisão tática e o conhecimento declarativo no voleibol: situações de ataque de rede. Dissertação de Mestrado. EEFFTOUFMG. Belo Horizonte.

Pereira, F., Mesquita, I.; Dos Santos Graça, A. (2010). A investigação sobre a eficácia pedagógica no ensino do desporto. Revista da Educação Física/UEM, 21 (1), 147-160.

Raab, M. (2003). Decision making in sports: Influence of complexity on implicit and explicit learning. International Journal of Sport and Exercise Psychology, 1 (4), 406-433.

Raab, M. (2015). SMART-ER: a Situation Model of Anticipated Response consequences in Tactical decisions in skill acquisition-Extended and Revised. Frontiers in psychology, 5, 1533.

Sampaio, J.; Maçãs, V. (2012). Measuring tactical behaviour in Football. International Journal of Sports Medicine, 33 (5), 395-401.

Santana, F. L., Rostaiser, E.; Sherzer, E.; Ugrinowitsch, C.; Barrera, J.; Lamas, L. (2015). Space protection dynamics in basketball: Validation and application to the evaluation of offense-defense patterns. Motriz: Revista de Educação Física, 21 (1), 34-44.

Serrabona, M. (1997). Generalizaciones sobre un proyecto de vida deportiva en el jugador de baloncesto. Revista Clinic, (37), 12-16. 


\section{ANEXOS}


ANEXO 1 - OPINIÓN DE LOS ENTRENADORES DE BASQUETBOL SOBRE LA ENSEÑANZA DEL SABER TÁCTICO EN LAS CATEGORÍAS FORMATIVAS

CUESTIONARIO SOBRE LA ENSEÑANZA DEL SABER TÁCTICO EN LAS CATEGORÍAS FORMATIVAS DE BASQUETBOL

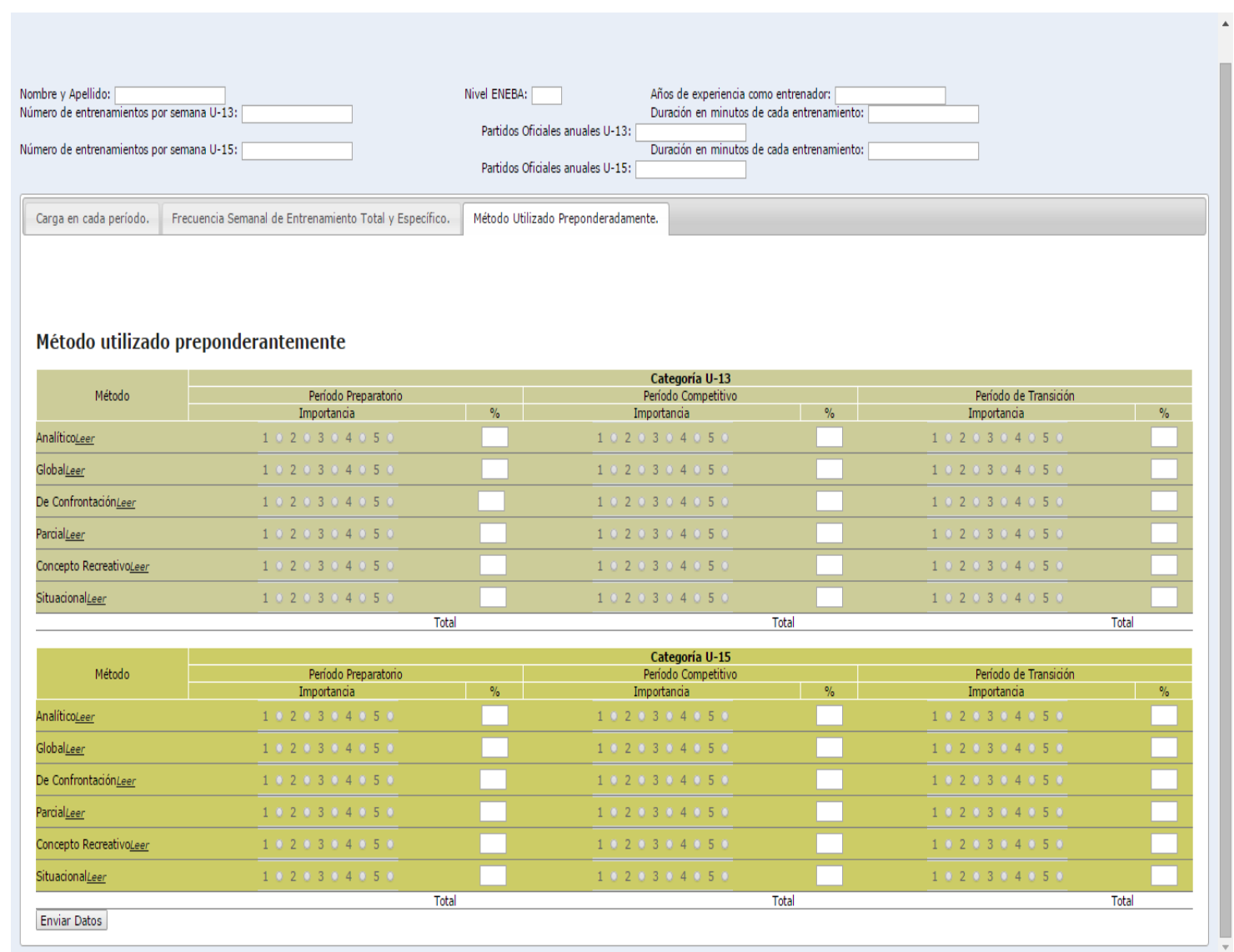




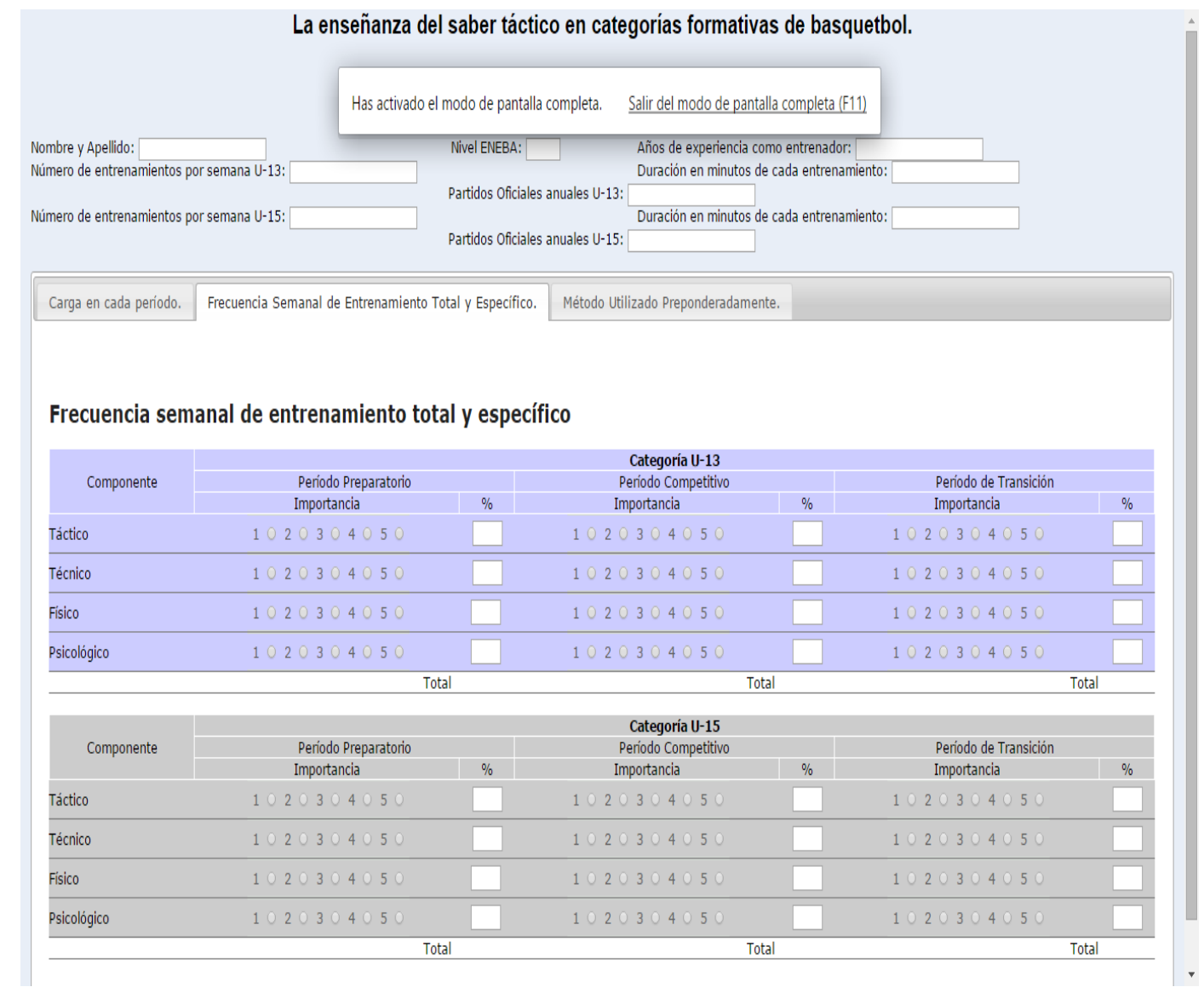

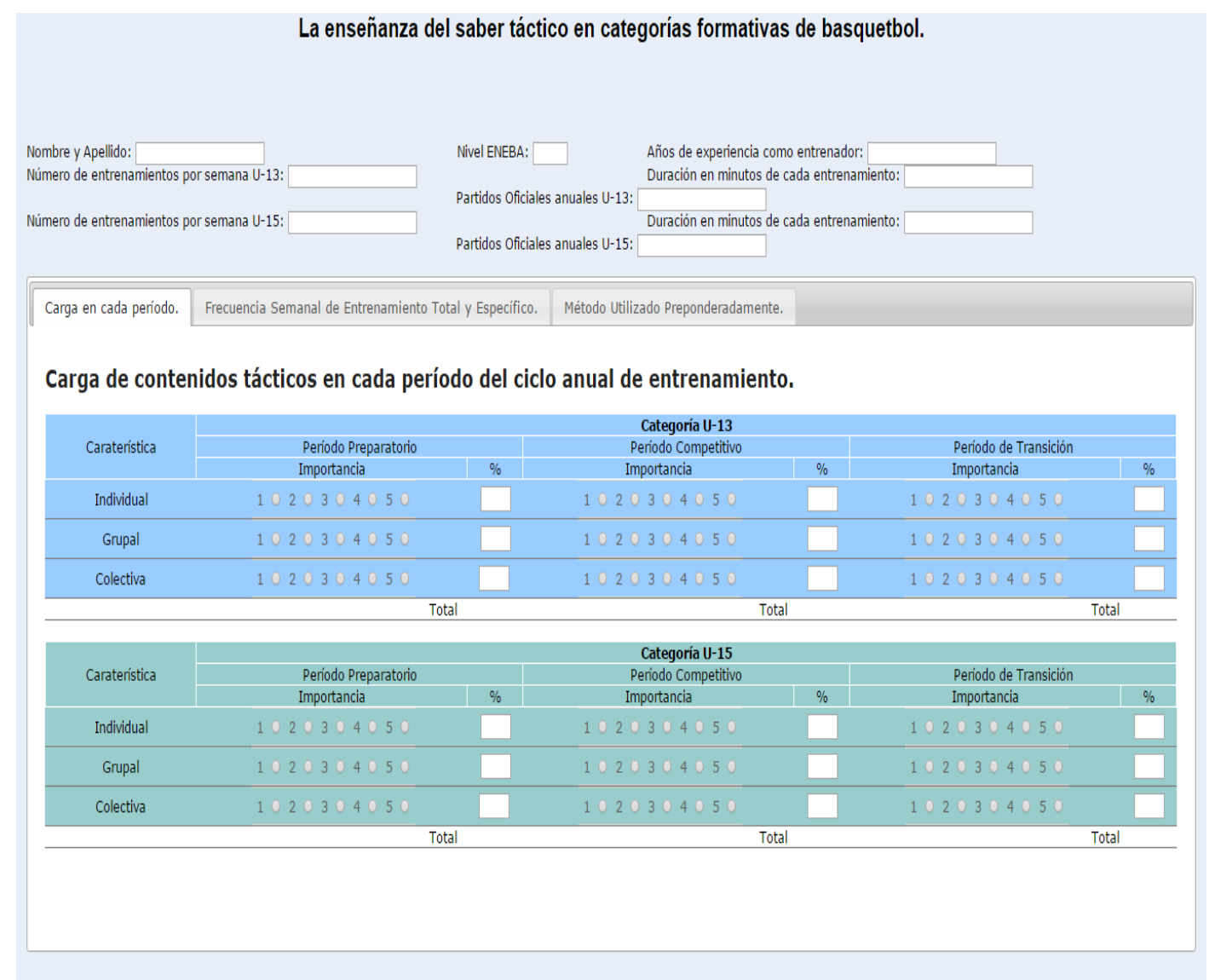




\section{ANEXO 2 - APLICACIÓN DEL SABER TÁCTICO EN CATEGORÍAS FORMATIVAS DE BASQUETBOL}

\section{CATEGORÍAS DE ANÁLISIS DEL JUEGO}

Para realizar el análisis del juego se utilizaron las DCE's (Dinámicas de Creación de Espacios) (LAMAS et al., 2011) y las DPE's (Dinámicas de Protección de Espacios) (LAMAS, 2012; SANTANA et al., 2015) propuestas y validadas en función de tres criterios: (i) el número de jugadores involucrados, lo que representa una medida objetiva dela coordinación interpersonal; (ii) el tipo de habilidad deportiva empleada, lo que describe la solución motora seleccionada frente a un determinado contexto; y (iii) el contexto de decisión, que indica la presencia o ausencia de coordinación colectiva definida a priori para que ocurra la acción de creación o protección de espacio. Las mismas se definen de la siguiente manera:

Las DCE's (Dinámicas de Creación de Espacios) son definidas como comportamientos ofensivos que tienen como objetivo crear espacio en el sector defensivo proporcionando las condiciones para que ocurra una finalización. Definiendo siete clases de dinámicas ofensivas: (i) DCBD (Desmarque con balón con drible): acciones individuales en las cuales la ventaja espacio-temporal para la finalización es creada por el jugador con balón utilizando el drible, sin la cooperación de los compañeros (ej. desplazamiento con uno o más dribles, distanciándose del defensor inmediato, seguido de la ejecución de un jump o penetración con finalización en bandeja); (ii) DCSD (Desmarque con balón sin drible): acciones individuales en las cuales la ventaja espacio-temporal para la finalización es creada por el jugador con balón sin utilizar el drible, usando solo técnicas de fintas, sin la cooperación de los compañeros (ej. finta seguida de lanzamiento); (iii) $A P e$ (Aclarado en el perímetro): el jugador con balón es aislado en el perímetro, normalmente en el área central de la media cancha ofensiva próximo a la línea de tres puntos, mientras los cuatro compañeros ocupan espacios laterales de manera que los defensores mantengan distancia del jugador con balón (ej. en los instantes finales de la posesión de balón, con el aclarado al mejor finalizador); (iv) Al (Aclarado interior): el jugador con balón es 
aislado en la zona restrictiva, mientras los cuatro compañeros ocupan espacios exteriores de manera que los defensores mantengan distancia del jugador con balón (ej. situación de alto-bajo o mismatch en el poste bajo). Tanto el APe como el Al son casos particulares de DCBD y de DCSD, dado que si bien el espacio es creado en una situación de $1 \times 1$, son considerados de forma separada por causa de la acción coordinada de todo el equipo; (v) DSB (Desmarque sin balón): acción de dos jugadores, donde uno crea el espacio y recibe el pase de su compañero (ej. situaciones de back-door); (vi) BD (Bloqueo directo): un jugador atacante se posiciona en la trayectoria del defensor, creando espacio para el jugador con balón (ej. acción de pick and roll); (vii) BI (Bloqueo indirecto): semejante al Bloqueo directo, sin embargo ninguno de los dos jugadores involucrados en la situación de bloqueo tiene posesión del balón. Luego de la interrupción de la trayectoria del defensor por el bloqueo, un tercer compañero de los jugadores de ataque pasa el balón para el jugador libre de marcación.

Mientras que las DPE's (Dinámicas de Protección de Espacios) son definidas como comportamientos defensivos que tienen como objetivo una ocupación del espacio de manera de impedir que ocurra una finalización y producir una recuperación del balón. Existiendo una relación de una DCE para diversas posibilidades de las respectivas DPE's.

Siendo las DPE's utilizadas para defender acciones de $D B C D, D C S D$ y $A P e$ las siguientes: (i) Neutro: no hay lado referencial para la penetración del atacante. De la región central del ataque hasta el lateral, el defensor mantiene su espalda siempre alineada con el cesto o paralela a la línea de fondo y los pies siempre están orientados de forma perpendicular a la línea de tres puntos. En la región de zona muerta (ej. después de una proyección imaginaria de la línea de tiro libre en dirección a la línea lateral, en dirección a la intersección de la línea de fondo con la línea lateral) la rotación corporal y la orientación de los pies son, respectivamente, perpendicular y paralela a la línea de fondo; (ii) Orientado para el fondo: el defensor orienta al atacante para el fondo de la cancha. La rotación corporal y el direccionamiento de los pies del defensor bloquean diagonalmente la progresión del atacante para la zona restrictiva (ej. negar el acceso al área próxima al cesto, desde los laterales de la cancha); (iii) Orientado para el medio: el defensor orienta al atacante para el medio de la cancha. La rotación corporal 
de defensor y el direccionamiento de sus pies bloquean diagonalmente la progresión del atacante para el fondo de la cancha.

Las DPE's utilizadas para defender acciones de Al son: (i) Por delante: el defensor se mantiene delante del atacante, sin un lado preferencial de direccionamiento; (ii) Por detrás: el defensor se mantiene atrás del atacante, sin un lado preferencial de direccionamiento; (iii) Orientado $3 / 4$ por detrás: el defensor situado con rotación corporal tal que envuelve $3 / 4$ del atacante, impidiendo el pase o el desplazamiento en la dirección de la línea de fondo; (iv) Orientado $3 / 4$ por delante: el defensor situado con rotación corporal tal que envuelve $3 / 4$ del atacante, impidiendo el pase o el desplazamiento en la dirección del centro de la zona restrictiva.

Las DPE's para defender al receptor del balón (jugador que corta) en acciones de DSB son: (i) Alejado (de la línea de pase): el atacante se desplaza y ocupa un espacio vacío sin ninguna obstrucción impuesta por el defensor, el cual lo "controla" a una distancia suficiente para no ser sobrepasado; (ii) Próximo: la línea de pase y la trayectoria de desplazamiento del atacante son obstruidas por el defensor.

Las DPE's para defender las acciones de BD y BI se caracterizan tanto para el defensor del jugador con balón como para el defensor del bloqueador.

En el caso del Bloqueo Directo, las DPE's para defender al jugador con balón son: (i) Por delante: el defensor pasa junto al atacante con balón, por delante del bloqueador, con la postura defensiva preservada y manteniéndose entre el atacante y el cesto; (ii) Por el medio: el defensor da continuidad a su trayectoria pasando entre el bloqueador y el defensor del bloqueador para seguir en la defensa del atacante con balón; (iii) Por detrás: el defensor del jugador con balón pasa por detrás del defensor del bloqueador para seguir defendiendo al jugador que recibió el bloqueo; (iv) Evitar el bloqueo: el defensor realiza una rotación corporal obstruyendo el desplazamiento del atacante en la dirección del bloqueo; (v) Cambio defensivo: el defensor del jugador con balón y el defensor del bloqueador cambian la defensa de sus respectivos atacantes; (vi) Doblaje defensivo: tanto el defensor del jugador con balón como el defensor del bloqueador defienden luego del bloqueo, momentáneamente y con elevada presión espacial, al jugador con balón. 
Asimismo, en el Bloqueo Directo, para defender al jugador que realiza el bloqueo son: (i) Contener: el defensor mantiene su posición próxima al atacante, con contacto físico imponiendo cierta restricción al posicionamiento del bloqueador atacante; (ii) Mostrarse: desplazamiento del defensor en la proyección de la posición ocupada por el atacante bloqueador, de manera de retardar la progresión del atacante con balón, cuyo defensor fue bloqueado; (iii) Alejarse: el defensor se aleja del atacante bloqueador para realizar la cobertura del defensor que fue bloqueado; (iv) Abrirse: el defensor del bloqueador se aleja de su atacante para dar paso al defensor bloqueado y retorna a su posición en la secuencia; (v) Cambio defensivo: el defensor del jugador con balón y el defensor del bloqueador cambian la defensa de sus respectivos atacantes; (vi) Doblaje defensivo: tanto el defensor del jugador con balón como el defensor del bloqueador defienden, luego del bloqueo, momentáneamente y con elevada presión espacial, al jugador con balón.

Mientras que para el Bloqueo Indirecto, en el caso de la defensa del receptor del bloqueo, las DPE's son: (i) Por delante: el defensor pasa junto al atacante por delante del bloqueador, con la postura defensiva preservada y manteniéndose entre el atacante y el cesto; (ii) Por el medio: el defensor da continuidad a su trayectoria pasando entre el bloqueador y el defensor del bloqueador para seguir en la defensa del atacante; (iii) Por detrás: el defensor del jugador que recibe el bloqueo pasa por detrás del defensor del bloqueador para seguir defendiendo al jugador que recibió el bloqueo; (iv) Evitar el bloqueo: el defensor realiza una rotación corporal obstruyendo el desplazamiento del atacante en la dirección del bloqueo; (v) Cambio defensivo: el defensor del jugador que va a recibir el bloqueo y el defensor del bloqueador cambian la defensa de sus respectivos atacantes; (vi) Doblaje defensivo: tanto el defensor del bloqueador como el defensor bloqueado defienden al atacante que recibió el bloqueo, momentáneamente y con elevada presión espacial, en caso que reciba el balón.

En el caso de la defensa del bloqueador en el Bloqueo indirecto, las DPE's utilizadas son: (i) Contener: el defensor mantiene su posición próxima al atacante, con contacto físico imponiendo cierta restricción al posicionamiento del bloqueador atacante; (ii) Mostrarse: desplazamiento del defensor en la proyección de la posición ocupada por el atacante bloqueador, de manera de 
retardar la progresión del atacante con balón, cuyo defensor fue bloqueado; (iii) Alejarse: el defensor se aleja del atacante bloqueador para realizar la cobertura del defensor que fue bloqueado; (iv) Abrirse: el defensor del bloqueador se aleja de su atacante para dar paso al defensor bloqueado y retorna a su posición en la secuencia; (v) Retrasar: el defensor del bloqueador obstruye la trayectoria del atacante bloqueado, retardando su progresión para facilitar la recuperación defensiva por parte de su defensor; (vi) Cambio defensivo: el defensor del jugador con balón y el defensor del bloqueador cambian la defensa de sus respectivos atacantes; (vii) Doblaje defensivo: tanto el defensor del bloqueador como el defensor bloqueado defienden al atacante que recibió el bloqueo, momentáneamente y con elevada presión espacial, en caso que reciba el balón.

\section{REFERENCIAS}

Lamas, L. (2012). Modelagem estratégico-tática em esportes coletivos de invasão: aplicação ao basquetebol. Tese (Doutorado) - Escola de Educação Física e Esporte, Universidade de São Paulo, São Paulo.

Lamas, L.; de Rose Jr., D.; Santana, F.; Rostaiser, E.; Negretti, L.; Ugrinowitsch, C. (2011b). Space creation dynamics in basketball offence: validation and evaluation of elite teams International Journal of Performance Analysis in Sports, $11,71-84$.

Santana, F. L., Rostaiser, E.; Sherzer, E.; Ugrinowitsch, C.; Barrera, J.; Lamas, L. (2015). Space protection dynamics in basketball: Validation and application to the evaluation of offense-defense patterns. Motriz: Revista de Educação Física, 21 (1), 34-44. 


\title{
APLICACIÓN DEL SABER TÁCTICO EN CATEGORÍAS FORMATIVAS DE BASQUETBOL
}

\author{
RELACIÓN DINÁMICAS DE CREACIÓN DE ESPACIOS - DINÁMICAS DE \\ PROTECCIÓN DE ESPACIOS
}

\begin{tabular}{|l|l|l|}
\hline N.J. & $\begin{array}{l}\text { Dinámicas de Creación de } \\
\text { Espacios }\end{array}$ & $\begin{array}{l}\text { Dinámicas de Protección de } \\
\text { Espacios }\end{array}$ \\
\hline $1 \times 1$ & $\begin{array}{l}\text { DCBD (desmarque con balón } \\
\text { con drible); DCSD (desmarque } \\
\text { con balón sin drible); APe } \\
\text { (aclarado en el perímetro) }\end{array}$ & $\begin{array}{l}\text { Neutro; Orientado para el fondo; } \\
\text { Orientado para el medio. }\end{array}$ \\
\hline $1 \times 1$ & Al (aclarado interior) & $\begin{array}{l}\text { Por delante; Por detrás; } \\
\text { Orientado 3/4 por detrás; } \\
\text { Orientado 3/4 por delante. }\end{array}$ \\
\hline $2 \times 2$ & DSB (desmarque sin balón) & $\begin{array}{l}\text { Alejado (de la línea de pase); } \\
\text { Próximo (a la línea de pase). }\end{array}$ \\
\hline $2 \times 2$ & $\begin{array}{l}\text { BD (bloqueo directo) - jugador } \\
\text { con balón }\end{array}$ & $\begin{array}{l}\text { Por delante; Por el medio; Por } \\
\text { detrás; Evitar el bloqueo; Cambio } \\
\text { defensivo; Doblaje defensivo. }\end{array}$ \\
\hline $2 \times 2$ & $\begin{array}{l}\text { BD (bloqueo directo) - jugador } \\
\text { que realiza el bloqueo }\end{array}$ & $\begin{array}{l}\text { Contener; Mostrarse; Alejarse; } \\
\text { Abrirse; Cambio defensivo; } \\
\text { Doblaje defensivo. }\end{array}$ \\
\hline $3 \times 3$ & $\begin{array}{l}\text { BI (bloqueo indirecto) - receptor } \\
\text { del bloqueo }\end{array}$ & $\begin{array}{l}\text { Por delante; Por el medio; Por } \\
\text { detrás; Evitar el bloqueo; Cambio } \\
\text { defensivo; Doblaje defensivo. }\end{array}$ \\
\hline $3 \times 3$ & $\begin{array}{l}\text { BI (bloqueo indirecto) - jugador } \\
\text { que realiza el bloqueo }\end{array}$ & $\begin{array}{l}\text { Contener; Mostrarse; Alejarse; } \\
\text { Abrirse; Retrasar; Cambio } \\
\text { defensivo; Doblaje defensivo. }\end{array}$ \\
\hline
\end{tabular}

Tabla: Dinámicas de Creación de Espacios (DCE) (LAMAS et al., 2011) y sus correspondientes Dinámicas de Protección de Espacio (DPE) (LAMAS, 2012; SANTANA et al., 2015), donde N.J. es el número de jugadores participantes. 


\section{APLICACIÓN DEL SABER TÁCTICO EN CATEGORÍAS FORMATIVAS DE BASQUETBOL}

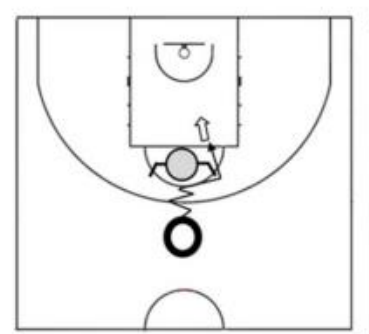

a)

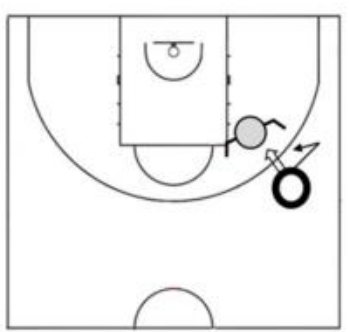

b)

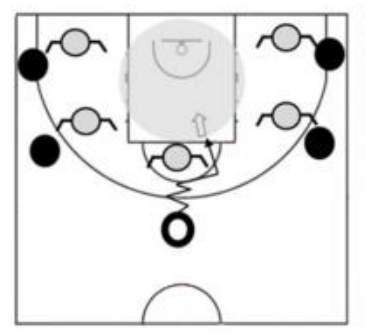

c)

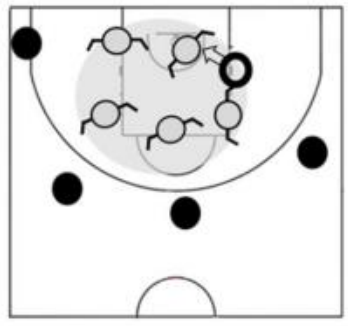

d)

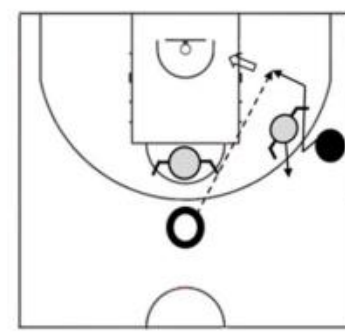

e)

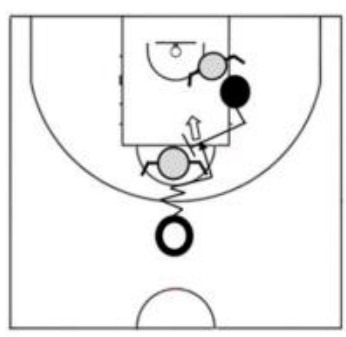

f)

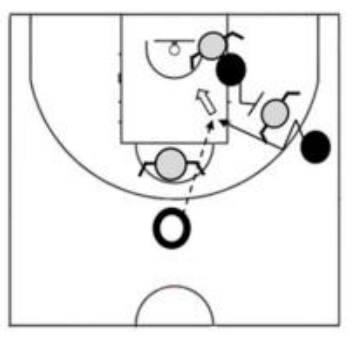

g)

Figura 1: DCE's (Dinámicas de Creación de Espacios): a) DCBD (desmarque con balón con drible); b) DCSD (desmarque con balón sin drible); c) APe (aclarado en el perímetro); d) Al (aclarado interior); e) DSB (desmarque sin balón); f) BD (bloqueo directo); g) BI (bloqueo indirecto).

Siendo:

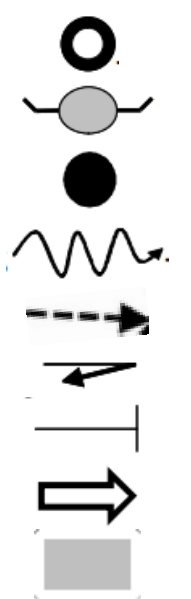

Jugador con balón

Defensor

Atacante sin balón

Desplazamiento con balón

Pase

Finta sin drible

Bloqueo

Finalización

Área vacía o congestionada por defensores 


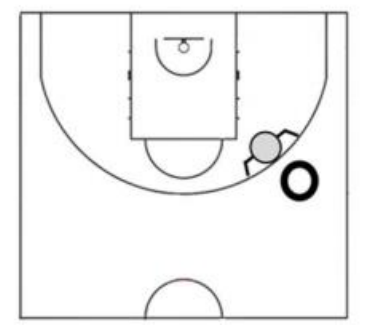

a)

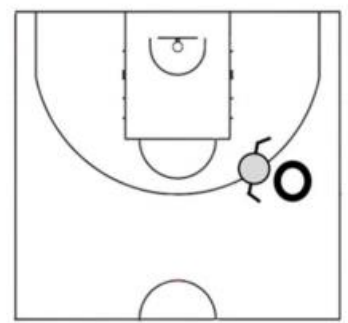

b)

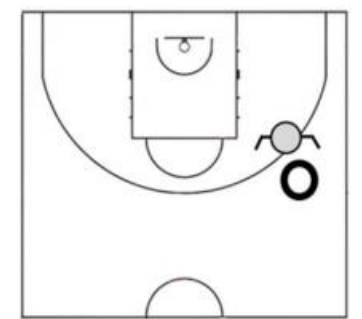

c)

Figura 2: DPE's (Dinámicas de Protección de Espacios) para la defensa de DBCD (desmarque con balón con drible), DCSD (desmarque con balón sin drible) y $\mathrm{APe}$ (aclarado en el perímetro): a) Neutro; b) Orientado para el fondo; c) Orientado para el medio.

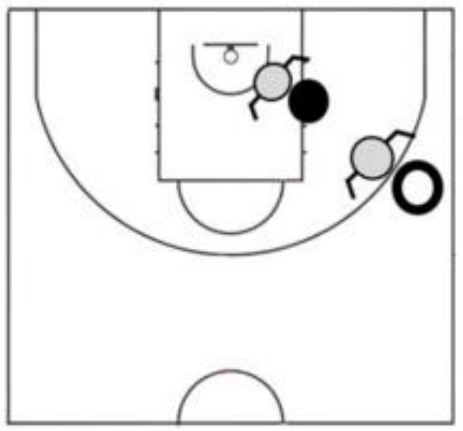

a)

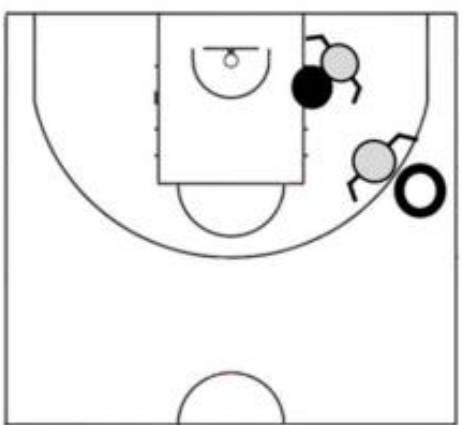

c)

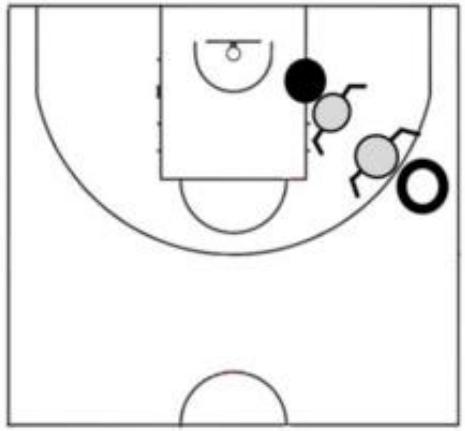

b)

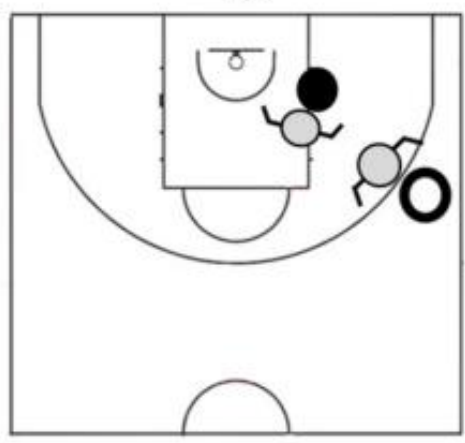

d)

Figura 3: DPE's (Dinámicas de Protección de Espacios) para la defensa del Al (aclarado interior): a) Por detrás; b) Por delante; c) Orientado $3 / 4$ por detrás; d) Orientado $3 / 4$ por delante. 


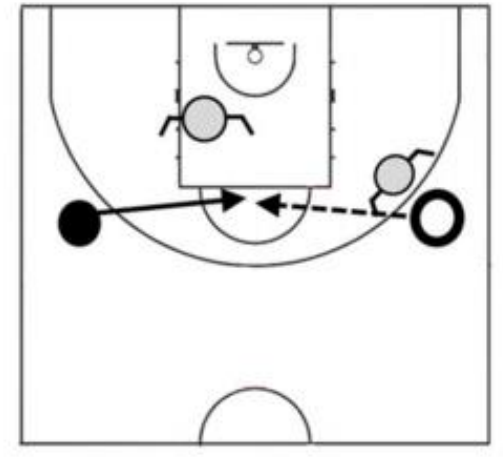

a)

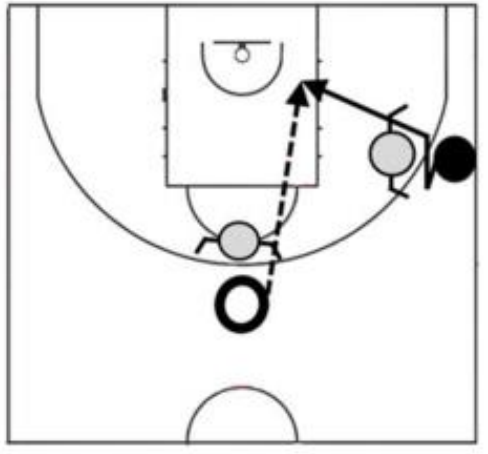

b)

Figura 4: DPE's (Dinámicas de Protección de Espacios) para la defensa del DSB (desmarque sin balón): a) Alejado (de la línea de pase); b) Próximo.

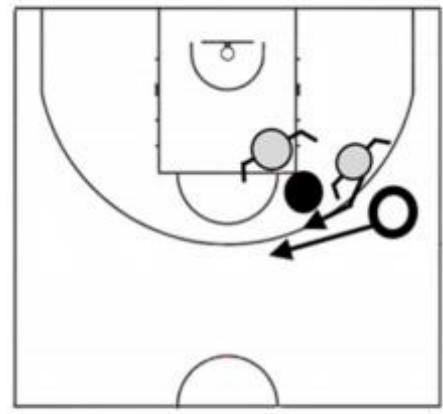

a)

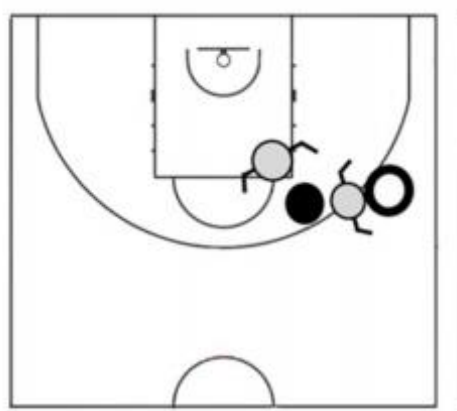

d)

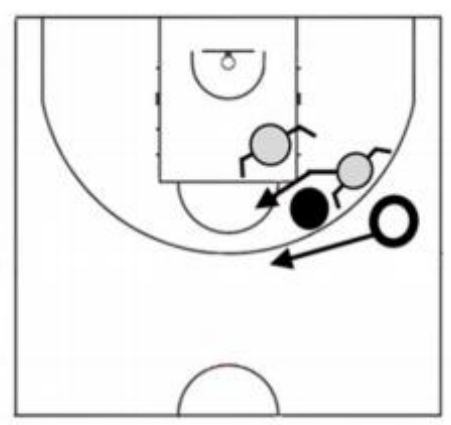

b)

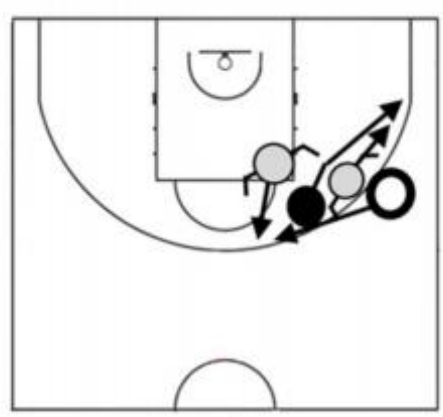

e)

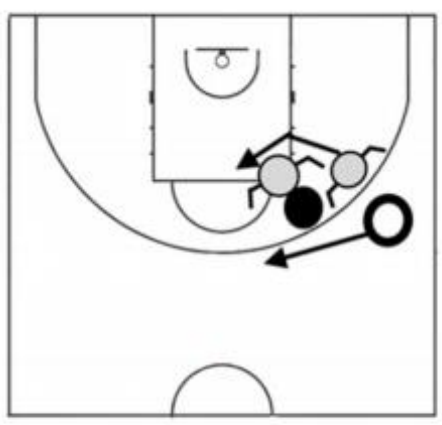

c)

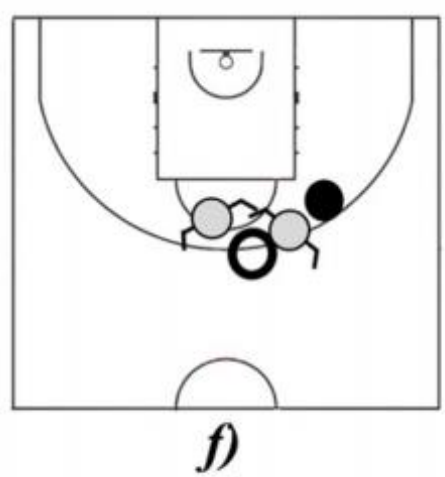

Figura 5: DPE's (Dinámicas de Protección de Espacios) para la defensa del BD (bloqueo directo) - defensa del jugador con balón: a) Por delante; b) Por el medio; c) Por detrás; d) Evitar el bloqueo; e) Cambio defensivo; f) Doblaje defensivo. 


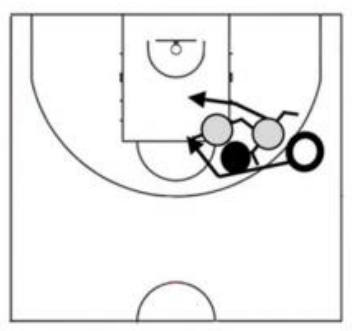

a)

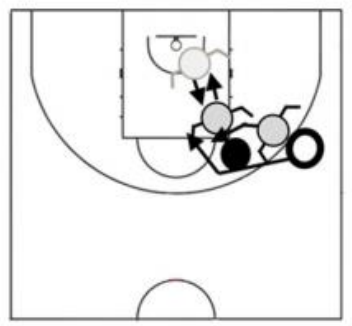

d)

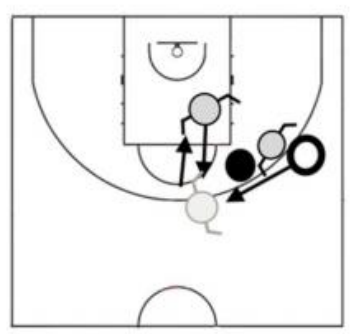

b)

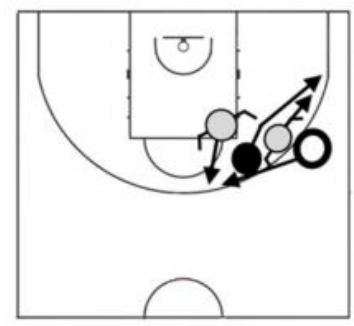

e)

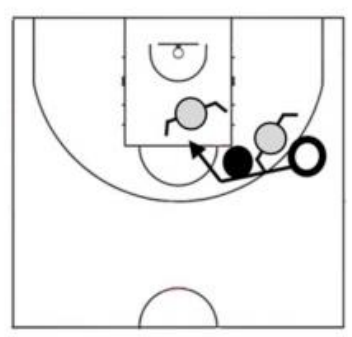

c)

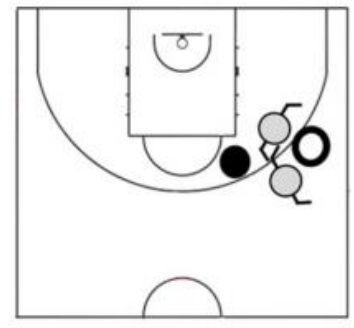

f)

Figura 6: DPE's (Dinámicas de Protección de Espacios) para la defensa del BD (bloqueo directo) - defensa del jugador que realiza el bloqueo: a) Contener; b) Mostrarse; c) Alejarse; d) Abrirse; e) Cambio defensivo; f) Doblaje defensivo.

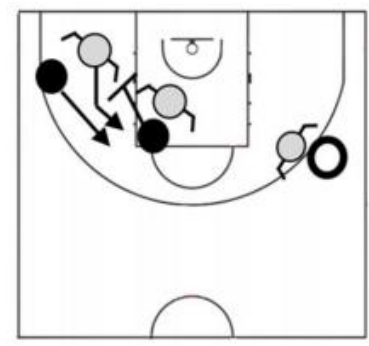

a)

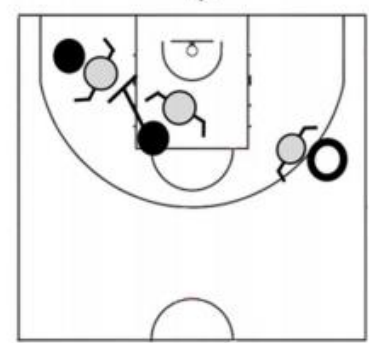

d)

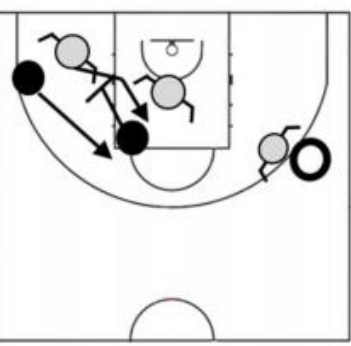

b)

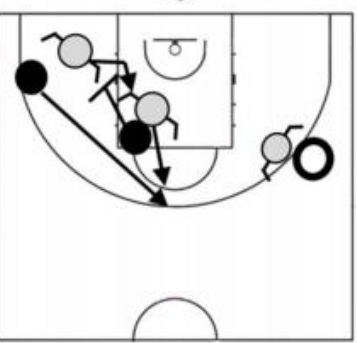

e)

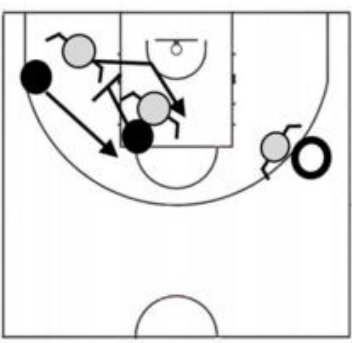

c)

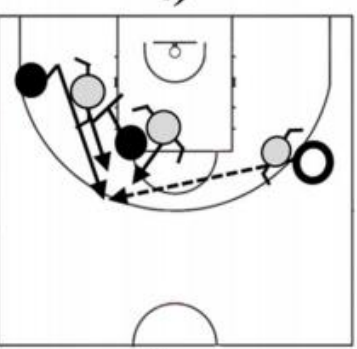

f)

Figura 7: DPE's (Dinámicas de Protección de Espacios) para la defensa del BI (bloqueo indirecto) - defensa del receptor del bloqueo: a) Por delante; b) Por el medio; c) Por detrás; d) Evitar el bloqueo; e) Cambio defensivo; f) Doblaje defensivo. 


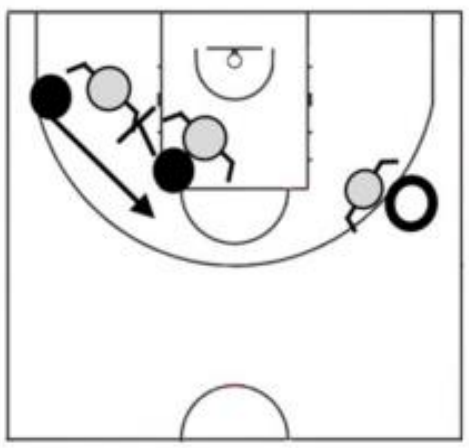

a)

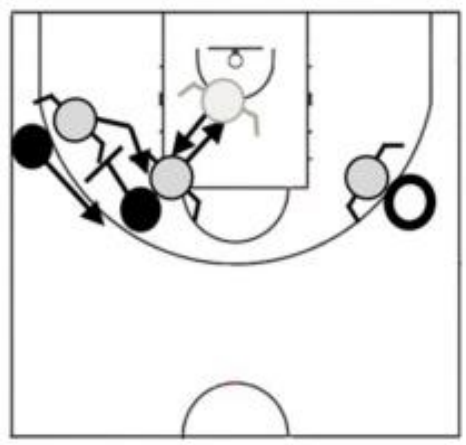

d)

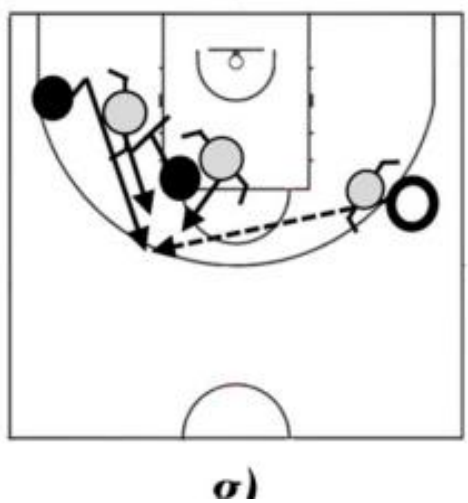

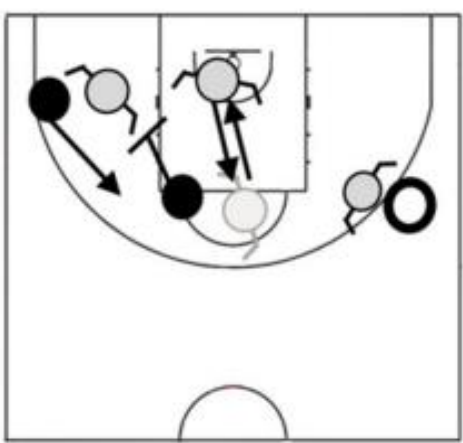

b)

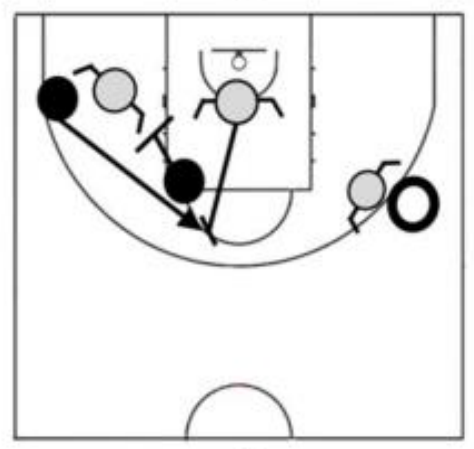

e)

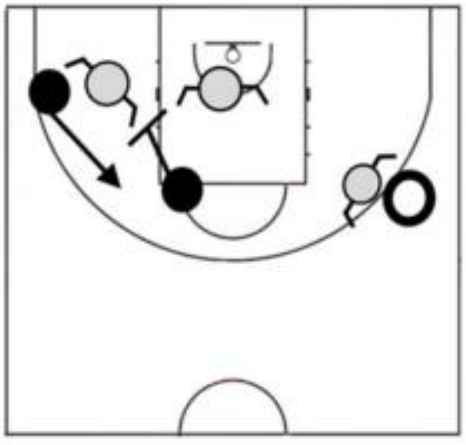

c)

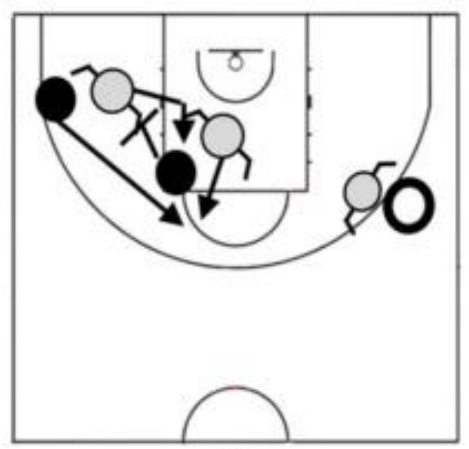

f)

Figura 8: DPE's (Dinámicas de Protección de Espacios) para la defensa del BI (bloqueo indirecto) - defensa del bloqueador: a) Contener; b) Mostrarse; c) Alejarse; d) Abrirse; e) Retrasar; f) Cambio defensivo; g) Doblaje defensivo. 


\section{APLICACIÓN DEL SABER TÁCTICO EN CATEGORÍAS FORMATIVAS DE BASQUETBOL}

\section{FORMULARIO PARA LA CARGA DE DATOS}

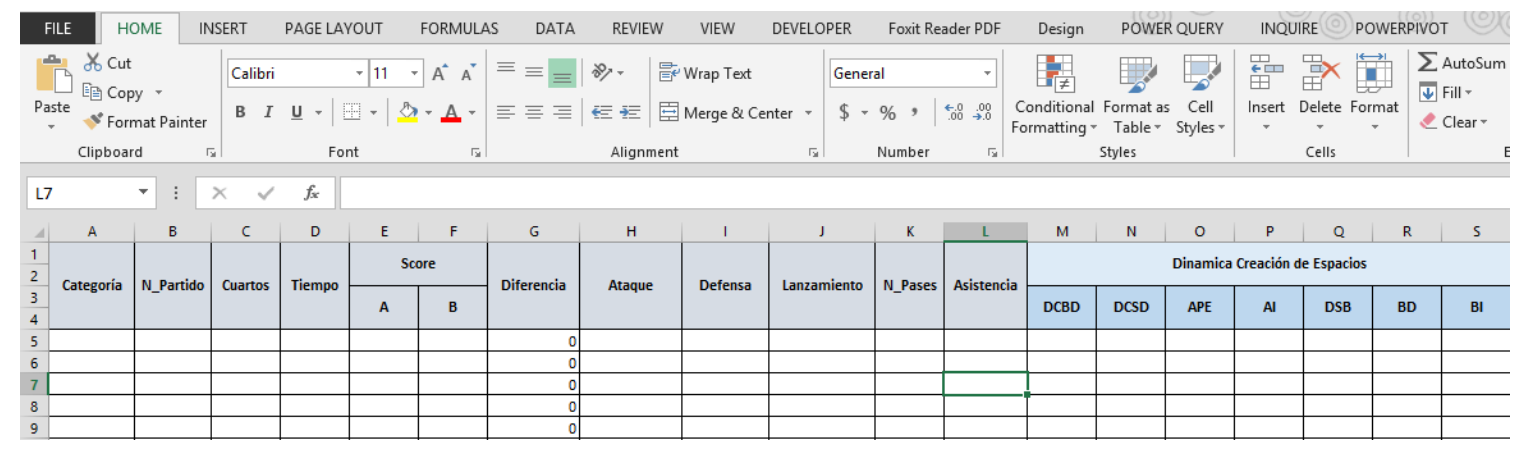

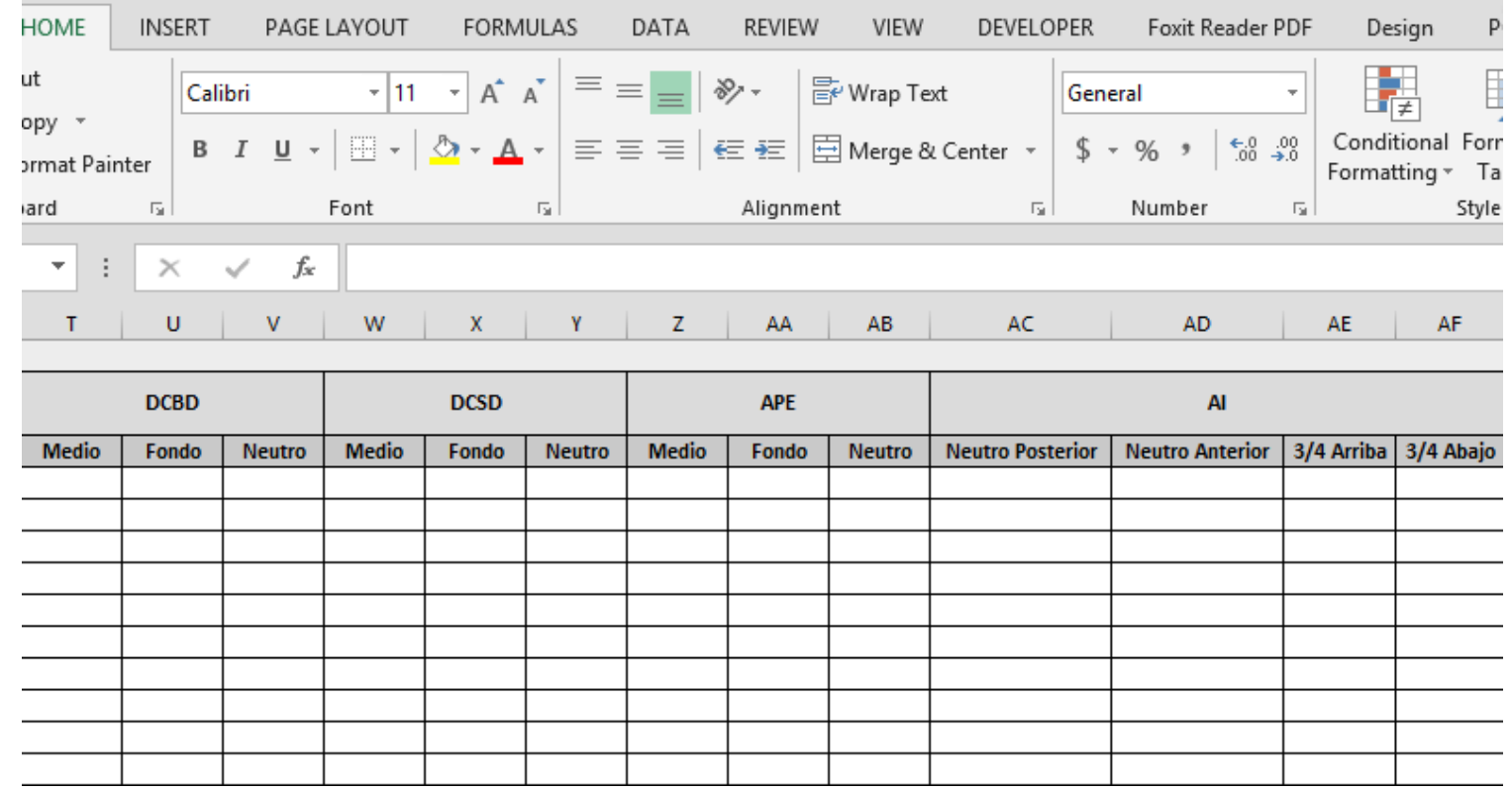




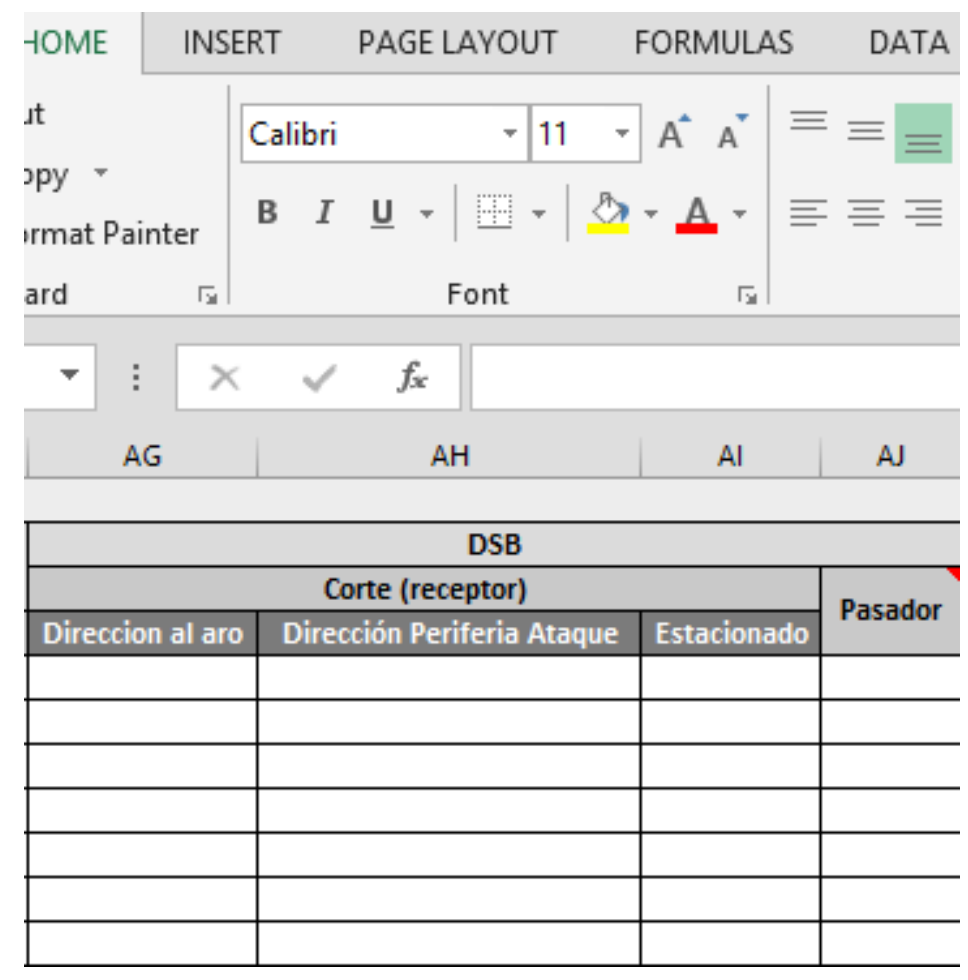

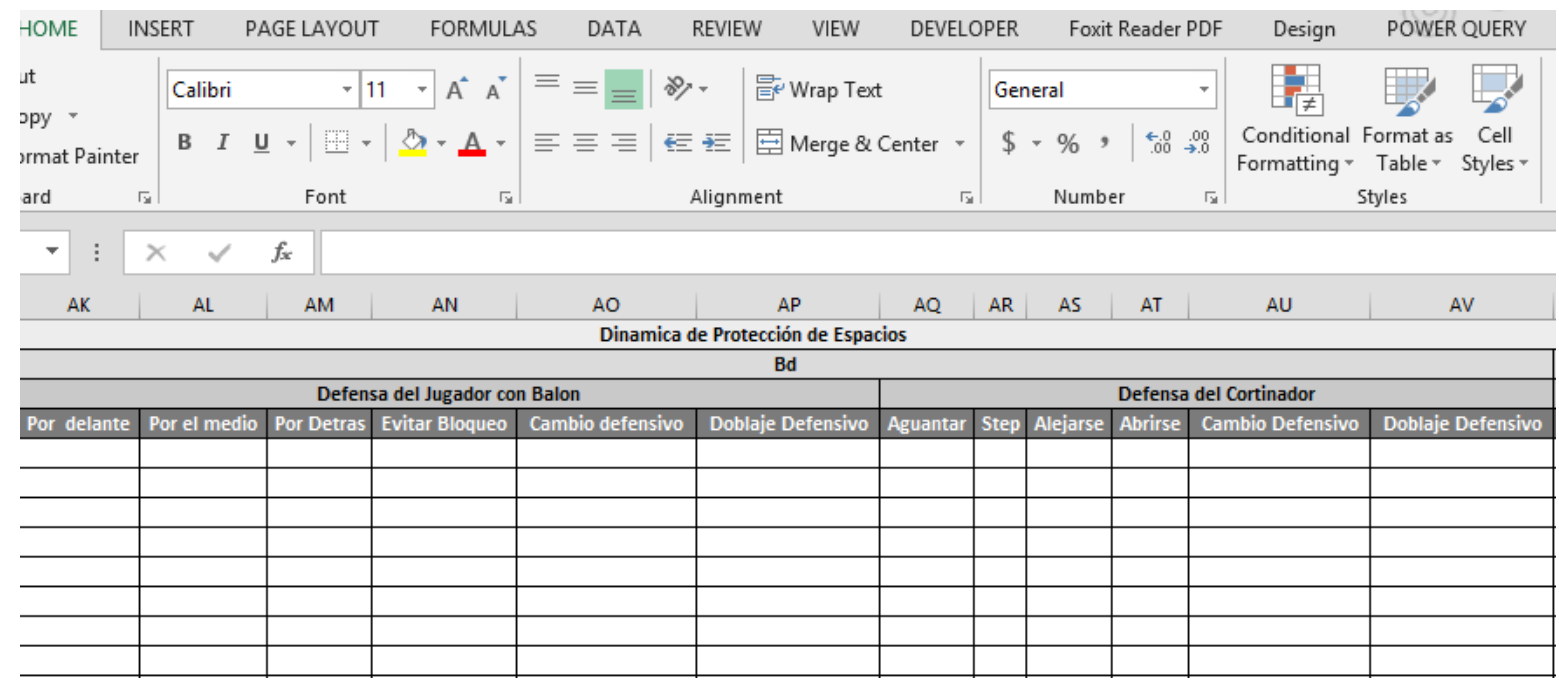




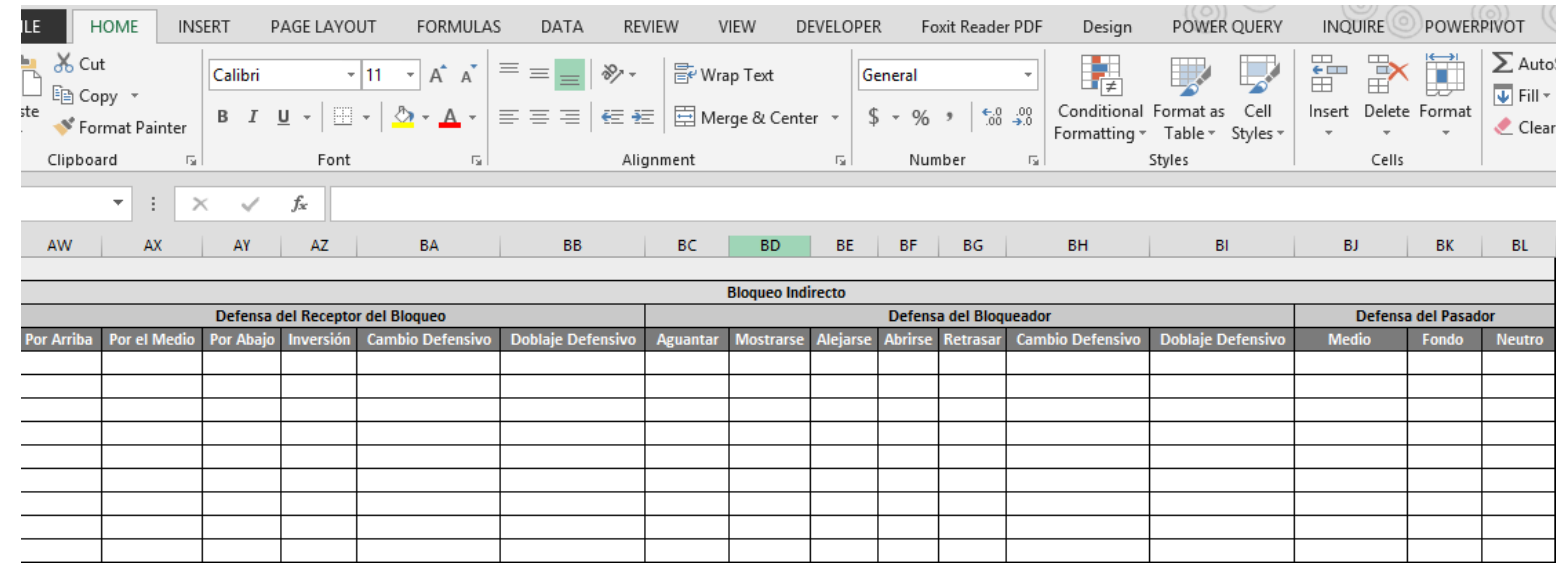

